FELIPE FAVA DE LIMA

EFEITO DA ESTIMULAÇÃO TRANSCUTÂNEA DA MEDULA ESPINHAL POR CORRENTE CONTÍNUA (tsDCS) NAS OSCILAÇÕES POSTURAIS,DURANTE A POSTURA ERETA ORTOSTÁTICA EM SERES HUMANOS 
FELIPE FAVA DE LIMA

\title{
EFEITO DA ESTIMULAÇÃO TRANSCUTÂNEA DA MEDULA ESPINHAL POR CORRENTE CONTÍNUA (tsDCS) NAS OSCILAÇÕES POSTURAIS DURANTE A POSTURA ERETA ORTOSTÁTICA EM SERES HUMANOS
}

\author{
Versão Original
}

Dissertação apresentada à Escola Politécnica da Universidade de São Paulo para óbtenção do Título de Mestre em Ciências.

Area de Concentração:

Sistemas Eletrônicos

Orientador:

Prof. Dr. André Fábio Kohn 
Autorizo a reprodução e divulgação total ou parcial deste trabalho, por qualquer meio convencional ou eletrônico, para fins de estudo e pesquisa, desde que citada a fonte.

\section{Catalogação-na-publicação}

\section{Lima, Felipe}

Efeito da estimulação transcutânea da medula espinhal por corrente contínua (tsDCS) nas oscilações posturais durante a postura ereta ortostática em seres humanos / F. Lima -- São Paulo, 2020. Versão Original.

$212 \mathrm{p}$.

Dissertação (Mestrado) - Escola Politécnica da Universidade de São Paulo. Departamento de Engenharia de Telecomunicações e Controle.

1.Estimulação transcutânea da medula espinhal por corrente contínua (tsDCS) 2.Controle postural 3.Engenharia Biomédica I.Universidade de São Paulo. Escola Politécnica. Departamento de Engenharia de Telecomunicações e Controle II.t. 


\section{AGRADECIMENTOS}

Este trabalho de mestrado é o resultado de uma longa jornada de um pequeno trecho que percorri do universo da ciência. Nessa travessia me deparei com inúmeras descobertas desse mundo pelo o qual sou apaixonado. Assim como aprendi com o Caminho de Santigado de Compostela, no qual andei $280 \mathrm{~km}$ em 2019, o percurso pelo mestrado demanda paciência do viajante e suporte daqueles que nos acompanham por essa viagem.

De modo a viabilizar uma jornada dessas é necessário que pessoas que já tenham realizado esse tipo de trajeto nos mostrem por onde caminhar para não nos perder. No meu percurso pelo mestrado tive a oportunidade de contar com os conselhos e orientação do prof. Dr. André Kohn, que já guiou muitos peregrinos pelo misterioso mundo da ciência. Outro guia importante, que me direcionou em momentos em que caminhava distraído, foi o prof. Dr. Henrique Moriya.

Tanto na travessia pelo mestrado quanto pelo Caminho de Santiago tive a companhia e a paciência da minha companheira da vida, Paola Zamariola. Em casa éramos dois peregrinos, ela percorrendo o doutorado em artes cênicas e eu o mestrado em engenharia biomédica.

Eu não conseguiria ter trilhado nenhum dos dois percursos se não contasse com o amor incondicional dos meus pais, Carlos Lima e Sandra Fava, que sempre me apoiaram em minhas escolhas. Meu entusiasmo por querer tentar desbravar o mundo da ciência veio de casa. Mais especificamente da casa dos meus pais! Quando era criança literalmente destruí diversos aparelhos eletrônicos da casa deles para tentar entender como as coisas funcionavam, e eles, de certa forma, ao não punirem esse meu extinto destruidor/descobridor, alimentaram esse meu desejo por ciência e por querer saber como o mundo funciona. Esse trabalho também foi amparado pelo amor dos meus irmãos, que tanto amo, Gabriel Lima (meu "pitchu") e Tatiane Lima, das minhas lindas sobrinhas Ágata Montijo e a pequena Isis e da minha querida avó Dona Nena.

Também não posso deixar de incluir o apoio dos meus amigos que já me acompanham por boa parte da minha jornada pela vida, Brayner Iorio, Laura Botton, Nicole Oliveira e Carlos Fernandes, a ajuda dos meus amigos de trabalho do Laboratório de Engenharia Biomédica (LEB), Diego, Edison, Fernando, Miguel, e as contribuições do Dr. Cristiano Rocha (parceiro e grande contribuidor desse trabalho), do Dr. Fernando Magalhães e do Dr. Renato Watanabe.

Parte desse trabalho de mestrado foi produzido em um ano atípico, o ano em que o mundo infelizmente enfrentou a pandemia do vírus COVID-19, sendo assim, acho fundamental agradecer a tod@s cientistas que se dispuseram a empregar a ciência de modo a tentar minimizar o número de vítimas.

Para mim, assim como já havia observado no Caminho de Santiago Compostela, o maior ensinamento obtido durante o mestrado foi que o mais importante é o caminho. Andar $280 \mathrm{~km}$ sem observar/aproveitar o entorno, as pessoas, as comidas e os vinhos não vale a pena! Da mesma forma, passar pelo mestrado sem aproveitar cada aprendizado também não vale! 


\section{RESUMO}

A estimulação transcutânea da medula espinhal por corrente contínua (tsDCS) é uma técnica de estimulação elétrica não invasiva da medula espinhal efetiva na indução de neuromodulação de circuitos neurais locais e distais do sistema nervoso central (SNC). Quando aplicada sobre a região da intumescência lombossacral da medula espinhal, a tsDCS pode provocar modificações de respostas eletrofisiológicas dos sistemas motor, proprioceptivo e nociceptivo e também pode alterar o desempenho de algumas tarefas motoras dos membros inferiores. Nesse estudo foi desenvolvido um modelo computacional simplificado do tronco humano para ser utilizado na análise de diferentes configurações de estimulação elétrica e também foi elaborado um protocolo experimental para verificar os efeitos da tsDCS no comportamento das oscilações posturais de indivíduos saudáveis durante a postura ereta ortostática (PEO), O modelo computacional simplificado do tronco humano permitiu a escolha de uma configuração que otimizasse o campo elétrico gerado na intumescência lombossacral da medula espinhal. O protocolo experimental adotado, com diferentes polarizações da tsDCS, não gerou alterações significavas do comportamento das oscilações posturais de indivíduos saudáveis durante a $\mathrm{PEO}$.

Palavras-Chave - tsDCS, estimulação elétrica transcutânea, medula espinhal, corrente contínua, COP, centro de pressão, oscilação postural, controle postural, membro inferior, postura ereta ortostática. 


\section{ABSTRACT}

Transcutaneous spinal direct current stimulation (tsDCS) is an effective non-invasive spinal cord electrical stimulation technique to induce neuromodulation of local and distal neural circuits of the central nervous system (CNS). When applied to the spinal cord lumbosacral region, tsDCS can change electrophysiological responses of the motor, proprioceptive and nociceptive systems and can also alter the performance of some lower limb motor tasks. In this study a simplified computational model of the human trunk was developed to analyse different electrical stimulation configurations and an experimental protocol was developed to verify effects of the tsDCS on postural sway of healthy individuals during quiet upright standing. The simplified computational model of the human trunk allowed the choice of a configuration that optimized the electric field generated in the spinal cord lumbosacral region. The experimental protocol indicated that different polarizations of tsDCS did not generate significant changes in the postural sway in healthy individuals during quiet upright standing.

Keywords - tsDCS, transcutaneous, spinal cord, direct current, electric stimulation, COP , center of pressure, postural sway, postural control, lower limb, quiet upright standing. 


\section{LISTA DE FIGURAS}

$1 \quad$ Estimulação elétrica utilizando peixe torpedo. . . . . . . . . . . . . . . . 22

2 Detalhes anatômicos gerais da medula espinhal. . . . . . . . . . . . . . 26

$3 \quad$ Detalhes da seção transversal da medula espinhal. . . . . . . . . . . . . . . 27

4 Detalhe da intumescência lombossacral. . . . . . . . . . . . . . . . . . . . . 28

$5 \quad$ Subdivisões da substância branca da medula espinhal em tratos. . . . . . . . 29

6 Lâminas de Rexed. . . . . . . . . . . . . . . . . . . . . . . . 30

$7 \quad$ Ilustração da tsDCS

$8 \quad$ Ilustração da geração e propagação de um|PA| . . . . . . . . . . . . . . . . . 33

$9 \quad$ Efeitos observados em um neurônio imerso em um volume condutor em que flui uma corrente elétrica $\mid$ CC] . . . . . . . . . . . . . . . . . . . . . . 35

$10 \quad$ Exemplo de diferenças da distribuição de corrente elétrica da $\mid$ tsDCS. $\ldots$. . . 37

11 Exemplo das polaridades da|tsDCST . . . . . . . . . . . . . . . . . . 38

12 Esquema do processo de simulação computacional. . . . . . . . . . . . . . . . 49

13 Modelos tridimensionais do tronco humano simples e complexo. . . . . . . 50

14 Ilustração da metologia de posturografia por plataforma de força. . . . . . 54

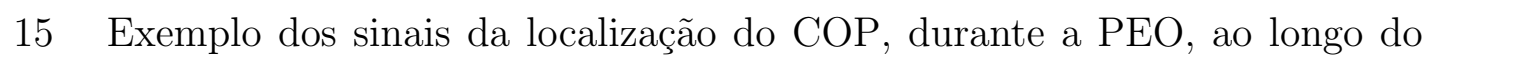

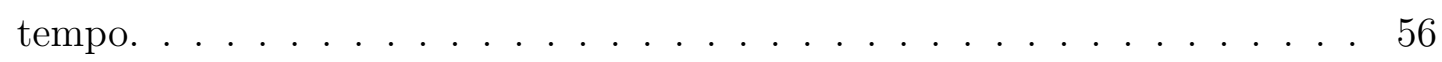

16 Parâmetro AREAE. . . . . . . . . . . . . . . . . . . . . . . 58

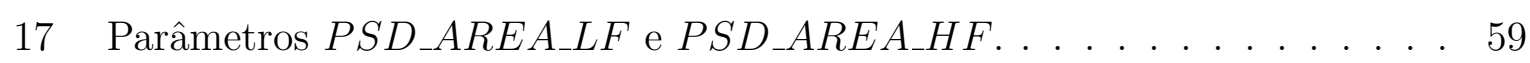

18 Parâmetro $f 50 p_{-} P S D . \ldots \ldots \ldots \ldots$. . . . . . . . . . . . 60

19 Parâmetro $f 80 p_{-} P S D$. . . . . . . . . . . . . . . . . . 61

$20 \quad$ Exemplo de sinais em diferentes escalas horizontais. . . . . . . . . . . . . . 63

21 análise de difusão do estabilograma (SDA) $\ldots \ldots$. . . . . . . . . . . . . . 64

22 análise fractal em frequências específicas (FsFA) . . . . . . . . . . . . . . 65 
23 Exemplos de|SDA|e de|FsFA $\ldots \ldots \ldots \ldots \ldots$

24 Sinais biológicos com diferentes complexidades. . . . . . . . . . . . . . 68

25 Exemplo de gráfico $(\operatorname{SampEn}(n) \mathrm{X}(n))$ da|MSE $\mid \ldots \ldots \ldots$

$26 \quad$ Sinais com diferentes índices de complexidade (CI). . . . . . . . . . . . 70

27 Decomposição Rambling e Trembling. . . . . . . . . . . . . . . . . . . 72

28 Hipótese 1 - Utilização de um modelo computacional simplificado. . . . . . 75

29 Hipótese 2 - Adição de um terceiro eletrodo. . . . . . . . . . . . . . . . . . 77

$30 \quad$ Hipótese 3 - Aumento da dimensão do eletrodo. . . . . . . . . . . . . . . 78

31 Hipótese 4 - Aumento da corrente de estimulação. . . . . . . . . . . . . . . 80

$32 \quad$ Hipótese 5 - Efeito da|tsDCS| na|PEO| $\ldots \ldots \ldots \ldots \ldots$. . . . . . . 81

33 Modelo tridimensional da medula espinhal. . . . . . . . . . . . . . . 82

34 Modelo tridimensional das costelas e das vértebras. . . . . . . . . . . . . 83

35 Modelo tridimensional representando o sacro e as cristas ilíacas. . . . . . . 84

36 Posicionamento das vértebras, das costelas, do sacro e das cistas ilíacas no modelo tridimensional. . . . . . . . . . . . . . . . . . . 85

$37 \quad$ Modelo tridimensional dos pulmões e das vísceras. . . . . . . . . . . . . 86

38 Modelo tridimensional completo envolvido pela pele, pelo tecido adiposo e

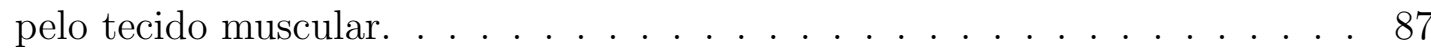

39 Modelo tridimensional e posicionamentos dos eletrodos. . . . . . . . . . . . 89

40 Gráfico apresentado em (FERNANDES et al., 2018). . . . . . . . . . . . . 91

41 Locais de afixação dos eletrodos da|tsDCS $\ldots$. . . . . . . . . . . . . 95

42 Diagramas das correntes elétricas dos protocolos de estimulação elétrica . . 97

$43 \quad$ Sistemas elétricos para garantia da qualidade e da segurança do protocolo de estimulação elétrica . . . . . . . . . . . . . . . . . . . . . . . . 98

44 Esquema do circuito limitador de corrente $\ldots \ldots \ldots \ldots$. . . . . . . 99

45 Esquema da $\mid \mathrm{PEO}$ durante a coleta de dados $\ldots$. . . . . . . . . . . . 100

$46 \quad$ Representação da camiseta utilizada no protocolo experimental . . . . . . . 102 
47 Representação do participante sobre a maca durante a colocação dos eletrodos 103

48 Esquema da ordem das sequências de aquisições de dados . . . . . . . . . . 106

49 Esquema representando uma sequência de aquisição de dados . . . . . . . . 107

50 Obtenção das componentes Rambling e Trembling do $\mathrm{COP}$. . . . . . . . . . 114

51 Módulo dos campos elétricos na medula espinhal obtidos por um modelo computacional complexo e pelo modelo computacional simplificado. . . . . 134

52 Módulo e diferença dos módulos dos campos elétricos na medula espinhal obtidos em um modelo computacional complexo e pelo modelo computacional simplificado . . . . . . . . . . . . . . . . . . 135

53 Valor dos campos elétricos, na direção $|\mathrm{AP}|$ na medula espinhal, obtido em \begin{tabular}{|c|c|}
\hline um modelo computacional complexo (FERNANDES et al., $[2018)$ e pelo \\
\hline
\end{tabular} modelo computacional simplificado . . . . . . . . . . . . 136

54 Valor dos campos elétricos, na direção|ML, na medula espinhal, obtido em \begin{tabular}{|c|c|}
\hline um modelo computacional complexo e pelo modelo computacional simpli- \\
\hline
\end{tabular} ficado . . . . . . . . . . . . . . . . . . . . . . 137

55 Valor e diferença dos valores dos campos elétricos, na direção $\mid \mathrm{RC}$, na me\begin{tabular}{|c|}
\hline dula espinhal, obtidos pelo modelo computacional complexo e pelo modelo \\
\hline
\end{tabular} - computacional simplificado . . . . . . . . . . . . . . . . 138

56 Módulo dos campos elétricos na medula espinhal obtidos no modelo com-

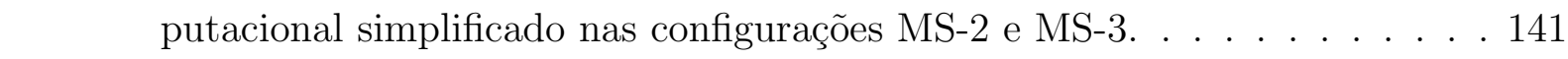

57 Módulo e diferença dos módulos dos campos elétricos na medula espinhal

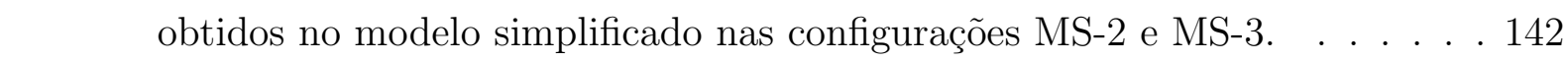

58 Valor dos campos elétricos, na direção $\mid \mathrm{AP}$, na medula espinhal, obtido no \begin{tabular}{|l|l|l|l|l|}
\hline modelo simplificado nas configurações & $\mathrm{MS}-2$ & $\mathrm{e}$ & $\mathrm{MS}-3$.
\end{tabular}

59 Valor dos campos elétricos, na direção $\mid$ ML \begin{tabular}{|l|l|l|l|l}
\hline modelo simplificado nas configurações & $\mathrm{MS}-2$ & $\mathrm{e}$ & $\mathrm{MS}-3$.
\end{tabular} . . . . . . . . . . . . 144

60 Valor e diferença dos valores dos campos elétricos, na direção $\mid \mathrm{RC}$, na me\begin{tabular}{|l|l|l|}
\hline dula espinhal, obtidos no modelo simplificado nas configurações & MS-2 & e \\
\hline
\end{tabular}

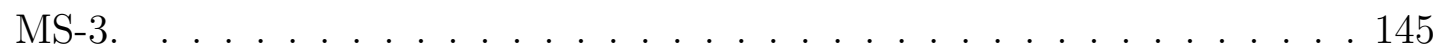

61 Módulo dos campos elétricos na medula espinhal obtidos no modelo computacional simplificado nas configurações $\mid$ MS-3 $\mid$ e $\mid$ MS-EXP| . . . . . . . . . . 148 
62 Módulo e diferença dos módulos dos campos elétricos na medula espinhal

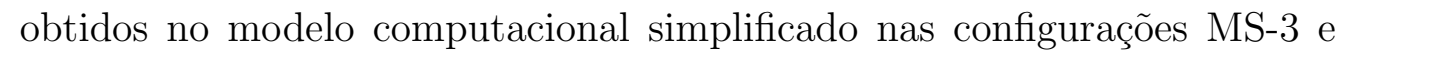
|MS-EXPt . . . . . . . . . . . . . . . . . . . . . . . . . 149

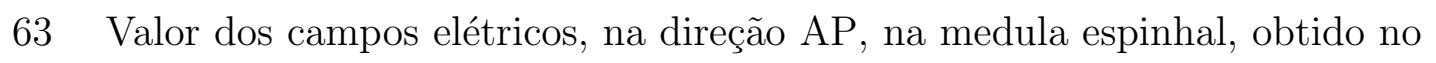

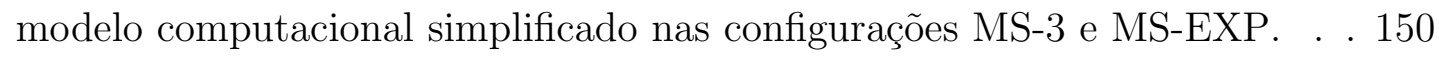

64 Valor dos campos elétricos, na direção $\mid$ ML

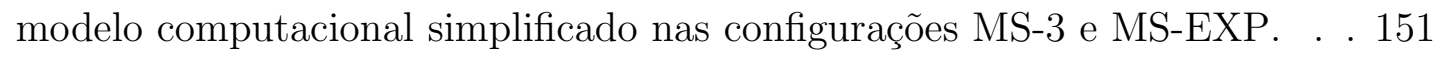

65 Valor e diferença dos valores dos campos elétricos, na direção $\mid \mathrm{RC}$, na me\begin{tabular}{|l|l|l|} 
dula espinhal, obtidos no modelo simplificado nas configurações & MS-3 & e \\
\hline
\end{tabular} |MS-EXP] . . . . . . . . . . . . . . . . . . . . . . . . . 152

66 Módulo dos campos elétricos na medula espinhal obtidos no modelo computacional simplificado na configuração $\mid$ MS-EXP $\mid$ com estimulação elétrica

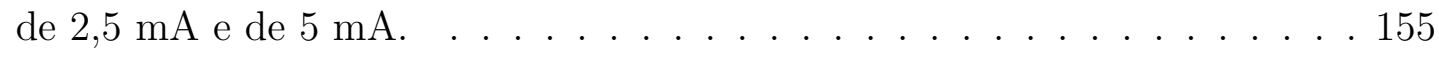

67 Módulo dos campos elétricos na medula espinhal obtidos no modelo com\begin{tabular}{|l|l|l|}
\hline putacional simplificado na configuração & MS-EXP & com estimulação elétrica \\
\hline
\end{tabular}

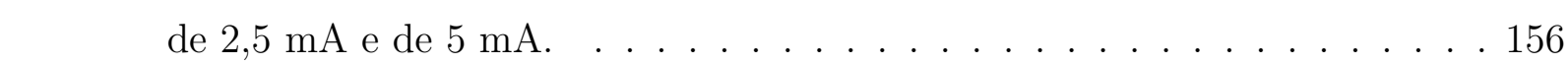

68 Valor dos campos elétricos, na direção $\mid \mathrm{AP}$, na medula espinhal, obtido \begin{tabular}{|c|c|c|}
\hline no modelo computacional simplificado na configuração & MS-EXP & com esti-
\end{tabular} mulação elétrica de $2,5 \mathrm{~mA}$ e de $5 \mathrm{~mA}$. . . . . . . . . . . . . . . . . . 157

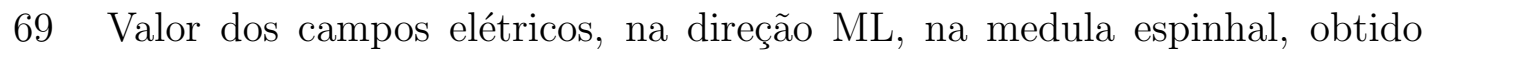

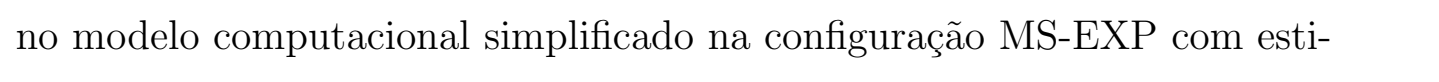
mulação elétrica de $2,5 \mathrm{~mA}$ e de $5 \mathrm{~mA}$. . . . . . . . . . . . . . . . . 158

70 Valor dos campos elétricos, na direção $\mid \mathrm{RC}$, na medula espinhal, obtidos no

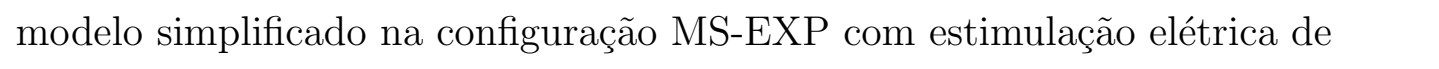

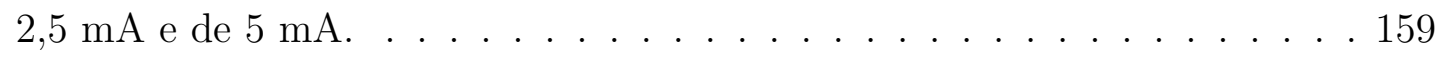

71 Valor dos módulos da densidade de corrente elétrica $(|J|)$, na medula es-

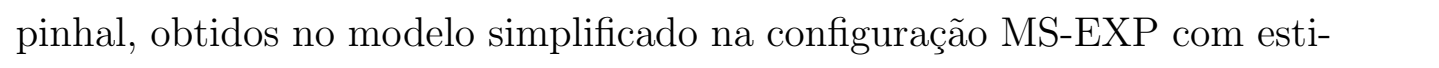
mulação elétrica de $5 \mathrm{~mA}$ e de $250 \mathrm{~mA}$. . . . . . . . . . . . . . . . 160

72 Dados de posturografia por plataforma de força obtidos de um participante durante o protocolo experimental . . . . . . . . . . . . . . . . . . 164

73 Dados experimentais do parâmetro $f 50 p P S D_{A P}$. . . . . . . . . . 170 
74 Dados experimentais do parâmetro $\alpha L_{M L} . \ldots \ldots \ldots \ldots \ldots$

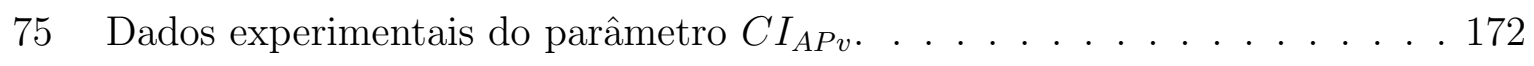

76 Dados experimentais do parâmetro $C I_{M L} . \ldots \ldots \ldots \ldots \ldots$ 


\section{LISTA DE TABELAS}

2 Condutividades elétricas utilizadas nas simulações. . . . . . . . . . . . . . . 90

3 Configuração das densidades de corrente elétrica na superfície dos eletrodos. 90

4 Parâmetros $S D, M V E L O, A R E A E, P S D \_A R E A$ e $f 50 p_{-} P S D$. . . . . 116

5 Parâmetros $\left.f_{-} 80 p_{-} P S D, \mid \mathrm{SDA}\right] \mid$ FsFA| $\mid \mathrm{MSE}$. . . . . . . . . . . . . . 117

6 Tamanho e localização da região da medula espinhal estimulada com campo elétrico maior do que $0,15 \mathrm{~V} / \mathrm{m}$ obtidos por um modelo computacional complexo e pelo modelo computacional simplificado . . . . . . . . . . . . . 139

7 Tamanho e localização da região da medula espinhal estimulada com campo elétrico maior do que $0,15 \mathrm{~V} / \mathrm{m}$ obtidos pelo modelo computacional sim-

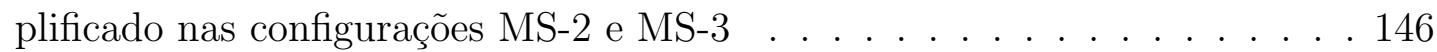

8 Tamanho e localização da região da medula espinhal estimulada com campo elétrico maior do que $0,15 \mathrm{~V} / \mathrm{m}$ obtidos pelo modelo computacional simplificado nas configurações $|\mathrm{MS}-3| \mathrm{e} \mid \mathrm{MS}-\mathrm{EXP}] \ldots$. . . . . . . . . . . . . 153

9 Tamanho e localização da região da medula espinhal estimulada com campo elétrico maior do que $0,15 \mathrm{~V} / \mathrm{m}$ obtidos pelo modelo computacional simplificado nas configurações $\mid$ MS-EXP $\mid$ com corrente de estimulação de 2,5 mA e $\mid$ MS-EXP $\mid$ com corrente de estimulação de $5 \mathrm{~mA}$. . . . . . . . . . . . . . 161

$10 \quad$ Informações dos participantes do protocolo experimental. . . . . . . . . . . 163

11 Resultados das ANOVAs realizadas nos valores dos parâmetros obtidos dos dados experimentais

12 Resultado da análise post hoc realizada nos parâmetros que apresentaram diferenças significativas $(p \leq 0,05) . \ldots \ldots$. . . . . . . . . . 169

13 Médias e desvios padrões dos resultados experimentais, . . . . . . . . . . 193 


\section{SIGLAS}

(A-T10,C-CiDeE) Ânodo sobre o processo espinhoso de T10 e cátodo sobre as cristas ilíacas direita e esquerda. 96, 97, 101, 105, 106, 131, 162, 164, $169,173,179,181$

(A-T10,C-Od) Ânodo sobre o processo espinhoso de T10 e cátodo sobre o ombro direito. 41, 42, 44, 45

(A-T10/T11,C-Od) Ânodo sobre o processo espinhoso de T10 e T11 e cátodo sobre o ombro direito. 42

(A-T11,C-In)

$(\mathrm{A}-\mathrm{T} 11, \mathrm{C}-\mathrm{Od})$ Ânodo sobre o processo espinhoso de T11 e cátodo sobre a região infraclavicular. 41

Ânodo sobre o processo espinhoso de T11 e cátodo sobre ombro direito. 44,46

(A-T11,C-Oe) Ânodo sobre o processo espinhoso de T11 e cátodo sobre ombro esquerdo. 44

(A-T11/T12,C-Bd) Ânodo sobre o processo espinhoso de T11 e T12 e cátodo sobre braço direito. 43

(A-T11/T12,C-U) Ânodo sobre o processo espinhoso de T11 e T12 e cátodo sobre umbigo. 45

(C-C6/T1,A-Od) Cátodo sobre o processo espinhoso de C6 até o processo espinhoso de T1 e ânodo sobre ombro direito. 43

(C-T10,A-CiDeE) Cátodo sobre o processo espinhoso de T10 e ânodo sobre as cristas ilíacas direita e esquerda. 95, 97, 101 . 105, 106, 131, 162, $169,173,179,181$,

(C-T10,A-Od) Cátodo sobre o processo espinhoso de T10 e ânodo sobre o ombro direito. 41, 43

(C-T11,A-In) Cátodo sobre o processo espinhoso de T11 e ânodo sobre a região infraclavicular. 41

(C-T11,A-Od) Cátodo sobre o processo espinhoso de T11 e ânodo sobre ombro direito. 44

abdutor digiti minimi 43 
ANOVA

AP

AVE

BDNF

BF

C1

C3

C6

C7

$\mathrm{CA}$

$\mathrm{CC}$

CI

$\mathrm{CM}$

COP

cSP

DC

DFA

EMG

EPS

$\mathrm{fBm}$

FEM

FES

FFT

fGn análise de variância $131,132,162,177,181$

anteroposterior $25,55,57,61,95,101,110,113,116$

117, 132, 133, 136, 140, 143, 146, 150, 153, 157, 177.

181

abdutor pollicis brevis 43

acidente vascular encefálico 24

gene do fator neurotrófico derivado do cérebro $42,46$. 179

bíceps femoral 41

primeira vértebra cervical 25, 74

terceira vértebra cervical 27

sexta vértebra cervical 43

sétima vértebra cervical 102, 103

corrente alternada 21,24

corrente contínua 21, 23, 24, 31, 33, 35, 40, 44, 49.

50, 80, 177,179

índice de complexidade 67

centro de massa 53.54

centro de pressão $53,62,64,67,61,73,110,112,117$,

131, 162, 177, 181, 183

período silente cortical 44,46

corrente contínua 179

análise de flutuações com a remoção de tendências lineares 62

eletromiografia $30,41,43$

sensibilidade à dor por estimulação elétrica 44

movimento Browniano fracionário $61,63,66$

método dos elementos finitos $47,51,90$

estimulação elétrica funcional 24

transformada rápida de Fourier 119

ruído Gaussiano fracionário $61,62,66$ 
HD

Hmáx

ICF

IEP

IQR

L-VGCC

L1

L2

L3

L5

LCR

LEB

LEP

MEP

ML

Mmáx

MPS

MRI

MS-2

MS-3

MS-EXP

MSE

MUNE depressão do reflexo $\mathrm{H} 41,42,44,177,178$

amplitude máxima da onda $\mathrm{H} 41$

facilitação intra-cortical 44

ponto de equilíbrio instantâneo 71,72

faixa interquartil 131

canais iônicos de cálcio tensão dependentes do tipo L

36, 180

primeira vértebra lombar $46,74,92,135,138$

segunda vértebra lombar $25,46,74$

terceira vértebra lombar 75

quinta vértebra lombar 46, 82, 83, 92, 93, $142,145$. 149 152, $1 5 6 \longdiv { 1 6 0 }$

líquido cefalorraquidiano $25,81,82$

Laboratório de Engenharia Biomédica 94,101

potencial evocado por laser 42,46

potencial motor evocado 24, 43, 44, 46, 178

mediolateral 55, 57, 61, 101, 110, 113, 116, 117, 133 .

137, 140, 144, 146, 151, 153, 158, 175, 181

amplitude máxima da onda $\mathrm{M} 41$

sensibilidade à dor por estimulação mecânica 44

imagem por ressonância magnética $43,49,50,74$

Modelo simplificado com 2 eletrodos de $25 \mathrm{~cm}^{2} 87$

89, 90, 92, 133, 136 146, 175

Modelo simplificado com 3 eletrodos de $25 \mathrm{~cm}^{2} 87$.

89, 90, 92, 93, 140, 146, 148, 153, 175, 176

Modelo simplificado com 3 eletrodos de $50 \mathrm{~cm}^{2} 88.90$.

93, 146, 148 161, 176

entropia multi-escala $67,69,71,117,127$

estimação do número de unidade motoras 43 
NM

NMDA

NP

NS

NU

NWR

PA

PAD

PEO

PPT

PSD

PSI

PSP

PTN

$\mathrm{RC}$

RI

RLS

RMS

RMT

SD

SDA

SEP

SICI

SNA

SNC

SNP

SO nervo mediano 41,43

receptores N-metil-D-aspartato 36,180

nervo peroneal 42

nervo sural 41

nervo ulnar 43

reflexo de retirada nociceptivo 45

potencial de ação $32,35,41,180$

despolarização aferente primária 43

postura ereta ortostática $52,56,62,71,73,80,81,99$. 100, 104, 107, 115, 130, 161, 164, 177, 180, 183

limiar à dor por pressão 46

densidade de potência espectral $58,61,66,116,117$ 119, 121, 181

inibição pré-sináptica $42,43,177$

período silente periférico 43

nervo tibial posterior 41,42

rostrocaudal $88,95,133,138,140,145,146,152,153$

159,161

inibição recíproca 42,43

síndrome das pernas inquietas 44

valor quadrático médio $56,125,126$

limiar motor em repouso 44

desvio padrão 56

análise de difusão do estabilograma $61,62,64,66$. 117, 122

potencial somatossensorial evocado $24,41,46,177$

inibição intra-cortical curta por pulso pareado 44

sistema nervoso autônomo 28,29

sistema nervoso central $21,25,28,30,39,51,52,55$

62,80

sistema nervoso periférico 28,29

sóleos 4143 
Período de tempo antes do protocolo de estimulação

T1

t1

T10

T11

T12

T2

t2

T8

T9

TA

TCLE

tDCS

TENS

TMS

TS

tsDCS

TST

USP elétrica 105, 106, 115, 131, $162,169,173,181$

primeira vértebra torácica 43

Período de tempo durante o protocolo de estimulação

elétrica 105, 106, 115, 131, 162, 169,173, 181

décima vértebra torácica $24,36,37,41,46,75,79,83$.

87 $97,102,104,133$ 141, $146,148,153,155,178,183$

décima primeira vértebra torácica $41,46,83,178$

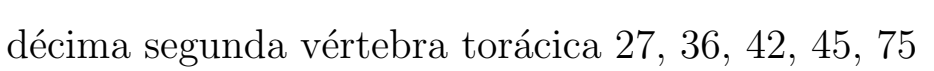

segunda vértebra torácica $27,82,83,83,85,86,92,93$. $135139,142,146,149,153,156,161$

Período de tempo depois do protocolo de estimulação elétrica 105, 115, 131, 162, $169,173,181$

oitava vértebra torácica $45,85,86$

nona vértebra torácica 27,83

tibial anterior 31

termo de consentimento livre e esclarecido 94,101 184

estimulação transcraniana de corrente contínua 21

23, 24, 36, 39, 96, 174, 176, 178, 180, 182

estimulação elétrica transcutânea de nervo 24

estimulação magnética transcraniana 43,44

tríceps sural 31

estimulação transcutânea da medula espinhal por cor-

rente contínua 21, 24, 31, 48, 50, 51, 74, 75, 77, 79, 81 .

91, 93 ,95, 130, $133,139,161,164,174,183$

limiar de somação temporal 45

Universidade de São Paulo 94,101 


\section{SUMÁRIO}

Siglas

\begin{tabular}{lll}
\hline 1 & Introdução & 21 \\
\hline
\end{tabular}

1.1 Breve revisão histórica $\ldots \ldots \ldots \ldots$. . . . . . . . . . . . . . . 21

1.1.1 Antes do século XVII . . . . . . . . . . . . . . . . . . 22

1.1 .2 Do século XVII ao século XIX . . . . . . . . . . . . . . . . . . 23

1.1 .3 Do século XX em diante . . . . . . . . . . . . . . . . . . . . 23

1.2 Anatomia da medula espinhal humana . . . . . . . . . . . . . . . . 25

1.2 .1 Estrutura geral da medula espinhal . . . . . . . . . . . . . . 25

1.2 .2 Substância branca da medula espinhal . . . . . . . . . . . . . . 28

1.2 .3 Substância cinzenta da medula espinhal . . . . . . . . . . . . . . . . 29

$1.2 .4 \quad$ Circuitos neurais da medula espinhal . . . . . . . . . . . . . . . 30

1.3 Estimulação elétrica do tipo tsDCS $\ldots \ldots$. . . . . . . . . . . . . 31

1.3 .1 Introdução sobre a $\mid$ tsDCS $\ldots \ldots \ldots$. . . . . . . . . . . 31

1.3 .2 Efeito da tsDCS nos neurônios da medula . . . . . . . . . . . . . . 32

$1.3 .3 \quad$ Características técnicas da ttsDCS $\ldots \ldots \ldots$. . . . . . . . . 36

1.3 .4 Segurança da tsDCS . . . . . . . . . . . . . . . . . 39

1.3.5 Protocolo experimental dettsDCS . . . . . . . . . . . . . . . . 40

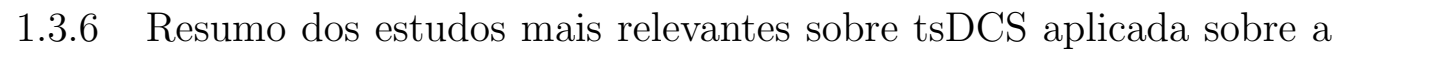
região da intumescência lombossacral . . . . . . . . . . . . . . . . . 41

1.4 Modelo computacional . . . . . . . . . . . . . . . . . . . . . 47

1.5 Controle postural . . . . . . . . . . . . . . . . . . . 51

1.5.1 Controle postural na postura ereta ortostática (PEO) . . . . . . . . 52

1.5 .2 Posturografia por plataforma de força . . . . . . . . . . . . 53 
$1.5 .3 \quad$ Parâmetros para quantificar o sinal do $\mathrm{COP}$. . . . . . . . . . . 55

\begin{tabular}{lll}
\hline 2 & Materiais e métodos & 74
\end{tabular}

2.1 Hipóteses do Trabalho . . . . . . . . . . . . . . . . . . . . . . . . . . . . . 74

2.1.1 Hipótese 1 - Utilização de um modelo computacional simplificado . 74

2.1 .2 Hipótese 2 - Adição de um terceiro eletrodo . . . . . . . . . . . . . 75

2.1 .3 Hipótese 3 - Aumento da dimensão do eletrodo . . . . . . . . . . . 77

2.1.4 Hipótese 4 - Aumento da corrente de estimulação . . . . . . . . . . 78

$2.1 .5 \quad$ Hipótese 5 - Efeito da|tsDCS na|PEO . . . . . . . . . . . . . . 80

2.2 Modelo computacional . . . . . . . . . . . . . . . . . . . . . . . . 81

2.2 .1 Modelo tridimensional . . . . . . . . . . . . . . . . . . . 81

$2.2 .2 \quad$ Configurações dos eletrodos utilizadas nas simulações $\quad$. . . . . . . . . 87

$2.2 .3 \quad$ Simulações $\ldots \ldots \ldots \ldots$

2.2 .4 Metodologia de análise das simulações $\quad$. . . . . . . . . . . . . . . . 91

2.2.4.1 Hipótese 1 - Utilização de um modelo computacional simplificado . . . . . . . . . . . . . . . . . . 9 91

2.2.4.2 Hipótese 2 - Adição de um terceiro eletrodo . . . . . . . . 92

2.2.4.3 Hipótese 3 - Aumento da dimensão do eletrodo . . . . . . 93

2.2.4.4 Hipótese 4 - Aumento da corrente de estimulação . . . . . 93

2.3 Protocolo Experimental $\ldots \ldots \ldots$. . . . . . . . . . . . . . . . . . . . . 94

$2.3 .1 \quad$ Participantes e recrutamento . . . . . . . . . . . . . . . . . . 94

2.3 .2 Protocolo deltsDCS $\ldots \ldots \ldots \ldots \ldots$

$2.3 .3 \quad$ Posturografia por plataforma de força . . . . . . . . . . . . . . . . . 99

2.3 .4 Protocolo experimental . . . . . . . . . . . . . . . . . . . . . . 101

2.3.4.1 Recepção do participante . . . . . . . . . . . . . . . . . 101

2.3.4.2 Posicionamento dos eletrodos . . . . . . . . . . . . 102

2.3.4.3 Posicionamento dos pés sobre a plataforma de força . . . . 104 
2.3.4.4 Conexão dos eletrodos ao estimulador elétrico . . . . . . . . 104

2.3.4.5 $\quad$ Instruções antes da coleta de dados $\ldots . . . . . .104$

2.3 .4 .6 Aquisição de dados . . . . . . . . . . . . . . . . 105

2.3.4.7 $\quad$ Sequência de cada aquisição de dados . . . . . . . . . . . 107

$2.3 .4 .8 \quad$ Finalização do experimento $\ldots$. . . . . . . . . . . . . . . . 108

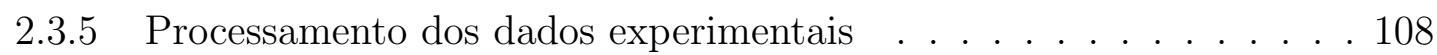

2.3.5.1 Transformação de unidades dos dados coletados da plataforma de força para o sistema métrico . . . . . . . . . . . 109

2.3.5.2 Cálculo da localização do COP . . . . . . . . . . . . . . . 110

2.3.5.3 Pré-processamento dos sinais . . . . . . . . . . . . . 110

2.3.5.4 Parâmetros do COP . . . . . . . . . . . . . 115

2.3.5.5 Parâmetros $S D, M V E L O$ e $A R E A E$. . . . . . . . 115

2.3.5.6 Parâmetros $P S D_{\_} A R E A, f 50 p_{-} P S D$ e $f 80 p_{-} P S D$. . . . 119

2.3.5.7 $\quad$ Parâmetros da SDA . . . . . . . . . . . . . . . . . . 122

2.3.5.8 Parâmetros da|FsFA . . . . . . . . . . . . . . . . 124

2.3.5.9 Parâmetros dalMSE . . . . . . . . . . . . . . . . . 127

$2.3 .6 \quad$ Análise do protocolo experimental . . . . . . . . . . . . . . . . . . . 130

2.3.6.1 Hipótese 5 - Efeito da|tsDCS na|PEO . . . . . . . . . . 130

\section{Resultados}

3.1 Resultados das simulações computacionais . . . . . . . . . . . . . . 133

3.1.1 Hipótese 1 - Utilização de um modelo computacional simplificado . 133

$3.1 .2 \quad$ Hipótese 2 - Adição de um terceiro eletrodo . . . . . . . . . . . . . 140

3.1 .3 Hipótese 3 - Aumento da dimensão do eletrodo . . . . . . . . . . . . 146

3.1 .4 Hipótese 4 - Aumento da corrente de estimulação . . . . . . . . . . 153

3.2 Resultados do protocolo experimental . . . . . . . . . . . . . . . . . . . 161

$3.2 .1 \quad$ Hipótese 5 - Efeito da tsDCS $\mid$ na $\mid \mathrm{PEO} \ldots \ldots$. . . . . . . . . . . 161 
$\begin{array}{lll}4 & \text { Discussão } & 174\end{array}$

5 Conclusão 183

\begin{tabular}{ll}
\hline Anexos & 184
\end{tabular}

A.1 Termo de consentimento livre e esclarecido (TCLE) . . . . . . . . . . . . 184

A.2 Questionário 1 do protocolo experimental . . . . . . . . . . . . . . . . . . 188

A.3 Questionário 2 do protocolo experimental . . . . . . . . . . . . . . . . . . . 190

A.4 Parâmetros da plataforma de força . . . . . . . . . . . . . . . . . . . . 192

A.5 Resultados experimentais . . . . . . . . . . . . . . . . . . 193

$\begin{array}{ll}\text { Referências } & 197\end{array}$ 


\section{INTRODUÇÃO}

Técnicas de estimulação elétrica para fins terapêuticos são utilizadas desde o início do século I (SARMIENTO; SAN-JUAN; PRASATH, 2016). Atualmente técnicas de estimulação elétrica são empregadas no tratamento de dor crônica (NNOAHAM; KUMBANG, 2008), na reabilitação (HOWLETT et al., 2015), no tratamento de tremor essencial (BENABID et al., 1991), no tratamento de alguns transtornos mentais (BRUNONI, 2016a) e na reversão de quadros de fibrilação ventricular (DESILVA et al., 1980). Essas técnicas são diferenciadas pela intensidade, pela duração, pelo posicionamento dos eletrodos de estimulação e pela forma de onda do estímulo elétrico aplicado no corpo humano. O foco desse trabalho será o estudo da técnica de estimulação transcutânea da medula espinhal por corrente contínua (tsDCS). Nessa técnica uma corrente elétrica de corrente contínua (CC) de baixa intensidade é aplicada durante alguns minutos de forma não invasiva sobre a região da medula espinhal humana. Nos últimos anos, estudos publicados sobre essa técnica de estimulação evidenciaram efeitos localizados no sistema nervoso central (SNC), Entretanto, talvez por ser ainda uma técnica relativamente nova, na literatura ainda existem poucos estudos dos efeitos funcionais da tsDCS sobre o sistema neuromuscular, como por exemplo, o efeito dessa estimulação no controle postural humano.

\subsection{Breve revisão histórica}

Nessa seção será apresentada uma breve revisão histórica sobre alguns tipos de estimulações elétricas transcutâneas utilizadas para fins terapêuticos de modo que o leitor obtenha um panorama cronológico simplificado da utilização de algumas dessas técnicas. Mesmo a tsDCS sendo uma técnica de CC, nessa revisão também serão apresentados fatos históricos de estimulações elétricas de corrente alternada (CA) uma vez que o progresso histórico das técnicas de estimulação de CC está atrelado à evolução da estimulação de CA. Os dados históricos que serão apresentados foram obtidos principalmente de textos sobre estimulação elétrica não invasiva de CC do cérebro humano estimulação transcraniana de corrente contínua (tDCS) que é a estimulação precursora da tsDCS. 


\subsubsection{Antes do século XVII}

A primeira evidência histórica da realização de uma estimulação elétrica para fins terapêuticos é a descrita pelo médico romano Scribonius Largus (1 - 50 dC) que utilizava os pulsos elétricos gerados por peixes torpedo (Torpedo Sinuspersici) em seus pacientes para o tratamento de dores de cabeça (Figura 1) (SARMIENTO; SAN-JUAN; PRASATH, 2016). Esse peixe possui músculos falsos (musculi falcati) capazes de gerar potenciais elétricos pulsados utilizados para afugentar predadores e paralisar presas. O tratamento descrito por Scribonius consistia em posicionar um peixe torpedo sobre o couro cabeludo do paciente e por meio dos estímulos elétricos gerados pelo animal era realizado um tipo rudimentar de estimulação elétrica transcraniana. Outros tipos de terapias de eletroestimulação utilizando o peixe torpedo foram desenvolvidos e empregados ao longo dos anos (TSOUCALAS et al. 2014). Até o fim da idade média o peixe torpedo era utilizado no tratamento de dores de cabeça, de gota, de epilepsia e até mesmo de prolapso retal.

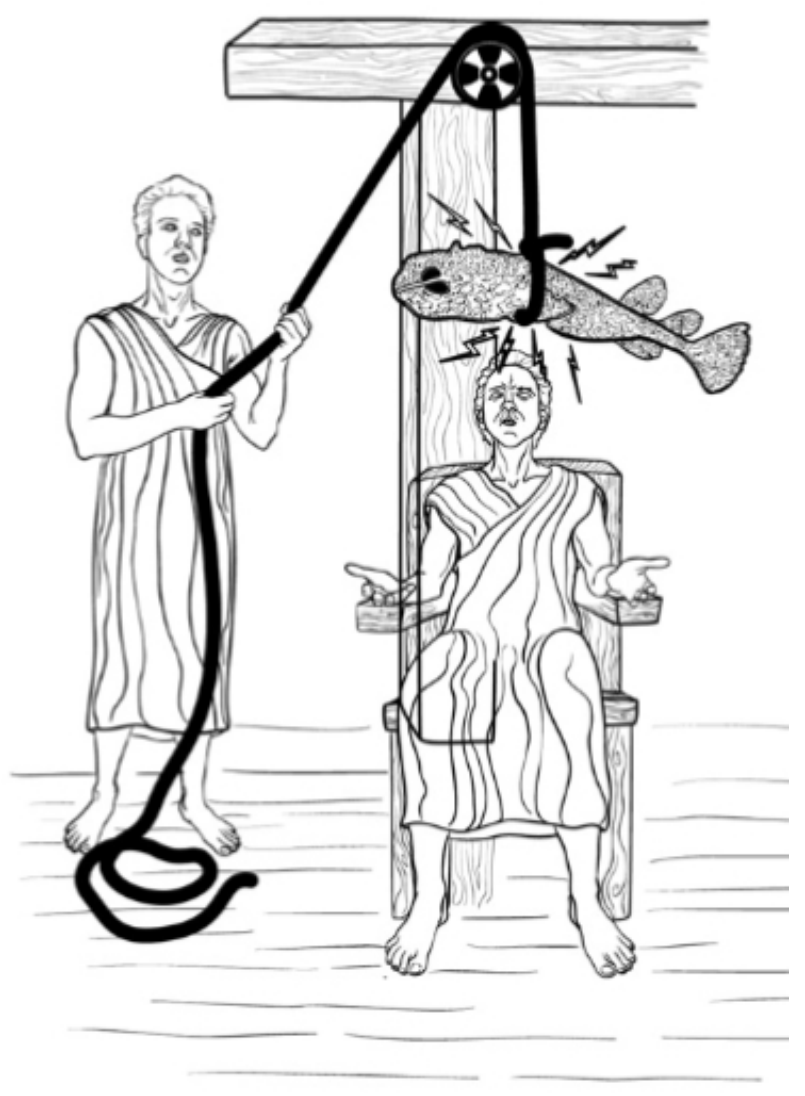

Figura 1: Representação da técnica de estimulação elétrica transcraniana utilizada por Scribonius Largus durante o século I para o tratamento de dores de cabeça utilizando a estimulação produzida por peixe torpedo.(Imagem adaptada de (GOLOVAC, 2010)) 


\subsubsection{Do século XVII ao século XIX}

No século XVII, a invenção do gerador eletrostático por Otto Von Guericke (16021686) e da garrafa de Leyden por Pieter van Musschenbroek (1692-1761) possibilitou que Jean Jallabert (1712 - 1768) realizasse as primeiras sessões de eletroterapia utilizando um aparato construído pelo ser humano, sem necessitar de estimulação elétrica produzida por um animal (MALMIVUO, 1995).

No século XVIII, os experimentos de eletrofisiologia de Luigi Galvani (1737-1798) e a invenção da bateria elétrica por Alessandro Volta (1745-1827) permitiram que Giovanni Aldini (1762 - 1834), sobrinho de Galvani, conduzisse experimentos de eletroestimulação em animais e em seres humanos utilizando pilhas elétricas (BRUNONI, 2016b), sendo uma das primeiras evidências históricas da realização de uma estimulação elétrica de CC. Aldini também realizava demonstrações públicas da aplicação de estímulos elétricos em cabeças de animais e em criminosos recém-executados, exibindo para a plateia o tremor de músculos mesmo após a morte. Na cidade de Glasgow do Reino Unido, Andrew Ure (1778-1857) também realizava demonstrações desse tipo. As exibições de Ure e Aldini possivelmente impulsionaram o surgimento de crenças populares sobre os "poderes milagrosos" da eletroestimulação e podem ter influenciado a escritora Mary Shelley (17971851) na elaboração do conhecido romance de terror gótico Frankenstein ou o Prometeu Moderno (1818) (BRUNONI, 2016b).

No século XIX, o médico neurologista Guillaume Duchenne (1806-1875), considerado pai da eletroterapia, empregava a eletroestimulação transcraniana para tratamento de patologias psiquiátricas, sendo esse tipo de tratamento popular até o final do século XIX (TSOUCALAS et al., 2014).

\subsubsection{Do século XX em diante}

No início do século XX, a falta de padronização de protocolos, o não entendimento dos mecanismos fisiológicos envolvidos e a obtenção de resultados controversos, fez com que a estimulação elétrica transcraniana passasse a ser vista com descrédito para utilização clínica pela comunidade científica (SARMIENTO; SAN-JUAN; PRASATH, 2016). Porém, na década de 60, motivados por estudos realizados em animais, LIPPOLD; REDFEARN verificaram que a tDCS de baixa intensidade (50-500uA) aplicada em seres humanos produzia a alteração do estado de alerta, de humor e da atividade motora dos pacientes (LIPPOLD; REDFEARN, 1964), promovendo o retorno do interesse da comunidade científica por esse tipo de estimulação (SARMIENTO; SAN-JUAN; PRASATH, 
2016).

Na década de 70, provavelmente com o surgimento de novas drogas efetivas no tratamento de patologias psiquiátricas, o interesse pela tDCS foi novamente reduzido. Porém, em 1998, com o estudo realizado por PRIORI et al. sobre os efeitos da tDCS na alteração do potencial motor evocado (MEP) em seres humanos, ocorreu o ressurgimento de trabalhos científicos nesse campo de estudo, originando a publicação de trabalhos com resultados significativos dos efeitos da tDCS (KNOTKOVA et al., 2019a).

Em 2008, COGIAMANIAN et al., influenciados pelos resultados dos estudos de tDCS, realizaram um estudo em seres humanos sobre os efeitos da estimulação elétrica de CC aplicada de forma não invasiva sobre a região da vértebra T10 com o objetivo de estimular a medula espinhal. Nesse estudo os autores verificaram que a tsDCS provocou alterações significativas no potencial somatossensorial evocado (SEP), promovendo o surgimento de trabalhos científicos nessa área nos anos seguintes.

A tsDCS e a tDCS utilizam corrente elétrica contínua e são empregadas com o principal objetivo de estimular tecidos do sistema nervoso. A principal diferença entre essas duas técnicas de estimulação é que a tDCS objetiva estimular os tecidos cerebrais, enquanto a tsDCS é utilizada para estimular os tecidos nervosos da medula espinhal. Como a tDCS é precursora da tsDCS e já é empregada clinicamente (BRUNONI, 2016a), os protocolos experimentais utilizados e mecanismos de ação propostos na tDCS podem, em algumas situações, ser utilizados para entender os efeitos datsDCS desde que as devidas diferenças entre as duas técnicas sejam levadas em conta.

Diversas outras técnicas de estimulação elétrica transcutânea, tanto de CC quanto de CA, com diferentes focos terapêuticos e não terapêuticos também foram desenvolvidas ao longo dos anos, como por exemplo a estimulação elétrica transcutânea de nervo (TENS) e a estimulação elétrica funcional (FES), que são amplamente empregadas em clínicas de fisioterapia para o tratamento de dor crônica e para a reabilitação motora de indivíduos que sofreram lesão medular ou acidente vascular encefálico (AVE) (NNOAHAM; KUMBANG, 2008; HOWLETT et al., 2015). Em face do enorme campo que ainda há pela frente em termos de aplicações clínicas, fica clara a importância da realização de estudos sobre novas técnicas de estimulação elétrica que podem vir a ser aplicadas em protocolos terapêuticos futuros. 


\subsection{Anatomia da medula espinhal humana}

\subsubsection{Estrutura geral da medula espinhal}

A medula espinhal é o alongamento do sistema nervoso central (SNC) na sua parte inferior e que fica alojado no canal da coluna vertebral (FORSEEN, 2015). A medula tem início na junção do crânio com a vértebra C1 e termina aproximadamente na altura da vértebra L2 (REIMANN; ANSON, 1944), tem dimensões aproximadas de 45,0 cm de comprimento, $1,0 \mathrm{~cm}$ de diâmetro transverso e $0,7 \mathrm{~cm}$ de diâmetro anteroposterior (AP) (FROSTELL et al., 2016). Em relação à superfície da pele, a medula se localiza a uma profundidade média de 5,5 cm (BRINKLEY; MASTERS, 1967).

Assim como o restante do SNC, a medula é revestida por três meninges, a dura-máter (mais externa), a aracnoide e a pia-máter (mais interna) (Figura 2). O espaço entre a duramáter e o canal vertebral (espaço epidural) é preenchido por tecido adiposo e por plexos venosos, enquanto que o espaço entre a aracnoide e a pia-máter (espaço subaracnóide) é preenchido por líquido cefalorraquidiano (LCR). 


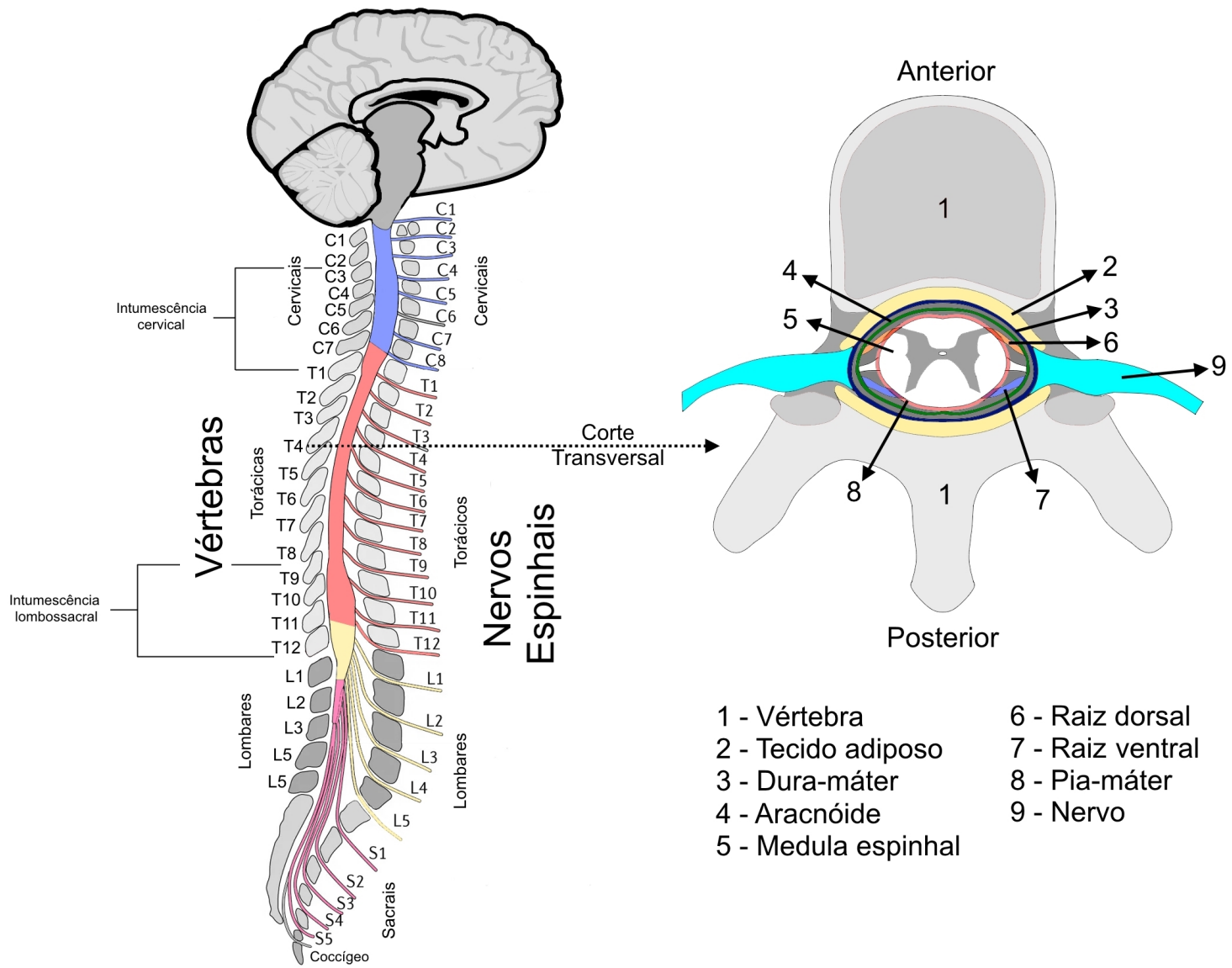

Figura 2: Esquema com detalhes anatômicos gerais da medula espinhal humana. À esquerda) localização da medula espinhal em relação às vértebras e localização das intumescências. À direita) corte transversal representativo da medula evidenciando as meninges.

Da medula emergem 31 pares de nervos espinhais, sendo 8 cervicais, 12 torácicos, 5 lombares, 5 sacrais e 1 coccígeo (CARPENTER, 1976). Em geral os nervos espinhais mais rostrais inervam regiões rostrais do corpo humano enquanto que os nervos mais caudais inervam regiões caudais. Cada nervo espinhal contém axônios tanto de neurônios periféricos aferentes quanto eferentes de diferentes sistemas (somatossensorial, motor e autônomo), sendo assim denominados de nervos mistos. Antes de se unirem à medula, os nervos espinhais se ramificam em duas raízes (Figura 3), uma dorsal, com axônios de neurônios aferentes, e uma ventral, com axônios de neurônios eferentes. A região de união das raízes à medula define os segmentos medulares. As raízes dorsais se unem à medula pelos chifres posteriores e as raízes ventrais pelos chifres anteriores da medula espinhal. $\mathrm{Na}$ raiz dorsal de cada nervo espinhal existe uma protuberância denominada gânglio que 
é formada pelos corpos celulares dos neurônios aferentes.

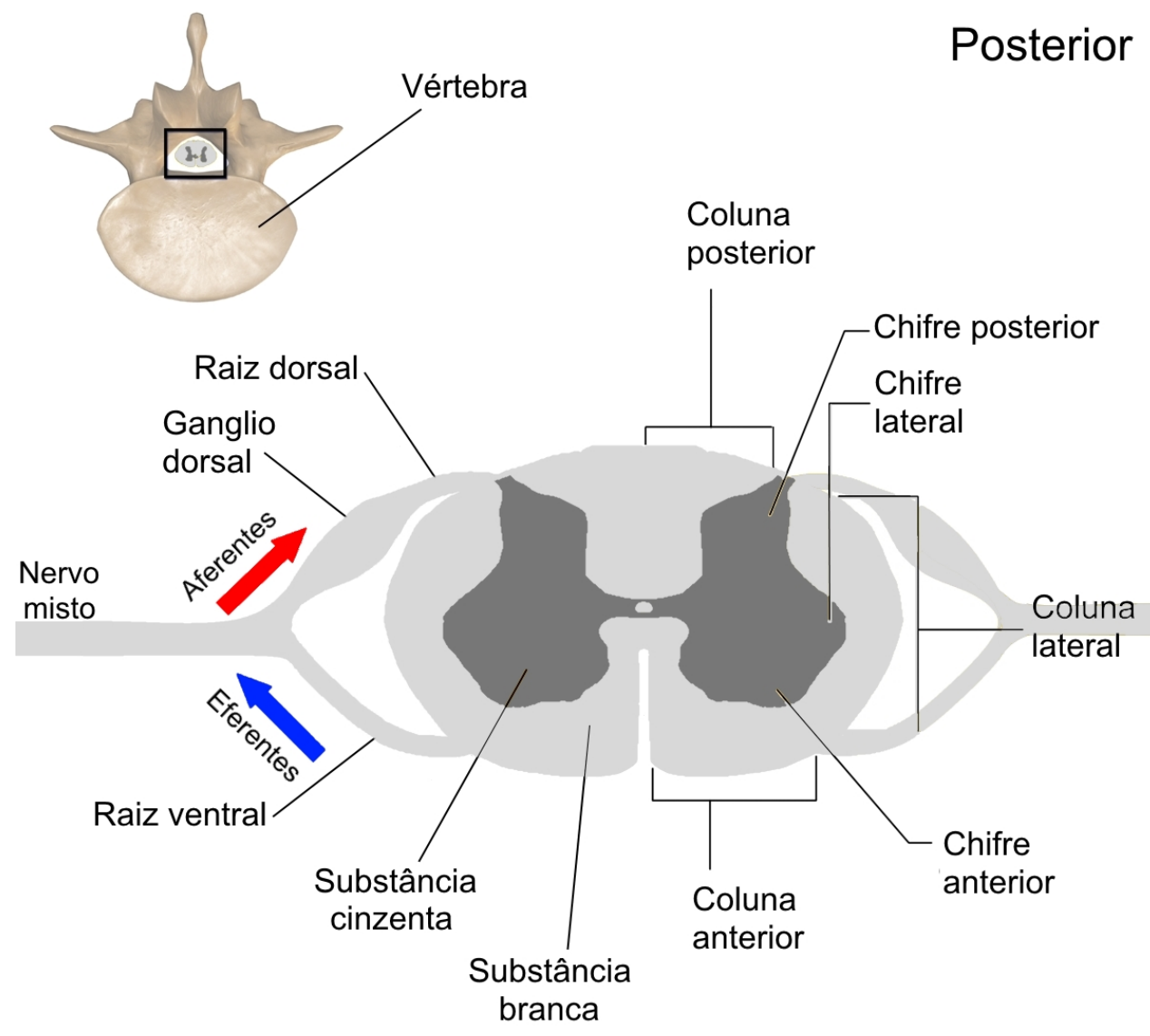

\section{Anterior}

Figura 3: Esquema de exemplificação dos detalhes da seção transversal da medula espinhal.

Ao longo da extensão da medula espinhal duas regiões de maior diâmetro são observadas, a intumescência cervical e a intumescência lombossacral (PUTZ, 2000). A intumescência cervical se encontra na região entre os segmentos medulares C3 e T2 (WARWICK, 1973), correspondendo à região entre as vértebras C3 e T2. A intumescência lombossacral se localiza entre os segmentos medulares L1 e S3, equivalendo à região que se estende da vértebra T9 à vértebra T12 (WARWICK, 1973), podendo se estender a níveis vertebrais mais baixos, dependendo da extensão total da medula espinhal (REIMANN; ANSON, 1944). As intumescências estão associadas às regiões de uniões dos nervos espinhais que inervam os membros superiores (mãos, braços e antebraços) e inferiores (pés, pernas e coxas), sendo que a intumescência cervical corresponde ao ponto de união de nervos originários dos membros superiores e a intumescência lombossacral dos membros inferiores (Figura 4). 


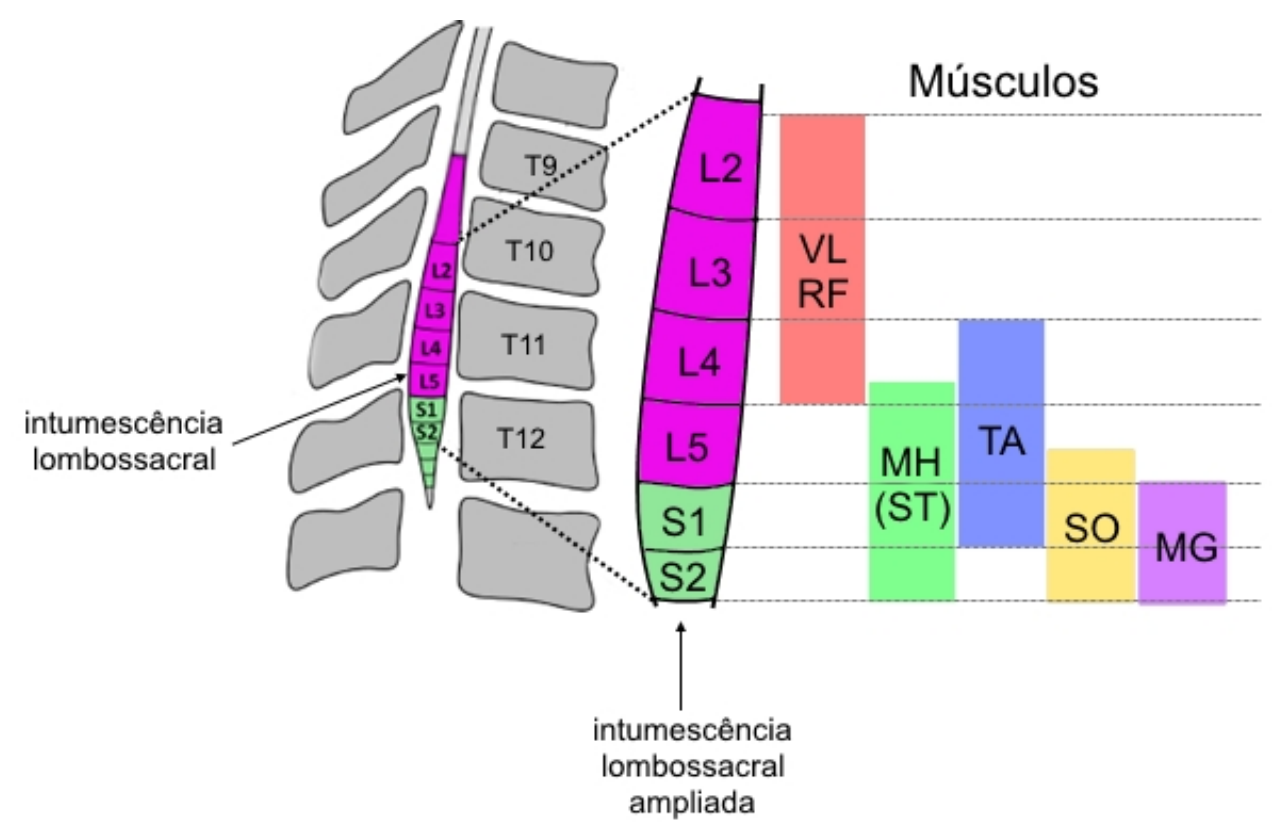

Figura 4: Detalhe da intumescência lombossacral exibindo a relação entre os segmentos medulares e os músculos inervados dos membros inferiores. Figura adaptada de (SAYENKO et al., 2015).VL, vasto lateral; RF, reto femoral; MH, isquiotibiais mediais; ST, semitendinoso; TA, tibial anterior; SO, sóleos; MG, gastrocnêmio medial.

A vista do corte transverso da medula (Figura 3) revela duas regiões distintas, uma externa denominada de substância branca e outra interna definida como substância cinzenta (DAFNY, 1997).

\subsubsection{Substância branca da medula espinhal}

A substância branca é a região mais externa da medula e é constituída principalmente por células gliais e por axônios dos neurônios do SNC, do sistema nervoso periférico (SNP) e do sistema nervoso autônomo (SNA). Essa região pode ser dividida em quatro regiões denominadas colunas (coluna dorsal, coluna ventral e colunas laterais) (Figura 3). Cada coluna pode ser fragmentada em sub-regiões designadas tratos (DAFNY, 1997) (Figura 5). Os tratos são definidos pelo agrupamento de axônios de neurônios que possuem pontos de origem e de destino similares. Os tratos podem ser ascendentes, formados por axônios de neurônios que enviam informações da medula ou de nervos periféricos para regiões supramedulares, ou descendentes que trazem informações de regiões supramedulares para a medula. Os nomes dos tratos são compostos pelo nome do local de origem seguido pelo nome do local de destino dos axônios, como por exemplo, o trato vestibuloespinhal que tem como origem o núcleo vestibular e como destino diferentes regiões da medula 
espinhal.

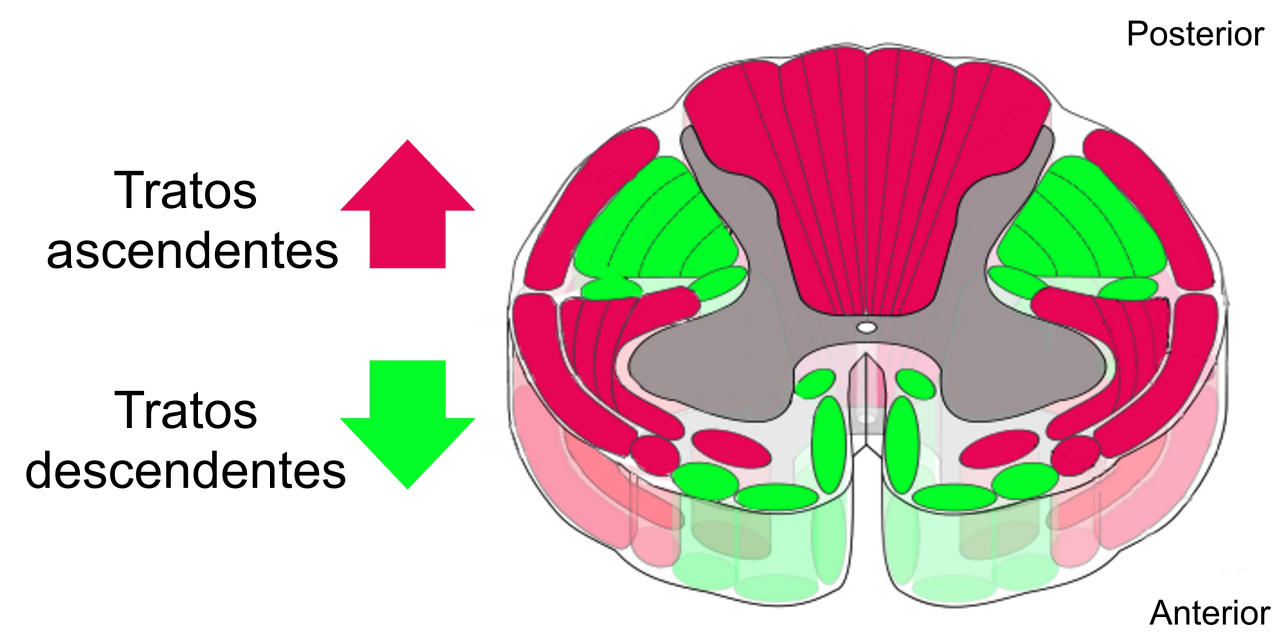

Figura 5: Esquema de exemplificação das subdivisões da substância branca da medula espinhal em tratos.

\subsubsection{Substância cinzenta da medula espinhal}

A substância cinzenta, localizada na parte mais central da medula espinhal, apresenta contorno parecido ao de uma borboleta (Figura 6) e é constituída principalmente por células gliais, por interneurônios, por corpos celulares e respectivas arborizações dendríticas de motoneurônios e por somas e partes dos axônios dos neurônios de outras regiões do SNC, do SNP e do SNA. É nessa região que ocorrem as sinapses de neurônios do SNP (neurônios aferentes e aferentes), do SNC (interneurônios e neurônios de regiões supramedulares) e do SNA. A substância cinzenta pode ser segmentada em 10 lâminas (lâminas de Rexed) (CARPENTER, 1976) (Figura 6) definidas pelas funções de cada segmento. De modo geral, em diferentes lâminas ocorrem sinapses de diferentes sistemas neurais, sendo que em geral em lâminas mais ventrais (anteriores) ocorrem principalmente sinapses relacionadas ao sistema motor e em lâminas mais dorsais (posteriores) sinapses relacionadas ao sistema somatosensorial . 


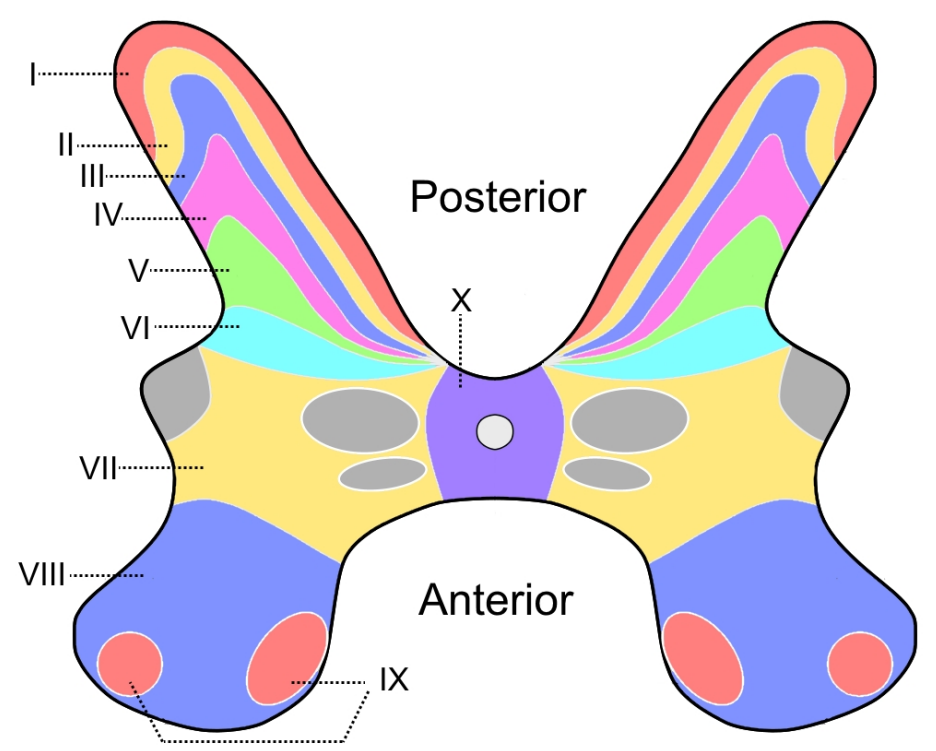

Figura 6: Esquema de exemplificação da divisão da medula espinhal em lâminas de Rexed.

\subsubsection{Circuitos neurais da medula espinhal}

O sistema nervoso humano é formado por bilhões de neurônios (HERCULANOHOUZEL, 2009) que realizam trilhões de sinapses (TANG et al., 2001). A maior parte dos circuitos neurais formados por esse complexo sistema de neurônios e sinapses ainda não foi desvendada ou não foi compreendida em sua totalidade.

Em seres humanos, diferentes metodologias experimentais são empregadas para o estudo dos circuitos neurais da medula espinhal, como por exemplo por meio da utilização de algum tipo de perturbação (elétrica, mecânica, térmica, nociva ou farmacológica) em alguma região do corpo (por exemplo nervo, pele ou músculo) e consequente mensuração de um parâmetro fisiológico afetado por essa perturbação (por exemplo, por meio da eletromiografia (EMG) ou por potenciais evocados) permitindo assim testar hipóteses sobre estruturas e comportamentos dos circuitos neurais da medula (DESSEILLIGNY,BURKE, 2012). Nessas pesquisas, também podem ser utilizados modelos animais (FINKEL; REDMAN, 1983 ) e/ou computacionais (CISI, 2007) que auxiliam na elaboração de novas hipóteses sobre as possíveis estruturas dos circuitos neurais que podem ser encontrados na medula espinhal bem como sobre suas possíveis formas de funcionamento.

Na região da intumescência lombossacral da medula espinhal estão localizados alguns dos primeiros circuitos neurais responsáveis pela integração das informações de neurônios associados aos membros inferiores e o SNC e alguns circuitos neurais relacionados com o sistema autonômico motor que atua nos órgãos reprodutivos, na bexiga e no intestino grosso (KANDEL JAMES H. SCHWARTZ, 2012). Na intumescência lombossacral 
alguns circuitos neurais oligossinápticos são conhecidos, como por exemplo alguns dos circuitos que atuam diretamente nos motoneurônios dos músculos tríceps sural (TS) e tibial anterior (TA) que estão relacionados com o sistema de controle postural humano (DESSEILLIGNY,BURKE, 2012).

\subsection{Estimulação elétrica do tipo tsDCS}

\subsubsection{Introdução sobre a tsDCS}

A estimulação transcutânea da medula espinhal por corrente contínua (tsDCS) é a técnica de estimulação elétrica que tem como principal objetivo estimular eletricamente o tecido nervoso da medula espinhal de forma não invasiva com corrente elétrica contínua. Nessa técnica é utilizada uma corrente elétrica de baixa intensidade, aplicada durante alguns minutos, por um par de eletrodos afixados à pele e conectados a uma fonte de corrente elétrica que induz a passagem de corrente elétrica contínua pelo tronco humano e consequentemente pela medula espinhal (Figura 7). A passagem de corrente elétrica contínua pela medula causa a alteração do comportamento elétrico dos neurônios dessa região (KNOTKOVA et al., 2019b) que, em alguns casos, pode ser observada mesmo após algumas horas do término da estimulação (LIM; SHIN, 2011). Por utilizar uma forma de onda simples (CC de baixa intensidade) esse tipo de estimulação pode ser gerado por dispositivos de baixo custo, que podem ser operados por pessoas com pouco treinamento fora do ambiente clínico/hospitalar, o que torna essa técnica atrativa para possíveis aplicações terapêuticas futuras. 


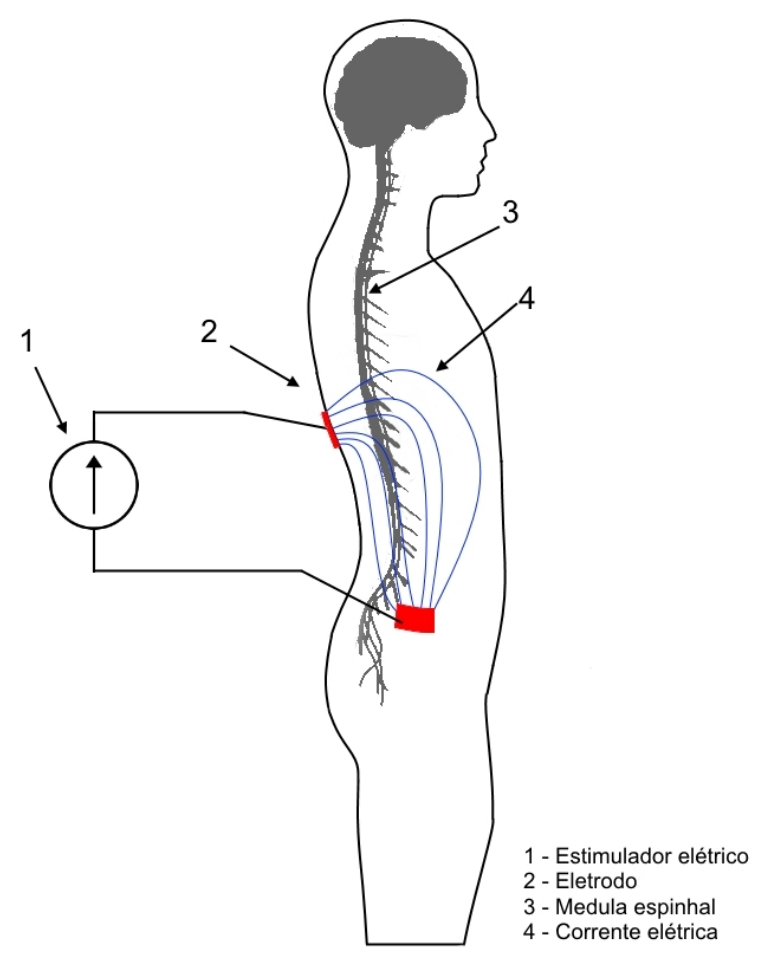

Figura 7: Esquema ilustrativo dattsDCS, Em geral esse tipo de estimulação é realizada com um par de eletrodos afixados à pele e conectados a uma fonte de corrente elétrica constante que induz a circulação de corrente elétrica pelo tronco humano, e consequentemente pela medula espinhal.

\subsubsection{Efeito da tsDCS nos neurônios da medula}

Neurônios são as células responsáveis pela integração e transmissão de informações no sistema nervoso. Os neurônios possuem em sua membrana celular canais iônicos que permitem a passagem seletiva de íons entre o meio extracelular e o meio intracelular. Devido à diferença de concentrações iônicas e à permeabilidade seletiva de íons da membrana celular, existe uma diferença de potencial elétrico entre o meio extracelular e o meio intracelular, denominada potencial de membrana. Como a dinâmica da condutividade iônica de alguns dos canais iônicos é controlada pelo potencial de membrana, quando um dado neurônio é influenciado pela atividade de outros neurônios, poderá haver a geração de potencial de ação (PA) que se propaga ao longo da extensão da membrana celular (Figura 8), sendo esse o fenômeno fundamental para a geração e para a transmissão de informações no sistema nervo. (BEAR; CONNORS; PARADISO, 2001). 


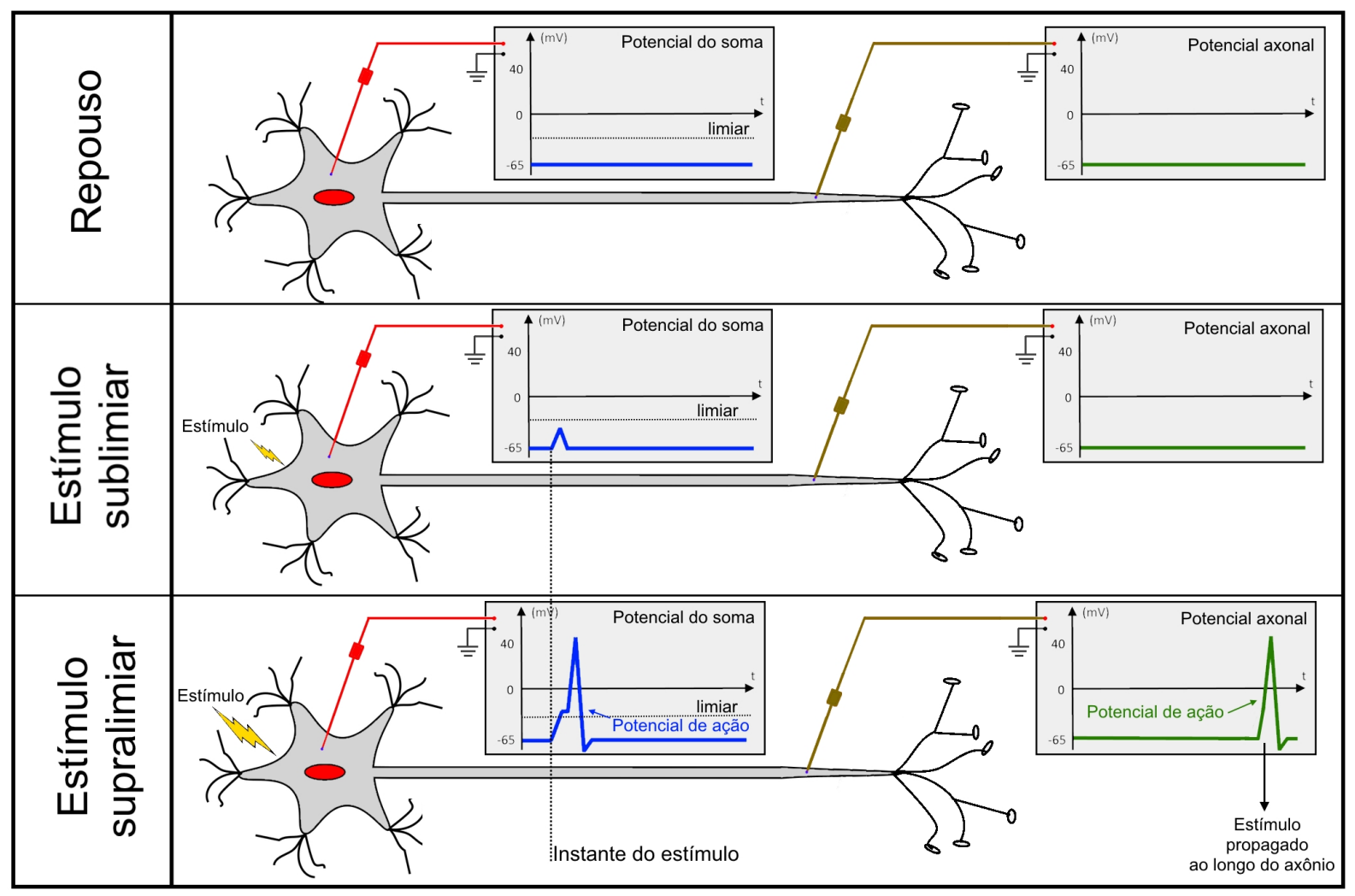

Figura 8: Ilustração da geração e propagação de um $\mathrm{PA}$ em um neurônio. Repouso) Nessa situação o neurônio se encontra em repouso e em geral possui potencial elétrico do meio intracelular menor do que o meio extracelular. Estímulo sublimiar) Nessa situação o neurônio é estimulado por um estímulo que despolariza o meio intracelular mas que não é suficiente para gerar um PA. Estímulo supralimiar) Nessa situação o neurônio é estimulado por um estímulo que despolariza o meio intracelular de modo que ocorre a geração e propagação de um $\mathrm{PA}$ devido à dinâmica de condutividade dos canais iônicos da membrana celular do neurônio.

Em um neurônio imerso em um volume condutor em que flui uma corrente elétrica $\mathrm{CC}$, como é o caso de um neurônio localizado na região da medula espinhal estimulada pela tsDCS, parte da corrente elétrica que percorre o volume condutor atravessa o neurônio, já que esse apresenta condutividade elétrica não nula. Dependendo da orientação dos compartimentos do neurônio (axônio, soma ou dendrito) em relação ao campo vetorial de densidade de corrente elétrica $(\vec{J})$ gerado pelo campo elétrico, os potenciais de membrana dos compartimentos podem sofrer modificações (Figura 9, página 35). Devido à baixa intensidade de corrente utilizada em protocolos de tsDCS, a modificação do potencial de membrana é muito menor do que a necessária para resultar no disparo de PAs (KUCK; 
STEGEMAN; ASSELDONK, 2017). Porém mesmo uma pequena alteração do potencial de membrana é suficiente para modificar a excitabilidade do neurônio a excitação ou inibição gerados por outros neurônios. Pequenas hiperpolarizações causadas pela tsDCS podem fazer com que estímulos que geravam disparos de PAs antes da tsDCS não gerem PAs durante a tsDCS. Assim como pequenas despolarizações podem transformar estímulos que não geravam disparos de $\mathrm{PA}$ em estímulos capazes de gerar $\mathrm{PA}$ (Figura 9, página 35 . 


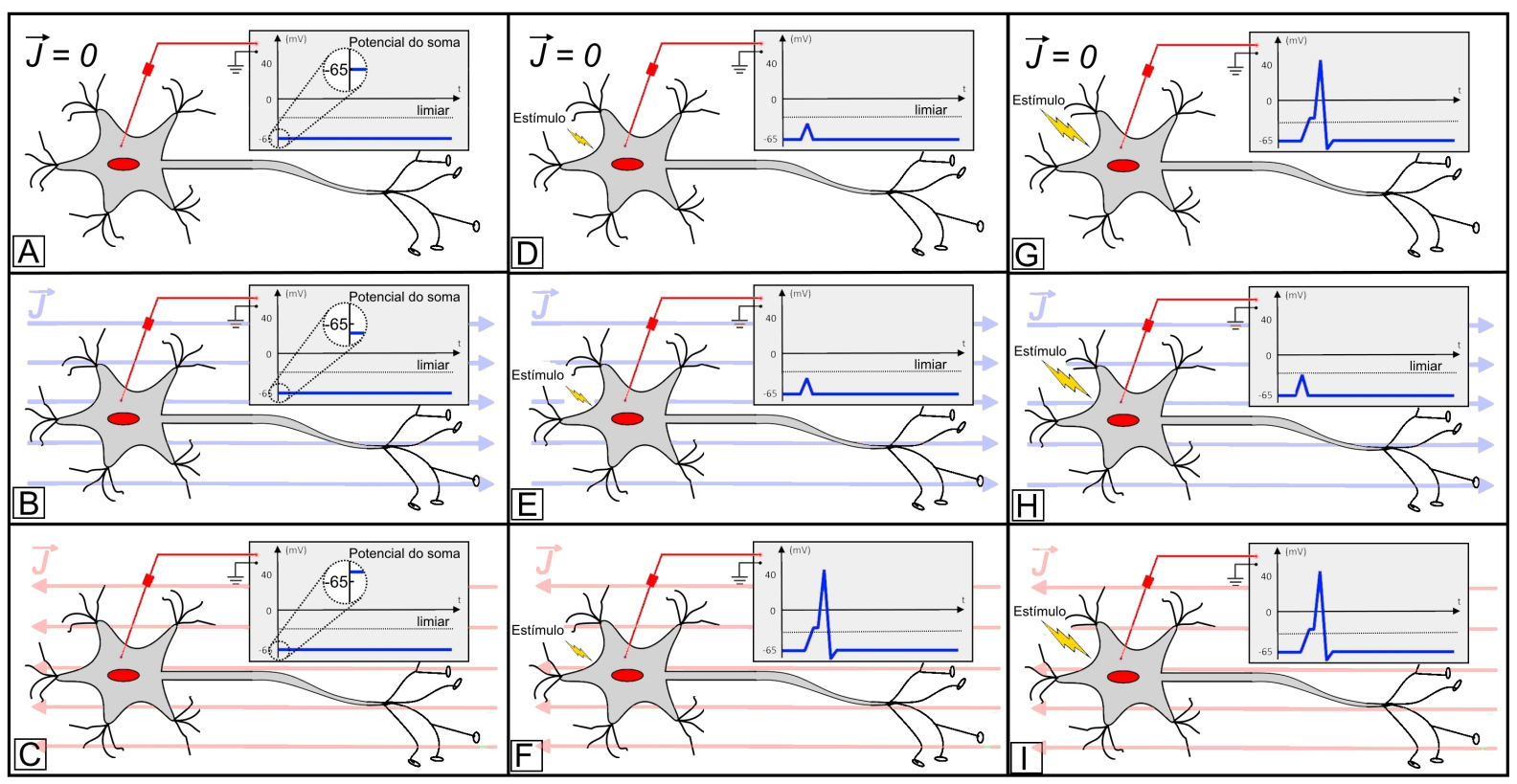

Figura 9: Efeitos observados em um neurônio imerso em um volume condutor em que flui uma corrente elétrica CC, A) Neurônio em repouso imerso em um volume condutor em que não flui corrente elétrica $(\vec{J}=0)$. B) Neurônio em repouso imerso em um volume condutor em que flui corrente elétrica de baixa intensidade fluindo na direção do soma para o axônio, resultando em uma leve hiperpolarização do soma. C) Neurônio em repouso imerso em um volume condutor em que flui corrente elétrica de baixa intensidade fluindo na direção do axônio para o soma, resultando em uma leve despolarização do soma. D) Neurônio nas mesmas condições de "A" que recebe estímulo sublimiar próximo ao limiar de disparo.E) Neurônio nas mesmas condições de "B" que recebe estímulo semelhante ao de "D" que também não resulta em um PA, já que nessa situação o soma se encontra levemente hiperpolarizado. F) Neurônio nas mesmas condições de "C" que recebe estímulo semelhante ao de "D" porém devido a leve despolarização do soma, resulta em um PA, G) Neurônio nas mesmas condições de "A" que recebe estímulo supralimiar próximo ao limiar de disparo. H) Neurônio nas mesmas condições de "B" que recebe estímulo semelhante ao de "G" porém que que não resulta em umPA devido a leve hiperpolarização inicial do soma. I) Neurônio nas mesmas condições de "C" que recebe estímulo de mesma intensidade do que em "G" que resulta em um PAjá que o soma estava levemente depolarizado.(Ilustração elaborada com base nas informações de (KNOTKOVA et al., 2019b))

Uma pequena alteração da excitabilidade de alguns neurônios provocada pela tsDCS pode induzir alterações na frequência e nos instantes de disparos de $\mathrm{PA} s$, tanto destes neurônios quanto de outros que estão a eles interligados. Podendo assim resultar em mo- 
dificações nos canais iônicos da membrana celular desses neurônios, como por exemplo nos canais iônicos de cálcio tensão dependentes do tipo L (L-VGCC) e nos receptores N-metil-D-aspartato (NMDA), sendo esse um dos possíveis mecanismos responsáveis pela persistência dos efeitos da tsDCS após o término da estimulação (KNOTKOVA et al., 2019b). Outros mecanismos também ocorrer durante a tsDCS, como por exemplo a migração espacial dos canais iônicos da membrana celular dos neurônios induzida pelo campo elétrico gerado pela estimulação elétrica, a atuação da tsDCS em tecidos não neuronais, como por exemplo em células gliais e/ou em vasos sanguíneos, a alteração de concentração de neurotransmissores provocada pela migração dessas moléculas pelo campo elétrico gerado pela tsDCS e/ou a ocorrência de micro-galvanotropismo sináptico KNOTKOVA et al. 2019b).

Estudos teórico-computacionais sobre tDCS (MIRANDA et al., 2013; DMOCHOWSKI et al., 2011; SATURNINO; ANTUNES; THIELSCHER, 2015), estimaram que o campo elétrico induzido em neurônios da região cortical estimulada em protocolos em que foram observados efeitos significativos, era de no mínimo 0,15 V/m. Essa intensidade de campo elétrico pode ser adotada como valor suficiente para a indução de algum tipo de neuromodulação na medula espinhal em protocolos de tsDCS (FERNANDES et al., 2018).

\subsubsection{Características técnicas da tsDCS}

Dependendo do posicionamento dos eletrodos no corpo humano, a tsDCS pode atuar em diferentes regiões da medula espinhal. Para o estudo dos efeitos dessa técnica em regiões da medula relacionadas com os membros inferiores, os eletrodos são posicionados de modo que a corrente elétrica atravesse a região da intumescência lombossacral. Sendo assim, em geral, um dos eletrodos é posicionado sobre a região entre as vértebras T10 e T12 e outro eletrodo é posicionado em uma região distante da medula, como por exemplo sobre os ombros, sobre os braços ou sobre as cristas ilíacas. A distribuição de corrente elétrica gerada na medula espinhal depende tanto do eletrodo posicionado sobre a região da medula quanto do eletrodo posicionado em uma posição mais afastada (PARAZZINI et al. 2014), desta forma, por exemplo, a distribuição de corrente elétrica no tronco humano obtida pelo posicionamento de um eletrodo sobre a vértebra T10 e outro sobre o ombro direito é diferente da distribuição obtida por um eletrodo sobre a vértebra T10 e outro sobre a crista ilíaca direita (Figura 10). Para otimizar a estimulação da região da intumescência lombossacral o eletrodo sobre a medula espinhal deve ser posicionado sobre a vértebra T10 e o eletrodo distante da medula deve ser posicionado sobre a crista ilíaca direita, resultando em uma maior densidade de corrente sobre essa região FERNANDES 
et al. 2018).

Por definição ânodo é o eletrodo que atrai ânions (íons com carga elétrica negativa) e cátodo é o eletrodo que atrai cátions (íons com carga elétrica positiva). Dessa forma, na tsDCS o eletrodo conectado ao terminal positivo $(+)$ do estimulador elétrico atua como ânodo e o conectado ao terminal negativo (-) atua como cátodo.
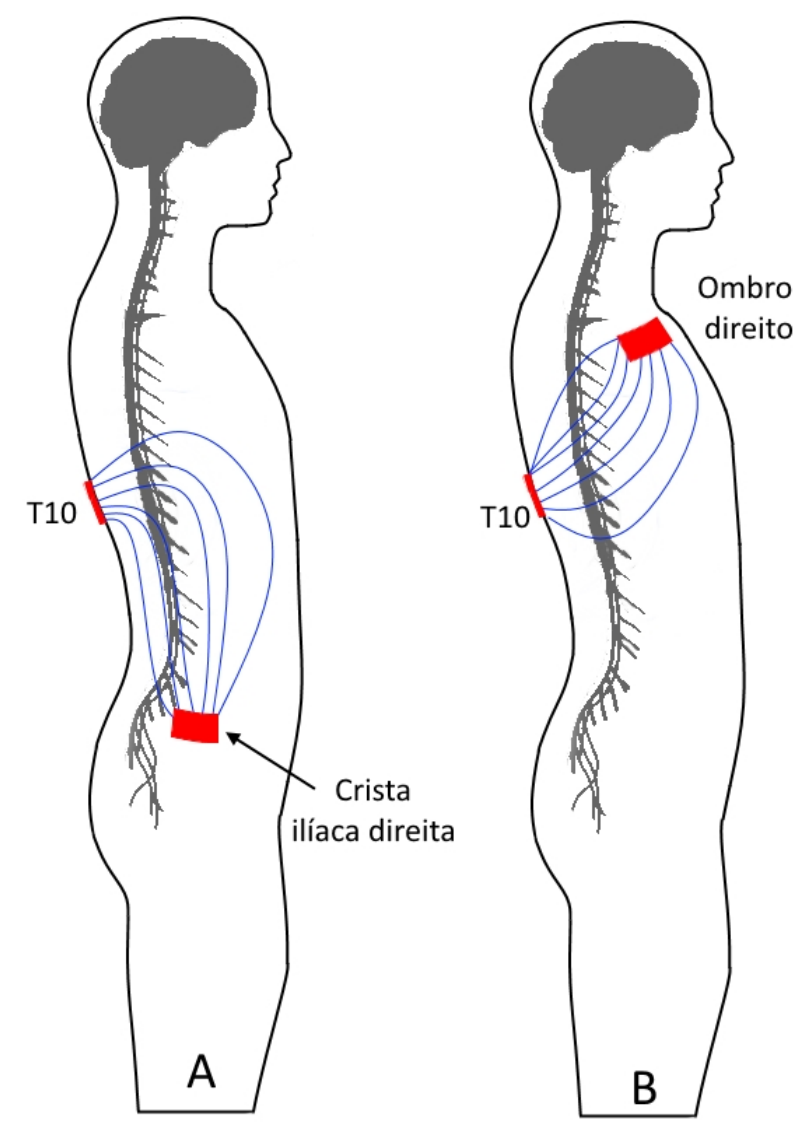

Figura 10: Ilustração das diferenças da distribuição de corrente elétrica no tronco humano causadas pelo posicionamentos de eletrodos, mesmo quando o eletrodo posicionado sobre a medula espinhal (nesse caso sobre a vértebra T10) se mantém na mesma posição. A) Eletrodos sobre a vértebra T10 e sobre a crista ilíaca direita. B) Eletrodos sobre a vértebra T10 e sobre o ombro direito. (Ilustração elaborada com base nos resultados obtidos por (KUCK; STEGEMAN; ASSELDONK, 2017))

$\mathrm{Na}$ tsDCS os eletrodos em contato com a pele permitem que a corrente elétrica do estimulador elétrico seja transformada em corrente iônica que flui pelo corpo humano (WEBSTER, 2009). Podem ser utilizados eletrodos do tipo auto-adesivos descartáveis (WINKLER; HERING; STRAUBE, 2010) ou eletrodos de esponja embebida em solução salina com concentração de 0,9\% (LENOIR; JANKOVSKI; MOURAUX, 2018). A maior parte dos estudos são conduzidos com eletrodos de esponja embebida em solução salina 
com área total de $35 \mathrm{~cm}^{2}$. A intensidade de corrente elétrica utilizada em protocolos de tsDCS em geral possui valores de $2 \mathrm{~mA}$ a $2,5 \mathrm{~mA}$ e a estimulação possui duração total de até 20 minutos (Verificar subseção 1.3.6.).

Os possíveis efeitos da tsDCS, na maior parte das vezes, são investigados utilizando-se duas polaridades: 1) eletrodo sobre a medula espinhal como ânodo e eletrodo distante da medula como cátodo, ou 2) eletrodo sobre medula como cátodo e eletrodo distante como ânodo (Figura 11).

No início da estimulação elétrica, em geral, a corrente elétrica é aplicada de forma gradual, por exemplo, com razão de $0,25 \mathrm{~mA} / \mathrm{s}$, de modo a minimizar mudanças bruscas de correntes que possam ocasionar a contração de músculos ou o disparo terminações nervosas subcutâneas.

Um protocolo de tsDCS pode ser caracterizado por quatro parâmetros: 1) dimensão e posicionamento dos eletrodos, 2) duração da estimulação, 3) polaridade dos eletrodos e 4) intensidade da corrente elétrica de estimulação.

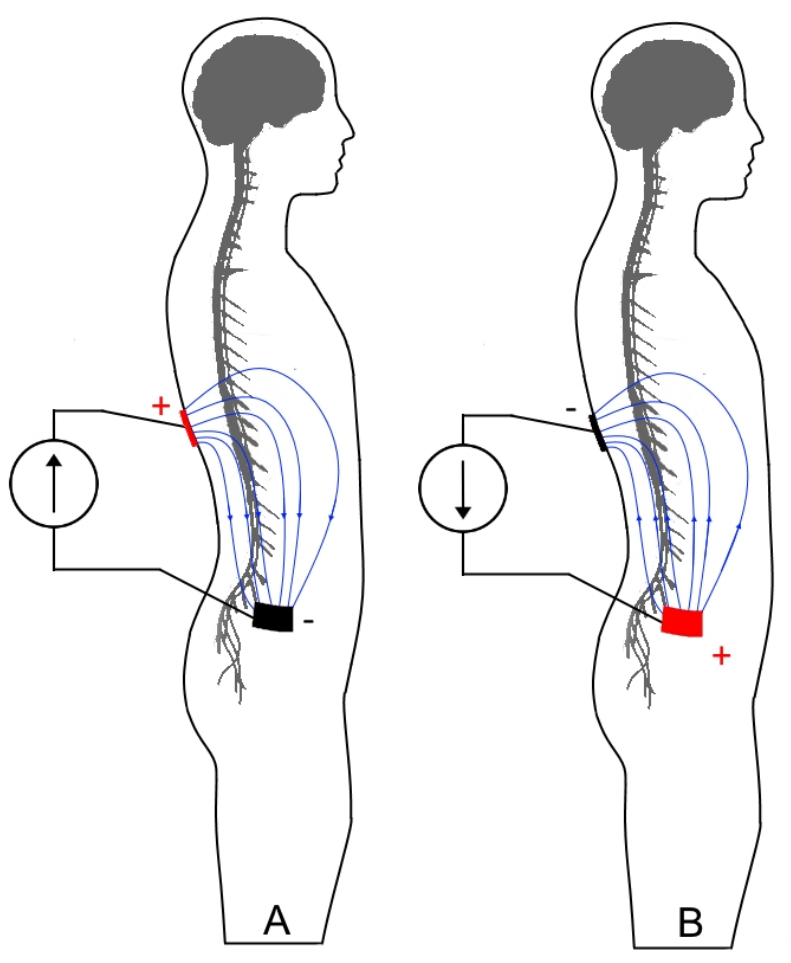

Figura 11: Ilustração das duas possíveis polaridades de aplicação da tsDCS, A) Eletrodo sobre a medula como ânodo e eletrodo distante da medula espinhal como cátodo. B) Eletrodo sobre medula como cátodo e eletrodo distante como ânodo.(Ilustração elaborada com base nos resultados obtidos por (KUCK; STEGEMAN; ASSELDONK, 2017))

Durante os minutos iniciais da estimulação elétrica, é comum a percepção de algumas 
experiências sensoriais na região da pele em contato com os eletrodos como, por exemplo, coceira, formigamento e/ou queimação. A intensidade e a duração dessas sensações depende da densidade de corrente empregada no protocolo. Quanto menor a densidade de corrente, menor a duração e a percepção das experiências sensoriais iniciais. Também é comum a ocorrência de eritema (vermelhidão da pele) na região dos eletrodos após o término da sessão de estimulação.

\subsubsection{Segurança da tsDCS}

A intensidade de corrente elétrica utilizada em um protocolo experimental de tsDCS é selecionada de modo a não causar qualquer dano ao indivíduo submetido a essa técnica. Os critérios de segurança utilizados em protocolos de tsDCS são baseados nos critérios adotados em estudos de tDCS que indicam que a densidade de corrente aplicada em tecidos neurais não pode ser superior a 6,3 A/m² (KNOTKOVA et al., 2019c). Essa densidade de corrente em um protocolo típico de tDCS, com eletrodos com área de $25 \mathrm{~cm}^{2}$, é alcançada com uma intensidade de corrente elétrica de $67 \mathrm{~mA}$, já em protocolos de tsDCS, com eletrodos com área de $35 \mathrm{~cm}^{2}$, essa corrente máxima seria de aproximadamente 94 $\mathrm{mA}$, valor muito maior do que a intensidade que tem sido empregada em protocolos de tsDCS,

Estudos em humanos utilizando tDCS verificaram que embora fosse notado eritema moderado temporário na região da pele em contato com os eletrodos, não foi possível identificar qualquer tipo de lesão permanente no SNC ou em outros tecidos (KNOTKOVA et al. 2019c). Resultado semelhante também foi obtido em estudo de tsDCS com humanos (COGIAMANIAN et al., 2008). Em geral a tDCS não provoca elevação de temperatura significativa na pele em contato com os eletrodos de estimulação, evidenciando a impossibilidade de ocorrência de danos irreversíveis em tecidos nervosos por aquecimento (KNOTKOVA et al., 2019c). Também não foram encontradas evidências diretas em experimentos em humanos de lesões teciduais ou alterações de comportamento relacionadas a lesões do SNC (KNOTKOVA et al., 2019c).

De modo a evitar caminhos de alta condutividade elétrica gerados por micro lesões na região da pele em contato com os eletrodos, que podem resultar em lesões e desconforto durante a tsDCS, a pele em contato com os eletrodos de estimulação deve ser limpa apenas com algodão e álcool e deve ser evitada a abrasão (KNOTKOVA et al., 2019c).

Em crianças, por terem o $\mathrm{SNC}$ ainda em desenvolvimento, em pacientes com implantes metálicos no corpo ou em indivíduos com algum tipo de malformação devem ser adotados critérios mais rigorosos de segurança, já que nesses casos a estimulação elétrica pode 
induzir efeitos não conhecidos.

\subsubsection{Protocolo experimental de tsDCS}

Os protocolos experimentais de tsDCS são desenvolvidos de modo que se possa realizar testes de hipóteses sobre esse tipo de estimulação, como por exemplo verificar se a tsDCS influencia a percepção de dor (COGIAMANIAN et al., 2011) ou se ela provoca alteração nos reflexos medulares (LAMY et al., 2012). Em geral os estudos sobre tsDCS são realizados em três sessões experimentais com os mesmos participantes, duas sessões em que a tsDCS é executada com polaridades distintas e uma sessão placebo em que é aplicada uma estimulação elétrica mimetiza a percepção da estimulação embora seja incapaz de gerar neuromodulação significativa. Em cada sessão experimental são realizadas coletas de dados antes, durante e depois da estimulação elétrica, permitindo a verificação da existência de efeitos significativos tanto no tempo (antes, durante e depois da tsDCS) de cada sessão quanto em sessões diferentes (placebo e em polaridades de corrente elétrica diferentes). As sessões experimentais são executadas em dias diferentes, com espaçamento mínimo de dois dias entre sessões, de modo a minimizar os efeitos que uma estimulação elétrica realizada em uma sessão experimental possa causar em outra.

Em estudos sobre tsDCS é comum a nomeação da sessão em que o cátodo é posicionado sobre a medula espinhal de tsDCS-catódica ou c-tsDCS, e a sessão em que o ânodo é posicionado sobre a medula espinhal de sessão tsDCS-anódica ou a-tsDCS. Esse tipo de nomeação facilita a identificação das sessões experimentais, porém ignora o fato de que em ambas sessões tanto o cátodo como o ânodo estão presentes e de que o efeito da tsDCS se deve tanto pelo posicionamento do cátodo como do ânodo (KNOTKOVA et al., 2019d). A sessão experimental placebo é desenvolvida de modo que o participante do experimento não consiga notar diferenças entre a sessão placebo e as outras sessões experimentais. Para alcançar esse objetivo algumas metologias experimentais podem ser empregadas, como por exemplo, tentar imitar as sensações produzidas pela tsDCS por meio de uma estimulação CC de curta duração (LAMY et al., 2012), ou por meio de uma estimulação elétrica pulsada (WINKLER; HERING; STRAUBE, 2010), ou ainda utilizar um creme anestésico na região da pele em contato com os eletrodos em todas as sessões experimentais (GUARIENTI et al., 2015). 


\subsubsection{Resumo dos estudos mais relevantes sobre tsDCS aplicada sobre a região da intumescência lombossacral}

Em 2008, COGIAMANIAN et al. observaram que a tsDCS (15 minutos, 2,5 mA, eletrodos de $35 \mathrm{~cm}^{2}$ sobre T10 e ombro direito) provocava a diminuição do potencial somatossensorial evocado (SEP) produzido pela estimulação do nervo tibial posterior (PTN), mesmo 20 minutos após o término da tsDCS. Esse resultado foi obtido apenas na sessão (A-T10,C-Od), Nas sessões (Placebo) e (C-T10,A-Od) o SEP não foi alterado. A interpretação dos autores para esse resultado foi que, possivelmente na sessão (A-T10,C-Od) ocorreu o bloqueio de $\mathrm{PA}$ s dos axônios do sistema somatossensorial na coluna posterior da medula espinhal por meio do fenômeno conhecido como bloqueio anódico. Nesse estudo os autores também observaram que não havia alteração significativa do SEP pela estimulação do nervo mediano (NM) utilizando os mesmos parâmetros de tsDCS, indicando que resultado obtido estava relacionado com a estimulação da região da medula espinhal localizada próxima ao eletrodo, e não com outras regiões medulares ou supramedulares. Nesse estudo, por meio da verificação da concentração de um marcador de danos neuronais, também foi constatado que, para as condições experimentais utilizadas, a tsDCS era uma técnica segura.

Em 2010, WINKLER; HERING; STRAUBE verificaram que, durante estimulação do PTN e captação de EMG do músculo sóleos (SO), a tsDCS (15 minutos, 2,5 mA, eletrodos de $40 \mathrm{~cm}^{2}$ sobre T11 e região infraclavicular) provocou alteração da depressão homossináptica (depressão da pós ativação do reflexo H ou depressão do reflexo H (HD)) enquanto que a relação entre a amplitude máxima da onda H (Hmáx) e a amplitude máxima da onda M (Mmáx) permaneceu constante. A alteração da HD foi significativa tanto durante quanto 15 minutos após o término da estimulação, apenas na sessão (A-T11,C-In), Nas sessões (Placebo) e (C-T11,A-In) não foi observada alteração significativa da HD. A interpretação desse resultado foi que, na sessão (A-T11,C-In), já que a relação Hmáx Mmáx permaneceu constante, o efeito possivelmente não foi induzido pela alteração direta da excitabilidade dos motoneurônios às entradas sinápticas e ocorreu a modulação da eficiência sináptica dos circuitos monossinápticos formados pelos motoneurônios e neurônios aferentes do tipo Ia do músculo $\mathrm{SO}$.

Em 2011, COGIAMANIAN et al. constataram que a tsDCS (15 minutos, 2,0 mA, eletrodos de $35 \mathrm{~cm}^{2}$ sobre T10 e ombro direito) alterou o reflexo nociceptivo de membros inferiores, com efeitos significativos tanto durante quanto depois de 30 minutos do término da estimulação elétrica. Nesse estudo o reflexo nociceptivo foi obtido pela estimulação do nervo sural (NS) e captação de EMG do músculo bíceps femoral (BF). Também foi reali- 
zada a análise do reflexo H pela estimulação do PTNe captação de EMG do músculo SO. $\mathrm{Na}$ sessão experimental (A-T10,C-Od) foi verificada a alteração significativa do reflexo nociceptivo enquanto que o reflexo H não apresentou alterações significativas. Os autores apresentaram a hipótese de atuação da tsDCS sobre o ganho na rede de transmissão de informação medular nociceptiva por meio da modulação da atividade de interneurônios dessa rede. A não alteração do reflexo H permitiu a conclusão de que o efeito observado poderia ser devido às alterações do circuito nociceptivo e não ser decorrente da modificação da excitabilidade dos motoneurônios.

Em 2011, TRUINI et al. verificaram que a tsDCS (20 minutos, 2,5 mA, eletrodos de $35 \mathrm{~cm}^{2}$ sobre T10 e ombro direito) provocou alterações do potencial evocado por laser (LEP) pela estimulação da parte dorsal do pé. Esse efeito só foi observado na sessão experimental (A-T10,C-Od), Os autores também observaram que a tsDCS aumentou a tolerância dos participantes à dor. Por meio da obtenção do LEP por estimulação da região perioral, concluíram que a tsDCS atuava localmente na medula, possivelmente não afetando circuitos supramedulares, e que o mecanismo de ação da tsDCS, nas condições do experimento, não estava relacionado com a teoria de portão de dor ou pela ativação de controles difusos inibitórios de dor, já que a mesma estimulação elétrica realizada em uma área distante da medula não provocou efeitos semelhantes.

Em 2012, LAMY et al. observaram que a tsDCS (25 minutos, 2,5 mA, eletrodos de 35 $\mathrm{cm}^{2}$ sobre T10 T11 e ombro direito), na situação ânodo sobre T10, deslocava a curva de recrutamento do reflexo H obtida pela estimulação do PTN e captação de EMG do SO, com utilização de intervalo entre estímulos do PTN suficiente para indução de HD. Em 2013, HUBLI et al. constataram que a tsDCS modulava o reflexo medular evocado pela estimulação não nociva de aferentes cutâneas do PTN em pacientes com dano medular severo, indicando a possibilidade de utilização da tsDCS em protocolos de reabilitação. Em 2013, LAMY; BOAKYE verificaram que a tsDCS (15 minutos, 2,5 mA, eletrodos de $35 \mathrm{~cm}^{2}$ sobre T10 T11 e ombro direito), na sessão (A-T10/T11,C-Od), deslocava a curva de recrutamento do reflexo $\mathrm{H}$ obtida pela estimulação do PTN e captação de EMG do $\mathrm{SO}$ em indivíduos portadores do alelo Val/Val do gene do fator neurotrófico derivado do cérebro (BDNF) enquanto que esse efeito não foi obtido em indivíduos portadores do alelo Met desse gene. Esse estudo demonstrou pela primeira vez a possível dependência da plasticidade medular induzida pela tsDCS com características genéticas dos participantes do protocolo.

Em 2013, YAMAGUCHI et al. analisaram os efeitos da tsDCS (15 minutos, 2,0 mA, eletrodos de $35 \mathrm{~cm}^{2}$ sobre T11/T12 e braço direito) na inibição recíproca (RI) e na inibição pré-sináptica (PSI) D1 por meio da estimulação dos nervos PTN e nervo peroneal (NP) e 
captação de EMG do SO. Também verificaram a excitabilidade cortical por meio da obtenção de MEP utilizando estimulação magnética transcraniana (TMS) do córtex motor e captação de EMG do SO, O resultado do trabalho foi que a tsDCS, na sessão experimental (A-T11/T12,C-Bd), alterou de forma significativa a inibição pré-sináptica D1 tanto durante quanto depois do término da estimulação, enquanto que a RI e o MEP não apresentaram mudanças significativas. A interpretação desses resultados foi que, a não alteração do MEP e da RI indicaria que possivelmente a tsDCS não teria efeito sobre as propriedades de condução das vias descentes da medula e nem sobre interneurônios inibitórios de curta latência, enquanto que o efeito observado na PSI indicaria possível atuação da tsDCS nos interneurônios de despolarização aferente primária (PAD). Em 2014, BOCCI et al. constataram que tanto a tsDCS (20 minutos, 2,5 mA, eletrodos de $35 \mathrm{~cm}^{2}$ sobre C6 T1 e ombro direito) quanto a tsDCS (20 minutos, 2,5 mA, eletrodos $35 \mathrm{~cm}^{2}$ sobre T10 e ombro direito), nas sessões (C-C6/T1,A-Od) e (C-T10,A-Od), foram capazes de modificar a estimação do número de unidade motoras (MUNE) e o período silente periférico (PSP) obtidos pela estimulação do nervo ulnar (NU) e do NM e captação EMG dos músculos abdutor digiti minimi (ADM) e abdutor pollicis brevis (APB). Os autores concluíram que a tsDCS provavelmente poderia ter alterado a excitabilidade de interneurônios da medula, já que foi verificado o aumento do recrutamento de unidades motoras. Esse estudo também indicou que a tsDCS possivelmente também modulava o comportamento de circuitos neurais em núcleos supramedulares já que a sessão (C-T10,AOd) também modificou o MUNE e o PSP no membro superior.

Em 2014, PARAZZINI et al., por meio de modelos computacionais baseados em dados antropométricos obtidos por imagem por ressonância magnética (MRI), estimaram as densidades de correntes elétricas induzidas na medula espinhal pela tsDCS em três configurações de eletrodos: 1) eletrodos sobre T11 e sobre ombro direito, 2) eletrodos sobre T11 e sobre umbigo e 3) eletrodos sobre T11 e sobre o couro cabeludo. Os autores concluíram que cada posicionamento de eletrodo resultava em distribuições de corrente elétricas distintas na medula espinhal, de forma que a configuração (1) induzia uma maior densidade de corrente na região mais rostral da medula espinhal, logo acima do eletrodo posicionado sobre T11, a configuração (2) induzia uma maior densidade de corrente na região mais caudal, logo abaixo do eletrodo sobre T11 e a configuração (3) gerava uma maior densidade de corrente na região cervical. Os autores também verificaram que as intensidades dos campos elétricos produzidos na medula, nessas configurações, era menor do que o necessário para causar crescimento axonal por galvanotropismo. Outra conclusão do trabalho foi que no plano anteroposterior, nas três configurações, tanto regiões ventrais como dorsais da medula espinhal apresentaram densidade de corrente semelhante, pos- 
sivelmente indicando que a tsDCS atue de forma semelhante em vias somatossensoriais, nocirreceptivas e motoras.

Em 2014, AHMED verificou que em ratos a tsDCS provocava alterações em respostas sensíveis às alterações sinápticas em circuitos medulares. Também verificou que uma estimulação CC alterava a excitabilidade do nervo ciático de modo dependente da polaridade, da duração e da direção da estimulação. O autor concluiu que possivelmente os efeitos da tsDCS estão relacionados tanto com mecanismos sinápticos quanto axonais. Além disso observou que era possível anular ou reverter os efeitos observados após o término da estimulação da tsDCS por meio de uma estimulação tsDCS de polaridade contrária à aplicada inicialmente.

Em 2014, HEIDE et al. analisaram os efeitos da thDCS (15 minutos, 2,5 mA, eletrodos de $45 \mathrm{~cm}^{2}$ sobre T11 e ombro direito) em pacientes com síndrome das pernas inquietas (RLS) por meio da análise da $\mathrm{HD}$ em membro inferior e da avaliação de sintomas. Nesse estudo os autores verificaram que a tsDCS induziu uma maior HD no grupo de participantes com RLS do que no grupo controle e que a tsDCS provocou uma melhora significativa dos sintomas da RLS tanto com (A-T11,C-Od) tsDCS quanto com (C-T11,A-Od) tsDCS. Em 2015b, BOCCI et al. verificaram que a tsDCS (20 minutos, 2,5 mA, eletrodos de 35 $\mathrm{cm}^{2}$ sobre T10 e ombro direito) não alterou o MEP, o limiar motor em repouso (RMT), a onda $\mathrm{F}$ e o reflexo $\mathrm{H}$ relacionados com o membro superior, enquanto que na sessão $(\mathrm{A}-\mathrm{T} 10, \mathrm{C}-\mathrm{Od})$ a tsDCS alterou apenas o RMT e o MEP relacionados com o membro inferior. Esse resultado, diferente do encontrado em 2014 pelo mesmo grupo, sugere apenas a atuação local na medula espinhal da tsDCS. Esse estudo também evidencia, pela não alteração da onda F, relacionada ao membro inferior, que as alterações do RMT e do MEP possivelmente não estão associadas à alteração da excitabilidade pós-sináptica dos motoneurônios.

Em 2015a, BOCCI et al., utilizando TMS, constataram que a tsDCS (20 minutos, 2,5 $\mathrm{mA}$, eletrodos de $35 \mathrm{~cm}^{2}$ sobre T10 e ombro direito) alterou o inibição intra-cortical curta por pulso pareado (SICI) enquanto não foram observadas alterações no período silente cortical (cSP) e na facilitação intra-cortical (ICF), indicando que a tsDCS possivelmente atue na modulação do driver GABA(A)érgico relacionado apenas com o membro inferior. Em 2015, MEYER-FRIESSEM et al. analisaram os efeitos da tsDCS (15 minutos, 2,5 $\mathrm{mA}$, eletrodos de $35 \mathrm{~cm}^{2}$ sobre T11 e ombro esquerdo) sobre a sensibilidade à dor por estimulação mecânica (MPS) e sobre a sensibilidade à dor por estimulação elétrica (EPS) em membros inferiores. Os autores verificaram que a (A-T11,C-Oe) tsDCS diminuiu a MPS e não alterou a EPS,

Em 2016, PERROTTA et al. constataram os efeitos da tsDCS (15 minutos, 2 mA, eletro- 
dos de $35 \mathrm{~cm}^{2}$ sobre T10 e ombro direito) sobre o limiar de somação temporal (TST) do reflexo de retirada nociceptivo (NWR). Os resultados desse estudo indicaram que a (AT10,C-Od) tsDCS induziu um aumento do limiar de somação temporal (TST) do reflexo de retirada nociceptivo (NWR).

Em 2016, JANKOWSKA et al. verificaram que em ratos os efeitos persistentes da tsDCS não foram influenciados pela ativação das aferentes do tipo Ia do nervo peroneal ou de aferentes cutâneas de baixo limiar do nervo sural durante a tsDCS, podendo indicar que alguns dos efeitos observados da tsDCS podem ser independentes da atividade neuronal. Em 2016, SAMADDAR et al. constataram que a tsDCS em ratos modulava a migração e proliferação de células recém-nascidas da medula espinhal.

Em 2016, SONG; MARTIN verificaram que a tsDCS em ratos modulava de forma diferente a atividade neural da região ventral da medula espinhal em comparação com a região dorsal.

Em 2017, KUCK; STEGEMAN; ASSELDONK, por meio de modelos computacionais, estimaram as alterações elétricas provocadas pela tsDCS na região lombar em neurônios da medula espinhal. Nesse trabalho os autores verificaram que, no modelo proposto, a tsDCS atuava principalmente nos terminais axonais dos neurônios e que a contribuição das modificações induzidas no soma e nos dendritos dos neurônios era desprezível. Os autores utilizaram o resultado obtido em um modelo computacional de rede de neurônios proposta por CISI; KOHN (CISI; KOHN, 2008) e observaram um deslocamento da curva do reflexo H, conforme observado experimentalmente por LAMY et al. Em 2017, BERRY; TATE; CONWAY verificaram o efeito da tsDCS (15 minutos, 2,5 mA, eletrodos sobre T11/T12 e umbigo) sobre a tarefa motora de salto vertical. Os autores constataram que os participantes desse experimento apresentaram aumento no desempenho do salto e maior resistência a fadiga na configuração (A-T11/T12,C-U), tsDCS. Em 2018, FERNANDES et al. observaram por meio de modelos computacionais os campos elétricos gerados na medula espinhal por diferentes posicionamentos de eletrodos na região lombar. Nesse trabalho os autores verificaram que para regiões da medula espinhal correlacionadas com circuitos neurais dos membros inferiores, os posicionamentos de eletrodos que produziam a maior intensidade de campo elétrico eram: 1) eletrodos sobre T8 e sobre crista ilíca direita e 2) eletrodos sobre T10 e sobre crista ilíaca direita.

Em 2018, KUCK et al. não obtiveram resultados semelhantes aos obtidos por LAMY et al. em 2012 no deslocamento da curva de recrutamento do reflexo $\mathrm{H}$ de membro inferior pela tsDCS (15 minutos, 2,5 mA, eletrodos sobre T11 e ombro esquerdo). Nesse trabalho os autores verificaram que a tsDCS (15 minutos, $2,5 \mathrm{~mA}$, eletrodos posicionados equidistantes $7 \mathrm{~cm}$ de T11 no sentido rostro caudal) provocava alteração da amplitude do reflexo 
H de membro inferior na situação em que o eletrodo proximal atuava como anodo. Os autores não observaram correlação entre o efeito da tsDCS e as características do gene BDNF dos participantes do experimento.

Em 2018, LENOIR; JANKOVSKI; MOURAUX analisaram os efeitos da tsDCS (15 minutos, $2,5 \mathrm{~mA}$, eletrodos de $35 \mathrm{~cm}^{2}$ sobre L1 L5 e ombro direito) sobre o SEP e sobre o LEP de membros inferiores. Nesse trabalho foi constatada a alteração apenas do LEP, indicando que o efeito da tsDCS foi possivelmente induzida por meio de modulação sináptica e não por bloqueio anódico, já que caso fosse por bloqueio anódico, seria verificada a alteração dos dois parâmetros.

Em 2018, MURRAY; TAHAYORI; KNIKOU verificaram que a tsDCS (30 minutos, 4 $\mathrm{mA}$, eletrodo de $10 \mathrm{~cm}^{2}$ sobre T11 e eletrodo de $100 \mathrm{~cm}^{2}$ sobre coxa) alterava concomitantemente o comportamento das regiões cortical, corticoespinhal e espinhal associadas ao sistema motor.

Em 2018, PEREIRA et al. observaram que a tsDCS (15 minutos, 2,5 mA, eletrodos sobre o processo espinhoso de L2 e sobre a crista ilíaca esquerda) não afetava os circuitos neurais medulares motores pois não observaram modificações na onda F e no reflexo H (obtidos em membro inferior), no cSP, no MEP e na resposta simpática cutânea. Por meio de um modelo computacional, os autores justificaram a ausência de efeito da tsDCS pelo fato de que o posicionamento de eletrodos adotado não estimulava o cone medular com campo elétrico com intensidade mínima de $0,15 \mathrm{~V} / \mathrm{m}$.

Em 2019, GIBSON; TREMBLAY verificaram que os efeitos da tsDCS (20 minutos, 2,5 $\mathrm{mA}$, eletrodos de $35 \mathrm{~cm}^{2}$ sobre o processo espinhoso de T10 e sobre o ombro direito) sobre o limiar à dor por pressão (PPT) em membros inferiores eram modulados pelo nível de atividade física dos participantes do experimento.

Em 2019, AWOSIKA et al. observaram que a tsDCS (20 minutos, 2,5 mA, eletrodos de $35 \mathrm{~cm}^{2}$ sobre o processo espinhoso de T11 e sobre o ombro direito), na configuração (AT11,C-Od), melhorou o desempenho de participantes saudáveis na tarefa de marcha no sentido reverso.

Em 2020, FIOCCHI et al., por meio de modelos computacionais, verificaram que protocolos de tsDCS, com intensidade de corrente de $3 \mathrm{~mA}$, não conseguiriam provocar alterações de temperaturas maiores do que $1,5 \mathrm{~m}^{\circ} \mathrm{C}$ nos tecidos do corpo humano, indicando que, possivelmente, hipóteses de que o aumento de temperatura, provocada pela tsDCS, poderia ativar mudanças metabólicas nos tecidos estimulados ou contribuir para efeitos colaterais não sejam válidas. 


\subsection{Modelo computacional}

Em seres humanos a medição do campo elétrico nos diferentes tecidos gerado por uma estimulação elétrica transcutânea se torna inviável pelo fato de nem sempre ser possível a inserção de eletrodos de medição no corpo sem que ocorram lesões proibitivas. Uma alternativa é a análise desses campos elétricos em um volume condutor semelhante ao corpo humano por meio de um modelo matemático.

No caso em que a diferença de potencial elétrico aplicada pelos eletrodos de estimulação é constante no tempo, como na tsDCS, o corpo humano pode ser modelado como um volume condutor elétrico puramente resistivo (PLONSEY; HEPPNER, 1967) e o campo elétrico pode ser descrito pela simplificação das equações de Maxwell para o caso quase estático, sendo obtido pela solução da seguinte equação de Poisson (LADENBAUER, 2008):

$$
\begin{cases}-\nabla \cdot(\boldsymbol{\sigma} \nabla \phi)=0 & \Omega, \\ \boldsymbol{\sigma} \nabla \phi=g & \partial \Omega_{0}, \\ \boldsymbol{\sigma} \nabla \phi=0 & \partial \Omega_{1}, \\ \boldsymbol{J}=\boldsymbol{\sigma} \boldsymbol{E} & \Omega\end{cases}
$$

Sendo:

$\phi \quad=$ potencial elétrico dentro do volume condutor.

$\boldsymbol{\sigma}=$ tensor de condutividade elétrica do volume condutor.

$\Omega=$ volume condutor.

$g \quad=$ densidade de corrente elétrica nos eletrodos de estimulação.

$\partial \Omega_{0}=$ superfície do volume condutor em contato com os eletrodos de estimulação.

$\partial \Omega_{1}=$ superfície do volume condutor que não está em contato com os eletrodos.

$\boldsymbol{J}=$ vetor de densidade de corrente elétrica.

$\boldsymbol{E}=$ vetor campo elétrico.

O corpo humano é um volume condutor complexo composto por tecidos de diferentes geometrias e condutividades elétricas anisotrópicas. Nessas condições a solução analítica da equação de Poisson (Equação 1.1) se torna impraticável e nesse caso podem ser empregadas técnicas de solução numérica para a obtenção da solução do problema, como por exemplo o método dos elementos finitos (FEM) (BRONZINO, 2000).

No caso da tsDCS os estudos realizados com modelos computacionais utilizam os resultados desses modelos principalmente para analisar diferentes posicionamentos de eletrodos de estimulação e para estimar o campo elétrico na medula espinhal (KUCK; STEGE- 
MAN; ASSELDONK, 2017; PARAZZINI et al., 2014; FERNANDES et al., 2018).

O processo de elaboração de um modelo computacional para o cálculo e a análise do campo elétrico e da densidade de corrente elétrica gerados pela tsDCS pode ser realizado pelos seguintes passos (Figura 12):

1. Criação de um modelo geométrico tridimensional representativo do tronco humano e seus respectivos tecidos.

2. Definição dos tensores de condutividade elétrica (termo $\boldsymbol{\sigma}$ da equação de Poisson) dos tecidos.

3. Definição do local de posicionamento dos eletrodos de estimulação (termo $\partial \Omega_{0}$ da equação de Poisson).

4. Definição da densidade de corrente elétrica aplicada pelos eletrodos de estimulação.

5. Divisão do modelo geométrico em pequenos elementos tetraédricos (meshing).

6. Solução da equação de Poisson (Equação 1.1) por meio do FEM. 

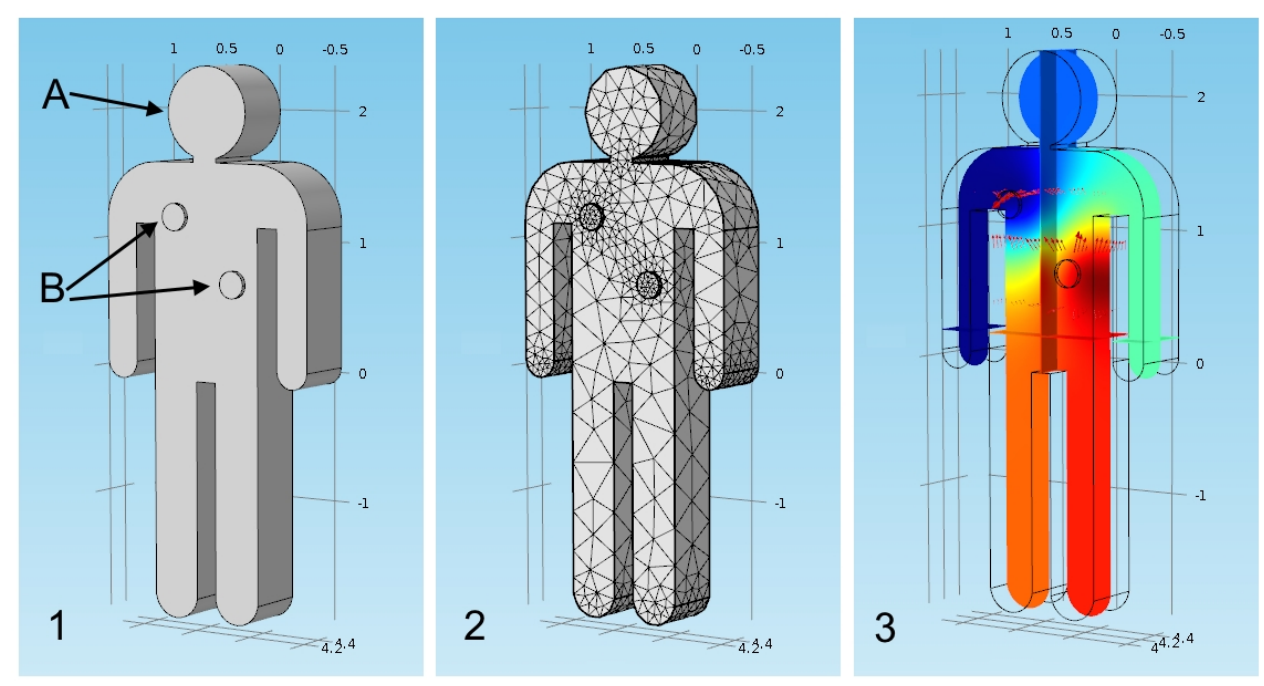

Figura 12: Esquema representativo dos passos adotados em uma análise do campo elétrico produzido por uma estimulação elétrica CC em um volume condutor utilizando FEM. 1) Elaboração do modelo geométrico tridimensional representando o volume condutor (A) e os eletrodos de estimulação (B). Após a elaboração do modelo tridimensional, são definidos os parâmetros elétricos do modelo (equação de Poisson a ser resolvida, condutividades elétricas das partes do modelo e as condições de contorno). 2) Divisão do modelo em elementos tetraédricos (meshing). 3) Solução do problema utilizando FEM. (Figura elaborada com o resultado obtido de um modelo extremamente simplificado do corpo humano, com dois eletrodos de estimulação, obtido no software Comsol (COMSOL Inc. EUA).

Dependendo da acurácia pretendida, o modelo geométrico tridimensional do corpo humano e dos diferentes órgãos pode ser ou elaborado por meio da segmentação automática de imagens de MRI de seres humanos (PARAZZINI et al., 2014), gerando um modelo tridimensional com alto detalhamento, ou, em um modelo com baixo detalhamento, utilizando formas geométricas simples com dimensões baseadas em dados antropométricos (HERNÁNDEZ-LABRADO et al., 2011; LADENBAUER, 2008), representando diferentes partes do corpo humano (Figura 13). Em geral modelos tridimensionais baseados em imagens de MRI permitem maior detalhamento da geometria dos diferentes tecidos e modelam um maior número de tecidos, tornando as soluções obtidas por esses modelos mais próximas de uma situação real do que as obtidas de modelos mais simplificados. 

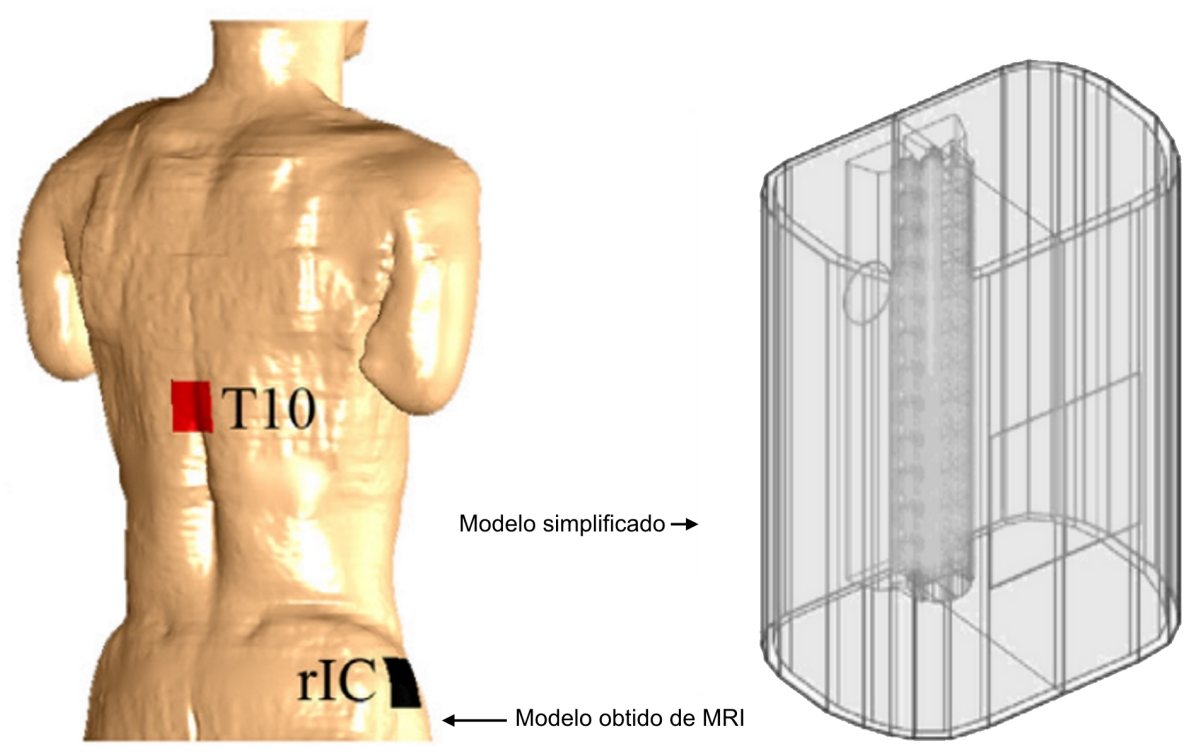

Figura 13: Exemplos de modelos tridimensionais do tronco humano.̀̀ esquerda) Modelo tridimensional baseado na segmentação de imagens de MRI (Imagem adaptada de (FERNANDES et al., 2018)). À Direita) Modelo tridimensional simplificado (LADENBAUER, 2008).

Dependendo da exatidão desejada, a condutividade elétrica dos tecidos pode ser considerada isotrópica ou anisotrópica. Modelos mais sofisticados consideram a condutividade elétrica dos tecidos como anisotrópica, nesse caso o tensor de condutividade elétrica $(\boldsymbol{\sigma})$ é calculado com base na orientação do tecido no volume condutor (HYDE; WARFIELD, 2011). A condutividade elétrica de tecidos biológicos é dependente da frequência do sinal elétrico e, dependendo da metodologia de medição empregada, pode apresentar diferentes valores nos estudos publicados (MIKLAVČIČ; PAVŠELJ; HART, 2006). No caso da tsDCS a condutividade elétrica deve ser obtida de estudos que analisaram essa grandeza em $\mathrm{CC}$.

A definição do local de posicionamento dos eletrodos de estimulação consiste em determinar a região da superfície externa do modelo tridimensional em que o fluxo de corrente elétrica que atravessa essa superfície é não nulo e apresenta densidade de corrente elétrica igual à intensidade da corrente de estimulação dividida pela área do eletrodo. Esse processo em geral é realizado com auxílio do software utilizado para a solução do problema numérico.

Após a definição do modelo tridimensional, das condutividades elétricas dos tecidos e do posicionamento e configuração dos eletrodos de estimulação, o modelo tridimensional é dividido em pequenos elementos, em geral tetraédricos, processo conhecido como meshing. Simplificadamente, no FEM, para cada elemento é definida uma equação polinomial que 
discretiza a equação de Poisson no volume dos elementos (LADENBAUER, 2008). A solução do problema é obtida pela solução do sistema de equações lineares, formado pelas equações obtidas de todos os elementos, por um método numérico direto (Como por exemplo MUMPS, PARDISO ou SPOOLES) ou iterativo (Como por exemplo o método conjugate gradients) (BRONZINO, 2000; BING; GREENHALGH, 2001). O tamanho dos elementos também é um dos fatores que determina a exatidão da solução obtida pelo modelo. Quanto menores os elementos, maior a exatidão da solução, porém maior o custo computacional necessário para sua obtenção. Em geral os elementos são gerados com dimensões diferentes em diferentes regiões do modelo por meio da metodologia adaptative meshing. Nessa metodologia, em regiões do modelo tridimensional que apresentam maiores complexidades geométricas ou de menores dimensões, elementos menores são empregados. Essa metodologia permite uma maior eficiência no dimensionamento do número de elementos necessários para a solução de determinado problema. Na maior parte dos casos os softwares que permitem a solução de problemas utilizando o FEM possuem ferramentas para a geração automática dos elementos de acordo com as dimensões do modelo tridimensional e da equação diferencial parcial a ser resolvida.

O emprego de modelos computacionais complexos permite a obtenção de resultados mais realistas porém exigem maior tempo computacional para a obtenção da solução do problema e maior tempo para o desenvolvimento do modelo. Sendo assim, a utilização de modelos com geometrias simplificadas pode ser uma ferramenta valiosa para a análise de diferentes configurações de eletrodos da tsDCS já que essa análise exige a solução e modificação do modelo inúmeras vezes.

A solução obtida de um modelo computacional representa apenas uma estimativa do campo elétrico gerado pela tsDCS que poderá ser observado in vivo. Cada indivíduo possui características específicas tanto anatômicas como de propriedades elétricas dos tecidos.

\subsection{Controle postural}

Controle postural é a tarefa, realizada pelo SNC, da ativação dos músculos esqueléticos para a posicionamento apropriado dos segmentos do corpo humano para a realização das tarefas do dia-a-dia e para a manutenção do equilíbrio (GAERLAN, 2010). A execução dessa tarefa exige que o SNC integre informações sensoriais dos sistemas visual, auditivo, vestibular e somatossensorial (MOCHIZUKI; AMADIO, 2006; VITKOVIC et al., 2016). As informações sensoriais enviadas para o SNC em geral são redundantes e em cada tarefa 
postural o SNC pode atribuir pesos diferentes às informações desses diferentes sistemas ASSLÄNDER; PETERKA, 2014; MOCHIZUKI; AMADIO, 2006).

\subsubsection{Controle postural na postura ereta ortostática (PEO)}

A postura ereta ortostática (PEO) consiste no ato de ficar em pé, com os dois pés em contato com o solo com distanciamento e angulação confortáveis, com os braços ao lado do corpo e sem a realização de movimentos, exceto os necessários para a manutenção do equilíbrio. Nessa postura o sistema de controle postural atua de forma que a projeção do centro de massa do corpo no solo não ultrapasse uma região limítrofe de estabilidade (DUARTE; ZATSIORSKY, 2002) e o corpo humano se mantém em um movimento oscilatório estocástico contínuo de pequena amplitude (DUARTE; FREITAS, 2010), nunca permanecendo completamente parado. $\mathrm{Na} \mathrm{PEO}$, o $\mathrm{SNC}$ utiliza principalmente a estratégia de tornozelo para a manutenção do equilíbrio (WINTER, 1995), empregando basicamente a ativação dos músculos da perna e as informações sensoriais oriundas do sistema somatossensorial de propriocepção dos membros inferiores e mecanorreceptores cutâneos das solas dos pés (DIENER et al., 1984a; LI; ZHANG; DOBSON, 2019; FITZPATRICK; MCCLOSKEY, 1994; FITZPATRICK; ROGERS; MCCLOSKEY, 1994), embora uma parcela não desprezível de informação sensorial do sistema visual seja utilizada no caso da PEO ser realizada com os olhos abertos (MOCHIZUKI; AMADIO, 2006). Durante a PEO, parte da integração das informações de aferentes sensoriais e do comando descendente supramedular é realizada pela rede de neurônios da região da intumescência lombossacral da medula espinhal (DESSEILLIGNY,BURKE, 2012; ELIAS; WATANABE; KOHN, 2014). Algumas condições podem influenciar a dinâmica das oscilações posturais durante a $\mathrm{PEO}$, como por exemplo: sono (SMITH; CHENG; KERR, 2012), fadiga muscular (YAGGIE; MCGREGOR, 2002), ansiedade (MAKI; MCLLROY, 1996), tarefa cognitiva (PELLECCHIA, 2003), posicionamento dos pés no solo (NEJC et al., 2010; CHIARI; ROCCHI; CAPPELLO, 2002), idade (DUARTE; STERNAD, 2008), ritmo respiratório e cardíaco (SCHMID et al., 2004, CONFORTO et al., 2001), patologias (DIENER et al., 1984b; MANCINI et al., 2012), uso de medicamentos (PATAT; FOULHOUX, 1985), temperatura corpórea (MÄKINEN et al. 2005), estímulos sonoros e visuais PARK et al. 2011; KAWAKITA et al., 2000), hora do dia (JORGENSEN et al., 2012) e a alteração de informações sensoriais KRISHNAMOORTHY; SLIJPER; LATASH, 2002; MAGALHÃES; $\mathrm{KOHN}, 2012$ ). 


\subsubsection{Posturografia por plataforma de força}

A análise do comportamento do controle postural, durante a $\mathrm{PEO}$, pode ser realizada pelo estudo das oscilações posturais por meio da metodologia conhecida como posturografia por plataforma de força (DUARTE; FREITAS, 2010). Nessa metodologia, uma plataforma de força é utilizada para a obtenção da localização do centro de pressão (COP), que corresponde à localização da força resultante de reação do solo às solas dos pés ao longo do tempo (Figura 14). Na PEO a localização do COP é aproximadamente igual a localização da projeção do centro de massa (CM) do corpo no solo (DUARTE; FREITAS, 2010), embora também apresente influência da dinâmica da ativação dos músculos da perna e ritmos respiratório (KUCZYŃSKI; WIELOCH, 2008) e cardíaco (este via hidrodinâmica) (CONFORTO et al., 2001). 


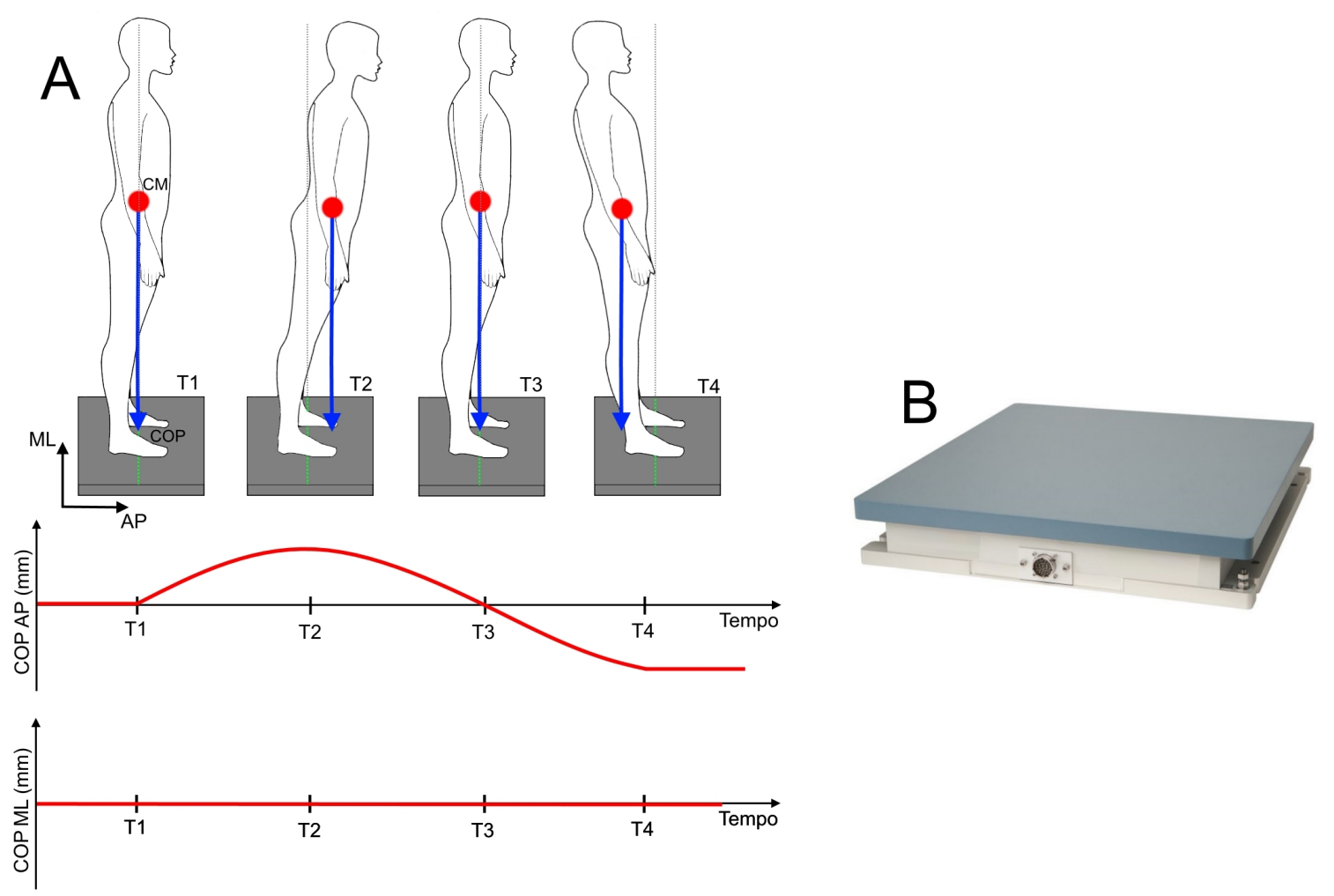

Figura 14: Ilustração da metologia de posturografia por plataforma de força. A plataforma de força permite a obtenção de dois sinais, o "COP AP (mm)", que registra movimentação do COP na direção anteroposterior e o "COP ML (mm)", que registra a movimentação na direção mediolateral. O COP é a força resultante da reação do solo às solas dos pés. A) Ilustração da utilização de uma plataforma de força para a obtenção de dados da oscilação postural durante a $\mathrm{PEO}$ com movimentação do corpo apenas na direção anteroposterior (situação meramente ilustrativa, na PEO também ocorre a movimentação do corpo humano na direção mediolateral). Desconsiderando a ativação dos músculos das pernas, nesse exemplo: Em T1 e em T3 a projeção do CM no solo se encontra sobre a posição nula da plataforma de força (indicada pela linha tracejada verde, desenhada sobre a plataforma de força), resultando em um "COP AP(mm)" nulo. $\boldsymbol{E m}$ T2, com a inclinação do corpo na direção anterior, a projeção do CM se desloca na direção anterior, resultando em um "COP AP $(\mathrm{mm})$ " não nulo (nesse caso, representado por um sinal positivo em T2). Em T4, com a inclinação do corpo humano na direção posterior, o sinal "COP AP(mm)" se torna negativo. Em uma situação real, quando o CM se desloca na direção medial ou lateral (situação não representada na ilustração), o sinal "COP ML" apresenta valor não nulo, de modo semelhante ao observado no sinal "COP AP $(\mathrm{mm})$ ". B) Imagem de uma plataforma de força comercial (Foto adaptada de AMTI Force and Motion WebSite (2020)). 
A posturografia por plataforma de força pode ser empregada tanto para a investigação de características do comportamento do sistema de controle postural (ROMAN-LIU, 2018; HAGIO; OBATA; NAKAZAWA, 2018; LEACH et al., 2018; SILVA; MAGALHÃES; KOHN, 2019) quanto para o diagnóstico de certas patologias do SNC (SANT'ANNA et al., 2019; MIGNARDOT et al., 2014).

\subsubsection{Parâmetros para quantificar o sinal do COP}

Os sinais da localização do COP ao longo do tempo podem ser obtidos na direção anteroposterior (AP) e na direção mediolateral (ML) (Figura 15) e podem ser processados para a obtenção de parâmetros que caracterizam a oscilação postural durante a PEO (PAILLARD; NOÉ, 2015). Diversos parâmetros, quantificadores da dinâmica do COP. podem ser obtidos a partir dos sinais coletados do COP durante a PEO (YAMAMOTO et al. 2015) e não há consenso sobre quais parâmetros devem ser utilizados para a identificação de alterações do controle postural (DUARTE; FREITAS, 2010; RUHE; FEJER; WALKER, 2010). De modo geral os parâmetros podem ser divididos em duas categorias: parâmetros globais e parâmetros estruturais (BARATTO et al., 2002). Os parâmetros globais quantificam o "tamanho" ou intensidade das oscilações do COP, quer no domínio do tempo quer no domínio da frequência. Os parâmetros estruturais mensuram aspectos relacionados com o padrão temporal do sinal do COP (DUARTE; FREITAS, 2010). 


\section{Estabilogramas}
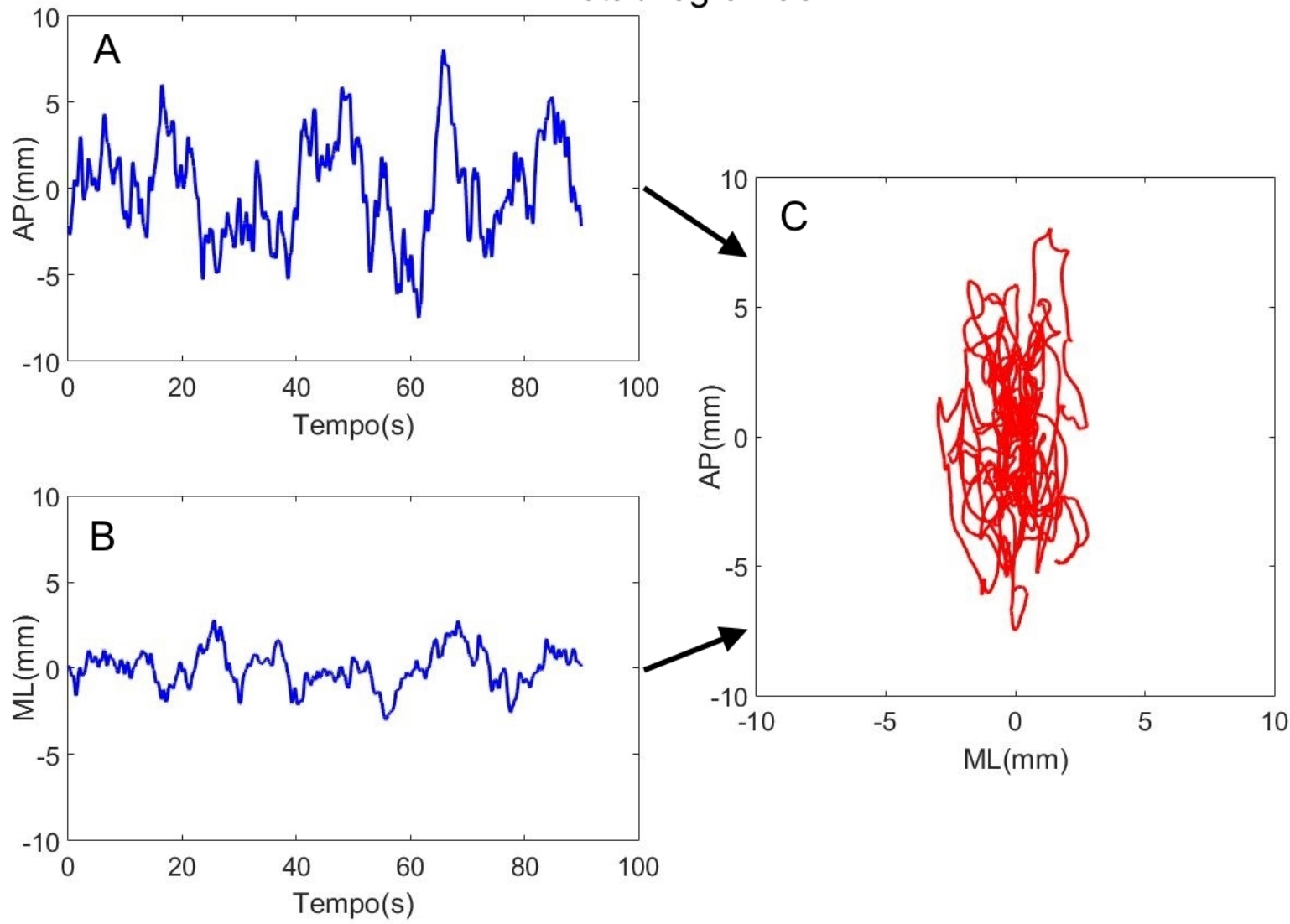

Figura 15: Exemplo dos sinais da localização do COP durante a $\mathrm{PEO}$ ao longo do tempo. A) Estabilograma ao longo do tempo na direção anteroposterior em uma coleta de dados com duração de 90 segundos. B) Estabilograma ao longo do tempo na direção mediolateral em uma coleta de dados com duração de 90 segundos. C) Estabilograma do COP elaborado com os sinais exibidos em (A) e em (B).(Figura elaborada com os sinais do COP obtidos de uma sessão experimental do protocolo experimental executado nesse trabalho).

Alguns dos principais parâmetros analisados em estudos de posturografia por plataforma de força são (DUARTE; FREITAS, 2010; PAILLARD; NOÉ, 2015; PALMIERI et al., 2002):

\section{Parâmetro globais:}

(a) Desvio padrão $(S D)$ 1. Parâmetro que quantifica a variabilidade do COP, na

\footnotetext{
${ }^{1}$ Alguma vezes, nos estudos de posturografia por plataforma de força, o parâmetro $S D$ é denominado de $R M S$. Nesses estudos a média do sinal do COP é eliminada antes do cálculo do valor quadrático médio (RMS). Esse procedimento equivale ao cálculo do desvio padrão do sinal. Dessa forma, nesse estudo, esse parâmetro será denominado desvio padrão (SD).
} 
direção AP ou na direção ML ao longo do tempo (PRIETO et al., 1996). O parâmetro $S D$ possui nível aceitável de confiabilidade para a detecção de um grande número de condições, por exemplo, de diferenças entre jovens e idosos e entre idosos sem medo de queda e idosos com medo de queda QIU; XIONG, 2015).

(b) Velocidade média ( $M V E L O)$ : Parâmetro que quantifica a velocidade média do COP, na direção AP ou na direção ML. Esse parâmetro é calculado pela razão entre a distância total percorrida pelo COP e duração total da aquisição de dados (PRIETO et al., 1996). Quanto menor o valor de MVELO, mais eficiente é considerado o controle postural (PAILLARD; NOÉ, 2015). O parâmetro MVELO, em comparação com outros parâmetros globais, apresenta maior confiabilidade ${ }^{2}$ em diferentes condições experimentais RAYMAKERS; SAMSON; VERHAAR, 2005; RUHE; FEJER; WALKER, 2010; QIU; XIONG, 2015).

(c) Área da elipse $(A R E A E)$ : Parâmetro que quantifica a área da elipse que engloba com 95\% de confiança o estabilograma obtido dos sinais do COP na direção AP e ML (Figura 16). Áreas menores são normalmente associadas a um melhor controle postural (PAILLARD; NOÉ, 2015).

\footnotetext{
${ }^{2}$ grau de fidelidade.
} 


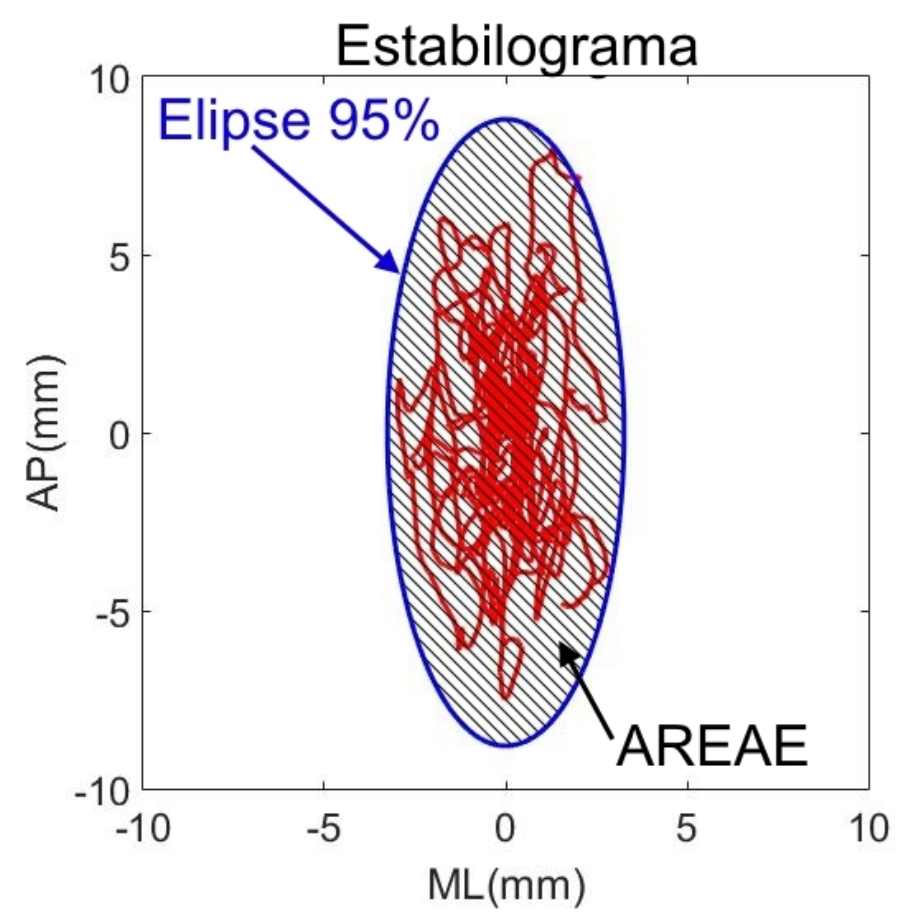

Figura 16: Exemplo da obtenção do parâmetro $A R E A E$ que quantifica a área da elipse que engloba com $95 \%$ de confiança o estabilograma obtido dos sinais do COP na direção AP e ML.(Estabilograma elaborado com os sinais do COP obtidos de uma sessão experimental do protocolo experimental executado nesse trabalho)

(d) Análise espectral em baixas e em altas frequências ( $P S D_{\_} A R E A_{\_} L F$ e $\left.P S D \_A R E A \_H F\right)$ : Parâmetros que quantificam a potência do sinal do COP. na direção AP ou na direção ML, em baixas frequências $(0,05 \mathrm{~Hz}$ a $0,5 \mathrm{~Hz}$, $\left.P S D_{-} A R E A_{-} L F\right)$ ou em altas frequências $\left(0,5 \mathrm{~Hz}\right.$ a $\left.2 \mathrm{~Hz}, P S D_{-} A R E A_{-} H F\right)$, obtidos pelo cálculo da área sob a curva da densidade de potência espectral (PSD) (Figura 17) SILVA; MAGALHÃES; KOHN, 2019; MAGALHÃES; KOHN, 2012; PAILLARD; NOÉ, 2015). Em baixas frequências (0,05 Hz a $0,5 \mathrm{~Hz}$ ) a localização do COP é aproximadamente igual à localização da projeção do centro de massa do corpo no solo (LAFOND; DUARTE; PRINCE, 2004). PAILLARD; NOÉ sugerem que em baixas frequências podem ser caracterizados os circuitos de realimentação neuronal, principalmente relacionados com o sistema visiovestibular e em altas frequências, circuitos de realimentação neuronal principalmente relacionados com o sistema cerebelar $(0,2 / 0,5-2 \mathrm{~Hz})$ e proprioceptivo ( $\geq 2 \mathrm{~Hz}$ ) (DUPUI et al., 1990). 


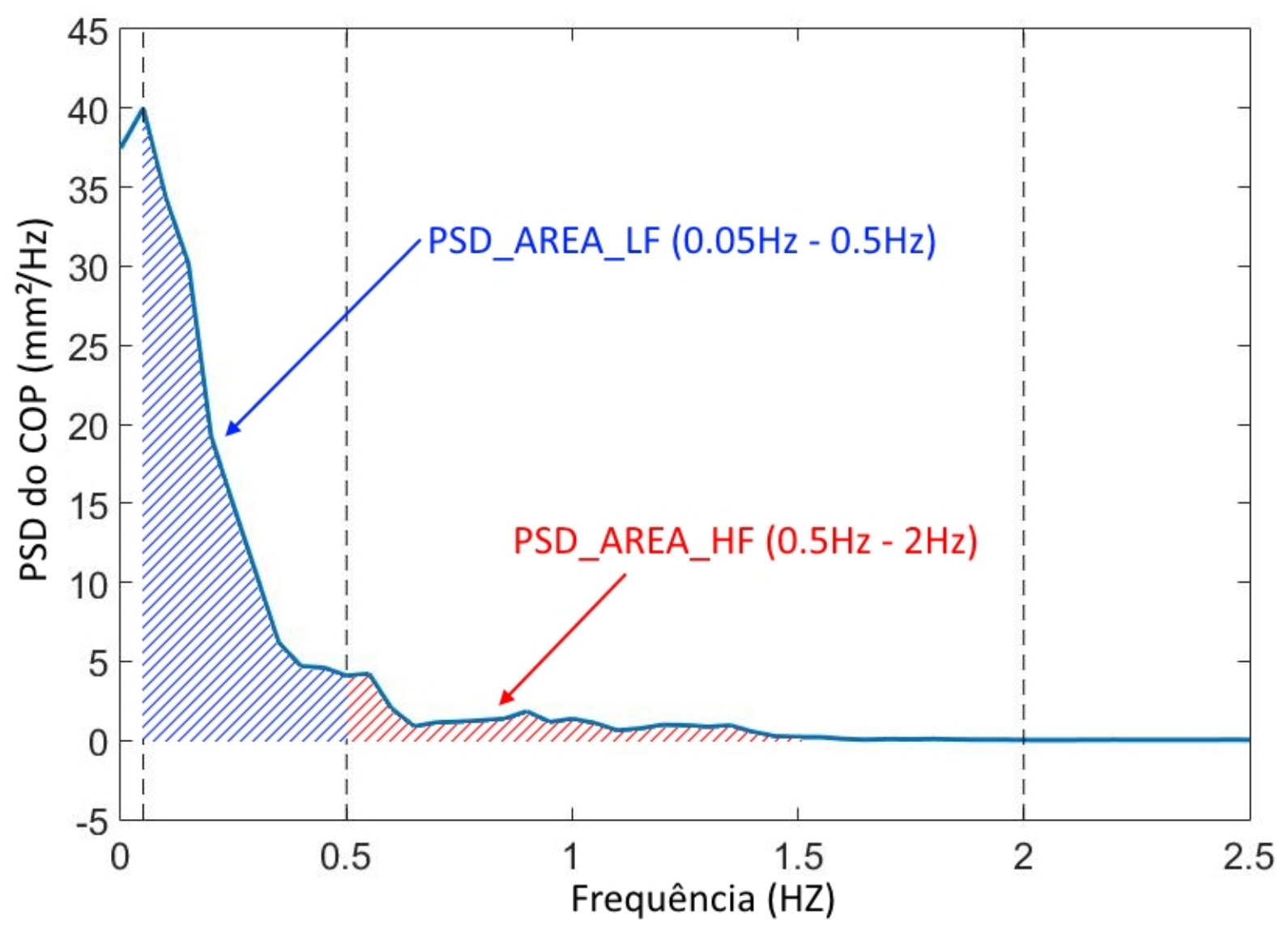

Figura 17: Exemplo da obtenção dos parâmetros $P S D_{-} A R E A \_L F$ e $P S D \_A R E A \_H F$. $P S D_{-} A R E A_{-} L F$ é o parâmetro que quantifica a potência do sinal do COP, na direção $\mathrm{AP}$ ou na direção $\mathrm{ML}$, na faixa de frequências de $0,05 \mathrm{~Hz}$ a $0,5 \mathrm{~Hz}$, obtido pelo cálculo da área sob a curva da $\mathrm{PSD}$ nessa faixa de frequências. $P S D_{-} A R E A_{-} H F$ é o parâmetro que quantifica a potência do sinal do COP na direção AP ou na direção ML, na faixa de frequências de $0,5 \mathrm{~Hz}$ a $2 \mathrm{~Hz}$, obtido pelo cálculo da área sob a curva da PSD nessa faixa de frequências.(Gráfico da PSD obtida dos sinais do COP de uma sessão experimental do protocolo experimental executado nesse trabalho).

(e) Frequências características da densidade de potência espectral (PSD) $\left(f 50 p_{-} P S D\right.$ e $\left.f 80 p_{-} P S D\right)$ : O parâmetro $f 50 p_{-} P S D$ indica a faixa inferior de frequências em que está contida metade da potência do sinal do COP, na direção AP ou na direção ML, obtida da análise da área sob a curva da PSD do COP entre $0,15 \mathrm{~Hz}$ e $5 \mathrm{~Hz}$ (PRIETO et al. 1996) (Figura 18). f50p_PSD maiores sugerem um controle postural realizado com correções mais rápidas (PAILLARD; NOÉ, 2015). O parâmetro $f 80 p_{P} S D$ indica a faixa de frequências em que é observada $80 \%$ da potência do sinal do COP, na direção AP ou 
na direção ML, também obtida da análise da área sob a curva da PSD do $\mathrm{COP}$ entre $0,15 \mathrm{~Hz}$ e $5 \mathrm{~Hz}$ (Figura 19). O parâmetro f $80 p_{-} P S D$ possibilita a melhor identificação de modificações do controle postural em comparação com o parâmetro $f 50 p_{-} P S D$ (BARATTO et al., 2002). A análise de frequências características da $\mathrm{PSD}$ também pode ser realizada no sinal de velocidade do $\mathrm{COP}$, obtido da derivada no tempo do sinal do COP, resultando nos parâmetros $f 50 p_{-} P S D_{v}$ e $f 80 p_{-} P S D_{v}$, que pode permitir uma melhor identificação de modificações da dinâmica do controle postural (RAHMATI et al., 2019).

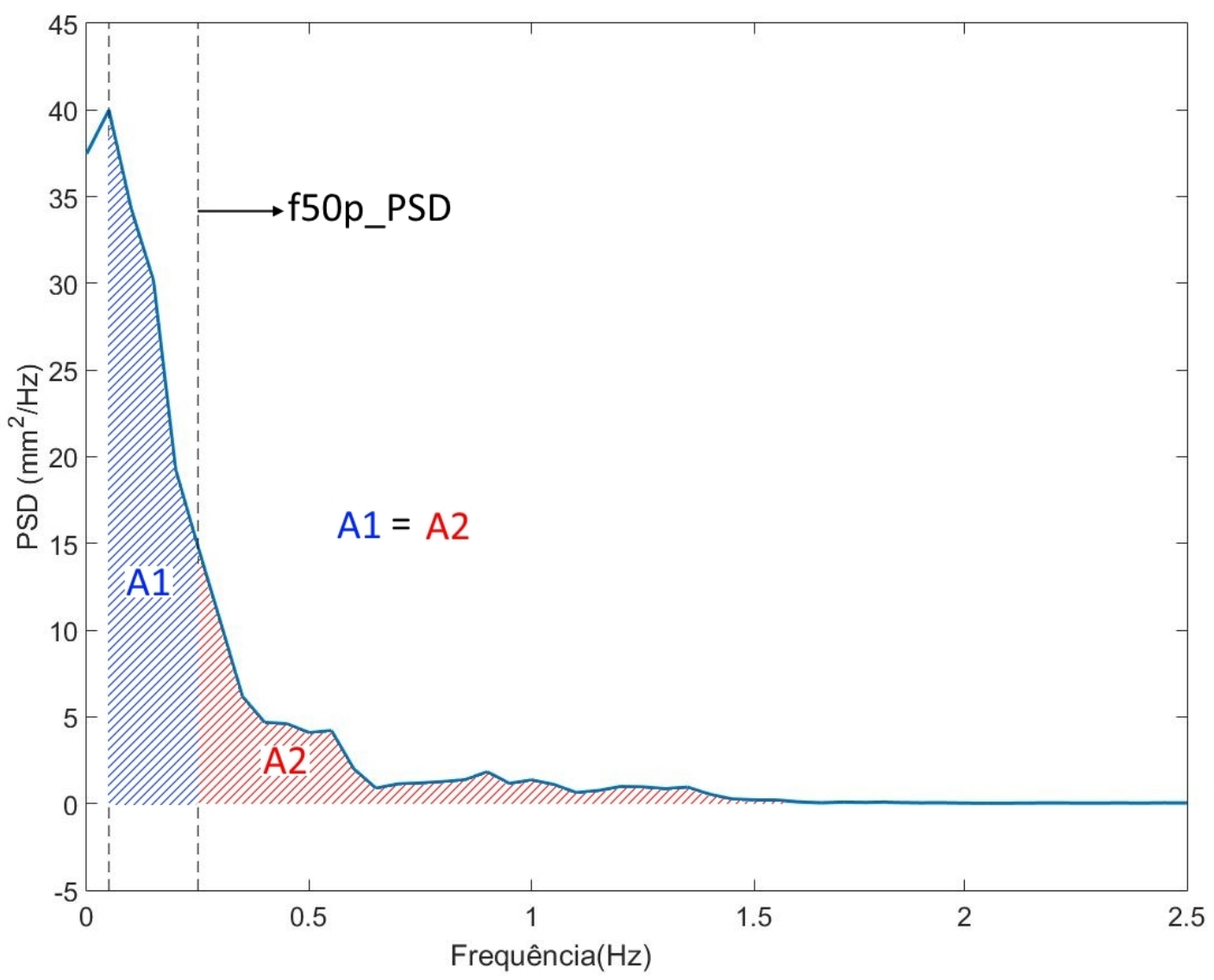

Figura 18: Exemplo da obtenção do parâmetro f50p_PSD. $f 50 p_{-} P S D$ é o parâmetro que indica a frequência em que é observada metade da potência do sinal do COP, na direção AP ou na direção ML, obtido da análise da área sob a curva da PSD do COP entre 0,15 $\mathrm{Hz}$ e $5 \mathrm{~Hz}$. (Gráfico da PSD obtida dos sinais do COP de uma sessão experimental do protocolo experimental executado nesse trabalho). 


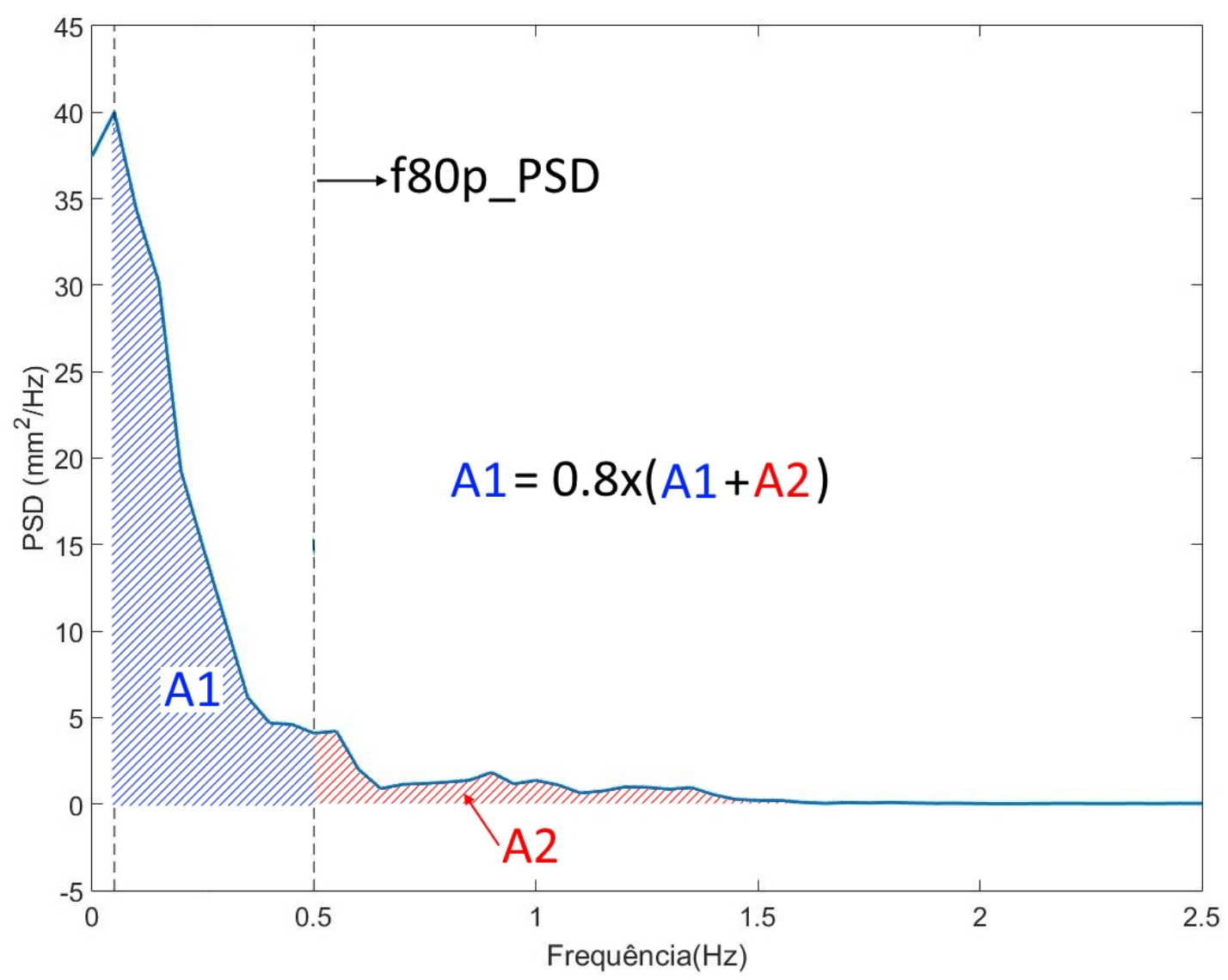

Figura 19: Exemplo da obtenção do parâmetro $f 80 p_{-} P S D$. $f 80 p_{-} P S D$ é o parâmetro que indica a frequência em que é observada $80 \%$ da potência do sinal do COP, na direção $\mathrm{AP}$ ou na direção ML, obtido análise da área sob a curva da PSD do COP entre 0,1 5Hz e 5 Hz. (Gráfico da PSD obtida dos sinais do COP de uma sessão experimental do protocolo experimental executado nesse trabalho).

\section{Parâmetros estruturais:}

(a) Análise fractal: Análise que utiliza conceitos da mecânica estatística para caracterizar a ocorrência de padrões estruturais semelhantes, em diferentes escalas de tempo, de um sinal (Figura 20. Nos sinais de COP essa análise é elaborada por meio da caracterização desses sinais como processos estocásticos do tipo correlated random walks (como por exemplo: movimento Browniano fracionário (fBm) e ruído Gaussiano fracionário (fGn) (COLLINS; LUCA, 1993 GILFRICHE et al., 2018, PENG et al., 1995). A análise fractal pode ser realizada pela metodologia proposta por COLLINS; LUCA análise de difusão do estabilograma (SDA) (Figura 21), que quantifica a persistência (tendência) dos sinais do $\mathrm{COP}$ caracterizando-os por um processo estocástico do tipo $\mathrm{fBm}$. em diferentes escalas de tempo, resultando nos parâmetros $D_{S}, D_{L}, \Delta T_{c}$ e 
$\left\langle\Delta X_{C O P}^{2}\right\rangle_{C}$. Os coeficientes de difusão $D_{S}$ e $D_{L}$ estão relacionados, em escala linear, com expoente de escalonamento do sinal (expoente de Hurst $(H)$ ) obtido em curta duração $\left(D_{S}\right)$ e em longa duração $\left(D_{L}\right)$ de tempo. O parâmetro $\Delta T_{c}$ identifica o intervalo de tempo médio, nas amostras dos sinais do COP, em que ocorre a alteração abrupta dos coeficientes de difusão (intervalo crítico). $\left\langle\Delta X_{C O P}^{2}\right\rangle_{C}$ quantifica a distância quadrática média entre amostras no intervalo de tempo correspondente a $\Delta T_{c}$. Embora a hipótese, originalmente elaborada por COLLINS; LUCA, de que a SDA poderia ser utilizada para identificar a existência de processos de malha aberta e de malha fechada no SNC durante o controle postural não ser mais aceita (PETERKA, 2000), os coeficientes da SDA podem ser utilizados para identificar alterações da dinâmica do controle postural. Além da SDA, a análise fractal também pode ser realizada por outras metodologias, como por exemplo, pela análise de flutuações com a remoção de tendências lineares (DFA) (PENG et al., 1995) ou pela análise fractal em frequências específicas (FsFA) (GILFRICHE et al., 2018). Na FsFA (Figura 22 é realizada a DFA em diferentes escalas de tempo, obtendo-se o parâmetro $\alpha_{-} F s f a$ em curtas durações e em longas durações que está relacionado, assim como os parâmetros $D_{S}$ e $D_{L}$, com o expoente de escalonamento do sinal. A FsFA, além de quantificar o escalonamento de sinais com dinâmica semelhante aofBm, também permite a quantificação do escalonamento de sinais com dinâmica semelhante aofGn. A SDA a FsFA possivelmente apresentam poder de discriminação de alterações nas oscilações posturais durante a $\mathrm{PEO}$ semelhantes (AMOUD et al. 2007), porém a SDA possivelmente apresenta maior sensibilidade em janelas de curta duração de tempo enquanto que a FsFA possui maior sensibilidade em janelas de longa duração de tempo GORSHKOV, 2012). 

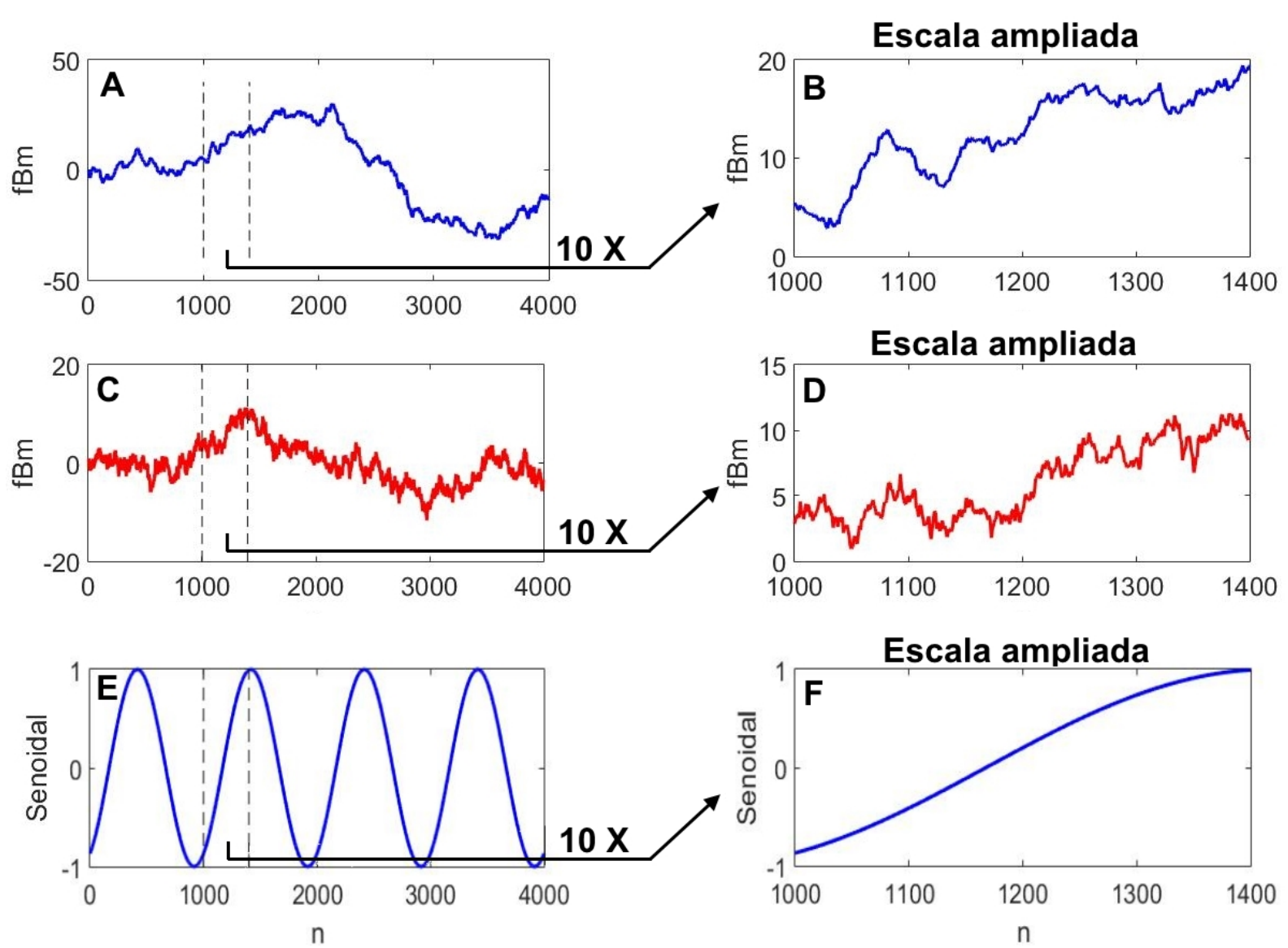

Figura 20: Exemplo de sinais em diferentes escalas horizontais. A) 4000 amostras (n) de $\mathrm{fBm}$ com expoente de Hurst igual a 0,6, geradas pela função wfbm() do Matlab. B) curva exibida em (A) ampliada em 10 vezes no eixo horizontal. C) 4000 amostras (n) de fBm com expoente de Hurst igual a 0,4 geradas pela função wfbm do Matlab.D) curva exibida em (C) ampliada em 10 vezes no eixo horizontal. Sinais de fBm exibem padrões semelhantes em diferentes escalas horizontais, como é possível notar em (A) e em (C), quando observadas as escala ampliadas (B) e (D). O coeficiente de Hurst varia de 0 a 1 . Sinais com coeficientes de Hurst menores do que 0,5 exibem "persistência" negativa, indicando que amostras futuras do sinal tendem a possuir sentido contrário de amostras passadas. Sinais com coeficientes de Hurst maiores do que 0,5 exibem "persistência" positiva, indicando que amostras futuras tendem a possuir sentido igual ao de amostras passadas. E) Senoide com frequência de $1 e^{-3}$ ciclos/amostras. F) curva exibida em (E) ampliada em 10 vezes no eixo horizontal. Visualmente é possível notar que a senoide (E) não apresenta padrões semelhantes em diferentes escalas $(\mathrm{F})$. 


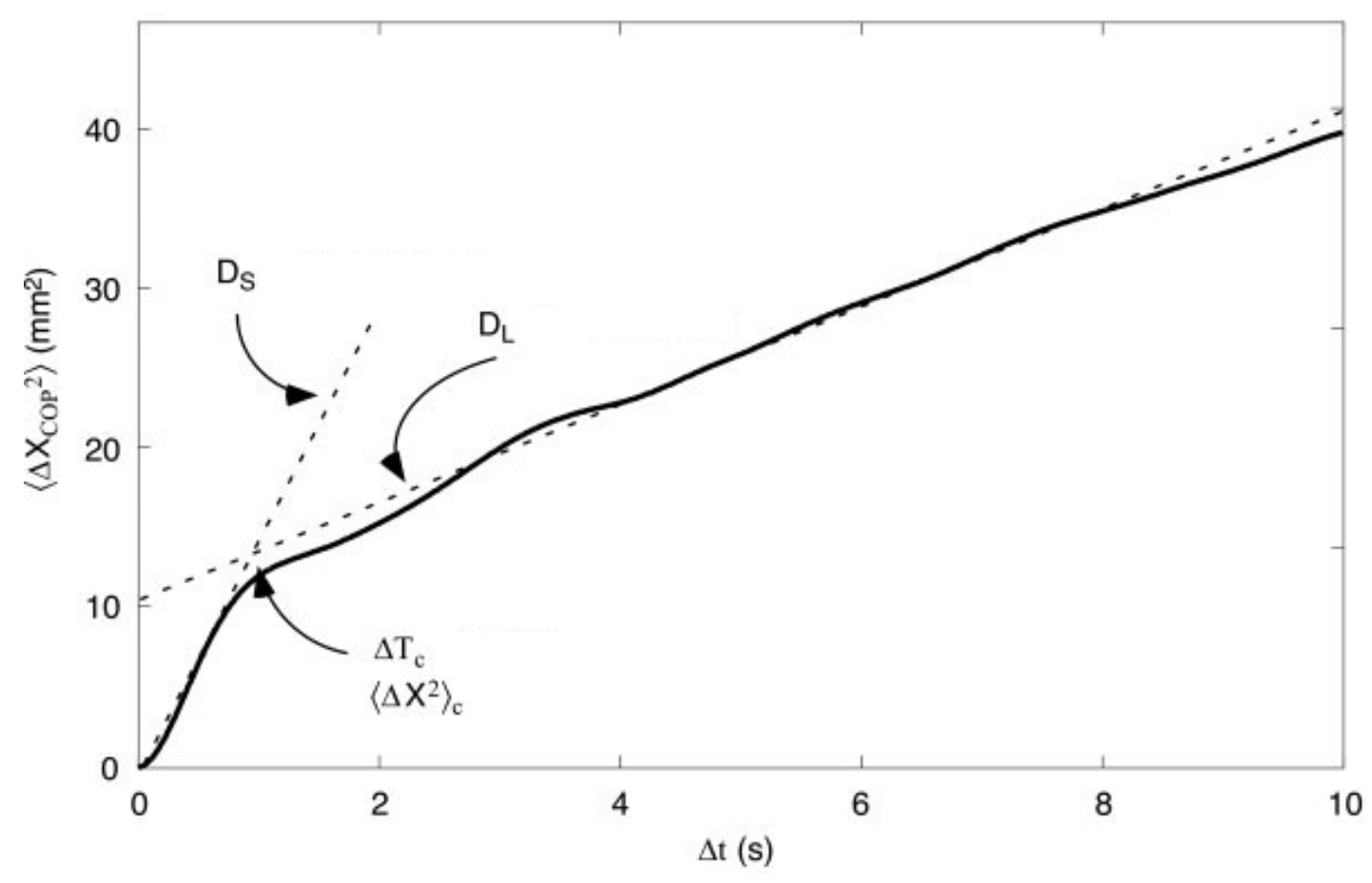

Figura 21: Exemplo de gráfico $\left(\left\langle\Delta X_{C O P}^{2}\right\rangle \times \Delta T\right)$ gerado durante a análise de difusão do estabilograma (SDA) para a obtenção dos parâmetros $D_{S}, D_{L}, \Delta T_{c}$ e $\left\langle\Delta X_{C O P}^{2}\right\rangle_{C}$. Os coeficientes de difusão $D_{S}$ e $D_{L}$ correspondem aos coeficientes angulares obtidos das retas obtidas no gráfico $\left(\left\langle\Delta X_{C O P}^{2}\right\rangle\right.$ x $\left.\Delta T\right)$ em curtas durações e em longas durações e estão relacionados, em escala linear, com o expoente de escalonamento do sinal (expoente de Hurst $(H))$ em curta duração $\left(D_{S}\right)$ e em longa duração $\left(D_{L}\right)$ de tempo. O parâmetro $\Delta T_{c}$ identifica o intervalo de tempo médio, entre amostras do sinal do COP, em que ocorre a alteração abrupta dos coeficientes de difusão (intervalo crítico). $\left\langle\Delta X_{C O P}^{2}\right\rangle_{C}$ quantifica a distância quadrática média entre amostras no intervalo de tempo correspondente a $\Delta T_{c}$ (Figura obtida de (MAURER; PETERKA, 2005)). 


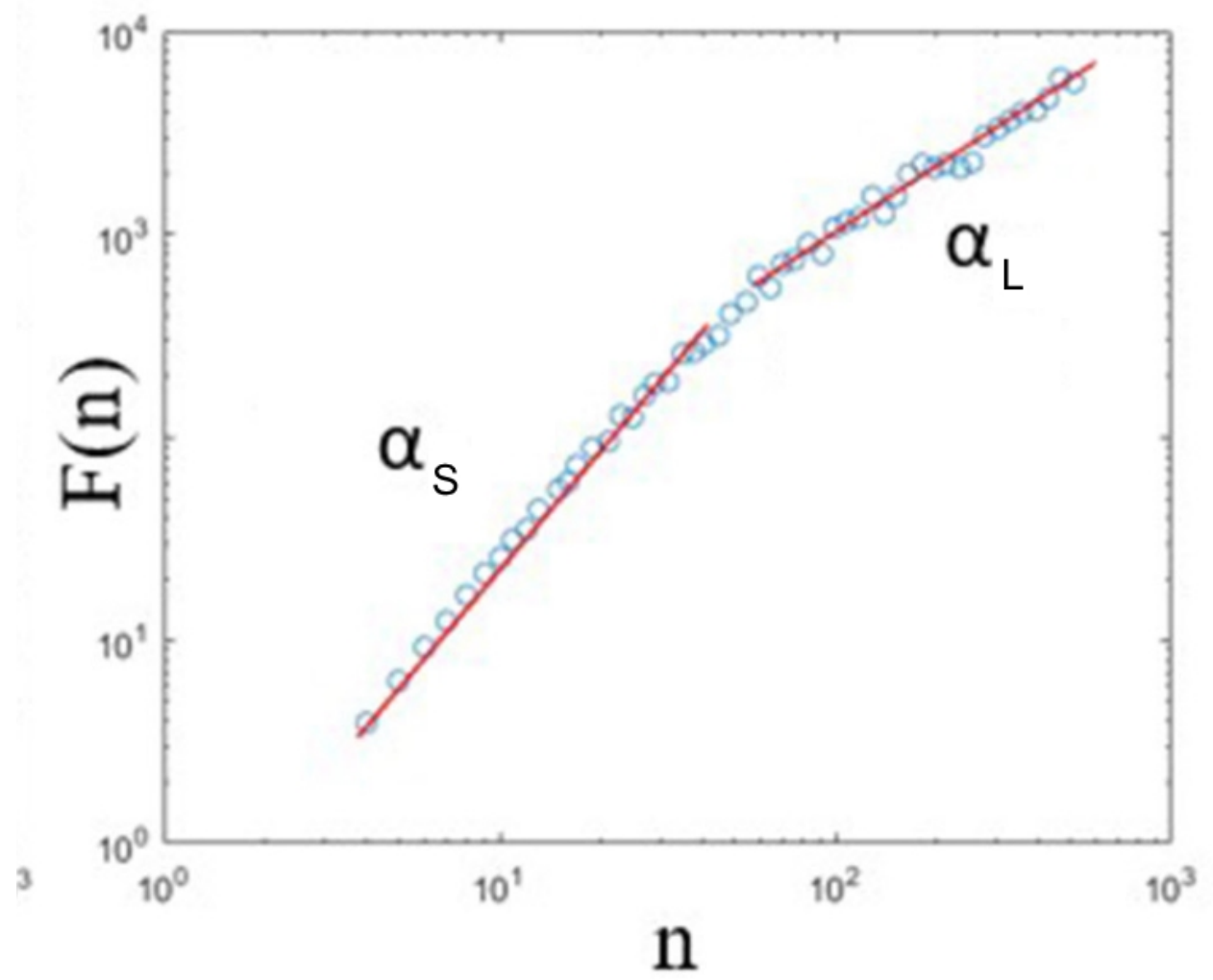

Figura 22: Exemplo de gráfico $(F(n)$ x $n)$ gerado durante a análise fractal em frequências específicas (FsFA) para a obtenção dos parâmetros $\alpha_{S}$ e $\alpha_{L}$. Os coeficientes $\alpha_{S}$, $\alpha_{L}$ correspondem aos coeficientes angulares obtidos das regressões lineares obtidas no gráfico $(F(n)$ x $n)$ em curtas durações e em longas durações e estão relacionados com o expoente de escalonamento do sinal (expoente de Hurst $(H)$ ) em curta duração $\left(\alpha_{S}\right)$ e em longa duração $\left(\alpha_{L}\right)$ de tempo. (Figura obtida de (GILFRICHE et al., 2018) 


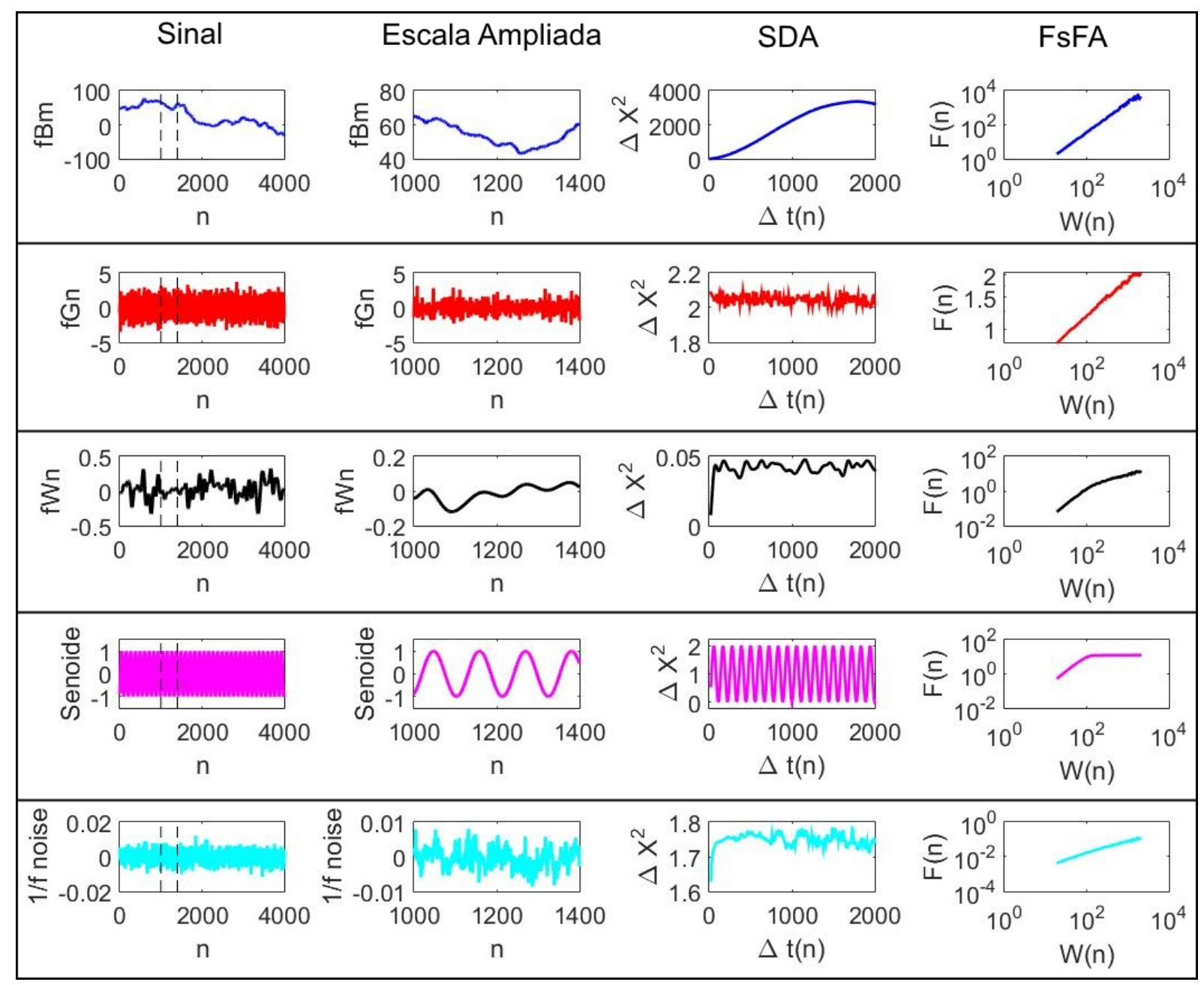

Figura 23: Exemplos dos gráficos obtidos com a SDA e com a FsFA. Na primeira coluna, da esquerda para a direita, cinco tipos de sinais são exibidos: $f \mathrm{Bm} \operatorname{com} \mathrm{H}=0,8$ (primeira linha), fGn com $\mathrm{H}=0,2$ (segunda linha), ruído branco com frequência de amostragem de $100 \mathrm{~Hz}$ e filtrado com filtro passa-baixas de $10 \mathrm{~Hz}$ (fWn) (terceira linha), sinal senoidal com frequência de 0,025 ciclos/amostras (quarta linha) e ruído com PSD com característica $1 / f$ (ruído rosa). Na segunda coluna, são exibidos os sinais da coluna à esquerda, ampliados em 10 vezes no eixo horizontal. Na terceira coluna, são exibidos os gráficos obtidos durante a SDA. Na quarta coluna são exibidos os gráficos obtidos durante a FsFA. Os sinais fBm, fGn e ruído $1 / f$ apresentam padrões semelhantes em diferentes escalas horizontais, enquanto que o sinal senoidal e o fWn aparentemente não apresentam (comparação entre primeira coluna e segunda coluna). O gráfico gerado durante a SDA apresenta inclinação média não nula apenas para o $\mathrm{fBm}$, indicando que os coeficientes de difusão da SDA são mais sensíveis a este tipo de sinal. Os gráficos obtidos na FsFA apresentam comportamento linear para os sinais fBm, fGn e ruído $1 / f$, como consequência, os coeficientes da FsFA são mais sensíveis a estes tipos de sinais. 
(b) Análise de entropia: Análise que verifica a aleatoriedade presente em sinais. Em geral, sistemas biológicos saudáveis apresentam dinâmica mais aleatória do que da de sistemas não saudáveis (Figura 24) KAPLAN; FURMAN; PINCUS, 1990 PINCUS, 1991). Por meio da análise de entropia é possível detectar alterações em sistemas biológicos que podem não ser detectáveis por meio de outras análises (PINCUS; GOLDBERGER, 1994). A entropia dos sinais do COP pode ser quantificada por metodologias baseadas na entropia de KolmogorovSinai, como por exemplo pela approximate entropy (ApEn) (PINCUS, 1991), pela sample entropy (SampEn) (RICHMAN; MOORMAN, 2000) ou pela control entropy (BOLLT; SKUFCA; MCGREGOR, 2009). Por meio de técnicas de análise de entropia também é possível quantificar a complexidade de sinais. Um sinal com características semelhantes às do ruído branco, apesar de possuir entropia elevada (nível de aleatoriedade elevado) não é um sinal complexo. Por outro lado, um sinal com características semelhantes às do ruído rosa (ruído 1/f, característico de muitos fenômenos naturais), também possui entropia elevada e, ao contrário do ruído branco, é um sinal complexo. A complexidade dos sinais do COP pode ser quantificada pela metodologia de entropia multi-escala (MSE) que calcula a entropia em diferentes escalas de tempo do sinal por meio da SampEn (Figura 25), resultando em um índice de complexidade (CI) do sinal do COP (Figura 26) COSTA; GOLDBERGER; PENG, 2002; BUSA; EMMERIK, 2016). A análise da complexidade do sinal do COP por meio da MSE é mais sensível a modificações da dinâmica do controle postural do que pela análise da entropia (COSTA; GOLDBERGER; PENG, 2002; HANSEN et al. 2017). De acordo com HANSEN et al. (2017) pode-se obter um aumento na sensibilidade do parâmetro CI por meio do cálculo da MSE utilizando o sinal de velocidade do COP em vez do sinal de localização do COP. 

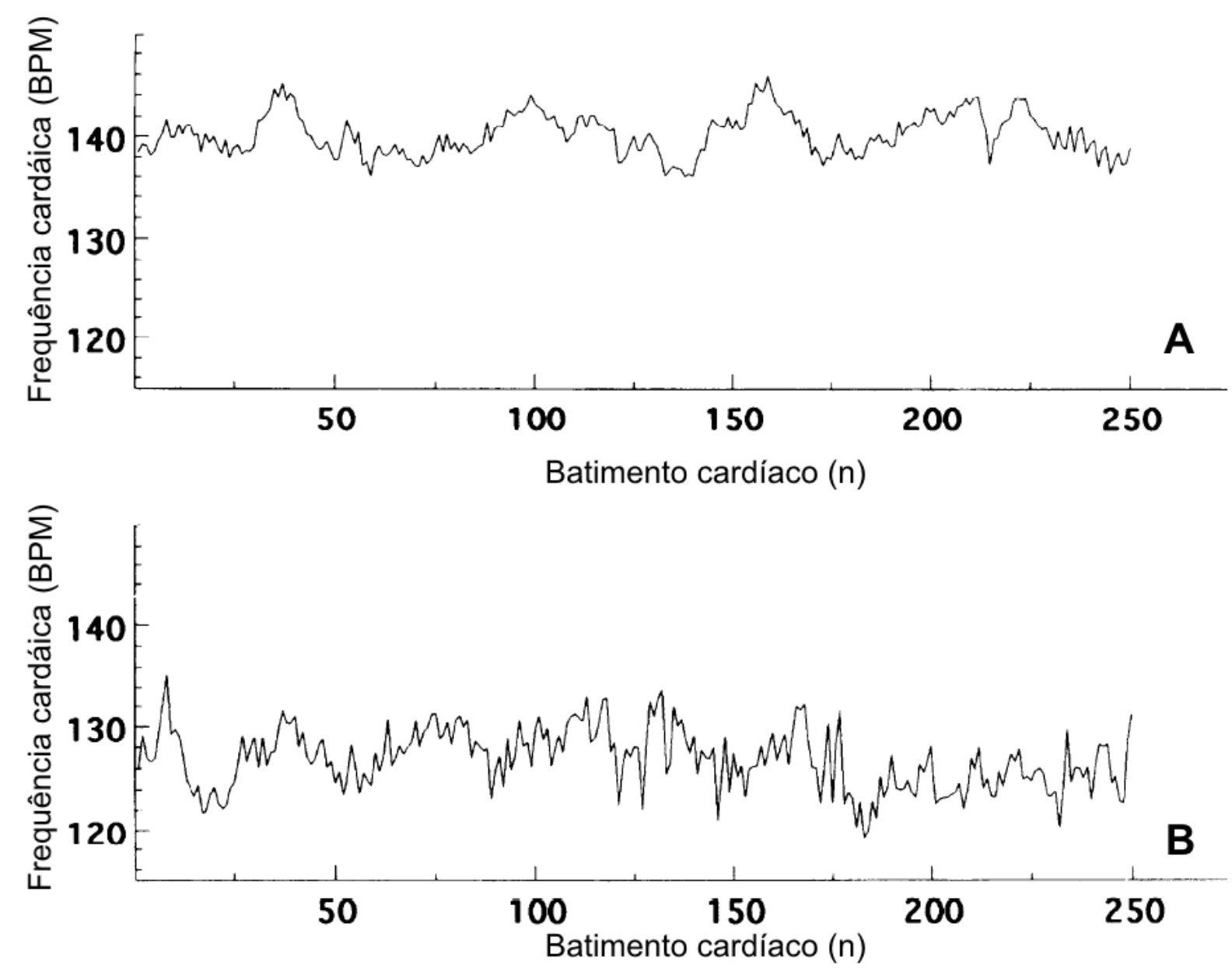

Figura 24: Exemplos de sinais biológicos com diferentes complexidades. A) dinâmica da frequência cardíaca de uma criança com síndrome da morte súbita infantil. B) dinâmica da frequência cardíaca de uma criança saudável. Sinais de sistemas biológicos saudáveis, em geral, possuem maior complexidade do que de sistemas biológicos não saudáveis. (Figura obtida de (PINCUS; GOLDBERGER, 1994)) 


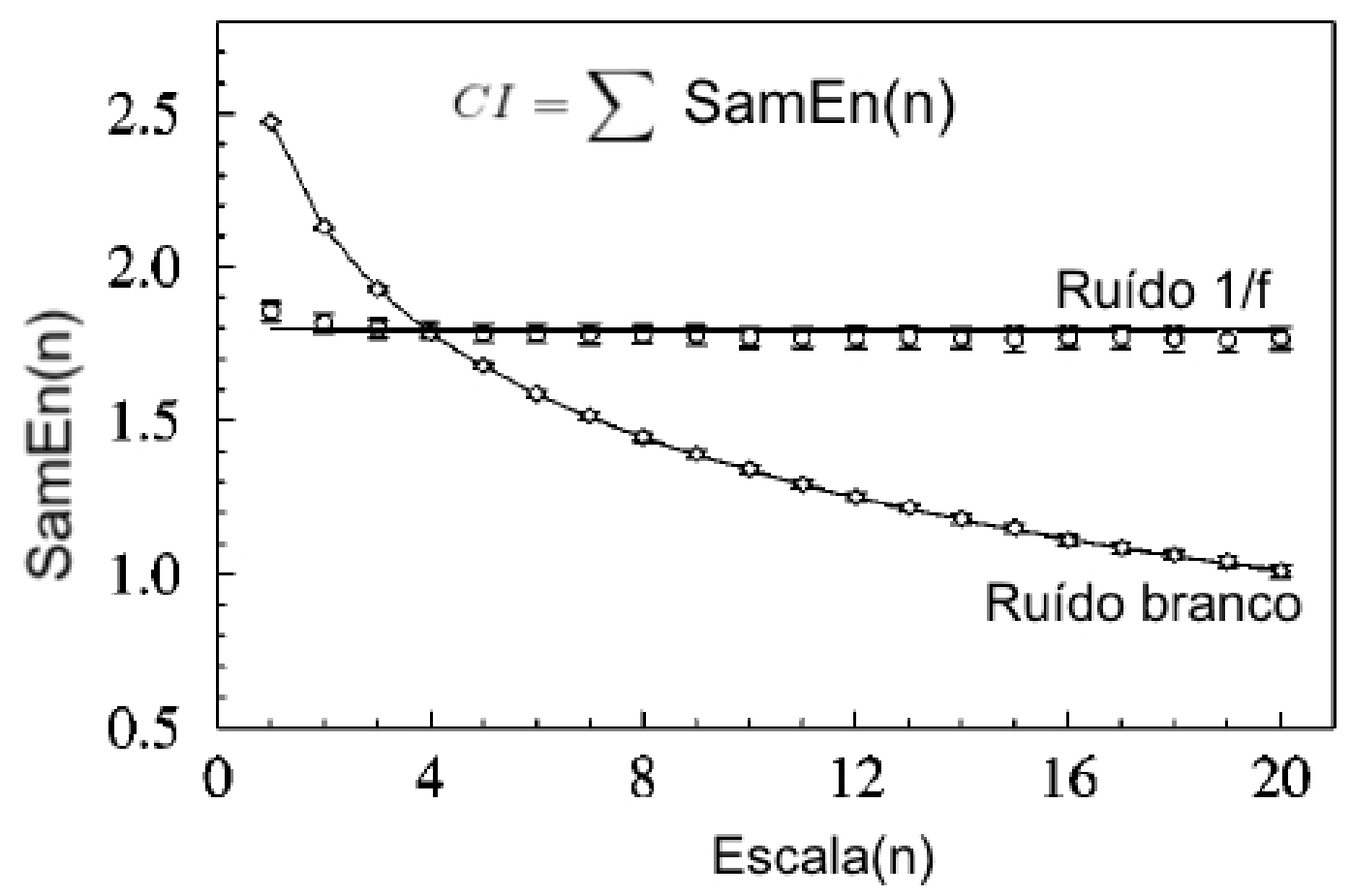

Figura 25: Exemplo de gráfico $(\operatorname{SampEn}(n) \mathrm{X}(n))$ obtido durante a MSE para os sinais ruído branco e ruído 1/f (ruído rosa). Na MSE a sample entropy (SampEn) é obtida em diferentes escalas de tempo, resultando nos valores $\operatorname{SampEn}(n)$. O coeficiente $C I$ (Figura 26) é obtido pela somatória dos resultados obtidos da SampEn $(F(n))$ em diferentes escalas. O ruído branco é um sinal que apresenta maior entropia do que o ruído $1 / f$, porém o ruído 1/f possui maior complexidade do que o ruído branco. A MSE permite quantificar essa diferença por meio do cálculo da entropia (SamEn) do sinal em diferentes escalas. (Figura obtida de (COSTA; GOLDBERGER; PENG, 2002)) 

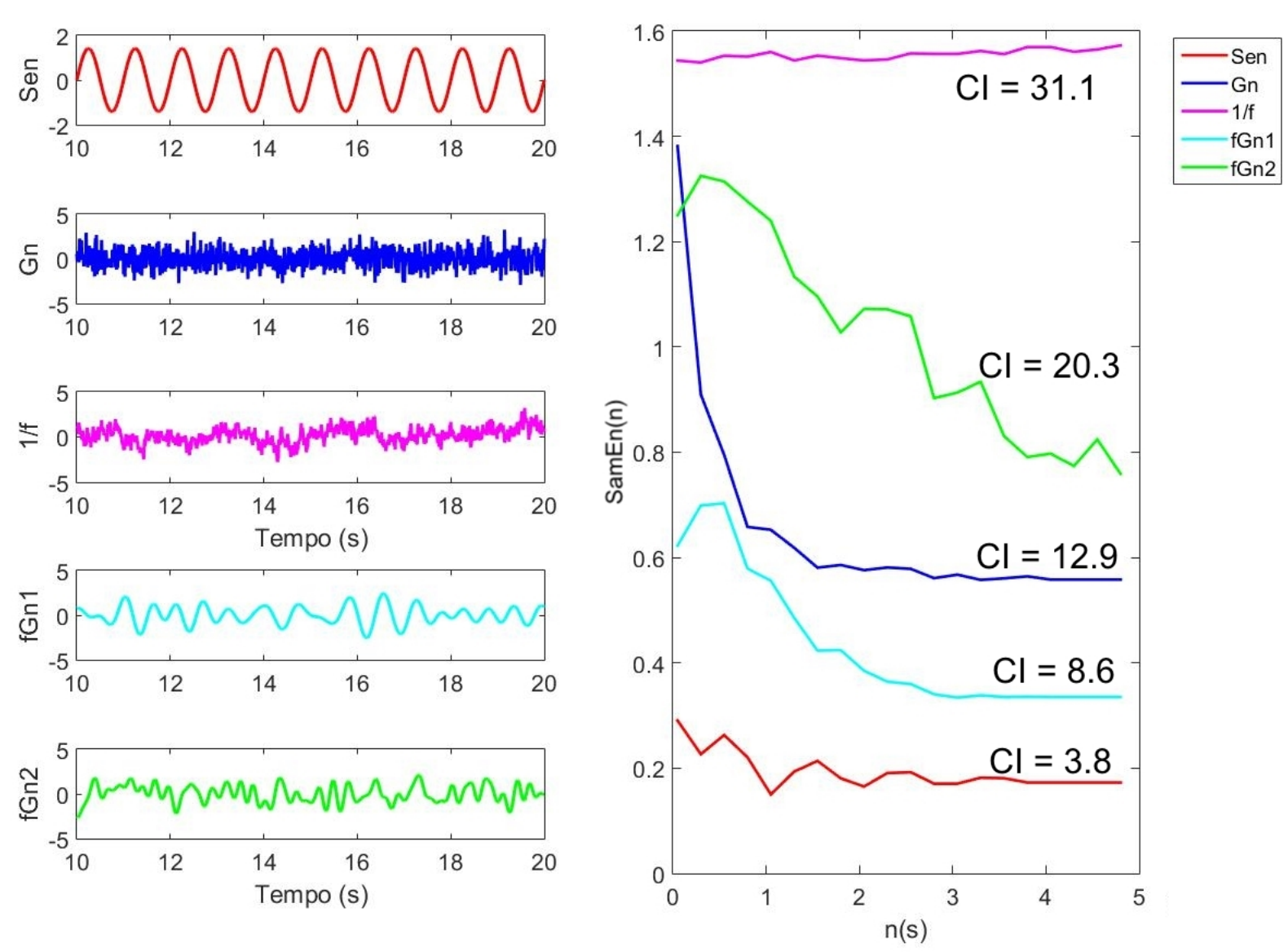

Figura 26: Exemplos de sinais com diferentes índices de complexidade (CI) quantificados pela MSE com parâmetros $m=2, r=2, F s=100 \mathrm{~Hz}$, em escalas de 0,05 segundos a 5 segundos. Na primeira linha à esquerda, de cima para baixo, senoide com frequência de $1 \mathrm{~Hz}$. Na segunda linha, ruído com distribuição gaussiana. Na terceira linha, ruído com característica 1/f (ruído rosa). Na quarta linha, ruído com distribuição gaussiana filtrado com filtro passa-faixas com frequências de corte de $1 \mathrm{~Hz}$ e $2 \mathrm{~Hz}$ (Butterworth $4^{a}$ ordem). Na quinta linha, ruído com distribuição gaussiana filtrado com filtro passa-faixas com frequências de corte de $0,1 \mathrm{~Hz}$ e $4 \mathrm{~Hz}$ (Butterworth $4^{a}$ ordem). Á direita são exibidos os gráficos $(\operatorname{SampEn}(n) \mathrm{X}(n))$ obtidos da MSE dos sinais exibidos à esquerda. O gráfico $(\operatorname{SampEn}(n) \mathrm{X}(n))$ exibe o valor da entropia $(\operatorname{SampEn}(n)$ obtido pela $\operatorname{SampEn})$ de cada sinal em diferentes escalas de tempo. O índice $C I$ da MSE é obtido pela somatória dos valores de entropia em diferentes escalas. Índices $C I$ mais elevados indicam sinais com complexidades maiores. Na MSE, dependendo dos parâmetros adotados, um ruído com distribuição gaussiana, como o apresentado na segunda linha, apesar de ser um sinal com elevada entropia, não apresenta alta complexidade, sendo esta uma das vantagens da utilização da MSE em relação a utilização da sample entropy em uma única escala. 
(c) Decomposição Rambling/Trembling: O sinal do COP pode ser decomposto em duas componentes denominadas Rambling e Trembling (Figura 27) (ZATSIORSKY; DUARTE, 2000; ZATSIORSKY; DUARTE, 1999). Segundo ZATSIORSKY; DUARTE, a componente Rambling representa o movimento do ponto de referência em que o corpo humano se mantêm em equilíbrio instantâneo, durante a $\mathrm{PEO}$, ao longo do tempo ponto de equilíbrio instantâneo (IEP) e a componente Trembling corresponde às oscilações do corpo humano em torno do IEP ao longo do tempo. A componente Trembling pode estar associada a atividade de circuitos medulares, enquanto que a componente Rambling a circuitos supramedulares (ZATSIORSKY; DUARTE, 2000; SHIN; MOTL; SOSNOFF, 2011). A identificação de modificações na dinâmica do controle postural pode ser feita por meio do cálculo de parâmetros globais ou estruturais das componentes Rambling e Trembling (Por exemplo, pela análise da MSE das componentes Trembling e Rambling em diferentes condições) (BOLBECKER et al., 2018). 


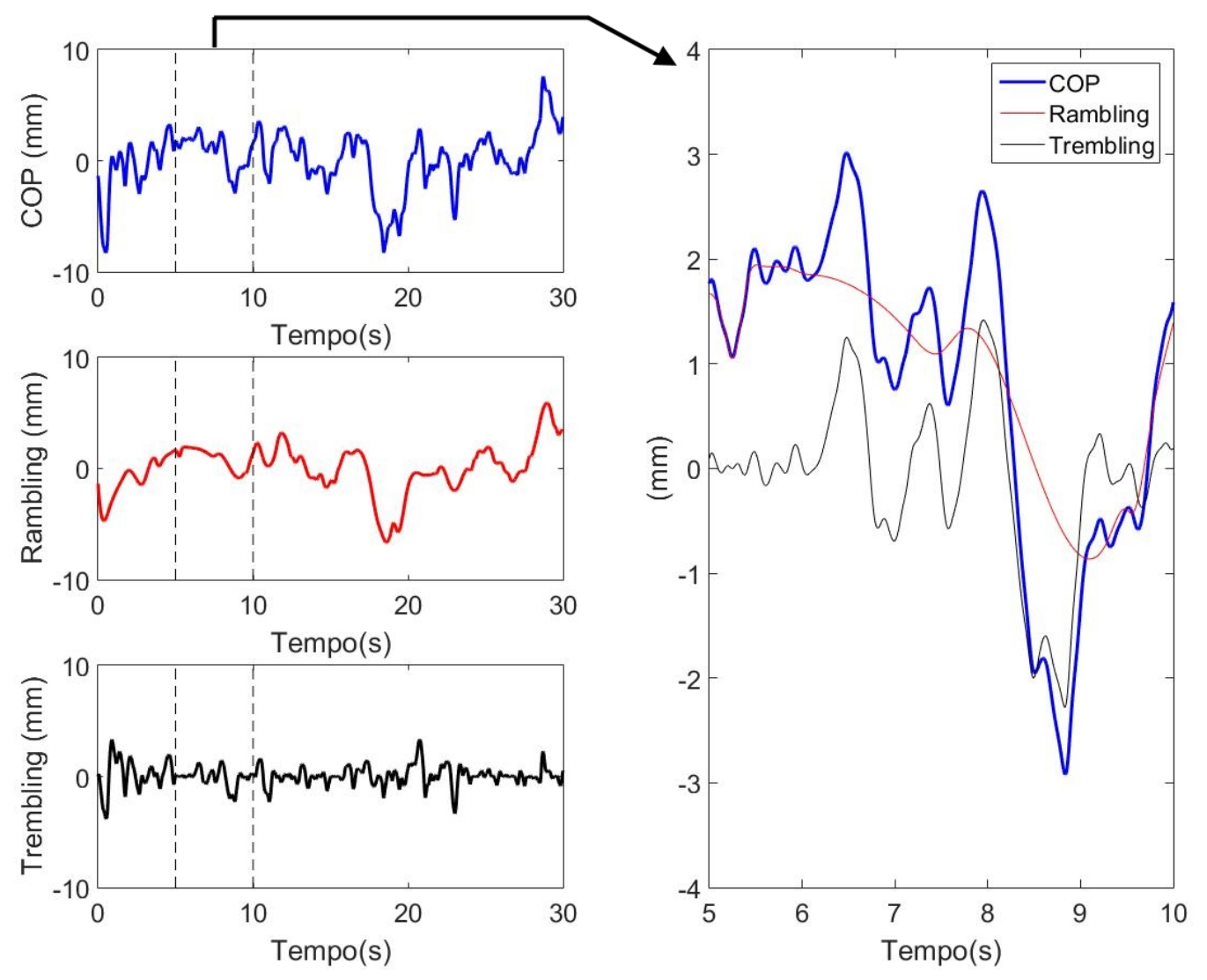

Figura 27: Exemplo da decomposição Rambling e Trembling do sinal do COP proposta por ZATSIORSKY; DUARTE (1999). A componente Rambling representa o movimento do ponto de referência, ao longo do tempo, em que o corpo humano se mantêm em equilíbrio instantâneo durante a PEO ponto de equilíbrio instantâneo (IEP). A componente Trembling corresponde às oscilações do corpo humano em torno do IEP ao longo do tempo. A soma da componente Rambling com a componente Trembling resulta o sinal do COP original.

A análise dos parâmetros obtidos do sinal do COP pode ser feita de forma individual, por meio da análise de cada parâmetro individualmente, ou de forma combinada, como por exemplo pela obtenção de descritores multivariáveis (KUO et al., 1998) ou pela a obtenção de coeficientes de um controlador proporcional integral derivativo (PID) que modela o sistema de controle postural (RAHMATI et al., 2019).

Alguns parâmetros são menos sensíveis a características antropométricas do que outros, sendo definidos como universais (YAMAMOTO et al., 2015), podendo ser empregados na análise de identificação de diferenças do controle postural durante a $\mathrm{PEO}$ entre diferentes grupos de indivíduos (CHIARI; ROCCHI; CAPPELLO, 2002) o que também pode ser 
realizado por meio da normalização dos sinais do COP em relação, por exemplo, à área do estabilograma (OLIVEIRA, 2017), caso parâmetros não universais sejam adotados. De modo a minimizar a variabilidade dos resultados da análise do COP, os parâmetros devem ser calculados com os sinais coletados de pelos menos 5 repetições da PEO com duração mínima de 60 segundos de cada repetição (DOYLE et al., 2007). De modo geral,também é recomendado que a digitalização dos sinais adquiridos da plataforma de força seja feita com frequência de amostragem de $100 \mathrm{~Hz}$ e que os sinais sejam filtrados por um filtro linear passa-baixas de 10Hz (RUHE; FEJER; WALKER, 2010). 


\section{MATERIAIS E MÉTODOS}

\subsection{Hipóteses do Trabalho}

\subsubsection{Hipótese 1 - Utilização de um modelo computacional sim- plificado}

- Hipótese: No processo de estimação do campo elétrico gerado na medula espinhal pela tsDCS, um modelo computacional elaborado com a geometria simplificada do tronco humano pode gerar resultados próximos ao de um modelo computacional desenvolvido com uma geometria mais complexa (Figura 28).

- Motivação: A elaboração de um modelo de tronco humano baseado em imagens de MRI demanda tempo de desenvolvimento e também requer alto poder computacional para a obtenção dos resultados. A utilização de um modelo computacional elaborado com a geometria simplificada do tronco humano, que permita a obtenção de resultados próximos aos obtidos por um modelo complexo, viabilizaria a análise básica dos parâmetros da tsDCS (posicionamento de eletrodos, tamanho de eletrodos e intensidade da corrente de estimulação) adotada no protocolo experimental nesse trabalho, sem recorrer a um modelo complexo.

- Teste da hipótese: Um modelo computacional utilizando a geometria simplificada de um tronco humano foi desenvolvido e os resultados obtidos por esse modelo foram comparados com os obtidos por um modelo mais complexo FERNANDES et al. 2018). A hipótese foi considerada verdadeira caso:

1. A diferença, entre os dois modelos, do tamanho e da localização da região da medula espinhal estimulada por um campo elétrico com intensidade de no mínimo $0,15 \mathrm{~V} / \mathrm{m}$ não fosse maior do que $15 \%$.

\footnotetext{
${ }^{1} \mathrm{O}$ critério de diferenças máximas permitidas de $15 \%$, adotado nesse trabalho, é um critério ad hoc elaborado com base nas diferenças anatômicas que podem ser encontradas entre indivíduos. Em média a medula possui comprimento total de $45 \mathrm{~cm}$ (FROSTELL et al., 2016), iniciando na vértebra C1 e terminando em média nas alturas das vértebras L1 e L2 (REIMANN; ANSON, 1944), podendo terminar
} 
2. A diferença, entre os dois modelos, da intensidade do campo elétrico, em regiões da medula com campo elétrico com intensidade maior do que $0,15 \mathrm{~V} / \mathrm{m}$, nas diferentes componentes, não fosse em média maior do que $15 \%$.
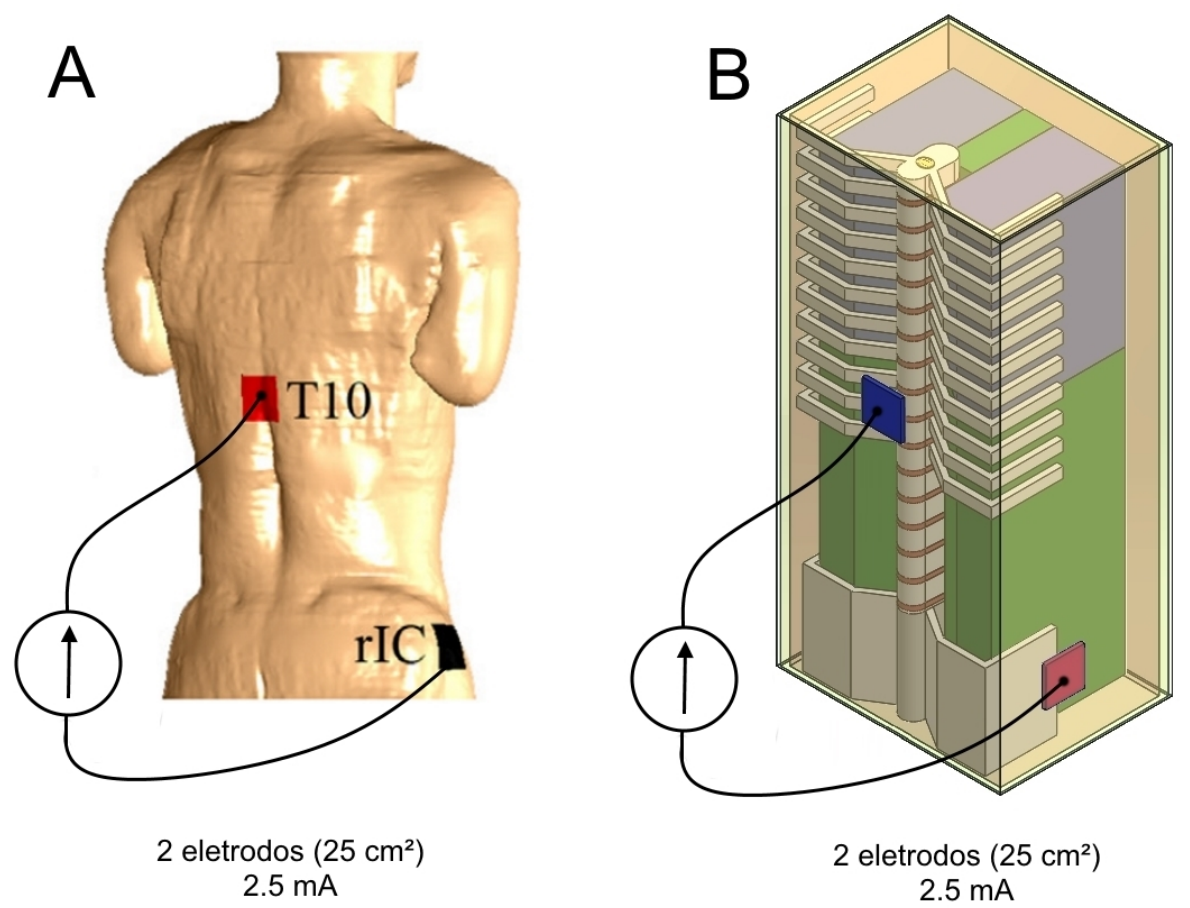

Figura 28: Hipótese 1 - Utilização de um modelo computacional simplificado: Um modelo computacional simplificado do tronco humano (B) pode gerar resultados próximos dos obtidos por um modelo mais complexo desenvolvido por FERNANDES et al. (A) (imagem adaptada de (FERNANDES et al., 2018)).

\subsubsection{Hipótese 2 - Adição de um terceiro eletrodo}

- Hipótese: Na configuração "um eletrodo de $25 \mathrm{~cm}^{2}$ sobre a vértebra T10 e um eletrodo de $25 \mathrm{~cm}^{2}$ sobre a crista ilíaca direita, estimulação de 2,5 mA" (FERNANDES et al., 2018), a adição de um terceiro eletrodo de $25 \mathrm{~cm}^{2}$, posicionado sobre a crista ilíaca esquerda, conectado eletricamente ao eletrodo da crista ilíaca direita, não deve modificar significativamente o campo elétrico gerado na medula espinhal (Figura 29).

- Motivação: As experiências sensoriais geradas pela tsDCS no início da estimulação elétrica podem prejudicar o cegamento do protocolo experimental. Como a intensi-

entre as alturas de T12 e L3, correspondendo à uma variação de aproximadamente $15 \%$ no comprimento da medula espinhal. 
dade dessas sensações depende da densidade de corrente elétrica do eletrodo em contato com a pele, a adição de um eletrodo sobre a crista ilíaca esquerda à configuração "um eletrodo sobre a vértebra T10 e um eletrodo sobre a crista ilíaca direita", reduziria a densidade de corrente aplicada na região da pele sobre as cristas ilíacas de modo a aumentar o cegamento experimental, sem modificações significativas do campo elétrico induzido na medula espinhal.

- Teste da hipótese: Por meio de um modelo computacional simplificado foi elaborada a comparação entre os campos elétricos induzidos na medula espinhal pelo posicionamento de eletrodos "um eletrodo de $25 \mathrm{~cm}^{2}$ sobre a vértebra T10 e um eletrodo de $25 \mathrm{~cm}^{2}$ sobre a crista ilíaca direita" e por esse posicionamento modificado pela adição de um terceiro eletrodo de $25 \mathrm{~cm}^{2}$ sobre a crista ilíaca esquerda, com corrente de estimulação de 2,5mA nas duas situações. A hipótese foi considerada verdadeira caso:

1. A diferença, entre as duas configurações, do tamanho e localização da região da medula espinhal estimulada por $0,15 \mathrm{~V} / \mathrm{m}$, não fosse maior do que $15 \%$.

2. A diferença, entre as duas configurações, da intensidade do campo elétrico, em regiões da medula com campo elétrico com intensidade maior do que $0,15 \mathrm{~V} / \mathrm{m}$, nas diferentes componentes, não fosse em média maior do que $15 \%$.. 

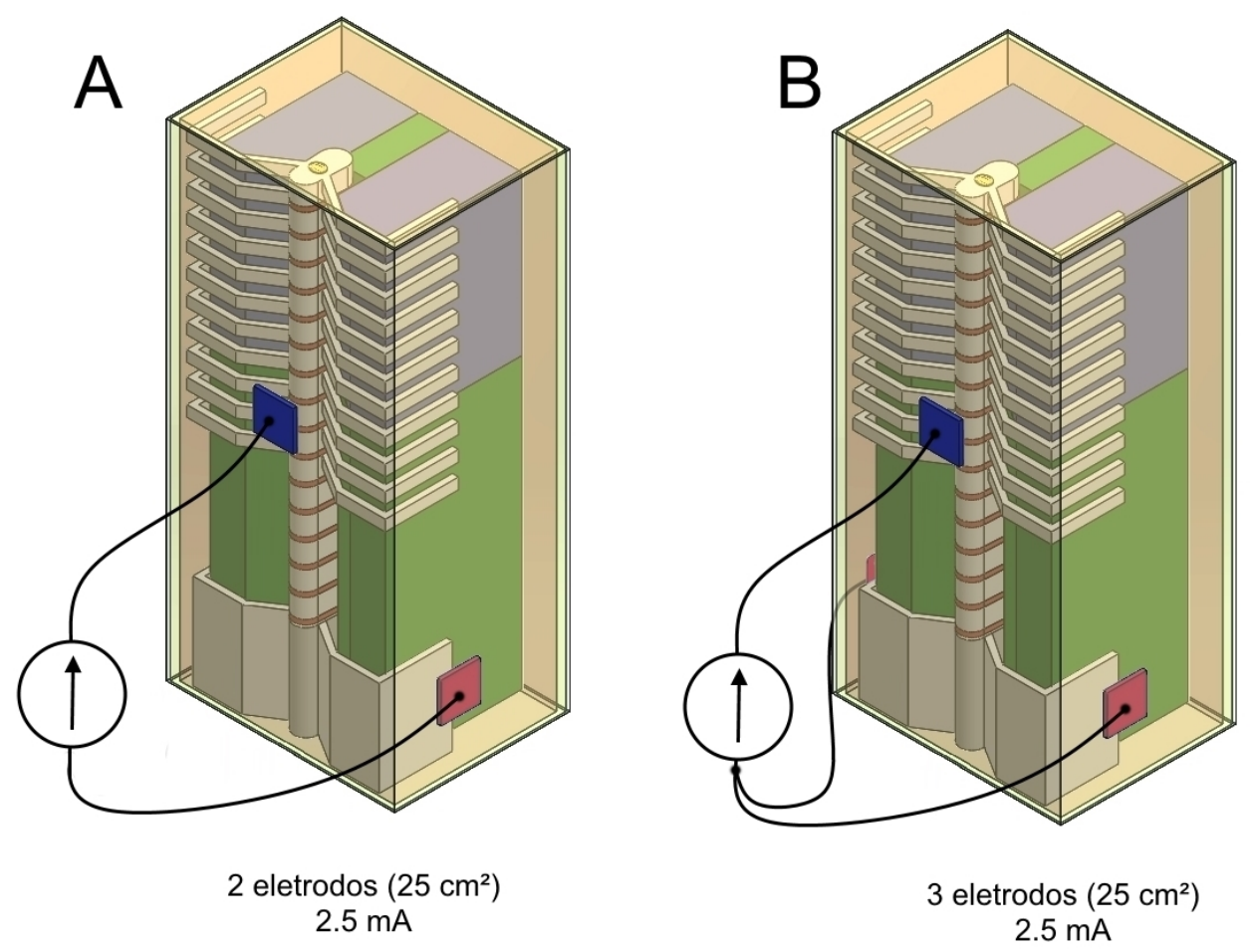

Figura 29: Hipótese 2 - Adição de um terceiro eletrodo: O campo elétrico induzido na medula espinhal pela configuração, "um eletrodo de $25 \mathrm{~cm}^{2}$ sobre a vértebra T10 e um eletrodo de $25 \mathrm{~cm}^{2}$ sobre a crista ilíaca direita, estimulação de $2,5 \mathrm{~mA}$ ” (A), pode não ser alterado quando um eletrodo adicional de $25 \mathrm{~cm}^{2}$, conectado eletricamente ao eletrodo da crista ilíaca direita, é posicionado sobre crista ilíaca esquerda (B).

\subsubsection{Hipótese 3 - Aumento da dimensão do eletrodo}

- Hipótese: A utilização de eletrodos de maior dimensão $\left(50 \mathrm{~cm}^{2}, 10 \mathrm{~cm} \mathrm{x} 5 \mathrm{~cm}\right)$ na configuração "um eletrodo sobre a vértebra T10, um eletrodo sobre a crista ilíaca direita e um eletrodo sobre a crista ilíaca esquerda, estimulação de 2,5mA”, pode permitir que uma região maior da medula espinal seja estimulada por um campo elétrico de no mínimo $0,15 \mathrm{~V} / \mathrm{m}$, em comparação com a utilização de eletrodos de menor dimensão $\left(25 \mathrm{~cm}^{2}, 5 \mathrm{~cm} \times 5 \mathrm{~cm}\right)$ (Figura 30).

- Motivação: Os efeitos da tsDCS dependem da região da medula espinhal estimulada. Para aumentar a probabilidade de sucesso na obtenção de efeitos estatisticamente significativos da tsDCS, a utilização de um eletrodo de maior dimensão ao longo da medula espinhal poderia aumentar a região da medula submetida a um campo elétrico de pelo menos $0,15 \mathrm{~V} / \mathrm{m}$, valor suficiente, segundo a literatura, para induzir neuromodulação. 
- Teste da hipótese: Um modelo computacional simplificado foi utilizado para estimar o campo elétrico gerado na medula espinhal por uma estimulação de $2,5 \mathrm{~mA}$ com eletrodos de $25 \mathrm{~cm}^{2}(5 \mathrm{~cm} \mathrm{x} 5 \mathrm{~cm})$ e outra empregando eletrodos de $50 \mathrm{~cm}^{2}$ $(10 \mathrm{~cm} \times 5 \mathrm{~cm})$. A hipótese foi considerada verdadeira caso a estimulação utilizando eletrodos de $50 \mathrm{~cm}^{2}$ estimulasse uma região da medula $15 \%$ maior, com campo elétrico de no mínimo $0,15 \mathrm{~V} / \mathrm{m}$, em relação à estimulação com eletrodos de $25 \mathrm{~cm}^{2}$.
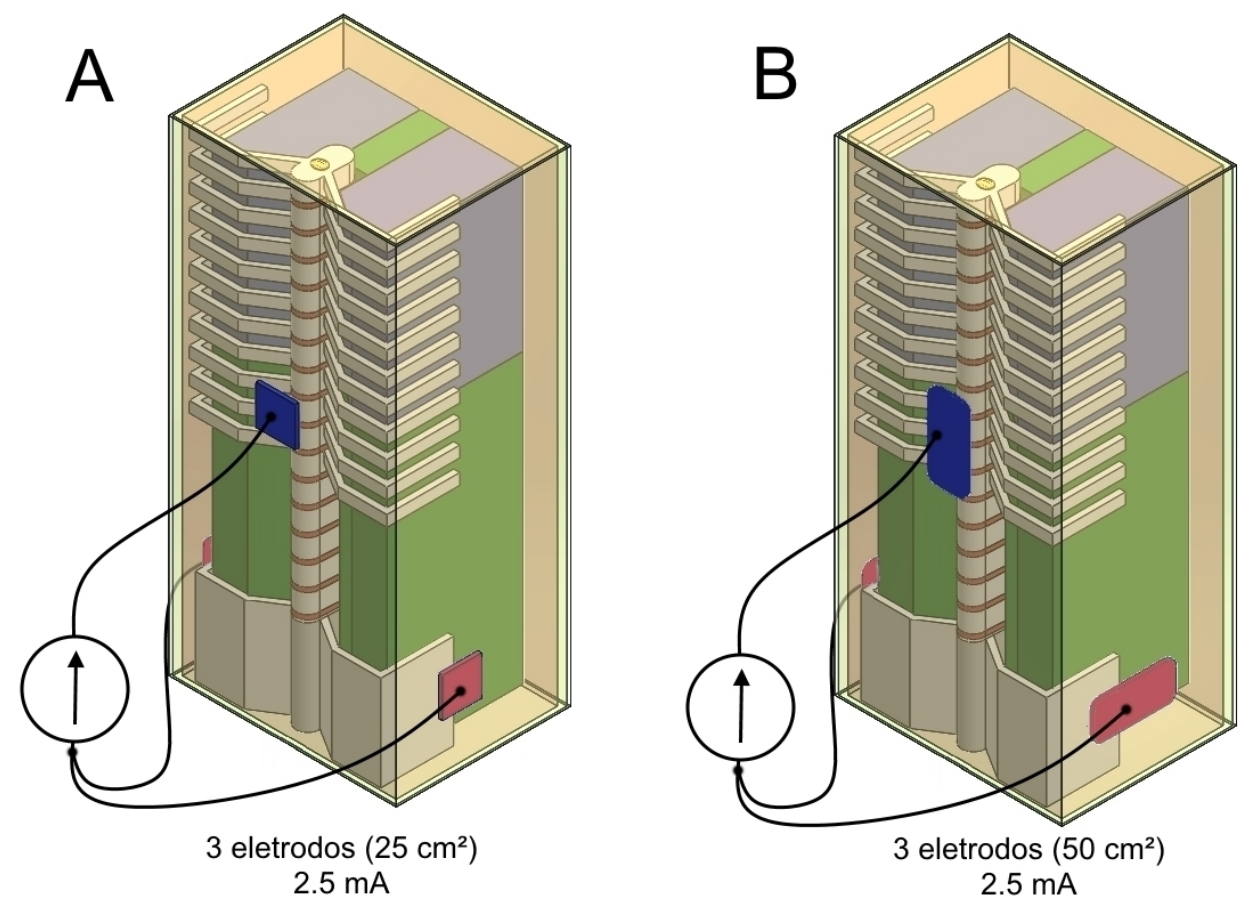

Figura 30: Hipótese 3 - Aumento da dimensão do eletrodo: A utilização de eletrodo com maior dimensão ao longo da medula espinhal $(10 \mathrm{~cm}$ x $5 \mathrm{~cm})$ (B) pode aumentar (verificar critério no teste da hipótese) a região da medula estimulada com campo elétrico de pelo menos $0,15 \mathrm{~V} / \mathrm{m}$ em relação a uma estimulação realizada com um eletrodo de menor dimensão $(5 \mathrm{~cm} \times 5 \mathrm{~cm})$. (A).

\subsubsection{Hipótese 4 - Aumento da corrente de estimulação}

- Hipótese: A utilização de uma estimulação de $5 \mathrm{~mA}$ no posicionamento "um eletrodo sobre a vértebra T10, um eletrodo sobre a crista ilíaca direita e um eletrodo sobre a crista ilíaca esquerda" com eletrodos de $50 \mathrm{~cm}^{2}$ pode estimular uma região maior da medula espinhal com campo elétrico de no mínimo $0,15 \mathrm{~V} / \mathrm{m}$, em relação a uma estimulação realizada com 2,5 mA, e também gera densidade de corrente elétrica na medula espinhal menor do que o limite máximo que causa danos em tecidos neurais (Figura 31. 
- Motivação: Os efeitos da tsDCS dependem da intensidade da corrente elétrica de estimulação. Para aumentar a região da medula espinhal com intensidade de campo elétrico maior do que o suficiente para indução de neuromodulação $(0,15 \mathrm{~V} / \mathrm{m})$, aumentando a probabilidade de sucesso na obtenção de efeitos estatisticamente significativos da tsDCS, o aumento de corrente elétrica da estimulação poderia ser uma alternativa desde que não produzisse densidade de corrente elétrica maior do que $6,3 \mathrm{~A} / \mathrm{m}^{2}$ na medula espinhal, intensidade mínima, segundo a literatura, suficiente para causar danos em tecidos neurais.

- Teste da hipótese: Um modelo computacional simplificado foi utilizado para estimar o campo elétrico gerado na medula espinhal por uma estimulação de $5 \mathrm{~mA}$ e por outra de $2,5 \mathrm{~mA}$, com eletrodos de $50 \mathrm{~cm}^{2}$, na configuração "um eletrodo sobre a vértebra T10, um eletrodo sobre a crista ilíaca direita e um eletrodo sobre a crista ilíaca esquerda". A hipótese foi considerada verdadeira caso:

1. A estimulação realizada com $5 \mathrm{~mA}$ estimulasse uma região da medula, com campo elétrico de no mínimo $0,15 \mathrm{~V} / \mathrm{m}, 15 \%$ maior do que a observada na estimulação elétrica realizada com 2,5 mA.

2. A densidade de corrente produzida na medula espinhal, produzida pela estimulação de $5 \mathrm{~mA}$, fosse menor do que $6,3 \mathrm{~A} / \mathrm{m}^{2}$ 

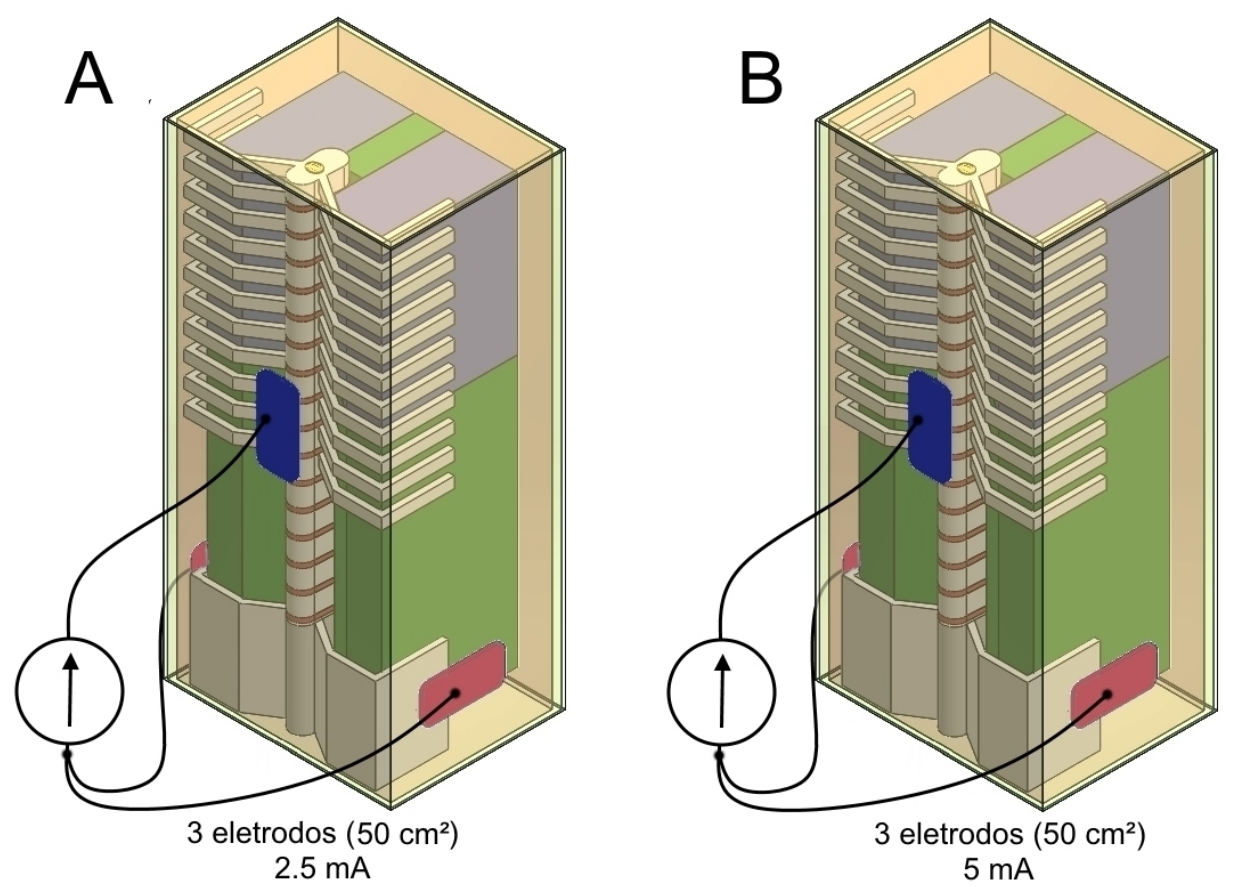

Figura 31: Hipótese 4 - Aumento da corrente de estimulação: A utilização de uma estimulação de $5 \mathrm{~mA}$ (B) pode estimular uma região maior da medula espinhal, com campo elétrico de no mínimo $0,15 \mathrm{~V} / \mathrm{m}$ e com densidade de corrente elétrica na medula espinhal menor do que o limite máximo observado para causar danos em tecidos neurais, em relação a uma estimulação realizada com $2,5 \mathrm{~mA}(\mathbf{A})$.

\subsubsection{Hipótese 5 - Efeito da tsDCS na PEO}

- Hipótese: A tsDCS (20 minutos, $5 \mathrm{~mA}$, eletrodos de $50 \mathrm{~cm}^{2}$ sobre T10 e sobre as duas cristas ilíacas) induz neuromodulação no SNC de modo a produzir modificação estatisticamente significativa na dinâmica das oscilações posturais em $\mathrm{PEO}$, quer durante, quer após 20 minutos de estimulação de CC (Figura 32).

- Motivação: Existem poucos trabalhos publicados que analisaram os efeitos da tsDCS em tarefas motoras BERRY; TATE; CONWAY, 2017; JADCZAK et al., 2019; CICCONE, 2018) e não foram encontrados estudos publicados sobre efeitos da tsDCS na PEO. Se a tsDCS puder alterar aspectos da oscilação postural isto poderia levar a aplicações terapêuticas, como por exemplo, a tsDCS poderia causar modificações no sistema nervoso central e/ou periférico que seriam úteis na área de reabilitação.

- Teste da hipótese: Um protocolo experimental foi elaborado para verificar se a tsDCS (20 minutos, $5 \mathrm{~mA}$, eletrodos de $50 \mathrm{~cm}^{2}$ sobre T10 e sobre as duas cristas 
ilíacas) induzia alterações no controle postural em PEO, durante ou após os 20 minutos de estimulação elétrica. A hipótese foi considerada verdadeira caso alterações estatisticamente significativas nos parâmetros mensurados das oscilações posturais em $\mathrm{PEO}$ fossem observadas .

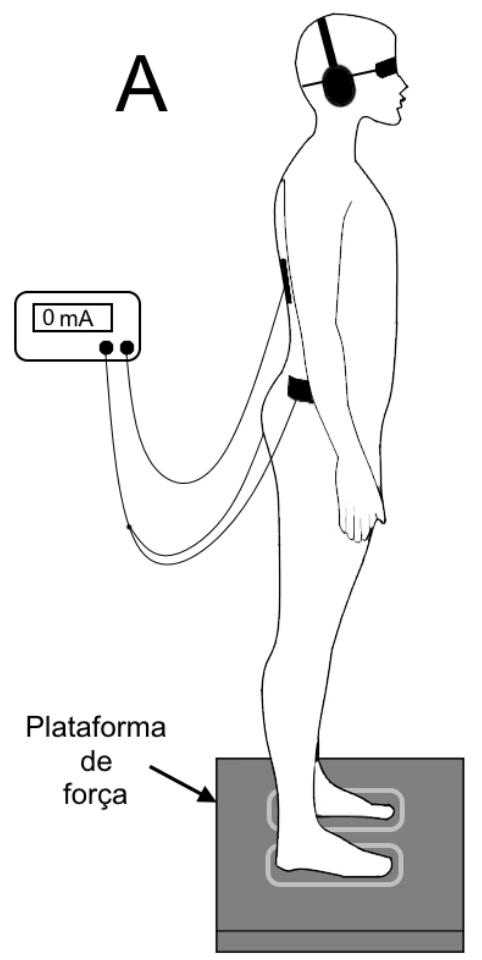

Sem tsDCS

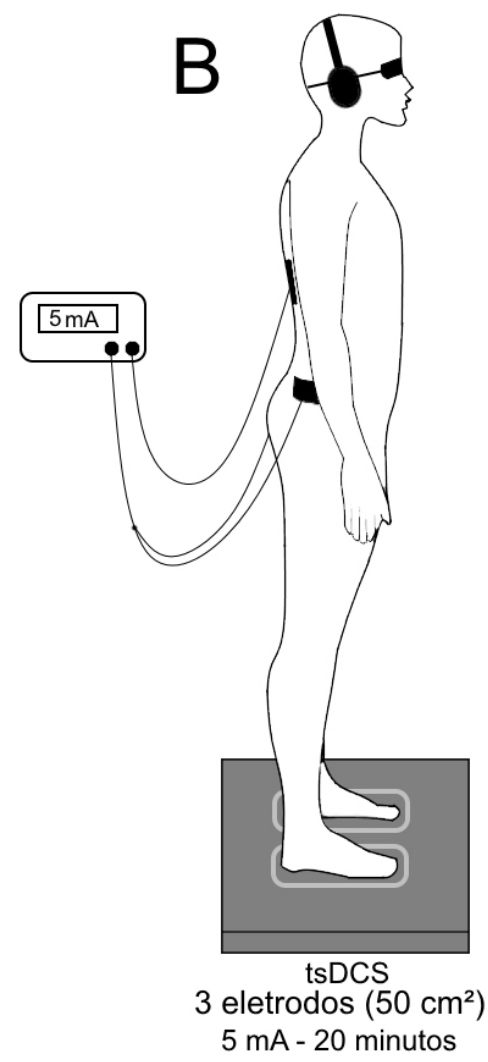

Figura 32: Hipótese 5 - Efeito da tsDCS na PEO: A tsDCS (20 minutos, 5 mA, eletrodos de $50 \mathrm{~cm}^{2}$ sobre T10 e sobre as duas cristas ilíacas) (B) pode alterar significativamente a dinâmica das oscilações posturais em $\mathrm{PEO}$ em relação a condição em que a PEO é executada sem a tsDCS (A).

\subsection{Modelo computacional}

\subsubsection{Modelo tridimensional}

Um modelo tridimensional simplificado do tronco humano, constituído pelos tecidos: pele, tecido adiposo sub-cutâneo, pulmões, vísceras, músculos, costelas, vértebras, discos intervertebrais, sacro, cristas ilíacas e medula espinhal envolvida por líquido cefalorraquidiano (LCR) e por tecido adiposo, foi elaborado no software SolidWorks 2016 
(Dassault Systemes, França). Os parâmetros antropométricos adotados nesse modelo foram baseados nos modelos tridimensionais do corpo humano disponibilizados no banco de dados BodyParts3D (National Bioscience Database Center, Japão e nas imagens de cortes transversais de cadáveres humanos do projeto The Visible Human Project (NIH U.S. National Library of Medicine, USA).

Nesse modelo, a medula foi representada por um cilindro elíptico com comprimento total de $476 \mathrm{~mm}$ envolvido por LCR e por uma camada de tecido adiposo (Figura 33).

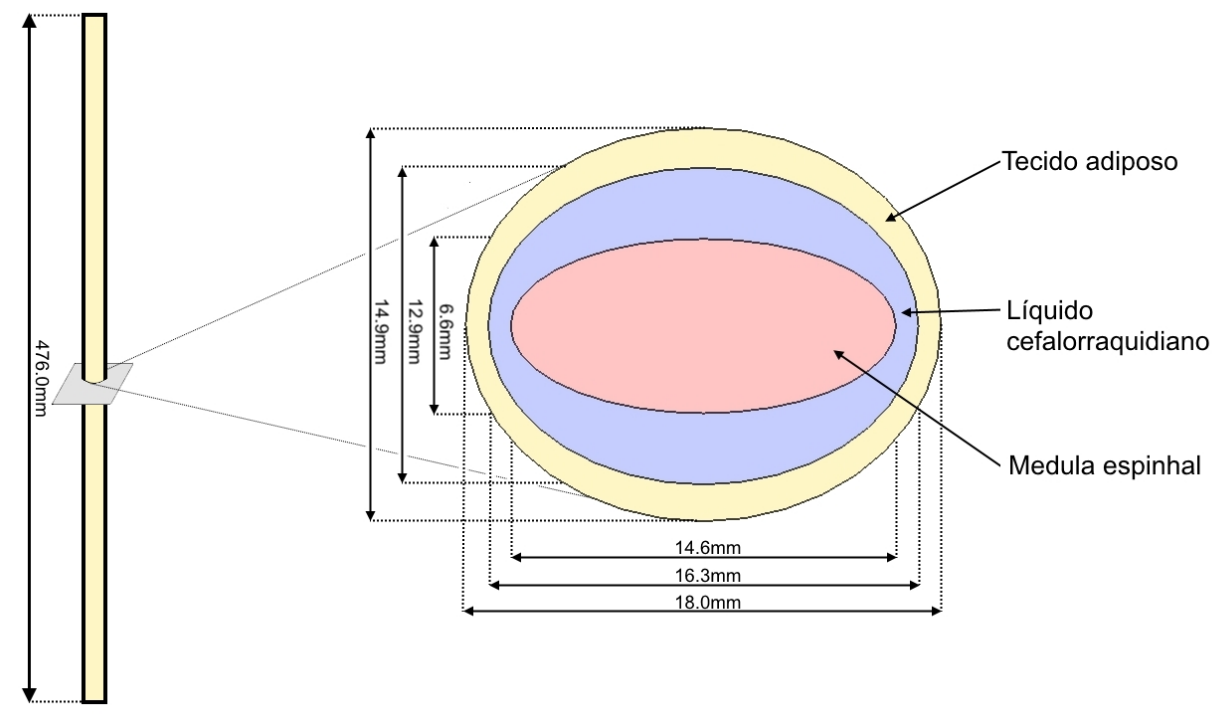

Figura 33: Modelo tridimensional da medula espinhal. Nesse modelo a medula foi representada por um cilindro elíptico com comprimento total de $476 \mathrm{~mm}$ envolto por LCR e tecido adiposo.

As vértebras, desde a vértebra T2 até a vértebra L5, foram todas representadas por uma geometria simplificada de dimensões semelhantes à da décima vértebra torácica humana (Figura 34). As vértebras apresentam um canal central por onde passa a medula espinhal. Da mesma forma, as costelas, desde a segunda costela até a décima segunda costela, foram representadas por uma geometria simplificada da décima costela humana. 


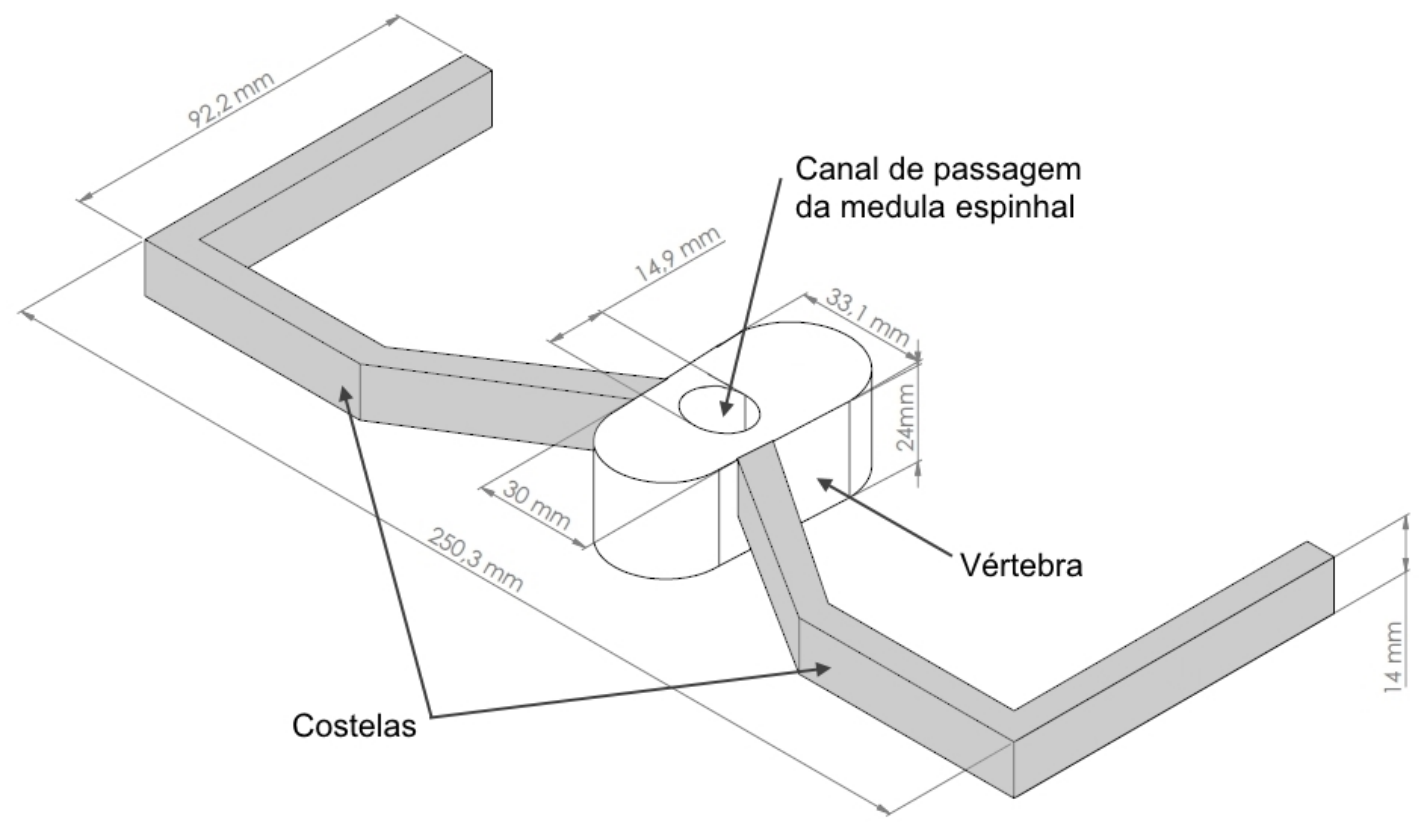

Figura 34: Modelo tridimensional adotado para representar as vértebras, desde vértebra T2 até a vértebra L5, e as costelas, desde a segunda costela até a décima segunda costela.

O sacro e as cristas ilíacas foram representados pelo modelo apresentado na Figura 35.

As vértebras, as costelas, o sacro e as cristas ilíacas foram posicionados de modo a formar um modelo de tronco humano com altura de aproximadamente $600 \mathrm{~mm}$ (Figura 36). O espaçamento intervertebral utilizado foi de $6 \mathrm{~mm}$, reproduzindo a média dos espaçamentos intervertebrais entre as vértebras T9 e T10, e entre as vértebras T10 T11 mensurados no banco de dados BodyParts3D. Os discos intervertebrais foram modelados por estruturas que preenchem os espaços intervertebrais de forma homogênea. A estrutura que representa a medula espinhal foi posicionada ao longo do canal das vértebras com início na vértebra T2 e término na vértebra L5. 


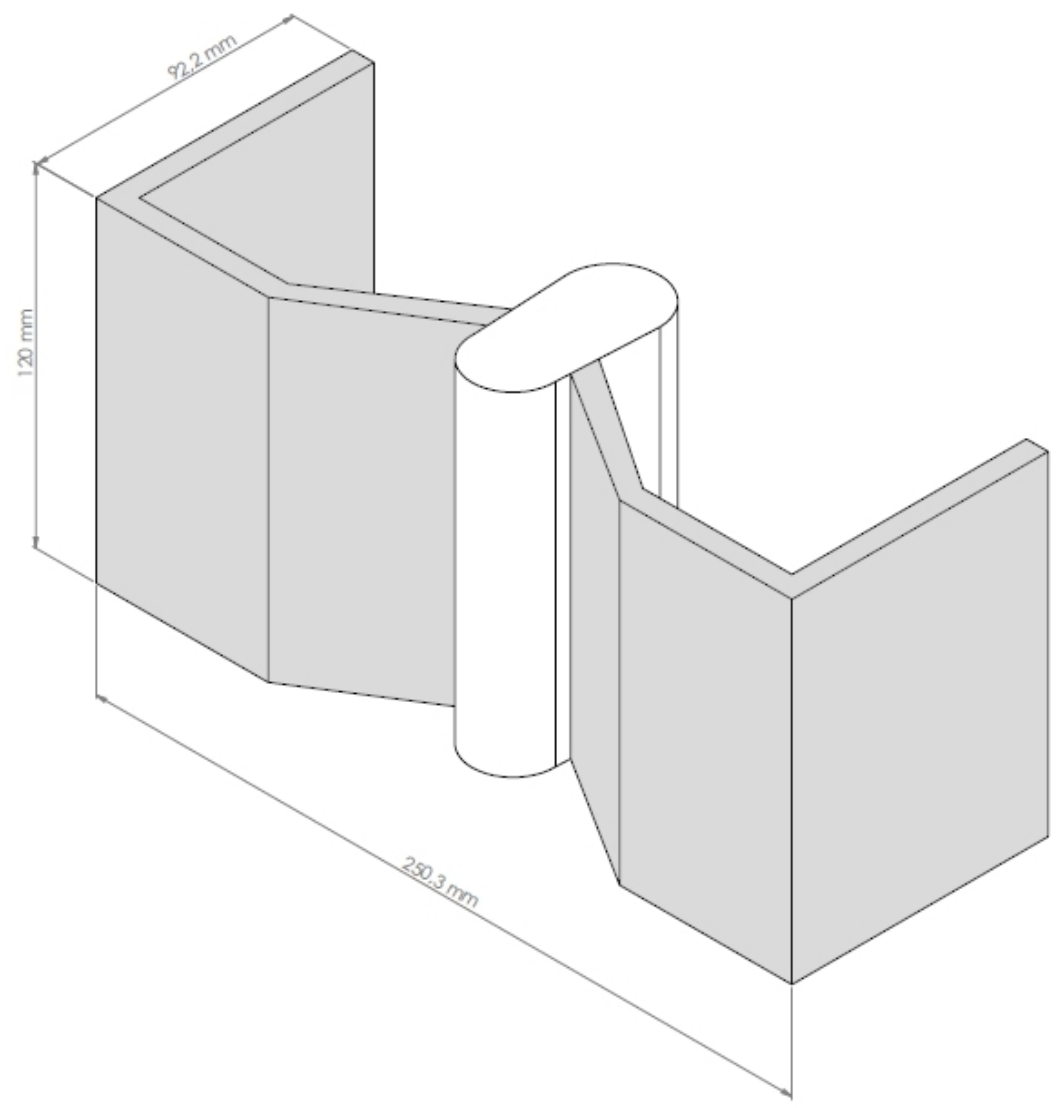

Figura 35: Modelo tridimensional representando o sacro e as cristas ilíacas. 


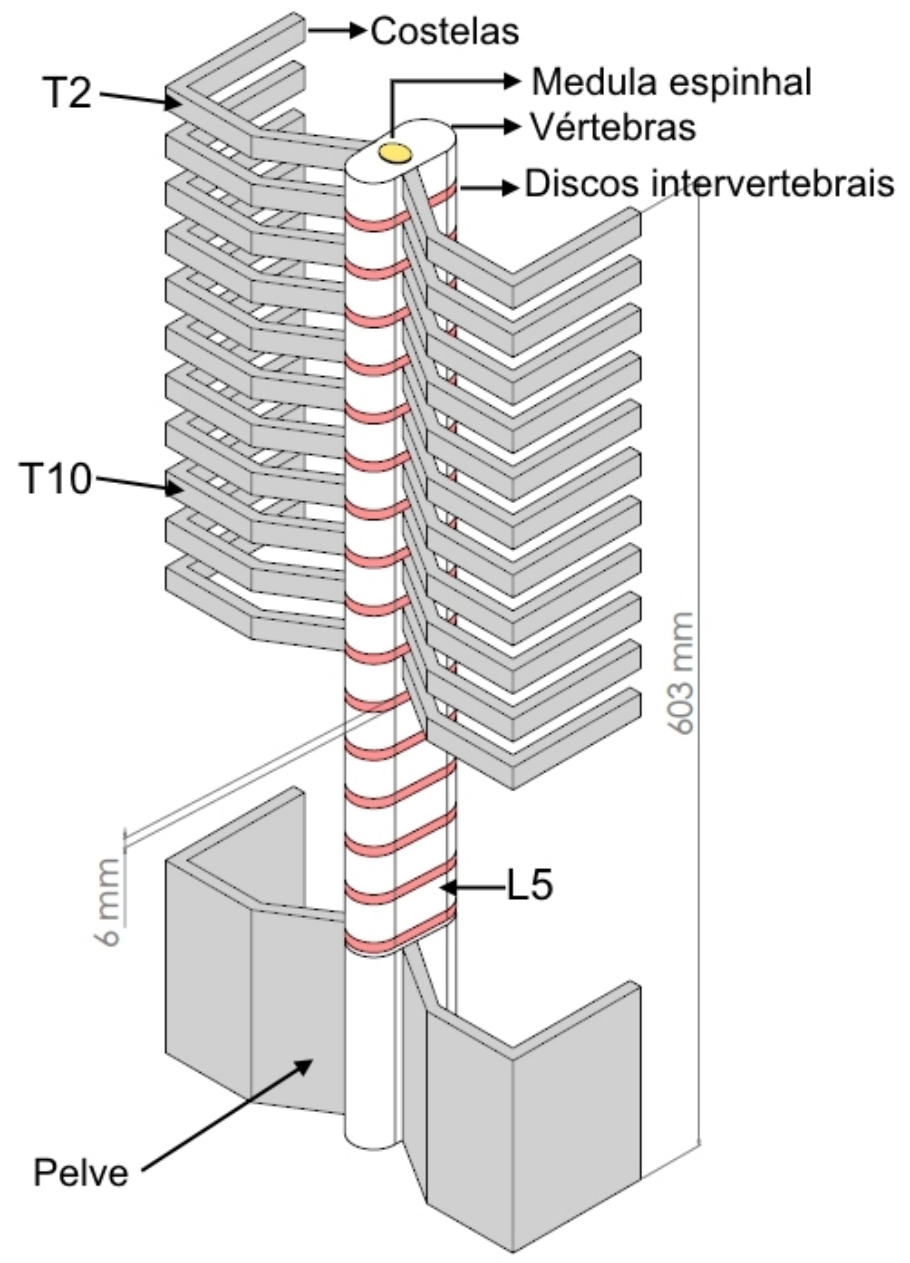

Figura 36: Posicionamento das vértebras, das costelas, do sacro e das cristas ilíacas no modelo tridimensional.O espaçamento intervertebral utilizado foi de $6 \mathrm{~mm}$.

Os pulmões foram modelados por uma forma geométrica com dimensões 172,1 mm x 91,2 $\mathrm{mm}$ x 200,mm posicionada entre as costelas, essa estrutura se estende desde a altura da vértebra T2 até a vértebra T8 (Figura 37). As vísceras foram representadas por uma forma geométrica que completa a região torácica entre e abaixo dos pulmões. 

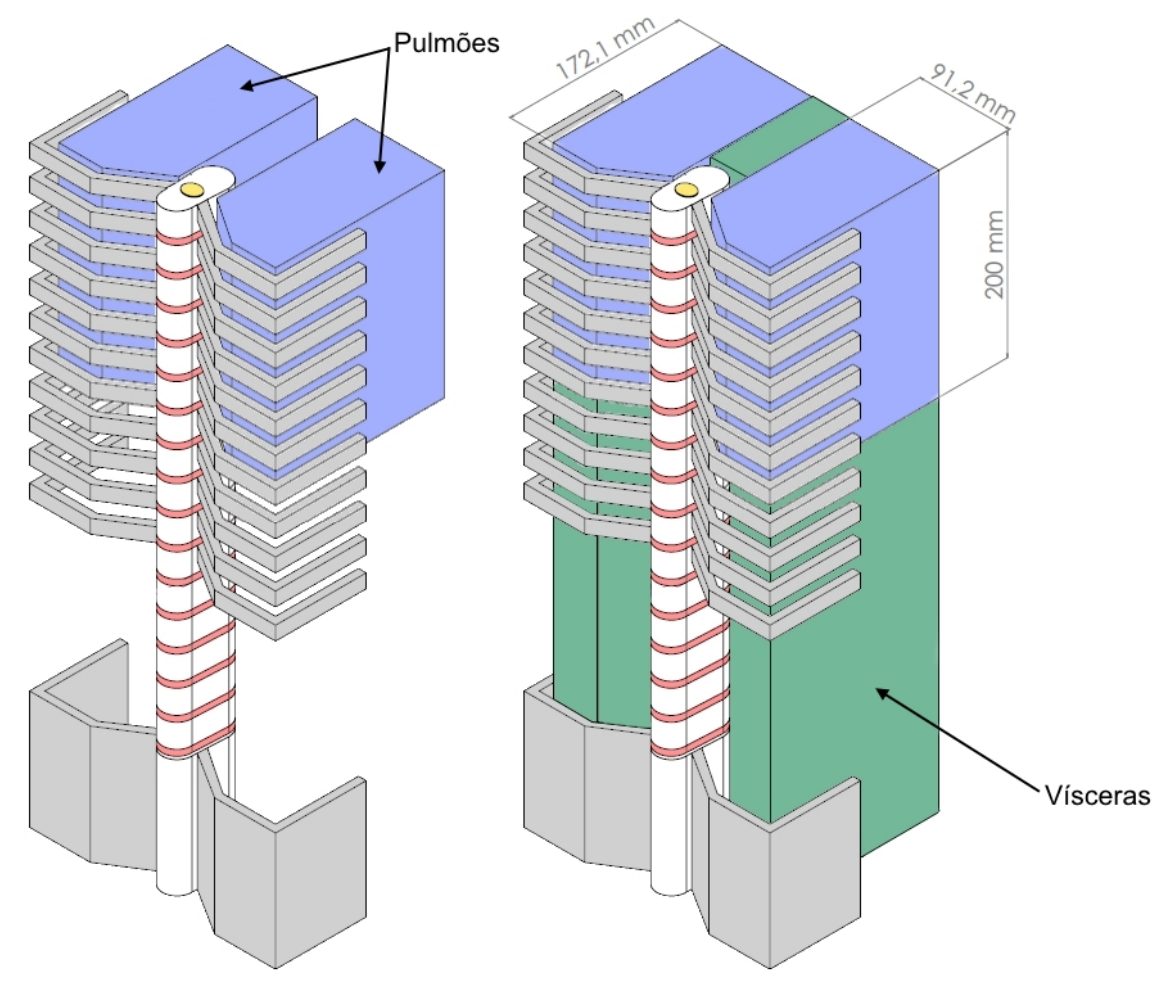

Figura 37: Modelo tridimensional dos pulmões e das vísceras. O pulmão foi modelado por uma forma geométrica com dimensões $172,1 \mathrm{~mm}$ x $91,2 \mathrm{~mm}$ x 200,0 $\mathrm{mm}$ posicionada entre a vértebra T2 até a vértebra T8. As vísceras foram representadas por uma forma geométrica que completa a região torácica entre e abaixo dos pulmões.

O tronco humano foi envolvido por três camadas de tecido com forma de paralelepípedo, o mais interno representando o tecido muscular, o intermediário o tecido adiposo e o mais externo a pele (Figura 38). A pele foi adotada com espessura de 2,5 $\mathrm{mm}$ e o tecido adiposo com espessura de $6,0 \mathrm{~mm}$. O tecido muscular preenche todo o espaço entre o tecido adiposo, as vísceras, as vértebras e as costelas. 


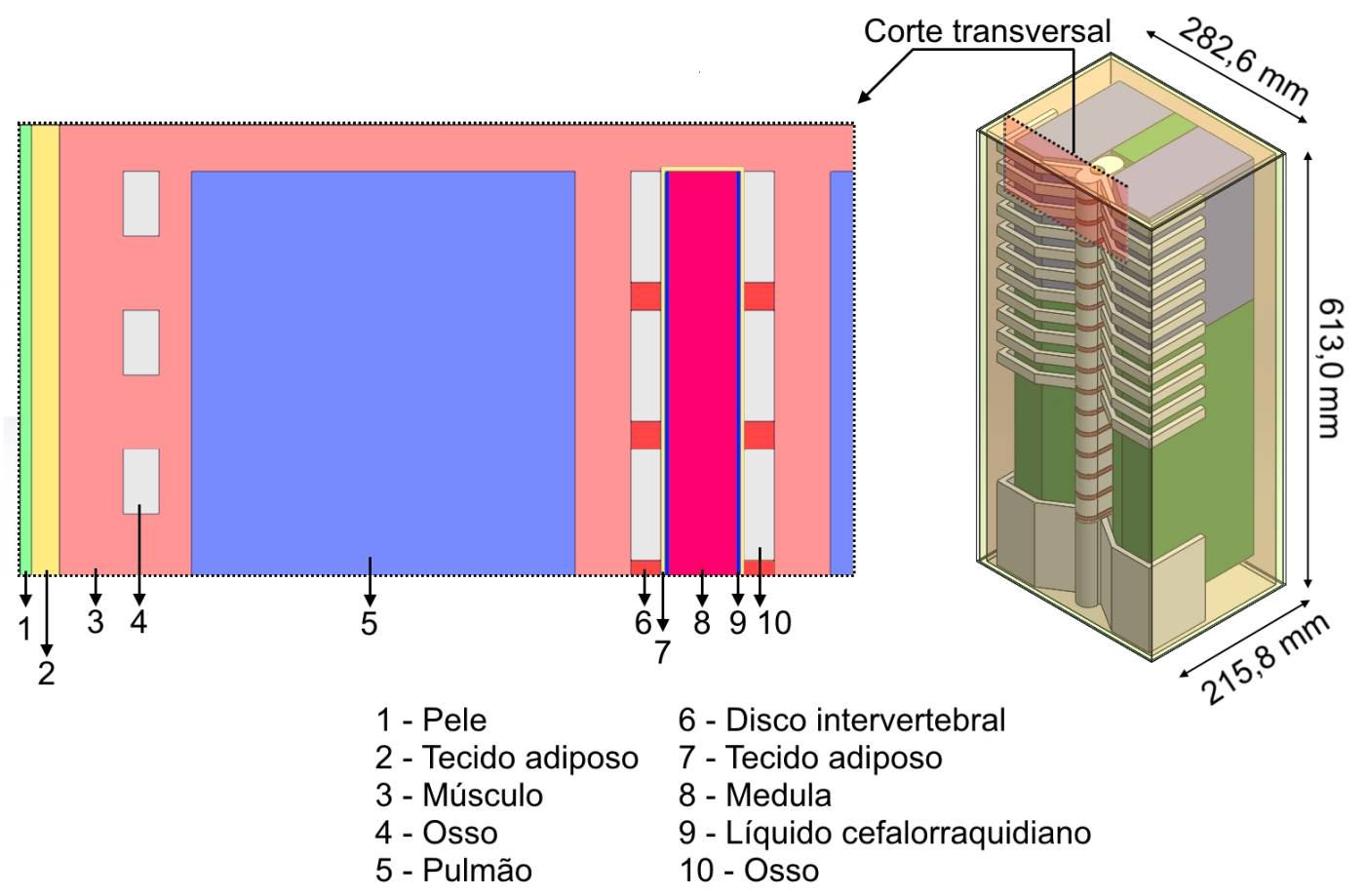

Figura 38: À direita) Modelo tridimensional completo envolvido pela pele, pelo tecido adiposo e pelo tecido muscular. À esquerda) Vista de uma seção transversal que passa pela medula espinhal e que exibe os diferentes tecidos nessa região do modelo. Nesse modelo a pele possui $2,5 \mathrm{~mm}$ de espessura $\mathrm{mm}$ e o tecido adiposo $6,0 \mathrm{~mm}$ de espessura.

\subsubsection{Configurações dos eletrodos utilizadas nas simulações}

As seguintes configurações de eletrodos foram avaliadas nas simulações computacionais:

1. Modelo simplificado com dois eletrodos de $25 \mathbf{c m}^{2}(\mathrm{MS}-2)$ - Eletrodos de 25 $\mathrm{cm}^{2}(5 \mathrm{~cm} \times 5 \mathrm{~cm})$ posicionados sobre a região da vértebra T10 e sobre a região da crista ilíaca direita (Figura 39, à esquerda). Posicionamento utilizado para o teste das hipóteses: Hipótese 1 - Utilização de um modelo computacional simplificado (Subseção 2.1.1) e Hipótese 2 - Adição de um terceiro eletrodo (Subseção 2.1.2).

2. Modelo simplificado com três eletrodos de $25 \mathbf{c m}^{2}$ (MS-3) - Eletrodos de $25 \mathrm{~cm}^{2}(5 \mathrm{~cm} \times 5 \mathrm{~cm})$ posicionados sobre a região da vértebra T10 e sobre a região tanto da crista ilíaca direita quanto da crista ilíaca esquerda (Figura 39 , ao centro). Posicionamento utilizado para o teste das hipóteses: Hipótese 2 - Adição de um terceiro eletrodo (Subseção 2.1.2) e Hipótese 3 - Aumento da dimensão do eletrodo (Subseção 2.1.3). 
3. Modelo simplificado com três eletrodos de $50 \mathrm{~cm}^{2}$ MS-EXP - Eletrodos de $50 \mathrm{~cm}^{2}(10 \mathrm{~cm} \times 5 \mathrm{~cm})$ posicionados sobre a região da vértebra T10, com a maior dimensão paralela à direção rostrocaudal (RC), e sobre a região tanto da crista ilíaca direita quanto da crista ilíaca esquerda, com a maior dimensão paralela à direção ventrodorsal (Figura 39, à direita). Posicionamento utilizado para o teste das hipóteses: Hipótese 3 - Aumento da dimensão do eletrodo (Subseção 2.1.3) e Hipótese 4 - Aumento da corrente de estimulação (Subseção 2.1.4). 


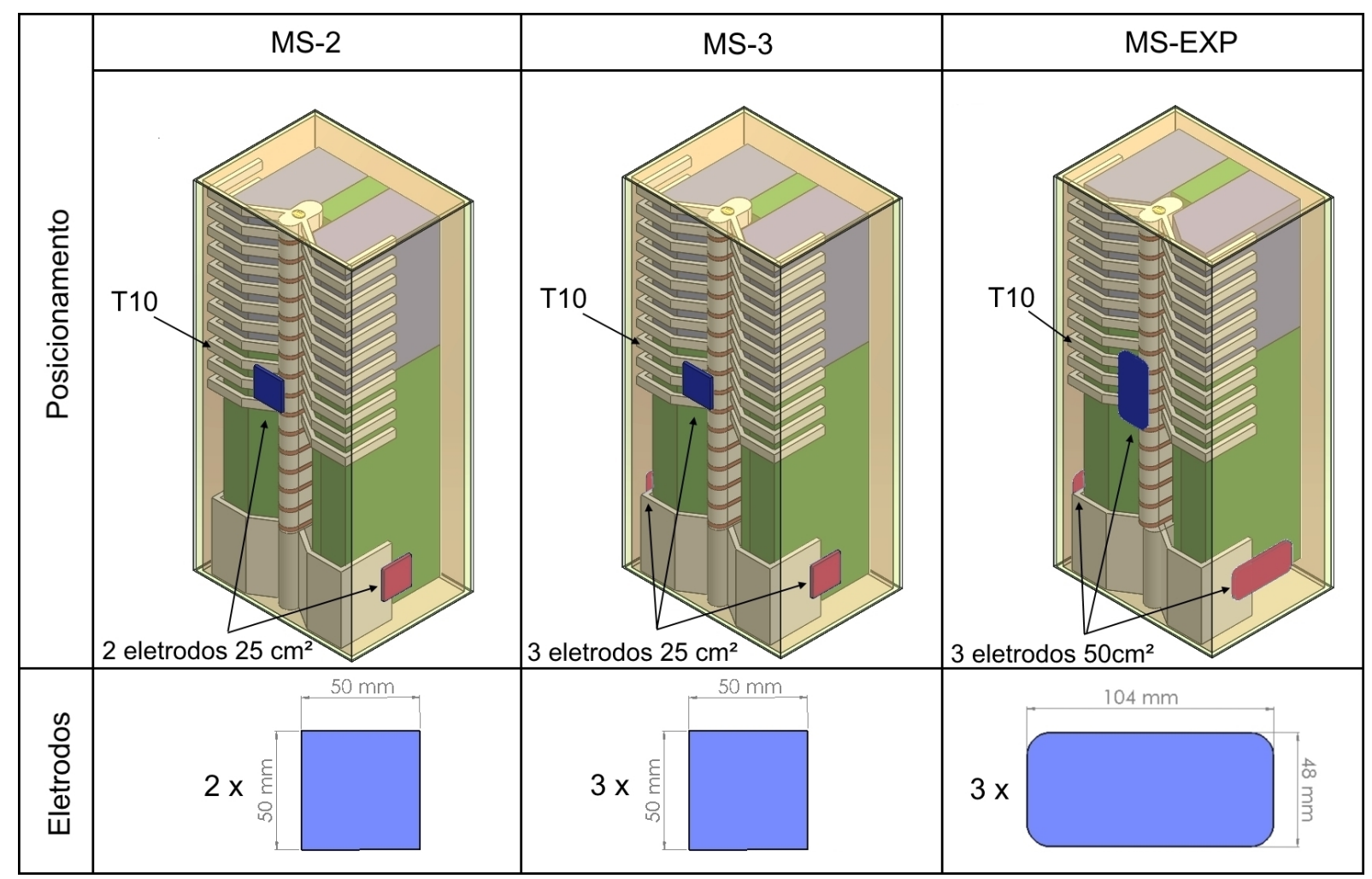

Figura 39: Modelo tridimensional simplificado do tronco humano e posicionamentos dos eletrodos utilizados nas simulações computacionais. À esquerda) Modelo simplificado com dois eletrodos de $25 \mathrm{~cm}^{2}$ MS-2 - Modelo com eletrodos de $25 \mathrm{~cm}^{2}$ (5 cm X 5 $\mathrm{cm})$ posicionados sobre a vértebra T10 e sobre a crista ilíaca direita, utilizado para o teste de hipóteses: Hipótese 1 - Utilização de um modelo computacional simplificado, com corrente de estimulação de 2,5mA (Subseção 2.1.1) e Hipótese 2 - Adição de um terceiro eletrodo, com corrente de estimulação de 2,5mA (Subseção 2.1.2). Ao centro) Modelo simplificado com três eletrodos de $25 \mathrm{~cm}^{2}$ MS-3 - Modelo com um eletrodo $(5 \mathrm{~cm} \times 5 \mathrm{~cm})$ sobre a vértebra T10 e dois eletrodos $(5 \mathrm{~cm} \times 5 \mathrm{~cm})$ sobre as regiões das cristas ilíacas, utilizado para o teste de hipóteses: Hipótese 2 - Adição de um terceiro eletrodo, com corrente de estimulação de $2,5 \mathrm{~mA}$ (Subseção 2.1.2) e Hipótese 3 - Aumento da dimensão do eletrodo, com corrente de estimulação de 2,5 mA (Subseção 2.1.3. À direita) Modelo simplificado com três eletrodos de de $50 \mathrm{~cm}^{2}$ MS-EXP Modelo com eletrodos de $50 \mathrm{~cm}^{2}(10 \mathrm{~cm} \mathrm{x} 5 \mathrm{~cm})$ posicionados sobre a vértebra T10 e sobre as cristas ilíacas, utilizado para o teste de hipóteses: Hipótese 3 - Aumento da dimensão do eletrodo, com corrente de estimulação de 2,5mA (Subseção 2.1.3) e Hipótese 4 - Aumento da corrente de estimulação, com corrente de estimulação de $5 \mathrm{~mA}$ (Subseção 2.1.4. 


\subsubsection{Simulações}

O modelo tridimensional do tronco humano simplificado, nas três configurações de posicionamento de eletrodos (Figura 39), foi utilizado no módulo $A C / D C$ Electric Currents (ec) do software COMSOL Multiphysics 5.1 (COMSOL Inc., EUA) para a obtenção da solução numérica de estimação da densidade de corrente elétrica e do campo elétrico na região da medula espinhal por meio do FEM.

Todos os tecidos foram considerados isotrópicos e as condutividades elétricas adotadas foram idênticas às utilizadas por FERNANDES et al. (Tabela 2), com exceção da condutividade elétrica adotada para a medula espinhal, obtida da média aritmética simples das condutividades elétricas da substância cinzenta e da substância branca da medula espinhal, e da condutividade elétrica adotada para o pulmão que, por ser preenchido por ar, foi considerado um isolante elétrico quase perfeito.

Tabela 2: Condutividades elétricas utilizadas nas simulações.

\begin{tabular}{|l|c|}
\hline \multicolumn{1}{|c|}{ Tecido } & Condutividade $\mathbf{( S / m )}$ \\
\hline Pele & 0,435 \\
\hline Tecido adiposo & 0,040 \\
\hline Músculo & 0,355 \\
\hline Osso & 0,006 \\
\hline Discos intervertebrais & 0,200 \\
\hline Medula espinhal & 0,200 \\
\hline CFS & 1,790 \\
\hline Pulmão & $1,000 \mathrm{e}-10$ \\
\hline Visceras & 0,123 \\
\hline
\end{tabular}

A superfície externa dos eletrodos posicionados sobre a vértebra T10 foi configurada para possuir densidade de corrente elétrica apropriada para cada configuração de corrente de estimulação (Table 3). A superfície externa dos eletrodos posicionados sobre as cristas ilíacas foi configurada para ser a referência elétrica $(\mathrm{V}=0 \mathrm{~V})$ do modelo e todas as outras superfícies externas do modelo foram configuradas para serem isolantes elétricas perfeitas. O gerador de malhas (mesh generator) foi configurado para gerar elementos tetraédricos

Tabela 3: Configuração das densidades de corrente elétrica na superfície dos eletrodos.

\begin{tabular}{|c|c|c|c|}
\hline $\begin{array}{c}\text { Posicionamento de } \\
\text { eletrodos }\end{array}$ & $\begin{array}{c}\text { Corrente elétrica } \\
\text { de estimulação }\end{array}$ & $\begin{array}{c}\text { Densidade de corrente } \\
\text { elétrica no eletrodo } \\
\text { sobre T10 }\end{array}$ & $\begin{array}{c}\text { Teste de } \\
\text { Hipótese }\end{array}$ \\
\hline MS-2 & $2,5 \mathrm{~mA}$ & $1 \mathrm{~A} / \mathrm{m}^{2}$ & $1 \mathrm{e} 2$ \\
\hline$\overline{\mathrm{MS}}-3$ & $2,5 \mathrm{~mA}$ & $1 \mathrm{~A} / \mathrm{m}^{2}$ & $2 \mathrm{e} 3$ \\
\hline$\overline{\mathrm{MS}-\mathrm{EXP}}$ & $2,5 \mathrm{~mA}$ & $0,5 \mathrm{~A} / \mathrm{m}^{2}$ & $3 \mathrm{e} 4$ \\
\hline$\overline{\mathrm{MS}-\mathrm{EXP}}$ & $5 \mathrm{~mA}$ & $1 \mathrm{~A} / \mathrm{m}^{2}$ & 4 \\
\hline
\end{tabular}


com tamanho "finer" utilizando a sequência de geração Physics-controlled mesh. Outras configurações do gerador não foram alteradas.

O software foi configurado para obter a solução do problema utilizando o método iterativo de solução de sistemas de equações lineares conjugate gradients, com configurações padrões.

\subsubsection{Metodologia de análise das simulações}

\subsubsection{Hipótese 1 - Utilização de um modelo computacional simplificado}

Para possibilitar a comparação entre os resultados obtidos do modelo elaborado com a geometria simplificada do tronco humano e os obtidos de um modelo desenvolvido com uma geometria mais complexa (FERNANDES et al., 2018), o gráfico apresentado por FERNANDES et al. (Figura 40), que exibe o campo elétrico ao longo da medula espinhal, gerado pela tsDCS $\left(2,5 \mathrm{~mA}\right.$, eletrodos de $25 \mathrm{~cm}^{2}$, sobre a vértebra T10 e sobre a crista ilíaca direita), foi convertido em uma tabela de dados por meio do software online WebPlotDigitizer (Ankit Rohatgi, 2019).

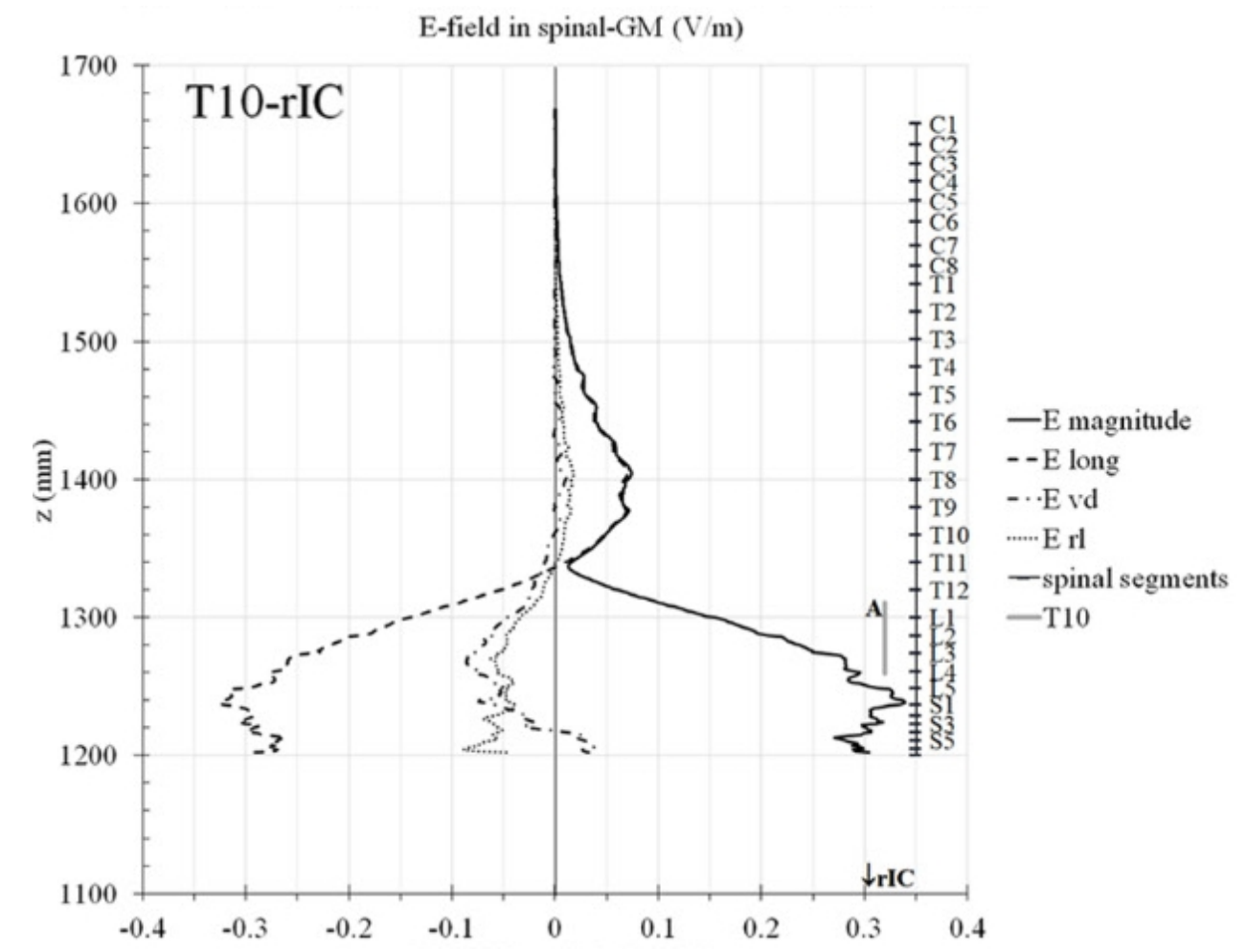

Figura 40: Gráfico apresentado em (FERNANDES et al. 2018) que exibe o campo elétrico ao longo da medula espinhal, gerado pela tsDCS $\left(2,5 \mathrm{~mA}\right.$, eletrodos de $25 \mathrm{~cm}^{2}$, sobre a vértebra T10 e sobre a crista ilíaca direita), obtido de um modelo computacional elaborado com geometria complexa do tronco humano. 
Do modelo simplificado do tronco humano, utilizando o posicionamento de eletrodos MS-2 (eletrodos de $25 \mathrm{~cm}^{2}$, sobre a vértebra T10 e sobre a crista ilíaca direita) e estimulação elétrica de 2,5 mA, foi obtido o campo elétrico ao longo do centro da medula espinhal, desde a vértebra T2 até a vértebra L1.

Os seguintes parâmetros do campo elétrico, dos dois modelos, foram obtidos: módulo do campo elétrico $(|E|)$, campo elétrico na direção anteroposterior $\left(E_{A P}\right)$, campo elétrico na direção mediolateral $\left(E_{M L}\right)$ e campo elétrico na direção rostrocaudal $\left(E_{R C}\right)$.

Gráficos e tabelas exibindo os resultados obtidos dos dois modelos foram elaborados no software Matlab (MathWorks, EUA) possibilitando o teste da hipótese por meio da:

- Comparação do tamanho e da localização da região da medula espinhal estimulada com campo elétrico $(|E|)$ maior do que $0,15 \mathrm{~V} / \mathrm{m}$.

- Análise das diferenças entre os parâmetros dos campos elétricos em intensidades maiores do que $0,15 \mathrm{~V} / \mathrm{m}$.

\subsubsection{Hipótese 2 - Adição de um terceiro eletrodo}

Do modelo simplificado do tronco humano, utilizando os posicionamentos de eletrodos MS-2 (eletrodos de $25 \mathrm{~cm}^{2}$, sobre a vértebra T10 e sobre a crista ilíaca direita) com estimulação de 2,5 mA, e MS-3 (eletrodos de $25 \mathrm{~cm}^{2}$, sobre a vértebra T10 e sobre as cristas ilíacas) com estimulação de $2,5 \mathrm{~mA}$, foram obtidos os campos elétricos ao longo do centro da medula espinhal, desde a vértebra T2 até a vértebra L5.

Os seguintes parâmetros do campo elétrico, nos dois posicionamentos de eletrodos, foram obtidos: módulo do campo elétrico $(|E|)$, campo elétrico na direção anteroposterior $\left(E_{A P}\right)$, campo elétrico na direção mediolateral $\left(E_{M L}\right)$ e campo elétrico na direção rostrocaudal $\left(E_{R C}\right)$.

Gráficos e tabelas exibindo os resultados obtidos nos dois posicionamentos de eletrodos foram elaborados no software Matlab (MathWorks, EUA) possibilitando o teste da hipótese por meio da:

- Comparação do tamanho e da localização da região da medula espinhal estimulada com campo elétrico $(|E|)$ maior do que $0,15 \mathrm{~V} / \mathrm{m}$.

- Análise das diferenças entre os parâmetros dos campos elétricos em intensidades maiores do que $0,15 \mathrm{~V} / \mathrm{m}$. 


\subsubsection{Hipótese 3 - Aumento da dimensão do eletrodo}

Do modelo simplificado do tronco humano, utilizando os posicionamentos de eletrodos MS-3 (eletrodos de $25 \mathrm{~cm}^{2}$, sobre a vértebra T10 e sobre as cristas ilíacas) com estimulação de 2,5 mA, e MS-EXP (eletrodos de $50 \mathrm{~cm}^{2}$, sobre a vértebra T10 e sobre as cristas ilíacas) com estimulação de 2,5 mA, foram obtidos os campos elétricos ao longo do centro da medula espinhal, desde a vértebra T2 até a vértebra L5. O módulo do campo elétrico $(|E|)$ foi obtido para os dois tamanhos de eletrodos.

Gráficos e tabelas exibindo os resultados obtidos para os dois tamanhos de eletrodos foram elaborados no software Matlab (MathWorks, EUA) possibilitando o teste da hipótese por meio da comparação do tamanho e localização da região da medula espinhal estimulada com módulo do campo elétrico $(|E|)$ maior do que $0,15 \mathrm{~V} / \mathrm{m}$.

\subsubsection{Hipótese 4 - Aumento da corrente de estimulação}

Do modelo simplificado do tronco humano, utilizando o posicionamento de eletrodos MS-EXP (eletrodos de $50 \mathrm{~cm}^{2}$, sobre a vértebra T10 e sobre as cristas ilíacas) com estimulação de $2,5 \mathrm{~mA}$ e de $5 \mathrm{~mA}$, foram obtidos os campos elétricos ao longo do centro da medula espinhal, desde a vértebra T2 até a vértebra L5. O módulo do campo elétrico $(|E|)$ foi calculado nas duas intensidades de estimulação.

O módulo da densidade elétrica ao longo da medula foi calculado para a estimulação de 5 mA. Também foi realizada uma análise para determinar a maior corrente de estimulação elétrica que poderia ser utiliza durante o protocolo de tsDCS de modo que a densidade de corrente elétrica na medula espinhal fosse menor do que $6,3 \mathrm{~A} / \mathrm{m}^{2}$.

Gráficos e tabelas exibindo os resultados obtidos para as duas intensidades de estimulação foram elaborados no software Matlab (MathWorks, EUA) possibilitando o teste da hipótese por meio da comparação do tamanho e localização da região da medula espinhal estimulada com módulo do campo elétrico $(|E|)$ maior do que $0,15 \mathrm{~V} / \mathrm{m}$ e a análise do valor máximo de densidade de corrente elétrica na medula espinhal na estimulação de $5 \mathrm{~mA}$. 


\subsection{Protocolo Experimental}

\subsubsection{Participantes e recrutamento}

Participantes saudáveis, sem más-formações anatômicas aparentes, de ambos os sexos, com idade entre 19 a 30 anos, que não possuíam próteses metálicas no corpo, que não estavam fazendo uso de medicamentos ou de substâncias que influenciassem os resultados experimentais, que possuíam índice de massa corpórea (IMC) menor do que 30 e que não possuíam conhecimentos prévios sobre protocolos de tsDCS, foram recrutados.

Cartazes com um convite para a participação nesse projeto de pesquisa foram afixados em pontos estratégicos do campus de São Paulo da Universidade de São Paulo (USP). Os interessados eram previamente informados que deveriam ter disponibilidade para participar de três sessões experimentais realizadas em dias diferentes, com espaçamento mínimo de 3 dias entre sessões, e que cada sessão duraria em torno de 1 hora e 30 minutos. Cada participante, após explicações detalhadas sobre o procedimento experimental, assinou um termo de consentimento livre e esclarecido (TCLE) (Anexo A.1), previamente aprovado pelo Comitê de Ética em Pesquisa da Escola de Educação Física da Universidade de São Paulo (CAAE 09592919.0.0000.5391).

Por se tratar de um trabalho de pesquisa inédito, o tamanho do espaço amostral empregado foi calculado com base em trabalhos anteriores conduzidos no Laboratório de Engenharia Biomédica (LEB) da USP, que realizaram posturografia por plataforma de força. Nesses trabalhos foram adotados tamanhos de espaços amostrais maiores do que dez e menores do que quinze participantes SILVA; MAGALHÃES; KOHN, 2019; MAGALHÃES; KOHN, 2012). De modo a viabilizar o cronograma desse estudo foi empregado um espaço amostral de dezessete participantes.

\subsubsection{Protocolo de tsDCS}

A corrente elétrica para a tsDCS foi gerada por um estimulador elétrico isolado, STMISOL-1 (BIOPAC System,Inc. EUA), configurado para operar no modo de estimulação de corrente contínua, controlado por um dispositivo USB multifuncional, USB6212 National Instruments ${ }^{T M}$, EUAb), e por um software desenvolvido em LabView 2014 National Instruments ${ }^{T M}$ EUAa). Os participantes foram conectados ao estimulador por meio de três eletrodos autoadesivos não reutilizáveis de $10 \mathrm{x} 5 \mathrm{~cm}^{2}$ ValuTrode VL4595 (Axelgaard Manufacturing CO., LTD. EUA), afixados sobre o processo espinhoso da vértebra T10 e sobre as cristas ilíacas direita e esquerda (Figura 41). O eletrodo 
sobre a vértebra T10 foi posicionado com eixo de maior dimensão alinhado com a direção $\mathrm{RC}$, e os eletrodos sobre as cristas ilíacas foram posicionados lateralmente, logo abaixo da linha formada pelas bordas superiores das cristas ilíacas, com o eixo de maior dimensão orientado na direção AP.

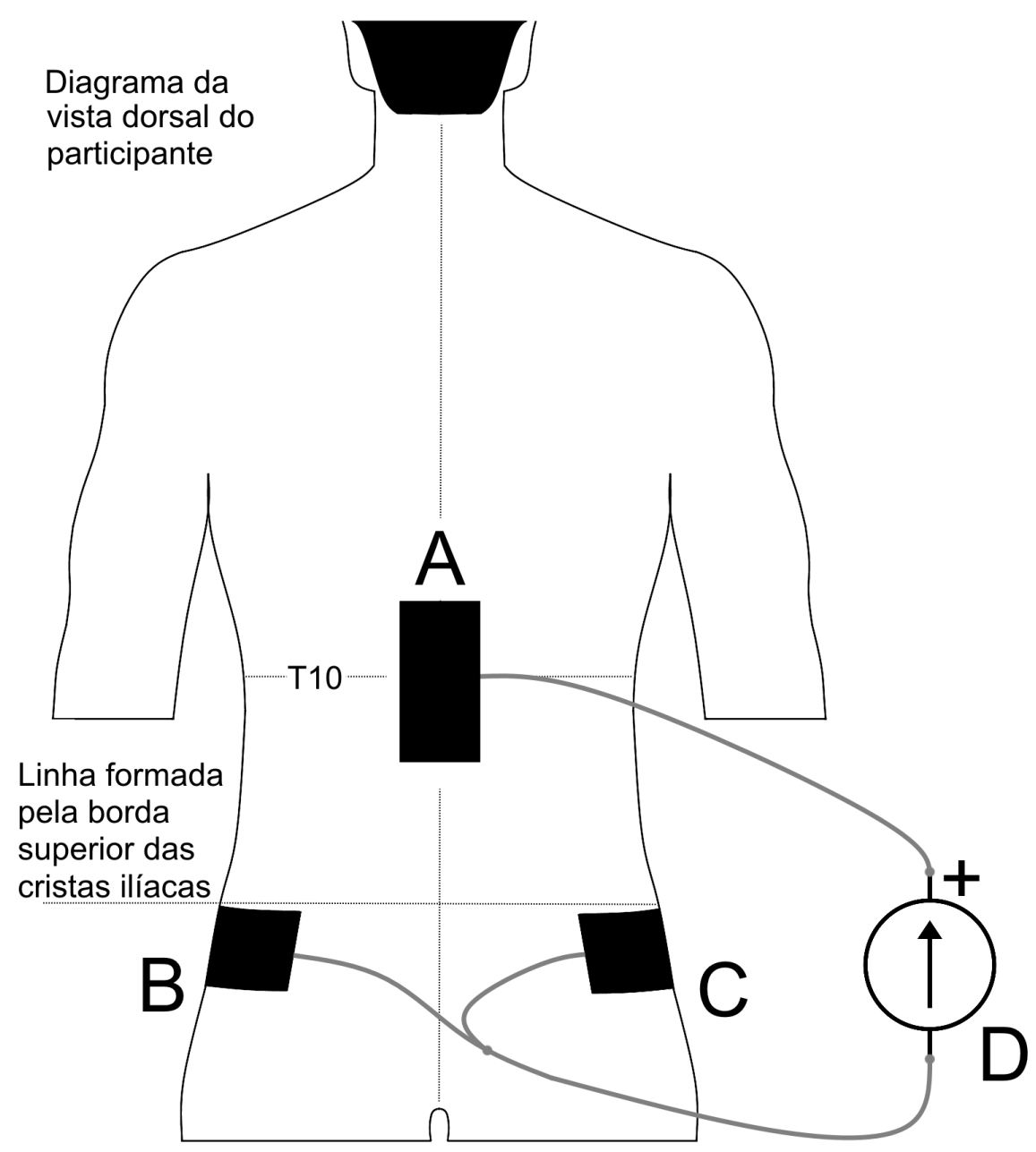

Figura 41: Diagrama da vista dorsal do participante exibindo o local de afixação dos eletrodos para aplicação da tsDCS. A) Eletrodo não reutilizável autoadesivo de dimensões $10 \mathrm{~cm}$ x $5 \mathrm{~cm}$ centralizado sobre o processo espinhoso de T10, com a borda de maior dimensão alinhada com a direção RC, B) e C) Eletrodos não reutilizáveis autoadesivos de dimensões $10 \mathrm{~cm}$ x $5 \mathrm{~cm}$ posicionados lateralmente logo abaixo da linha formada pelas bordas superiores das cristas ilíacas direita e esquerda, com a borda de maior dimensão orientada na direção AP, D) Representação do sistema de estimulação elétrica.

Três protocolos de estimulação elétrica foram executados:

1. (C-T10,A-CiDeE): Cátodo sobre o processo espinhoso de T10 e ânodo sobre as cristas ilíacas direita e esquerda. 
2. (A-T10,C-CiDeE). Ânodo sobre o processo espinhoso de T10 e cátodo sobre as cristas ilíacas direita e esquerda.

3. (PLACEBO): Eletrodos posicionados sobre sobre o processo espinhoso de T10 e sobre as cristas ilíacas direita e esquerda, sem estimulação elétrica.

Os três protocolos foram inicializados por uma estimulação elétrica de inicialização de 60 segundos, com uma estimulação de intensidade de $5 \mathrm{~mA}$, com cátodo em T10 e ânodo sobre a cristas ilíacas, nos 30 segundos iniciais, seguida por uma estimulação de $5 \mathrm{~mA}$, com ânodo em T10 e cátodo sobre as cristas ilíacas, nos 30 segundos finais (Figura 42). Após a estimulação de inicialização, nos protocolos (C-T10,A-CiDeE) e (A-T10,C-CiDeE), a tDCS foi aplicada por 20 minutos com a polarização específica de cada protocolo. No protocolo (PLACEBO), após a estimulação de inicialização, o estimulador elétrico permaneceu desligado durante 20 minutos. Os três protocolos possuíram duração total de 22 minutos e toda variação de corrente elétrica nos eletrodos foi realizada linearmente com razão de $0,5 \mathrm{~mA} / \mathrm{s}$. Nas sessões experimentais, a densidade máxima de corrente elétrica na área de contato entre os eletrodos e a pele do participante foi de no máximo $0,1 \mathrm{~mA} / \mathrm{cm}^{2}$ e a carga elétrica total máxima aplicada foi de aproximadamente $120 \mathrm{mC} / \mathrm{cm}^{2}$, valores abaixo dos limiares de danos teciduais (NITSCHE, 2003). 


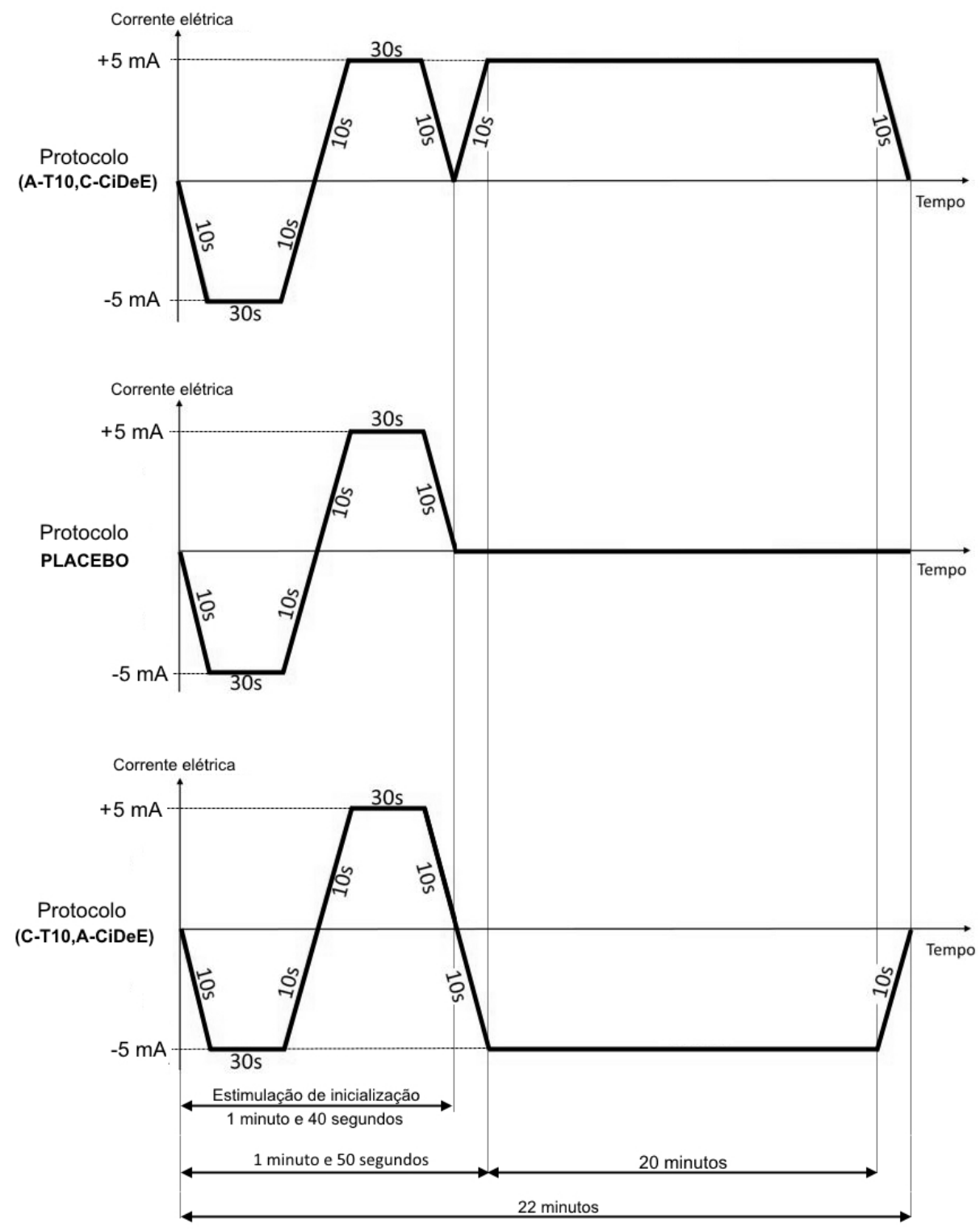

Figura 42: Diagramas das correntes elétricas de estimulação em cada um dos três protocolos de estimulação elétrica. A corrente elétrica foi variada linearmente com razão de 0,5 $\mathrm{mA} / \mathrm{s}$. Os três protocolos foram iniciados por uma estimulação elétrica de inicialização de 60 segundos com uma estimulação de $5 \mathrm{~mA}$, com cátodo sobre T10, nos 30 segundos iniciais, seguida por uma estimulação de $5 \mathrm{~mA}$ com ânodo sobre T10, nos 30 segundos finais. De cima para baixo são exibidos os protocolos (A-T10,C-CiDeE), PLACEBO e (C-T10,A-CiDeE), nessa ordem. Depois da estimulação de inicialização, no protocolo (A-T10,C-CiDeE) o eletrodo posicionado sobre T10 foi configurado como ânodo por 20 minutos com intensidade de $5 \mathrm{~mA}$. No protocolo PLACEBO, após a inicialização, o estimulador elétrico ficou desligado. No protocolo (C-T10,A-CiDeE), após a estimulação de inicialização, o eletrodo sobre T10 foi configurado como cátodo por 20 minutos e intensidade de $5 \mathrm{~mA}$. Os três protocolos de estimulação possuíram duração total de 22 minutos. 
De modo a garantir a segurança e a qualidade da execução do protocolo de estimulação elétrica, um amperímetro calibrado e energizado por bateria (MD5880, Icel, Brasil) foi instalado em série com o estimulador elétrico e permitiu a medição da intensidade da corrente elétrica durante o protocolo de estimulação elétrica. Também foi desenvolvido um circuito eletrônico (Figura 44), conectado à saída do estimulador elétrico, para limitar a corrente de estimulação em no máximo $10 \mathrm{~mA}$, pois o estimulador elétrico utilizado permitia a aplicação de correntes elétricas contínuas de até $100 \mathrm{~mA}$ e não possuía sistema para restringir a intensidade de corrente elétrica de estimulação em caso de falhas. Antes do início de cada sessão experimental, o sistema formado pelo estimulador elétrico, pelo amperímetro e pelo limitador de corrente (Figura 43) foi verificado por meio da medição da corrente elétrica com um resistor de 470 Ohm conectado à saída desse sistema, simulando a impedância do corpo humano. A verificação foi conduzida nas situações em que o estimulador elétrico foi configurado para aplicar corrente elétrica de $5 \mathrm{~mA}$ e de $50 \mathrm{~mA}$. O sistema foi considerado válido para utilização na sessão experimental caso, na situação de $5 \mathrm{~mA}$, a corrente elétrica medida pelo amperímetro estivesse no intervalo de 4,9 mA a 5,1 $\mathrm{mA}$, indicando o correto funcionamento do estimulador elétrico, e na situação de $50 \mathrm{~mA}$, a corrente elétrica medida fosse menor do que $10 \mathrm{~mA}$, indicando o correto funcionamento do circuito limitador de corrente.

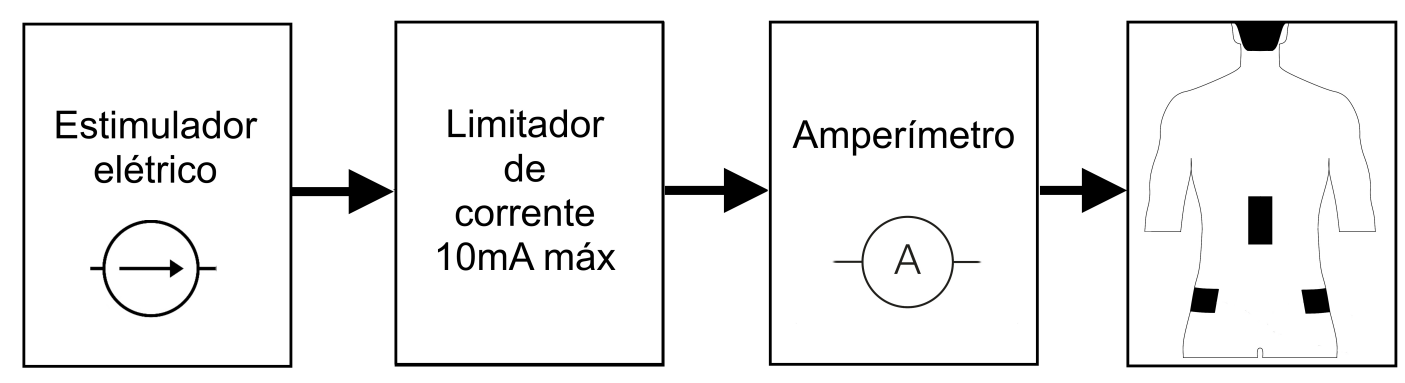

Figura 43: Sistemas elétricos para garantia da qualidade e da segurança do protocolo de estimulação elétrica. Em série com a saída do estimulador elétrico foi conectado um amperímetro calibrado e um circuito limitador de corrente elétrica. O amperímetro permitiu a medição da corrente elétrica aplicada no participante do experimento durante todo o protocolo de estimulação elétrica. O circuito limitador de corrente elétrica garantiu que, em caso de problemas com o estimulador elétrico, a corrente elétrica aplicada no participante, nunca ultrapassasse o valor de $10 \mathrm{~mA}$. 


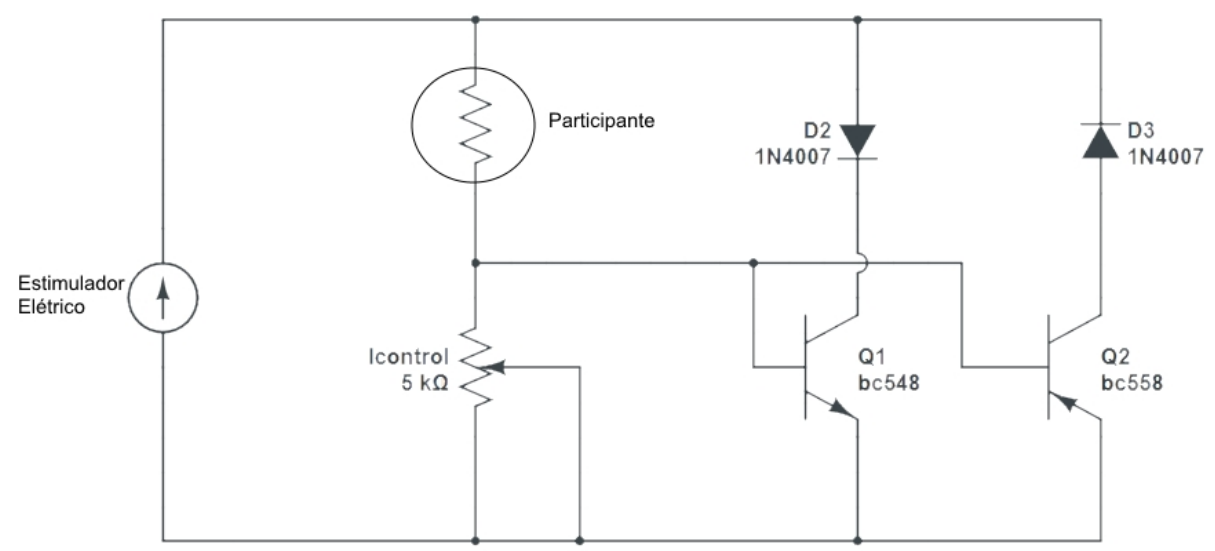

Figura 44: Circuito eletrônico que foi utilizado para limitar a corrente de estimulação em no máximo 10 mA. Funcionamento do circuito: Nesse circuito, o potenciômetro Icontrol está conectado em série com o participante. Para correntes elétricas que circulam pelo participante e que geram tensão elétrica menor do que $0,7 \mathrm{~V}$ no potenciômetro Icontrol, os transistores Q1 e Q2 não entram em condução e a corrente elétrica do estimulador elétrico circula apenas pelo participante. Caso a corrente que circula pelo participante produza uma tensão próxima de $0,7 \mathrm{~V}$ no potenciômetro Icontrol, a base de um dos transistores é polarizada (Q1 ou Q2, dependendo da polaridade da corrente) fazendo com que o transistor com a base polarizada entre em condução e, assim, com que parte da corrente aplicada pelo estimulador elétrico seja desviada para transistor em condução, limitando a corrente de estimulação do participante. A corrente máxima foi ajustada pelo potenciômetro Icontrol para apresentar valor de aproximadamente $10 \mathrm{~mA}$.

\subsubsection{Posturografia por plataforma de força}

Durante as coletas de dados utilizadas para a posturografia por plataforma de força, o participante do experimento se manteve em $\mathrm{PEO}$ sobre uma plataforma de força OR67-1000 AMTI Advanced Mechanical Technology, Inc. EUA descalço, com os pés posicionados lado a lado com orientação e distanciamento naturais e confortáveis dentro de marcações desenhadas na superfície da plataforma de força, com os braços relaxados ao lado do corpo, de olhos cobertos por um óculos opaco, e com um fone de ouvido bluetooth posicionado sobre as orelhas, reproduzindo ruído branco uniforme, em volume confortável, com banda limitada pela frequência de reprodução de $22 \mathrm{kHz}$ do sistema de áudio. Nessa condição, para cada aquisição de dados, foram adquiridos da plataforma de força os valores das três componentes de força $(\mathrm{Fx}, \mathrm{Fy}$ e $\mathrm{Fz})$ e de momento ( $\mathrm{Mx}$, My e Mz) por uma 
interface de aquisição de dados Power1401 Cambridge Electronic Desing Limited, Reino Unido) com frequência de amostragem de $1 \mathrm{kHz}$ durante 90 segundos (Figura 45).

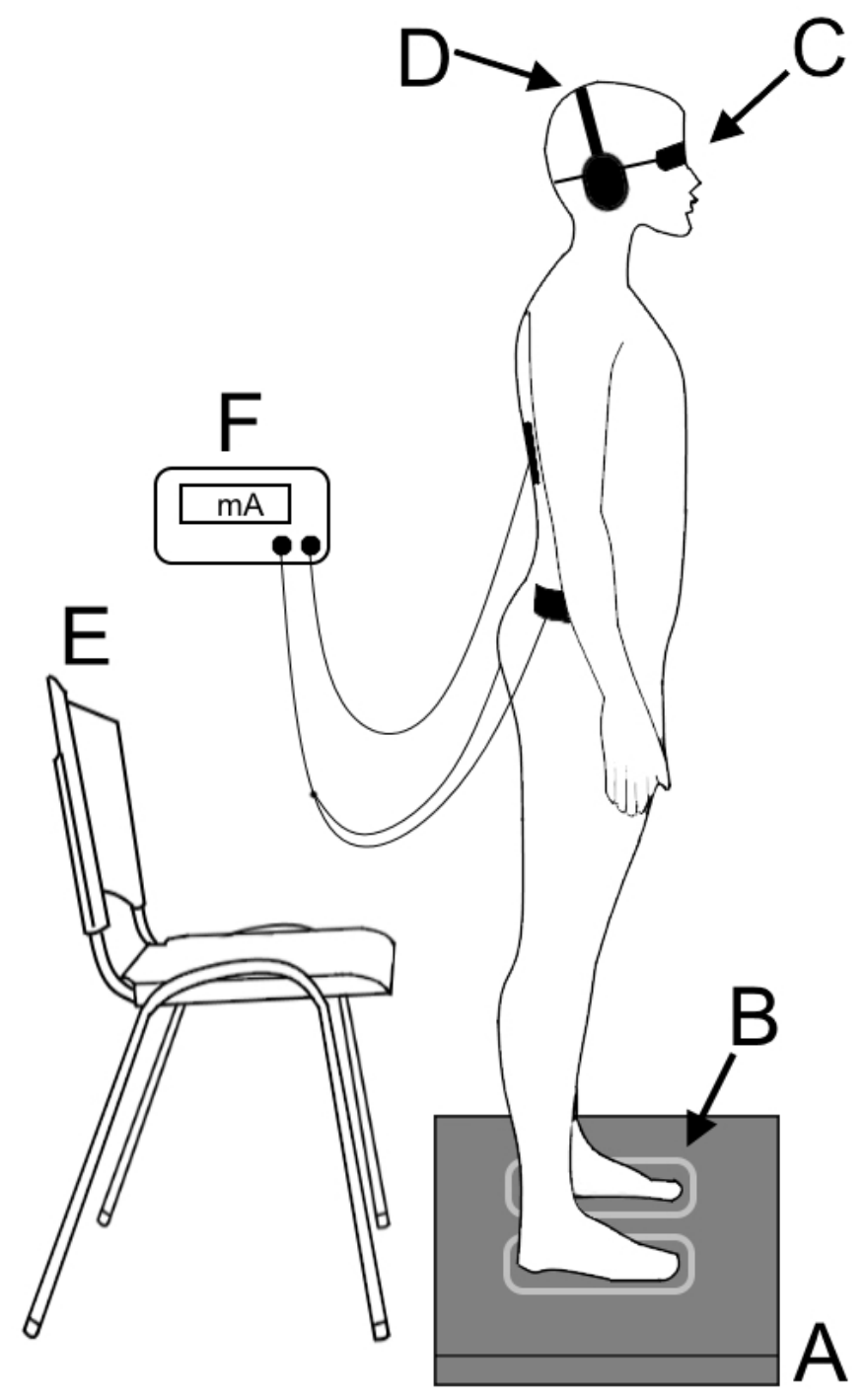

Figura 45: Esquema da vista lateral do participante durante uma coleta dados em PEO sobre a plataforma de força, descalço, com os pés posicionados lado a lado com orientação e distanciamento naturais e confortáveis, com os braços relaxados ao lado do corpo, de olhos cobertos por um óculos opaco e com um fone de ouvido bluetooth posicionado sobre as orelhas reproduzindo ruído branco uniforme e em volume confortável. A) Plataforma de força, B) Marcações na plataforma de força utilizadas para a padronização do posicionamento dos pés durante as coletas de dados C) Óculos opaco, D) Fone de ouvido bluetooth utilizado para a reprodução do ruído sonoro, E) Cadeira posicionada próxima à plataforma e atrás do participante do experimento, para repouso durante o intervalo entre as coletas de dados e F) Estimulador elétrico. 
Para garantir a qualidade experimental, antes do início de cada sessão experimental, foram realizadas aquisições de dados para a validação da plataforma de força em três condições: 1) 15 segundos com a plataforma de força sem carga, 2) 15 segundos com uma massa de $45 \mathrm{~kg}$ posicionada no centro da plataforma de força e 3) 15 segundos com uma massa de $45 \mathrm{~kg}$ posicionada no canto posterior direito da plataforma de força (em relação ao corpo do participante), com distanciamento do centro, tanto no sentido AP quanto no sentido ML, de $15 \mathrm{~cm}$. A validação permitiu a verificação do correto funcionamento da plataforma de força, minimizando a ocorrência de possíveis erros experimentais.

\subsubsection{Protocolo experimental}

O protocolo experimental foi realizado de acordo com a declaração de Helsinki (WORLD MEDICAL ASSOCIATION et al., 2001) e foi submetido à avaliação e à aprovação do comitê de ética em pesquisa da Escola de Educação Física da USP (CAAE 09592919.0.0000.5391) antes de ser realizado.

Todos os participantes compareceram ao LEB para a realização de três sessões experimentais com duração de 1 hora e 30 minutos cada e com espaçamento mínimo entre sessões de 3 dias. As sessões experimentais foram diferenciadas pelo protocolo de estimulação elétrico utilizado (PLACEBO, (A-T10,C-CiDeE) ou (C-T10,A-CiDeE) $)$. A ordem das sessões foi aleatorizada para cada participante.

\subsubsection{Recepção do participante}

Antes do início da sessão experimental, um vídeo explicativo, detalhando todos os procedimentos realizados durante o protocolo experimental, era exibido ao interessado em participar do estudo. Esse vídeo explicativo foi elaborado de forma a não informar qualquer detalhe específico sobre a estimulação elétrica ou sobre o objetivo do estudo. Caso, após o vídeo, o interessado concordasse em participar do estudo, era solicitado que o interessado realizasse a leitura atenta, e posterior assinatura, do TCLE (Anexo A.1). Também era reforçado verbalmente que o interessado poderia desistir da participação no estudo a qualquer momento, sem qualquer tipo de prejuízo ou constrangimento e que, caso concordasse com a participação, todos os dados pessoais coletados seriam mantidos em sigilo, garantindo a confidencialidade da participação.

Após o preenchimento e assinatura do TCLE, era realizada uma avaliação de saúde por meio do preenchimento de um questionário (Anexo A.2) que era analisado, antes do início do experimento, para identificar qualquer impedimento para a execução do estudo. Caso 
o participante respondesse "SIM" às questões 1, 2, 3, 4, 5, 6, 7, 8, 9 e/ou 10 do questionário de avaliação de saúde, o procedimento experimental era cancelado.

\subsubsection{Posicionamento dos eletrodos}

Ao participante era solicitado que ficasse descalço, com os pés protegidos por propé, e que vestisse uma camiseta especial de algodão, com recortes na região das costas (Figura 46), e um shorts de tecido leve.
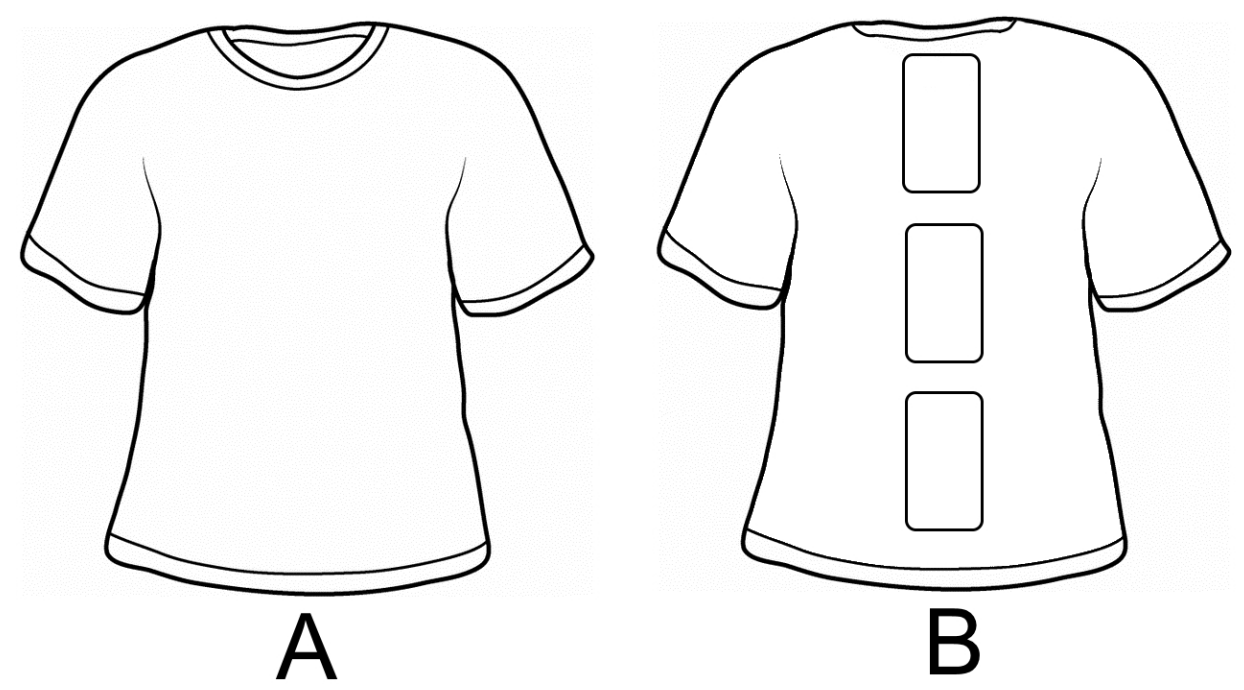

Figura 46: Representação da camiseta de algodão que era fornecida ao participante para a realização do experimento. A) Vista anterior da camiseta. B) Vista dorsal da camiseta exibindo os recortes que permitiram o acesso à região das costas do participante para o posicionamento do eletrodo de estimulação sobre T10

Com o participante posicionado sobre uma maca, em decúbito ventral, com o tronco erguido pelos cotovelos, mantendo o contato do umbigo com a superfície da maca e com os músculos do pescoço relaxados (Figura 47, A), era realizada a localização e demarcação do processo espinhoso da vértebra $\mathrm{C7}$ por palpação. Ainda em decúbito ventral, com a cabeça apoiada sobre maca e virada para um dos lados, com os músculos do pescoço relaxados e com as mãos posicionadas debaixo das coxas das pernas (Figura 47, B), era realizada a palpação e contagem dos espaços intervertebrais desde o processo espinhoso de C7 até a localização e marcação com lápis dermatográfico do processo espinhoso de T10. Após a região da pele sobre T10 ser limpa com algodão e álcool 70\%, o eletrodo de estimulação autoadesivo era fixado de modo centralizado sobre o processo espinho. 

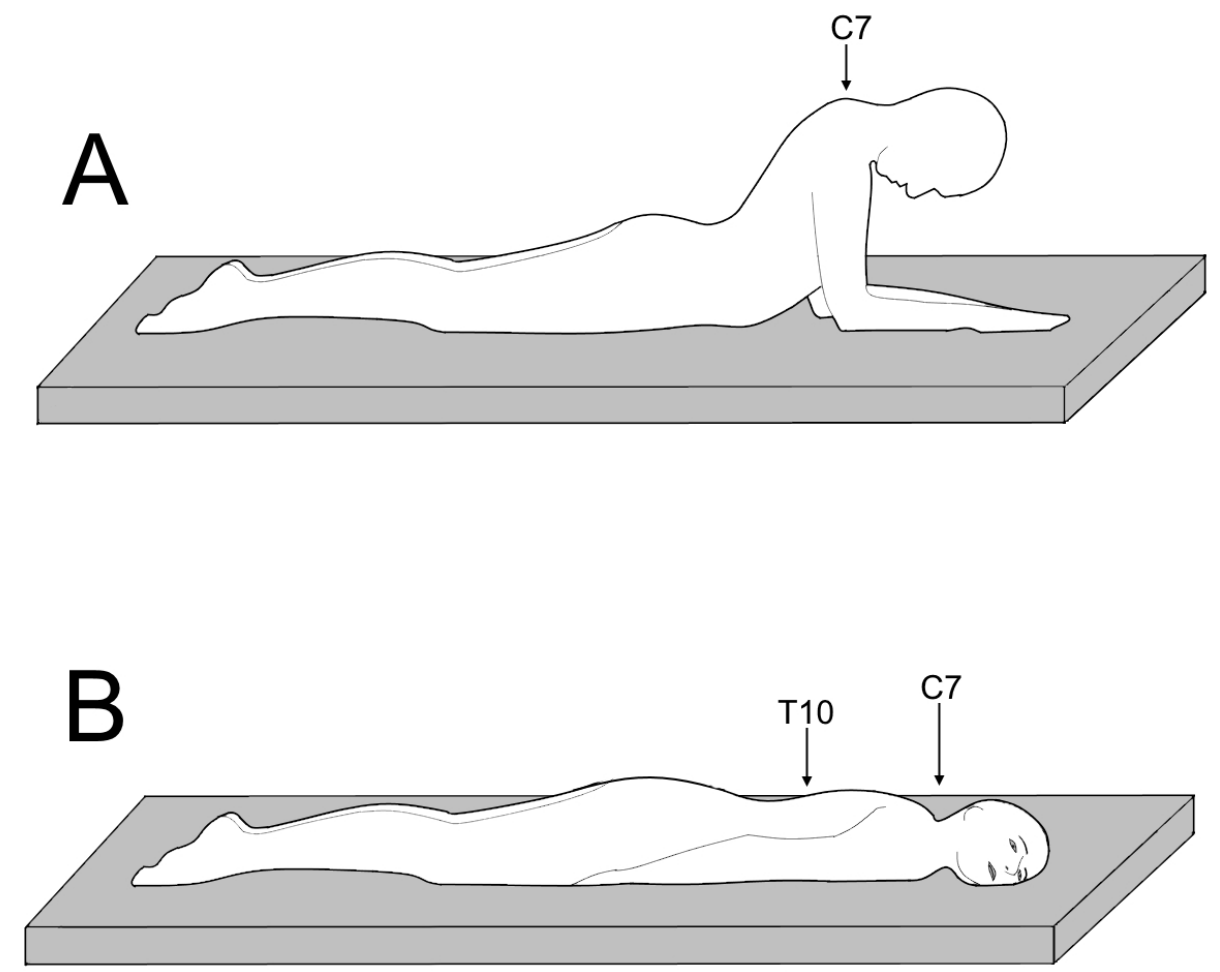

Figura 47: Representações dos posicionamentos do participante na maca durante o processo de localização e posicionamento do eletrodo de estimulação elétrica sobre o processo espinhoso de T10. A) O participante inicialmente ficava em decúbito ventral com o tronco erguido pelos cotovelos e mantendo o contato do umbigo com a maca. Nessa posição era localizado e marcado o processo espinhoso de C7 (maior protuberância na região dorsal do pescoço) com lápis dermatográfico. B) Em seguida o participante ficava com a cabeça apoiada na maca e virada para um dos lados, com os músculos do pescoço relaxados e com as mãos posicionadas debaixo das coxas das pernas para palpação e contagem dos espaços intervertebrais desde o processo espinhoso de C7 até a localização e marcação do processo espinhoso de T10, para a limpeza da pele e colocação do eletrodo de estimulação elétrica.

Ao descer da maca, o participante era posicionado em pé, para a localização e marcação das regiões mais laterais das bordas superiores das cristas ilíacas direita e esquerda, para afixação, após a limpeza da pele, de dois eletrodos de estimulação elétrica autoadesivos um do lado direito e o outro do lado esquerdo do corpo. 


\subsubsection{Posicionamento dos pés sobre a plataforma de força}

O participante era posicionado sobre a plataforma de força para encontrar o melhor posicionamento dos pés para se manter em $\mathrm{PEO}$. Era solicitado que primeiramente posicionasse os pés lado a lado, distanciados de forma natural e com o corpo aproximadamente localizado no centro da plataforma de força. Em seguida, era solicitado que fechasse os olhos, que se mantivesse ereto, quieto e com braços relaxados ao lado corpo, e que se concentrasse no posicionamento dos pés de modo a encontrar o distanciamento e angulação mais confortáveis para a realização da PEO. Após o participante encontrar uma posição natural e confortável, era utilizado um pincel marcador de quadro branco para desenhar o contorno dos pés na plataforma de força.

\subsubsection{Conexão dos eletrodos ao estimulador elétrico}

Os eletrodos eram conectados ao estimulador elétrico com o terminal identificado como positivo do estimulador elétrico conectado ao eletrodo posicionado sobre T10 e com o terminal identificado como negativo do estimulador elétrico conectado aos eletrodos posicionados sobre as crista ilíacas. Os fios que ligavam o estimulador elétrico aos eletrodos de estimulação eram posicionados e fixados ao corpo do participante de modo a minimizar a influência de pistas sensoriais cutâneas que pudessem ser conduzidas mecanicamente por esses contatos.

\subsubsection{Instruções antes da coleta de dados}

Antes de iniciar o protocolo experimental o participante era instruído para, toda vez que fosse solicitado para que permanecesse em repouso, que sentasse confortavelmente na cadeira posicionada atrás do participante, sem ter que se preocupar com o posicionamento dos pés. Também era instruído para, quando fosse solicitado para iniciar a $\mathrm{PEO}$, que se levantasse da cadeira, posicionasse os pés nas marcações desenhadas na plataforma de força, cobrisse os olhos com o óculos opaco, mantivesse os braços relaxados ao lado do corpo, que evitasse movimentações dos braços e do corpo não relacionadas à tarefa de se manter em pé e que tentasse se manter o mais imóvel possível.

Sobre a estimulação elétrica eram dadas as informações que, durante todo o experimento, diversas estimulações elétricas de baixa intensidade seriam aplicadas pelos eletrodos fixados à pele do participante, que seria normal a ocorrência de sensações cutâneas na região dos eletrodos e que no caso de qualquer desconforto moderado o participante informasse o operador do experimento. 


\subsubsection{Aquisição de dados}

Em cada sessão experimental eram realizadas 17 sequências de aquisição de dados com duração total de 70 minutos (Figura 48). Inicialmente eram executadas duas sequências para a familiarização do participante com o protocolo experimental (Figura 48, Sequências 1 a 2) que seriam descartadas da análise dos dados. Em seguida eram realizadas 5 sequências (Figura 48, Sequências 3 a 7) antes to do protocolo de estimulação elétrica , 5 sequências (Figura 48, Sequências 8 a 12) durante (t) o protocolo de estimulação elétrica (A-T10,C-CiDeE), PLACEBO ou (C-T10,A-CiDeE), e 5 sequências (Figura 48 , Sequências 13 a 17) após t te término do protocolo de estimulação. 


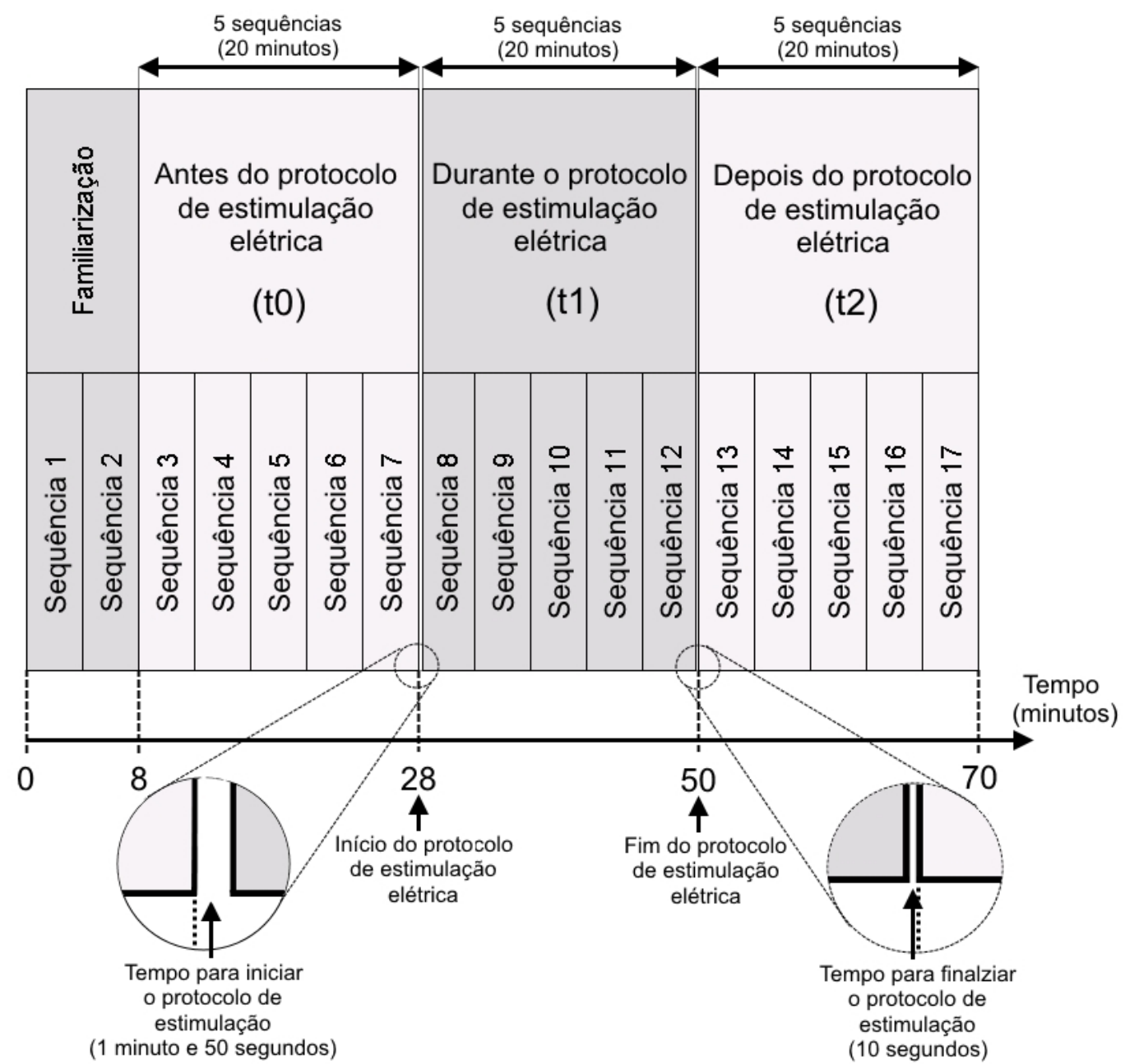

Figura 48: Esquema da ordem das sequências de aquisições de dados. No total eram realizadas 17 sequências de aquisições de dados, cada sequência possuía duração de 4 minutos (Figura 49) . As duas primeiras sequências (Sequências 1 a 2) eram utilizadas para a familiarização do participante do experimento com o protocolo e foram descartadas da análise de dados. Em seguida eram realizadas 5 sequências (Sequências 3 a 7 ) antes (t0) do protocolo de estimulação elétrica. Em seguida, um dos três protocolos de estimulação elétrica (A-T10,C-CiDeE), PLACEBO ou (C-T10,A-CiDeE) era iniciado e eram realizadas 5 sequências de aquisição de dados (Sequências 8 a 12) durante (t) protocolo de estimulação elétrica. A primeira sequência de aquisição de dados, realizada após o início do protocolo de estimulação (Sequência 8), era executada após o término da estimulação de inicialização. Após o término do protocolo de estimulação elétrica, eram realizadas 5 sequências de aquisição de dados finais. 


\subsubsection{Sequência de cada aquisição de dados}

No início de cada uma das 17 sequências de aquisição de dados, o participante do experimento permanecia por 100 segundos em repouso (Figura 49, intervalo de A a B), sentado de forma relaxada em uma cadeira. Em seguida, após um aviso sonoro, era dado ao participante 20 segundos para levantar da cadeira, posicionar os pés dentro de duas demarcações desenhadas sobre a plataforma de força, colocar o óculos opaco sobre os olhos e iniciar a $\mathrm{PEO}$ (Figura 49 , intervalo B a C). Um segundo aviso sonoro indicava ao participante que a aquisição de dados havia sido iniciada (Figura 49, instante C). Após 30 segundos do aviso de início da coletada de dados, dado ao participante, a aquisição de dados era efetivamente iniciada, permitindo a estabilização do participante na postura antes de iniciar a coleta dos dados (Figura 49 , período de $\mathrm{C}$ a E). Ao término da aquisição o participante retornava à posição de repouso, retirava o óculos opaco dos olhos e se sentava novamente na cadeira, aguardando o início de uma nova sequência.

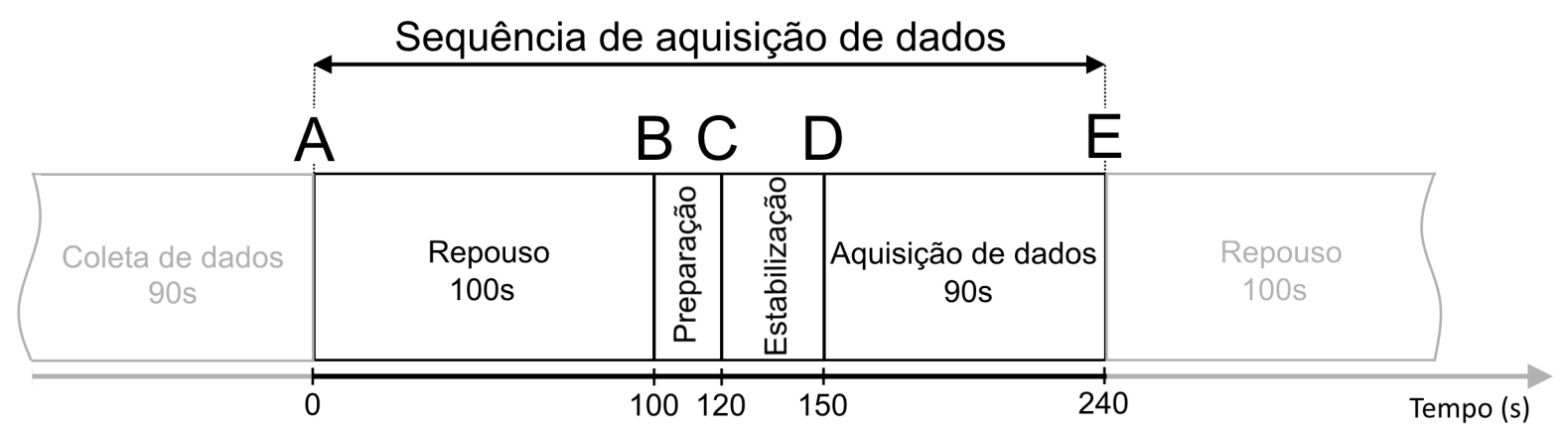

Figura 49: Esquema representando uma sequência de aquisição de dados. A) Inicialmente o participante permanecia em repouso sentado em uma cadeira por 100 segundos. B) Um aviso sonoro indicava para o participante levantar da cadeira, posicionar os pés sobre as demarcações na plataforma de força, ajustar o óculos opaco sobre os olhos e manter a PEO. C) Um segundo aviso sonoro indicava para o participante que a coleta de dados havia sido iniciada. D) Após 30 segundos do aviso de início de aquisição de dados, dado ao participante, a aquisição efetivamente era iniciada, de modo a garantir estabilização do participante na postura. E) Após 90 segundos, ao término da aquisição de dados, um terceiro aviso sonoro solicitava para que o participante sentasse na cadeira e permanecesse novamente em repouso, aguardando o início de uma nova sequência de aquisição de dados. Cada sequência possuía duração total de 240 segundos (4 minutos).

De modo a minimizar a sonolência durante a sessão experimental, era solicitado para 
que o participante escolhesse um estilo musical de seu agrado para a reprodução de videoclipes durante as fases de repouso das sequências de aquisição de dados. Os videoclipes eram reproduzidos de um website de streaming de mídia (YouTube). O áudio dos videoclipes era reproduzido em volume confortável pelo fone de ouvido bluetooth do experimento e o vídeo era exibido em um monitor posicionado à frente do participante.

O gerenciamento da execução das sequências de aquisição de dados era feita de forma automatizada por um software que foi desenvolvido em LabView 2014 (National Instruments ${ }^{T M}$, EUAa). O software desenvolvido era responsável por reproduzir os avisos sonoros de comando que instruíam o participante em cada uma das fases da sequência da aquisição de dados, por pausar o videoclipe que estava sendo reproduzido durante a fase de repouso, por gerar o ruído sonoro durante a aquisição de dados e por controlar o estimulador elétrico.

\subsubsection{Finalização do experimento}

Após a execução de todas as sequências de aquisição de dados, os eletrodos de estimulação elétrica eram retirados do participante e era solicitado o preenchimento de um questionário de avaliação da estimulação elétrica (Anexo A.3).

O participante trocava de roupas, devolvendo a camiseta e o shorts do experimento e, caso não fosse a última sessão experimental a ser realiza, era agendada uma próxima sessão experimental com intervalo de no mínimo 3 dias.

Toda sessão experimental era gravada em vídeo por uma Webcam. Os vídeos eram gravados em baixa resolução e poderiam ser utilizados na elucidação de dúvidas que poderiam surgir durante o processamento e análise dos dados.

Todos os dados da sessão experimental (vídeo gravado do experimento, foto do termo de consentimento assinado, questionários preenchidos pelo participante e dados coletados das sequências de aquisição) eram salvos tanto em um computador do laboratório quanto em um repositório online $(O S F)$ logo após o término de cada sessão experimental. Todos os dados eram armazenados sem acesso público e protegidos por senha, de forma a garantir o sigilo experimental.

\subsubsection{Processamento dos dados experimentais}

Os dados obtidos do protocolo experimental foram processados utilizando o software Matlab R2015a (MathWorks, EUA) na seguinte ordem:

1. Transformação de unidades dos dados coletados da plataforma de força para o sis- 
tema métrico (Subseção 2.3.5.1).

2. Cálculo da localização do COP (Subseção 2.3.5.2).

3. Cálculo dos parâmetros do COP (Subseção 2.3.5.4).

\subsubsection{Transformação de unidades dos dados coletados da plataforma de força para o sistema métrico}

Da plataforma de força foram obtidos 6 canais de dados brutos (3 canais de força Fx, Fy, Fz e 3 canais de momentos Mx, My, Mz) na unidade Volts (V). Por meio da matriz de sensibilidade cruzada $\left(\boldsymbol{M}_{\text {cross }}\right)$, das tensões de excitação de cada canal e dos ganhos do amplificador, obtidos do relatório da última calibração da plataforma de força, a seguinte equação, elaborada de acordo com manual do usuário da plataforma de força AMTI, 1991), foi utilizada para a transformação dos dados coletados para o sistema métrico (N e N.m):

$$
\boldsymbol{D} \boldsymbol{A} \boldsymbol{T} \boldsymbol{A}_{(N, N . m)}[n]=\left(\boldsymbol{D} \boldsymbol{A} \boldsymbol{T} \boldsymbol{A}_{(V, V)}[n] \times \boldsymbol{W}_{(6 \times 6)}\right) \times \boldsymbol{M}_{c r o s s}^{T}(6 \times 6)
$$

Sendo:

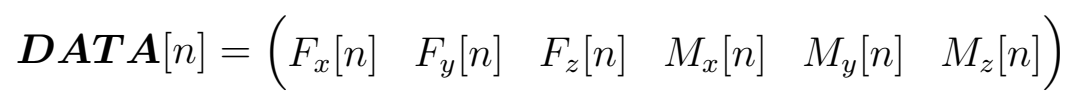

$$
\begin{aligned}
& \boldsymbol{W}_{(6 \times 6)}=1 e^{6}\left(\begin{array}{cccccc}
G_{F x} V_{F x} & 0 & 0 & 0 & 0 & 0 \\
0 & G_{F y} V_{F y} & 0 & 0 & 0 & 0 \\
0 & 0 & G_{F z} V_{F z} & 0 & 0 & 0 \\
0 & 0 & 0 & G_{M x} V_{M x} & 0 & 0 \\
0 & 0 & 0 & 0 & G_{M y} V_{M y} & 0 \\
0 & 0 & 0 & 0 & 0 & G_{M z} V_{M z}
\end{array}\right)^{-1}
\end{aligned}
$$


As tensões de excitação dos canais $\left(V_{F x}, V_{F y}, V_{F z}, V_{M x}, V_{M y}, V_{M z}\right)$ foram calculadas pela equação:

$$
V_{C h}=V_{A m p}-L * c_{c h}
$$

Sendo:

$V_{C h}=$ Tensão de excitação do canal $\left(V_{F x}, V_{F y}, V_{F z}, V_{M x}, V_{M y}, V_{M z}\right)(\mathrm{V})$.

$V_{A m p}=$ Tensão de excitação produzida pelo amplificador (V) (Anexo A.4).

$L=$ Comprimento do cabo de alimentação (m) (Anexo A.4).

$c_{c h}=$ Coeficiente de queda de tensão no canal $(\mathrm{V} / \mathrm{m}$ ) (Anexo A.4.).

\subsubsection{Cálculo da localização do COP}

A localização do COP ao longo do tempo foi obtida pela equação (ROBERTSON GRAHAM CALDWELL, 2004; LAFOND; DUARTE; PRINCE, 2004):

$$
\begin{aligned}
& A P[n]=\frac{\left(z_{0} F_{y}[n]+M_{x}[n]\right)}{F_{z}[n]} \times 1000 \\
& M L[n]=\frac{\left(z_{0} F_{x}[n]-M_{y}[n]\right)}{F_{z}[n]} \times 1000
\end{aligned}
$$

Sendo:

$n \quad=$ Número da amostra.

$A P$ e $M L=\mathrm{COP}$ na direção anterposterior (AP) e mediolateral (ML) (mm).

$x_{0}, y_{0}$ e $z_{0}=$ Localização do centro da plataforma de força (mm) (Anexo A.4).

$F_{x}, F_{y}$ e $F_{z}=$ Forças (nas direções x, y e z) obtidas da plataforma de força $(\mathrm{N})$.

$M_{x}$ e $M_{y}=$ Momentos (nas direções x, y e z) obtidos da plataforma de força (N.m).

\subsubsection{Pré-processamento dos sinais}

O pré-processamento dos sinais da plataforma de força foi realizado na seguinte sequência:

1. Decomposição Trembling e Rambling Os sinais Trembling e Rambling do COP foram obtidos da seguinte forma (ZATSIORSKY; DUARTE, 2000):

(a) Os sinais $A P[n], M L[n], F_{A P}[n], F_{M L}[n]$ ? obtidos da plataforma de força,

\footnotetext{
${ }^{2}$ Os sinais $F_{A P}[n]$ e $F_{M L}[n]$ correspondem aos sinais de força nas direções $\mathrm{AP}$ e $\mathrm{ML}$. No caso da plataforma utilizada no procedimento experimental, $F_{A P}[n]$ correspondia ao sinal $F_{x}[n]$ e $F_{M L}[n]$ ao sinal $F_{y}[n]$
} 
com frequência de amostragem de $1000 \mathrm{~Hz}$, foram filtrados por um filtro digital linear passa-baixas do tipo Butterworth de quarta ordem com frequência de corte de $10 \mathrm{~Hz}$, utilizando as funções butter() e filter() do Matlab. De modo que o período da inicialização do filtro digital não influenciasse os resultados experimentais, os primeiros $160 \mathrm{~ms}$ dos sinai: 3 , após a filtragem, foram descartados:

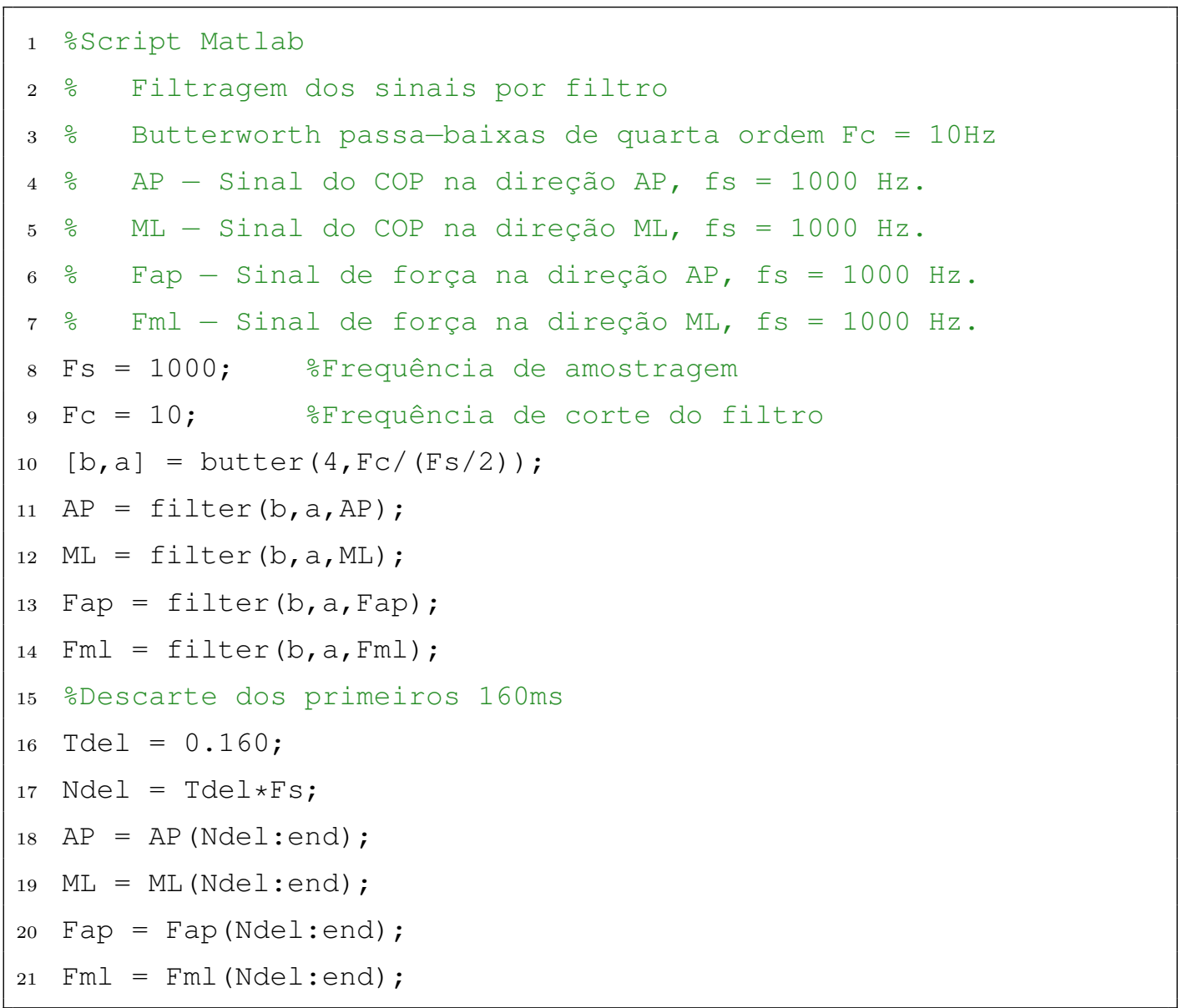

(b) Os níveis DC dos sinais $A P[n], M L[n], F_{A P}[n]$ e $F_{M L}[n]$ foram eliminados:

$$
x[n]=x[n]-\frac{1}{N} \sum_{n=1}^{N} x[n]
$$

Sendo:

$$
\begin{aligned}
& x[n]=A P[n], M L[n], F_{A P}[n] \text { ou } F_{M L}[n] . \\
& N=\text { número total de amostras coletadas. }
\end{aligned}
$$

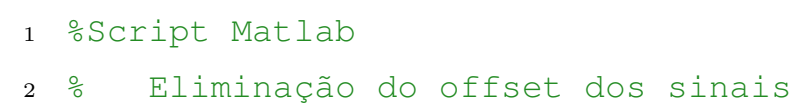

\footnotetext{
${ }^{3} 160 \mathrm{~ms}$ corresponde ao settling time do filtro Butterworth passa-baixas de quarta ordem com frequência de corte de $10 \mathrm{~Hz}$ quando um sinal do tipo degrau é aplicado em sua entrada. Esse valor pode ser obtido pela função stepinfo() do Matlab.
} 


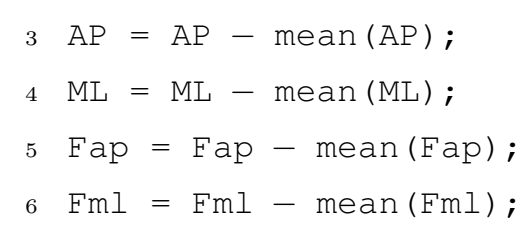

(c) Os instantes $n \mathrm{~s}(z F a p$ e $z F m l)$ em que os sinas $F_{A P}[n]$ e $F_{M L}[n]$ cruzam o zero foram obtidos (Item a da figura 50):

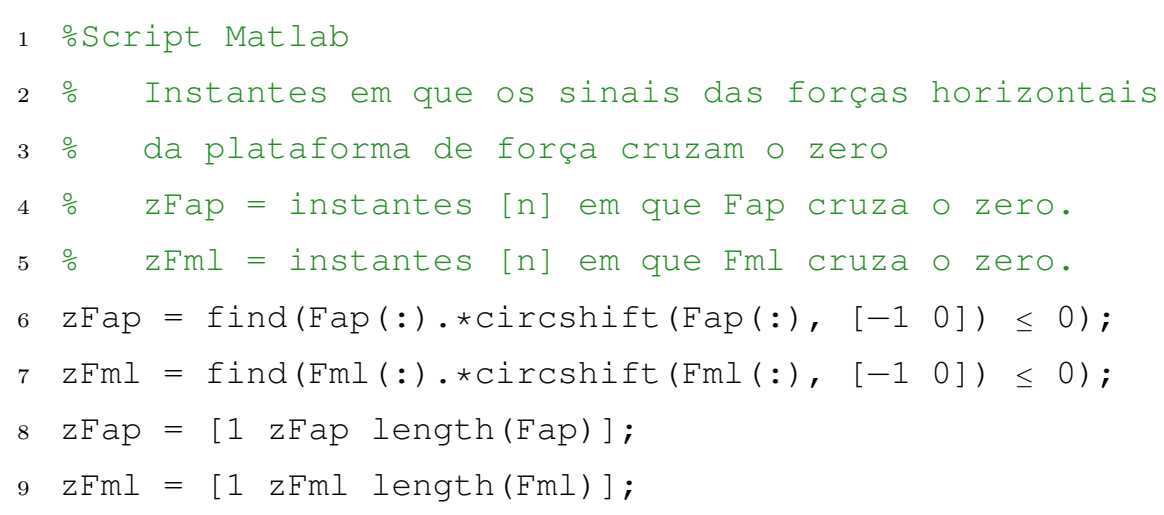

(d) Os valores do $\mathrm{COP}(A P[n]$ e $M L[n])$ nos instantes $z F a p$ e $z F m l$ foram obtidos:

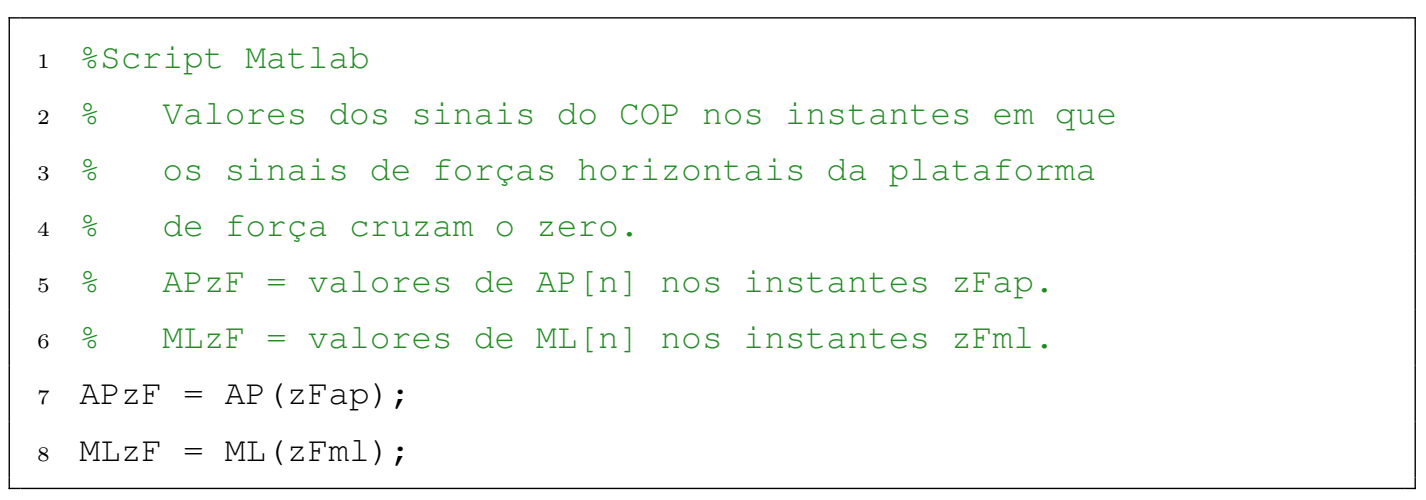

(e) Os sinais Rambling $\left(A P_{\text {Ram }}[n]\right.$ e $\left.M L_{\text {Ram }}[n]\right)$ foram obtidos pela interpolação por funções spline cúbicas dos valores de $A P z F$ e $M L z F$ (Item b da figura 50):

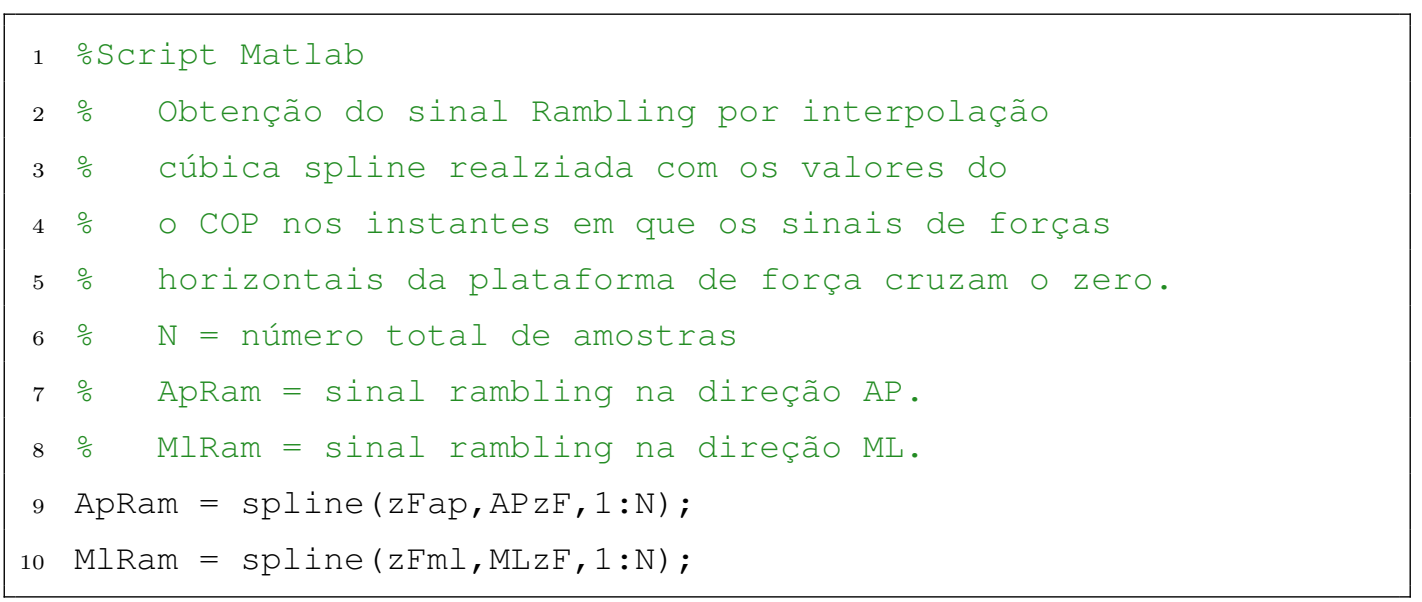


(f) Os sinais Trembling $\left(A P_{\text {Tre }}[n]\right.$ e $\left.M L_{\text {Tre }}[n]\right)$ foram obtidos da subtração dos sinais do COP com os sinais Rambling (Item c da figura 50):

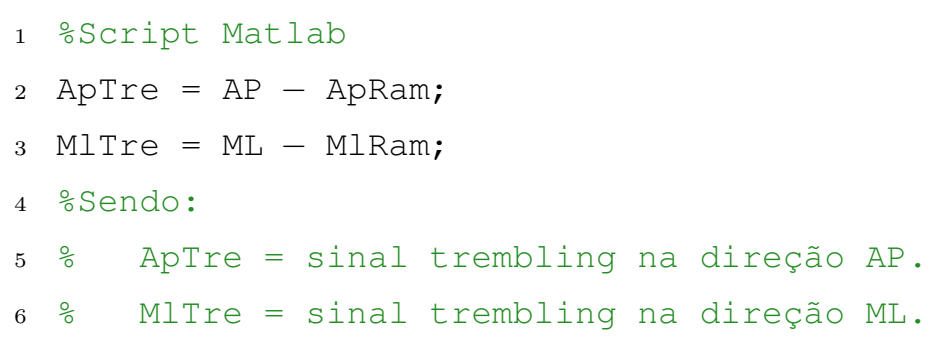

2. Reamostragem: Os sinais foram reamostrados para uma frequência de amostragem de $100 \mathrm{~Hz}$, por meio da função downsample(勾 do Matlab:

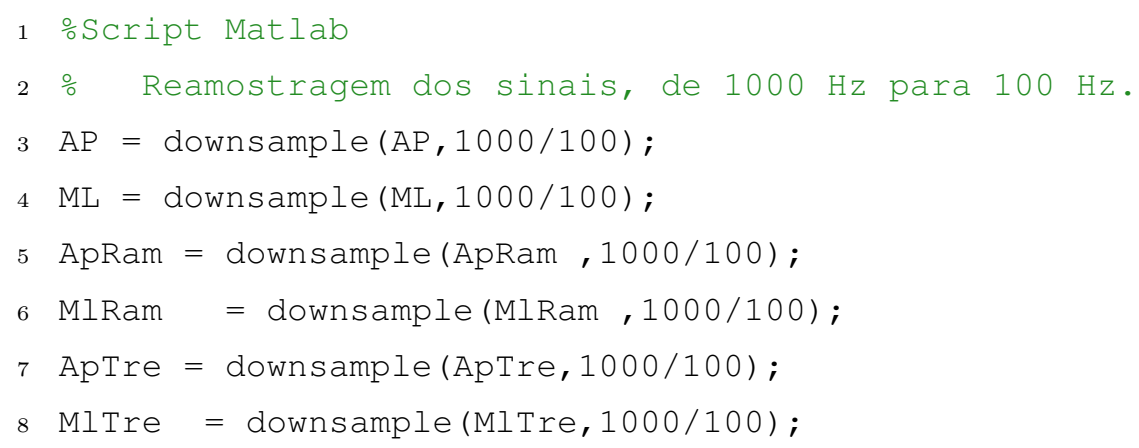

3. Sinal da velocidade do COP Os sinais de velocidade do COP $A P_{v}$ e $M L_{v}$ foram obtidos pelas equações:

$$
\begin{gathered}
A P_{v}[n]=\frac{A P[n+1]-A P[n]}{\Delta T}, n=1,2,3 \ldots N-1 \\
M L_{v}[n]=\frac{M L[n+1]-M L[n]}{\Delta T}, n=1,2,3 \ldots N-1
\end{gathered}
$$

Sendo:

$$
\begin{aligned}
& A P_{v}[n]=\text { velocidade do } \mathrm{COP} \text { na direção } \mathrm{AP} \\
& M L_{v}[n]=\text { velocidade do } \mathrm{COP} \text { na direção } \mathrm{ML} \\
& \Delta T \quad=\text { Intervalo de tempo entre amostras coletadas. } \\
& N \quad=\text { número total de amostras coletadas. }
\end{aligned}
$$

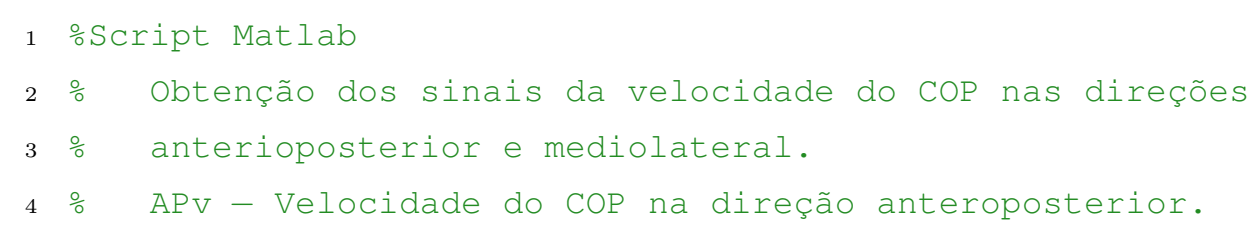

\footnotetext{
${ }^{4}$ Como, nessa etapa do pré-processamento, os sinais já haviam sido filtrados com filtro passa-baixas com frequência de corte de $10 \mathrm{~Hz}$, a função downsample() do Matlab pôde ser utilizada sem a ocorrência de aliasing nos sinais.
} 

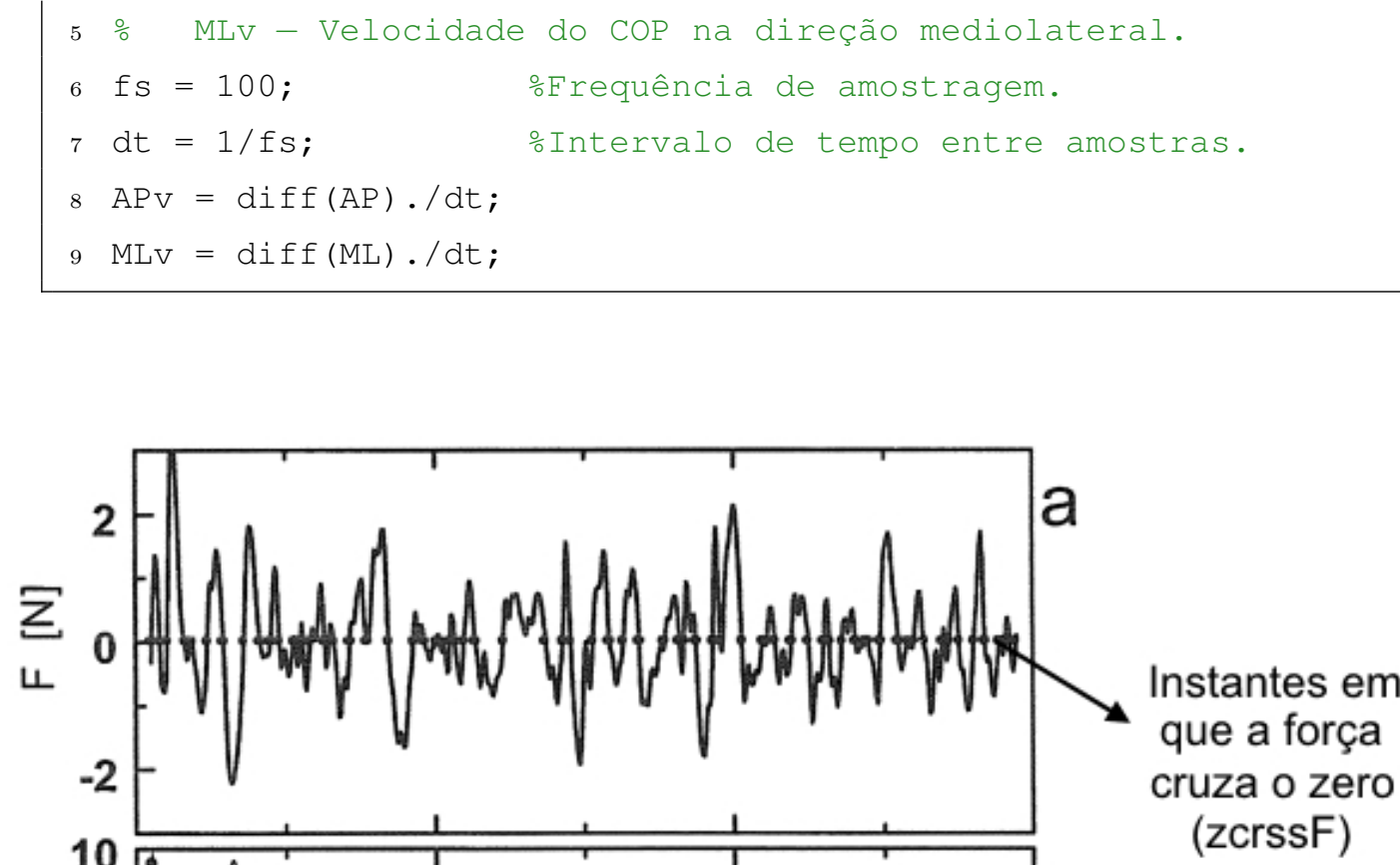

Figura 50: Obtenção das componentes Rambling e Trembling do COP. a) Obtenção dos instantes em que a força na direção horizontal $\left(F_{A P}\right.$ ou $\left.F_{M L}\right)$ cruza o zero. b) O sinal Rambling é obtido pela interpolação por funções spline cúbicas dos valores do COP obtidos nos instantes em que a força horizontal cruza o zero. c) O sinal Trembling é obtido da subtração do sinal COP como o sinal Rambling.(Imagem modificada de (ZATSIORSKY; DUARTE, 1999)) 


\subsubsection{Parâmetros do COP}

Os sinais da localização do COP ao longo do tempo, de cada aquisição de dados, foram processados para a obtenção de parâmetros (Tabelas 4 e 5) que permitiram a verificação de possíveis alterações da dinâmica do controle postural dos participantes na $\mathrm{PEO}$ antes to , durante $(\mathbf{t 1}$ e depois $(\mathbf{t 2}$ dos protocolos de estimulação elétrica.

\subsubsection{Parâmetros $S D, M V E L O$ e $A R E A E$}

As seguintes equações foram utilizadas para a obtenção dos parâmetros $S D, M V E L O$ e $A R E A E$ (PRIETO et al., 1996) e (KUO et al., 1998):

- Desvio padrão (SD) 5 ;

$$
S D[n]=\sqrt{\frac{1}{N-1} \sum_{n=1}^{N} x[n]^{2}}
$$

Sendo:

$$
\begin{aligned}
x[n] & =A P[n], \text { para } S D_{A P .} \\
x[n] & =M L[n], \text { para } S D_{M L .} \\
x[n] & =A P_{\text {Ram }}[n], \text { para } S D_{A P_{-R a m}} . \\
x[n] & =A P_{\text {Tre }}[n], \text { para } S D_{A P_{-} T r e} . \\
x[n] & =A P_{v}[n], \text { para } S D_{A P_{-} v} . \\
x[n] & =M L_{\text {Ram }}[n], \text { para } S D_{M L_{-} R a m} . \\
x[n] & =M L_{\text {Tre }}[n], \text { para } S D_{M L_{-} T r e} . \\
x[n] & =M L_{v}[n], \text { para } S D_{M L_{-} v} .
\end{aligned}
$$

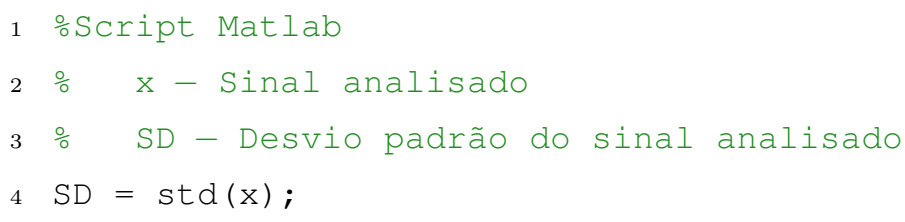

- Velocidade média (MVELO):

$$
M V E L O=\frac{\sum_{n=1}^{N-1}(x[n+1]-x[n])}{T}
$$

Sendo:

\footnotetext{
${ }^{5}$ Como no pré-processamento os níveis DC dos sinais foram removidos, a equação exibida para o cálculo do desvio padrão não apresenta a subtração de cada ponto pela média do sinal.
} 
Tabela 4: Parâmetros SD, MVELO, AREAE, PSD_AREA e f50p_PSD

\begin{tabular}{|c|c|}
\hline $\begin{array}{l}\text { Nome do } \\
\text { parâmetro }\end{array}$ & $\begin{array}{c}\text { Descrição } \\
\text { (Unidade)/Equacão }\end{array}$ \\
\hline$S D_{A P}$ & \multirow{8}{*}{$\begin{array}{l}\text { Desvio padrão (SD) } \\
\quad(\mathrm{mm}) / \text { Eq. } 2.7\end{array}$} \\
\hline$S D_{M L}$ & \\
\hline$S D_{A P \_T r e}$ & \\
\hline$S D_{A P \_R a m}$ & \\
\hline$S D_{A P_{-} v}$ & \\
\hline$S D_{M L \_T r e}$ & \\
\hline$S D_{M L_{-} \text {Ram }}$ & \\
\hline$S D_{M L \_v}$ & \\
\hline$M V E L O_{A P}$ & \multirow{6}{*}{$\begin{array}{l}\text { Velocidade média (MVELO) } \\
\qquad(\mathrm{mm} / \mathrm{s}) / \mathrm{Eq} \cdot 2.8\end{array}$} \\
\hline$M V E L O_{A P \_T r e}$ & \\
\hline$M V E L O_{A P \_R a m}$ & \\
\hline$M V E L O_{M L}$ & \\
\hline MVELO ${ }_{M L \_T r e}$ & \\
\hline$M V E L O_{M L_{-} R a m}$ & \\
\hline$A R E A E$ & \multirow{3}{*}{$\begin{array}{c}\text { Área da elipse } 95 \% \text { (AREAE) } \\
\left(\mathrm{mm}^{2}\right) / \text { Eq. } 2.9\end{array}$} \\
\hline$A R E A E_{\text {Tre }}$ & \\
\hline$A R E A E_{R a m}$ & \\
\hline$P S D \_A R E A_{-} L F_{A P}$ & \multirow{4}{*}{$\begin{array}{c}\text { Potência do sinal } \\
\text { em baixas e em altas frequências (PSD_AREA) } \\
\left(\mathrm{mm}^{2}\right) / \text { Eq. } 2.10 \mathrm{e} 2.11\end{array}$} \\
\hline$P S D \_A R E A \_H F_{A P}$ & \\
\hline$P S D \_A R E A \_L F_{M L}$ & \\
\hline$P S D \_A R E A \_H F_{M L}$ & \\
\hline$f 50 p_{-} P S D_{A P}$ & \multirow{8}{*}{$\begin{array}{l}\text { Frequência que divide pela metade (50\%) } \\
\text { a área sob a curva da PSD (f50p_PSD) } \\
\qquad(\mathrm{Hz}) / \mathrm{Eq} \cdot 2.12\end{array}$} \\
\hline$f 50 p_{-} P S D_{A P v}$ & \\
\hline$f 50 p_{-} P S D_{A P \_T r e}$ & \\
\hline$f 50 p_{-} P S D_{\text {AP_Ram }}$ & \\
\hline$f 50 p_{-} P S D_{M L}$ & \\
\hline$f 50 p_{-} P S D_{M L v}$ & \\
\hline$f 50 p_{-} P S D_{M L \_T r e}$ & \\
\hline$f 50 p_{-} P S D_{M L_{-} R a m}$ & \\
\hline \multicolumn{2}{|c|}{$\begin{array}{l}\text { AP - Parâmetro obtido do } \overline{\mathrm{COP}} \text { na direção } \overline{\mathrm{AP}} \\
A P v \text { - Parâmetro obtido da velocidade do } \overline{\mathrm{COP}} \text { na direção } \mathrm{AP} \text {. } \\
M L \text { - Parâmetro obtido do } \mathrm{COP} \text { na direção } \overline{\mathrm{ML}} \text {, } \\
M L v \text { - Parâmetro obtido da velocidade do } \overline{\mathrm{COP}} \text { na direção } \mathrm{ML} \\
\text { Ram - Parâmetro obtido da componente Rambling do } \mathrm{COP} . \\
\text { Tre - Parâmetro obtido da componente Trembling do } \overline{\mathrm{COP}} \text {. }\end{array}$} \\
\hline
\end{tabular}


Tabela 5: Parâmetros $f \_80 p \_P S D$, SDA, FsFA e MSE

\begin{tabular}{|c|c|}
\hline $\begin{array}{l}\text { Nome do } \\
\text { parâmetro }\end{array}$ & $\begin{array}{c}\text { Descrição } \\
\text { (Unidade)/Equação }\end{array}$ \\
\hline$f 80 p_{-} P S D_{A P}$ & \multirow{8}{*}{$\begin{array}{l}\text { Frequência que divide em } 80 \% \\
\text { a área sob a curva da } \mathrm{PSD}(\text { f80p_PSD) } \\
(\mathrm{Hz}) / \mathrm{Eq} \cdot 2.13\end{array}$} \\
\hline$f 80 p_{-} P S D_{A P v}$ & \\
\hline$f 80 p_{-} P S D_{A P \_T r e}$ & \\
\hline$f 80 p_{-} P S D_{A P \_R a m}$ & \\
\hline$f 80 p_{-} P S D_{M L}$ & \\
\hline$f 80 p_{-} P S D_{M L v}$ & \\
\hline$f 80 p_{-} P S D_{M L \_T r e}$ & \\
\hline$f 80 p_{-} P S D_{M L \_R a m}$ & \\
\hline$D_{S_{A P}}$ & \multirow{8}{*}{$\begin{array}{c}\text { Parâmetros da } \\
D_{L}\left(\mathrm{~mm}^{2} / \mathrm{s}\right) \text { - coeficiente de difusão em longa duração. } \\
D_{S}\left(\mathrm{~mm}^{2} / \mathrm{s}\right) \text { - coeficiente de difusão em curta duração. } \\
\Delta T c(\mathrm{~s}) \text { - intervalo critico. } \\
\left\langle\Delta X_{C O P}^{2}\right\rangle\left(\mathrm{mm}^{2}\right) \text { - distância média quadrática em } \Delta T c . \\
\text { Eq. } 2.14\end{array}$} \\
\hline$D_{L_{A P}}$ & \\
\hline$\Delta T c_{A P}$ & \\
\hline$\left\langle\Delta X_{C O P_{A P}}^{2}\right\rangle$ & \\
\hline$D_{S_{M L}}$ & \\
\hline$D_{L_{M L}}$ & \\
\hline$\Delta T c_{M L}$ & \\
\hline$\left\langle\Delta X_{C O P_{M L}}^{2}\right\rangle$ & \\
\hline$\alpha_{-} S_{A P}$ & \multirow{4}{*}{ 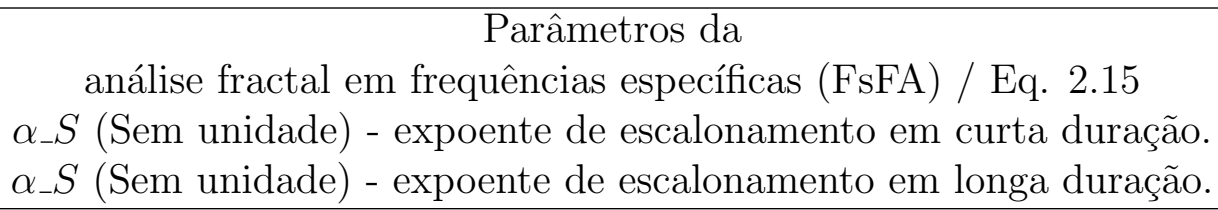 } \\
\hline$\alpha_{\_} L_{A P}$ & \\
\hline$\alpha \_S_{M L}$ & \\
\hline$\alpha_{-} L_{M L}$ & \\
\hline$C I_{A P}$ & \multirow{4}{*}{$\begin{array}{l}\text { Coeficiente de complexidade da análise de } \\
\qquad \frac{\text { entropia multi-escala (MSE) }}{\text { (Sem unidade)/Eq. } 2.16} \text { (CI) }\end{array}$} \\
\hline$C I_{A P_{v}}$ & \\
\hline$C I_{M L}$ & \\
\hline$C I_{M L_{v}}$ & \\
\hline $\begin{array}{l}A P \text { - Parâmetro ob } \\
A P v \text { - Parâmetro o } \\
M L \text { - Parâmetro ol } \\
M L v \text { - Parâmetro o } \\
\text { Ram - Parâmetro o } \\
T r e \text { - Parâmetro ob }\end{array}$ & $\begin{array}{l}\text { ido do } \overline{\mathrm{COP}} \text { na direção } \overline{\mathrm{AP}} \\
\text { tido da velocidade do } \overline{\mathrm{COP}} \text { na direção } \mathrm{AP} \text {. } \\
\text { ido do } \overline{\mathrm{COP}} \text { na direção } \overline{\mathrm{ML}} \text {. } \\
\text { tido da velocidade do } \overline{\mathrm{COP}} \text { na direção } \mathrm{ML} \\
\text { tido da componente Rambling do } \overline{\mathrm{COP}} . \\
\text { ido da componente Trembling do } \overline{\mathrm{COP}} \text {. }\end{array}$ \\
\hline
\end{tabular}


$x[n]=A P[n]$, para $M V E L O_{A P}$.

$x[n]=M L[n]$, para $M V E L O_{M L}$.

$x[n]=A P_{\text {Ram }}[n]$, para $M V E L O_{A P_{-} \text {Ram }}$.

$x[n]=A P_{\text {Tre }}[n]$, para $M V E L O_{A P_{-} \text {Tre }}$.

$x[n]=M L_{R a m}[n]$, para $M V E L O_{M L_{-} R a m}$.

$x[n]=M L_{T r e}[n]$, para $M V E L O_{M L_{-} T r e}$.

$T=$ Duração total da aquisição de dados em segundos.

$N=$ número de amostras coletadas.

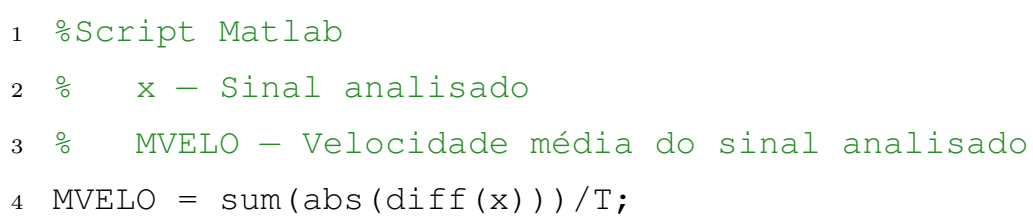

\section{- Área da elipse 95\% (AREAE)}

$$
A R E A E=9 \pi \sqrt{\operatorname{Var}_{x} \operatorname{Var}_{y}-\operatorname{Cov}_{x, y}^{2}}
$$

Sendo :

$$
\begin{aligned}
\operatorname{Var}_{x} & =\frac{1}{N-1} \sum_{n=1}^{N} x[n]^{2} \\
\operatorname{Cov}_{x, y} & =\frac{1}{N-1} \sum_{n=1}^{N} x[n] y[n] \\
\operatorname{Var}_{y} & =\frac{1}{N-1} \sum_{n=1}^{N} y[n]^{2}
\end{aligned}
$$

Com:

$$
\begin{aligned}
& (x[n], y[n])=(A P[n], M L[n]), \text { para } A R E A E . \\
& (x[n], y[n])=\left(A P_{\text {Ram }}[n], M L_{\text {Ram }}[n]\right), \text { para } A R E A E_{\text {Ram }} . \\
& (x[n], y[n])=\left(A P_{\text {Trem }}[n], M L_{\text {Trem }}[n]\right), \text { para } A R E A E_{\text {Tre }} .
\end{aligned}
$$

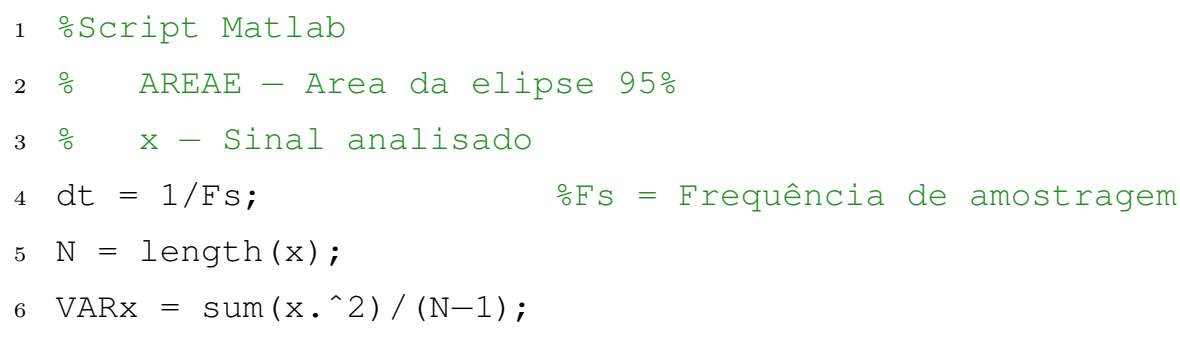

${ }^{6} \mathrm{~A}$ equação (18) de (PRIETO et al. 1996) foi corrigida para : AREA $-C E=$ $\pi F_{.05[2, n-2]}^{2} \sqrt{s_{A P}^{2} s_{M L}^{2}-s_{A P M P}^{2}}$. 
7 VARY $=\operatorname{sum}\left(y \cdot{ }^{\wedge} 2\right) /(\mathrm{N}-1) ;$

8 COVxy $=\operatorname{sum}(\mathrm{x} \cdot * \mathrm{Y}) /(\mathrm{N}-1)$;

$9 \operatorname{AREAE}=9 * \mathrm{pi} * \operatorname{sqrt}\left(\operatorname{VAR} x * \operatorname{VARY}-\operatorname{COVXY}^{\wedge} 2\right)$;

\subsubsection{Parâmetros $P S D \_A R E A, f 50 p_{-} P S D$ e $f 80 p_{-} P S D$}

A seguinte sequência foi adotada para a obtenção dos parâmetros PSD_AREA, $f 50 p_{-} P S D$ e $f 80 p_{-} P S D$ (PRIETO et al., 1996; VIEIRA; OLIVEIRA; NADAL, 2009):

1. As $\mathrm{PSD}$; do sinais foram estimadas pelo método de Welch 7 (JR, 1991) utilizando a função pwelch( (ل) do Matlab, com janela do tipo Hann de 20 segundos (Resolução da PSD de 0,05Hz) com sobreposição de 50\%:

$$
P S D_{x[n]}[f]=\operatorname{pwelch}(x[n])
$$

Sendo:

$$
P S D_{x[n]}[f]=\text { Estimador, nas frequências } f \mathrm{~s} \text {, da } \mathrm{PSD} \text { do sinal } x[n] \text {. }
$$

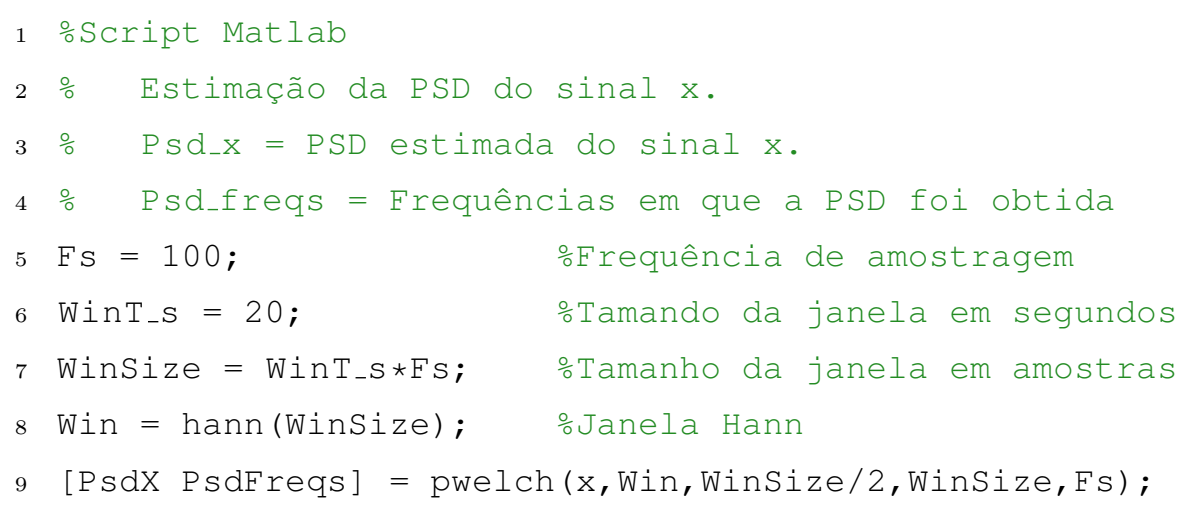

2. Os parâmetros PSD_AREA_LF e PSD_AREA_HF foram obtidos por:

$$
\begin{aligned}
& P S D \_A R E A \_L F=\sum_{f=0,05 H z}^{0.5 H z} P S D_{x[n]}[f] \\
& P S D \_A R E A \_H F=\sum_{f=0,5 H z}^{2 H z} P S D_{x[n]}[f]
\end{aligned}
$$

\footnotetext{
${ }^{7}$ No método de Welch, inicialmente, o sinal é dividido em $\mathrm{W}$ janelas de $\mathrm{N}$ amostras com sobreposição de D amostras. Em seguida, cada janela é multiplicada por uma função janela (Blackman-Harris, Kaiser,Hann, etc) de modo a reduzir o artefato espectral produzido pela divisão do sinal em janelas. Por fim é realizada a média do quadrado do módulo da transformada rápida de Fourier (FFT) de cada janela seguida de uma normalização, resultando no estimador da $\mathrm{PSD}$ do sinal.

${ }^{8}$ Função do software Matlab que estima a PSD pelo método de Welch.
} 
Sendo:

$$
\begin{aligned}
& x[n]=A P[n], \text { para } P S D \_A R E A_{-} L F_{A P} \text { e } P S D_{-} A R E A_{-} H F_{A P} . \\
& x[n]=M L[n], \text { para } P S D_{-} A R E A_{-} L F_{M L} \text { e } P S D_{-} A R E A_{-} H F_{M L} .
\end{aligned}
$$

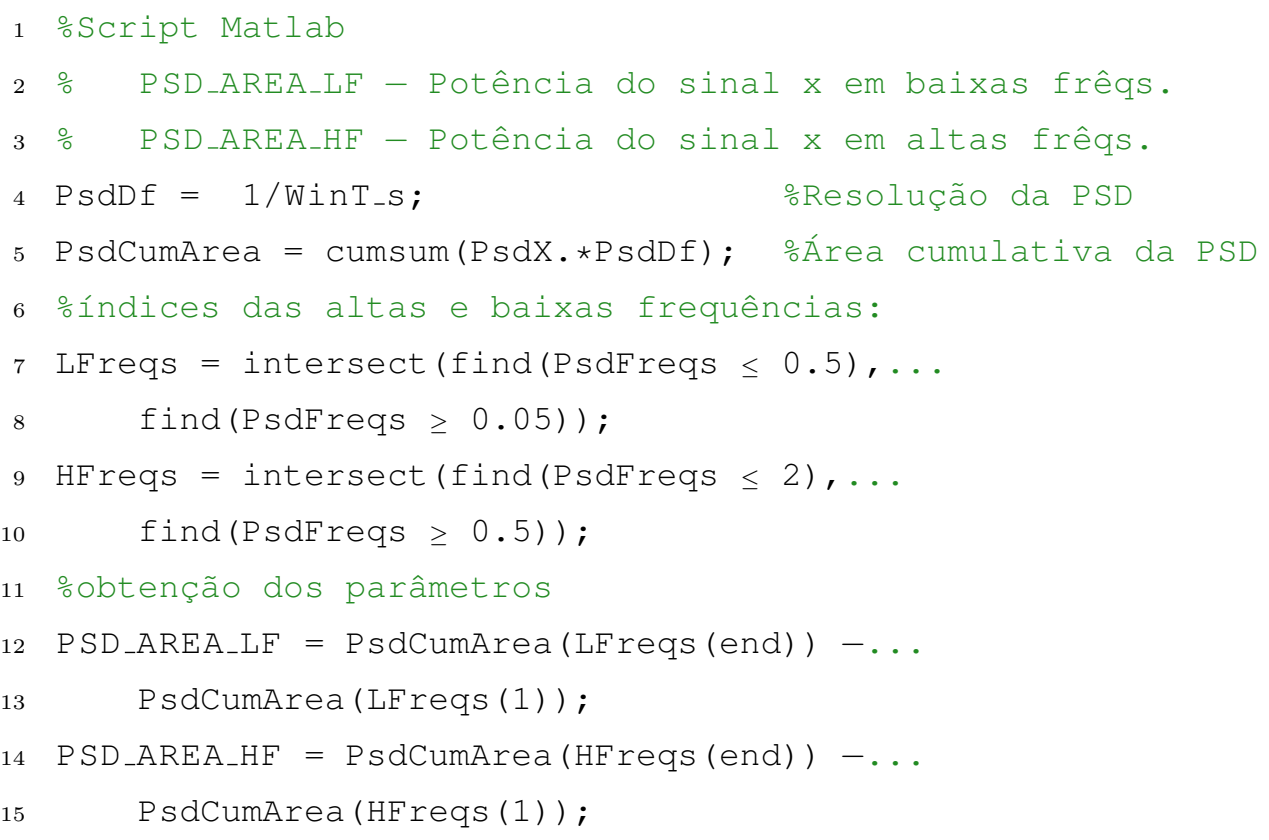

3. Os parâmetros f50p_PSD e f80p_PSD foram obtidos pelas menores frequências que satisfaziam as seguintes equações:

$$
\begin{aligned}
& \sum_{f=0.15 H z}^{f 50 p_{-} P S D} P S D_{x[n]}[f] . d f \geq \frac{P S D_{x[n]}[f]}{2} \\
& \sum_{f=0.15 H z}^{f 80 p_{-} P S D} P S D_{x[n]}[f] . d f \geq \frac{P S D_{x[n]}[f]}{1.25}
\end{aligned}
$$

Sendo: 


$$
\begin{aligned}
& x[n]=A P[n], \text { para } f 50 p_{-} A P \text { e } f 80 p_{-} A P \\
& x[n]=M L[n], \text { para } f 50 p_{-} M L \text { e } f 80 p_{-} M L \\
& x[n]=A P_{v}[n], \text { para } f 50 p_{-} A P_{v} \text { e } f 80 p_{-} A P_{v} \\
& x[n]=M L_{v}[n], \text { para } f 50 p_{-} M L_{v} \text { e } f 80 p_{-} M L_{v} \\
& x[n]=A P_{\text {Ram }}[n], \text { para } f 50 p_{-} A P_{\text {Ram }} \text { e } f 80 p_{-} A P_{\text {Ram }} \\
& x[n]=A P_{\text {Tre }}[n], \text { para } f 50 p_{-} A P_{T r e} \text { e } f 80 p_{-} A P_{T r e} \\
& x[n]=M L_{\text {Ram }}[n], \text { para } f 50 p_{-} M L_{\text {Ram }} \text { e } f 80 p_{-} M L_{\text {Ram }} \\
& x[n]=M L_{T r e}[n], \text { para } f 50 p_{-} M L_{T r e} \text { e } f 80 p_{-} M L_{T r e} \\
& d f=\operatorname{resolução~da~} \operatorname{PSD} .
\end{aligned}
$$

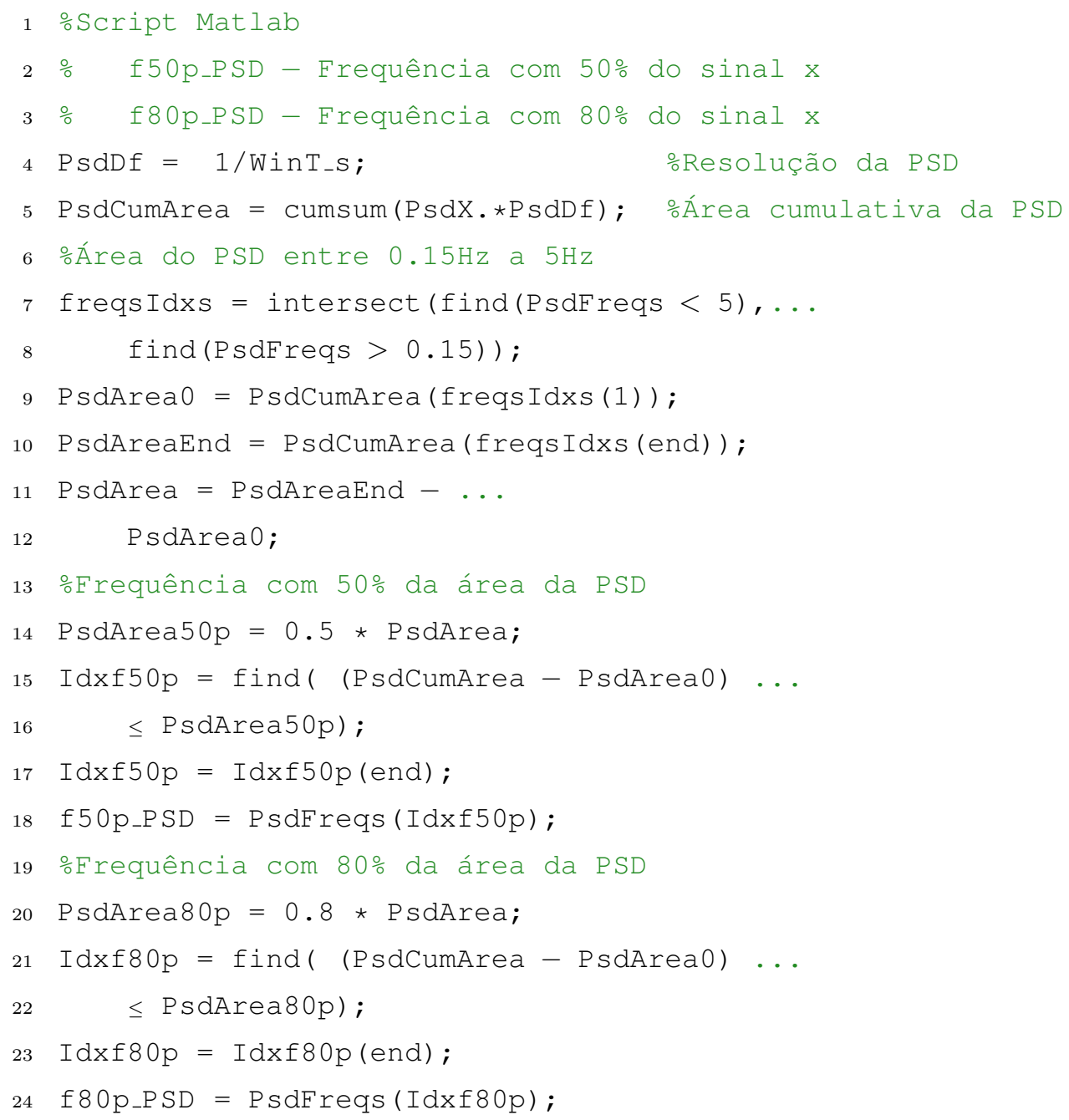




\subsubsection{Parâmetros da SDA}

Os parâmetros da $\mathrm{SDA}$ foram obtidos pela seguinte sequência de cálculos (COLLINS; LUCA, 1993):

1. A curva do gráfico $\left(\left\langle\Delta X^{2}\right\rangle \times \Delta T\right)$ foi obtida pela seguinte equação, com $\Delta T$ máximo de 10 segundos:

$$
\left\langle\Delta X^{2}\right\rangle[\Delta n]=\frac{\sum_{n=1}^{N-\Delta n}(x[n+\Delta n]-x[n])^{2}}{(N-\Delta n)}
$$

$$
\Delta n=\Delta T . F s
$$

Sendo:

$$
\begin{aligned}
& x[n]=A P[n], \text { para } D_{S_{A P}}, D_{L_{A P}}, \Delta T_{C_{A P}} \mathrm{e}\left\langle\Delta X_{C O P_{A P}}^{2}\right\rangle \\
& x[n]=M L[n], \text { para } D_{S_{M L}}, D_{L_{M L}}, \Delta T_{C_{M L}} \mathrm{e}\left\langle\Delta X_{C O P_{M L}}^{2}\right\rangle \\
& \Delta n=\text { distância entre amostras } \\
& \Delta T=\text { intervalo de tempo entre amostras (0 a } 10 \text { segundos) } \\
& F s=\text { Frequência de amostragem. } \\
& N \quad=\text { Número de amostras coletadas. }
\end{aligned}
$$

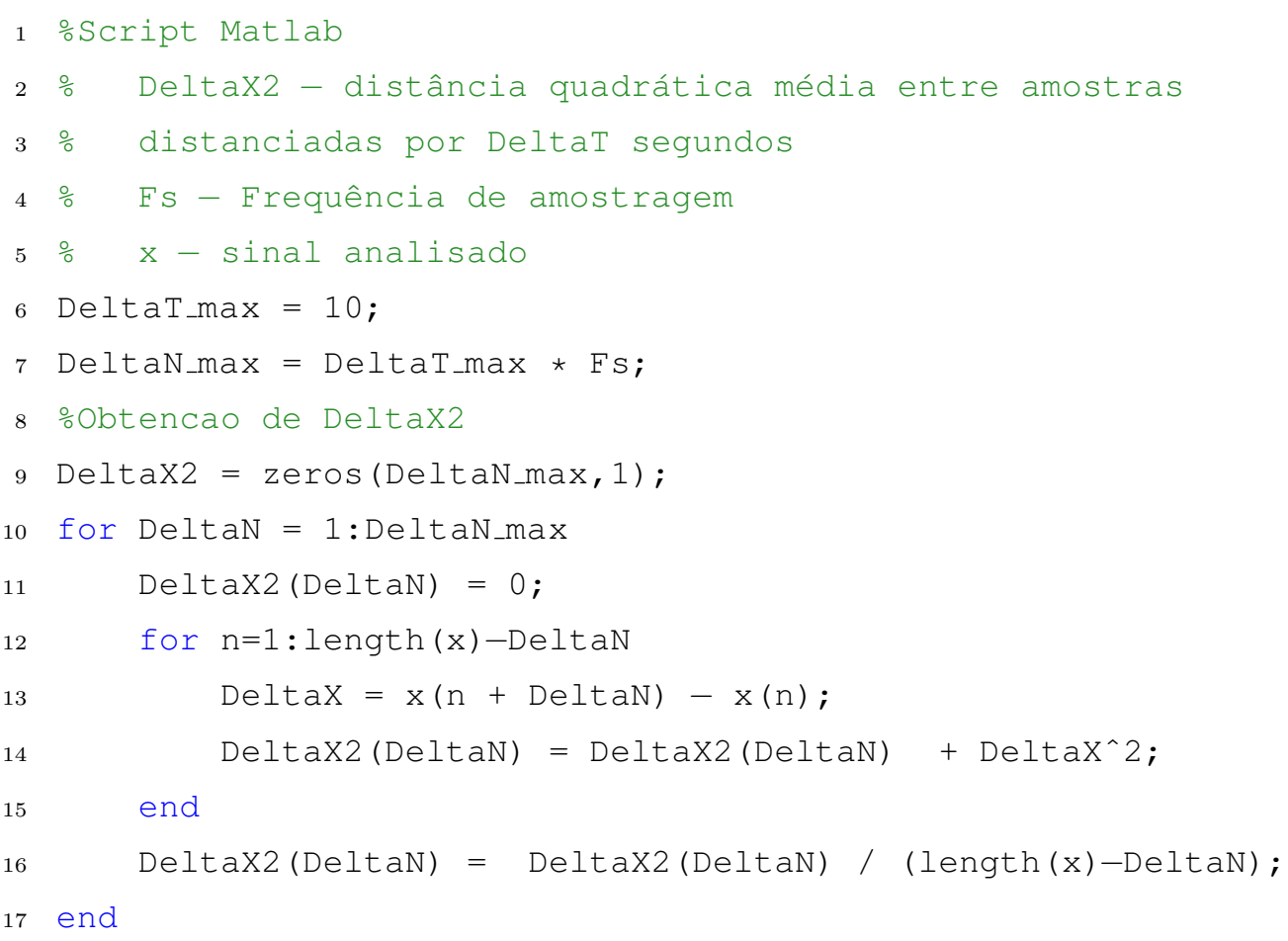

2. Os parâmetros $D_{S}$ e $D_{L}$ foram obtidos dos coeficientes angulares das regressões 
lineares realizadas em $\Delta T \leq 0.3$ segundos para $D_{S}$ e em $\Delta T \geq 2$ segundos para $D_{L}{ }^{9}$, por meio da função polyfit $(\sqrt{10}$ do Matlab:

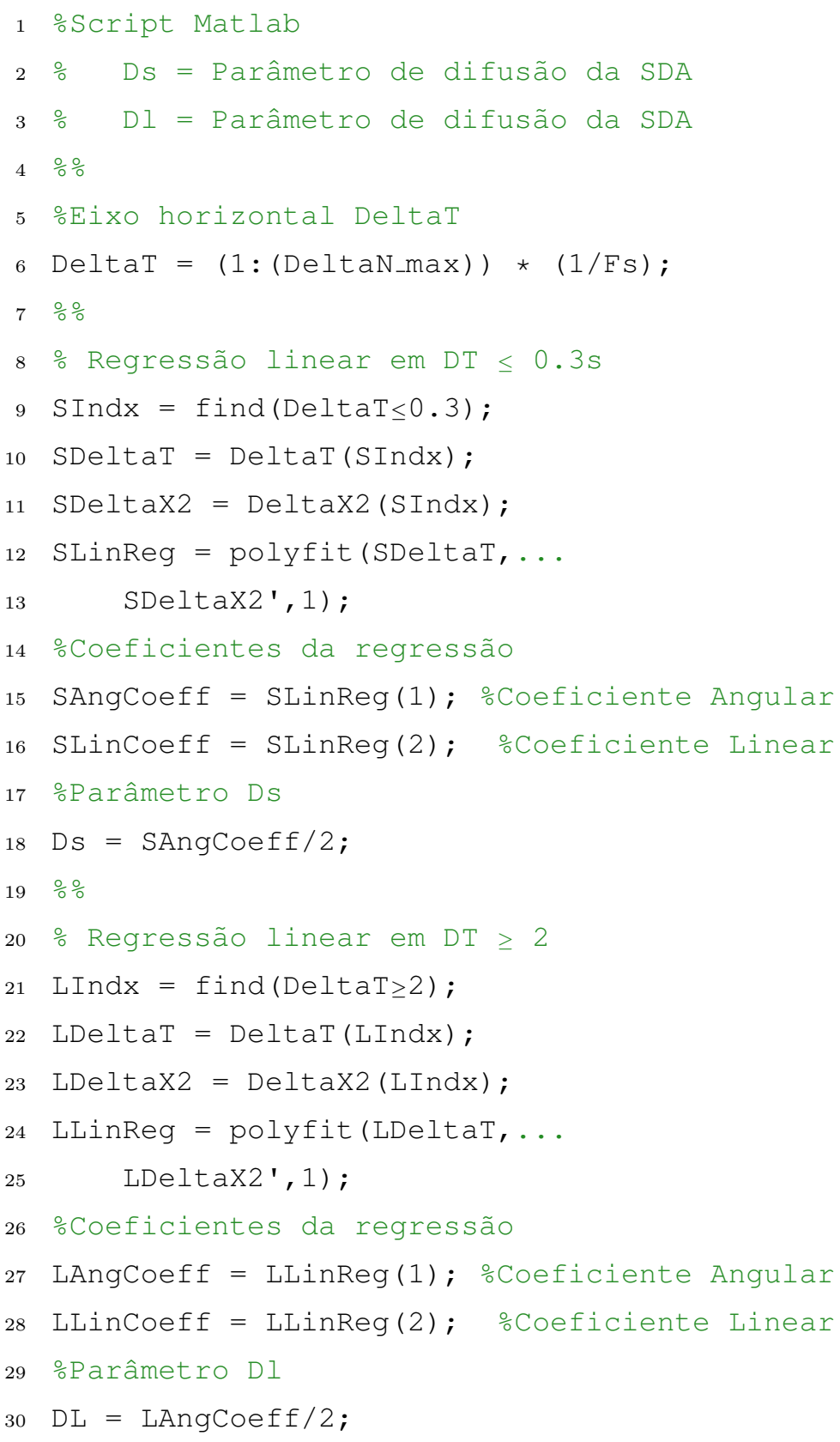

${ }^{9} \mathrm{O}$ método de obtenção dos parâmetros $D_{l}$ e $D_{s}$ não é padronizado. Nos trabalhos de COLLINS; LUCA (COLLINS; LUCA, 1993, COLLINS et al., 1995; COLLINS; LUCA, 1995) aparentemente os autores determinaram os intervalos de $\Delta T$ para a realização das regressões lineares por inspeção visual da curva $\left(\left\langle\Delta X^{2}\right\rangle \times \Delta T\right)$. PETERKA (2000) padroniza o intervalo $\Delta T$ para $0,01 \leq \Delta T \leq 0,5$ (segundos) para a realização da regressão linear para a obtenção de $D_{s}$ e $2 \leq \Delta T \leq 10$ (segundos) para a obtenção de $D_{l}$, sendo esse o método selecionado nesse trabalho.

${ }^{10}$ Função do software Matlab que retorna os coeficientes de um polinômio que melhor se ajusta, do ponto de vista do erro quadrático médio, à série-temporal de entrada. 
3. Os parâmetros $\Delta T_{c}$ e $\left\langle\Delta X^{2}\right\rangle_{c}$ foram obtidos do ponto de cruzamento das retas obtidas das regressões lineares:

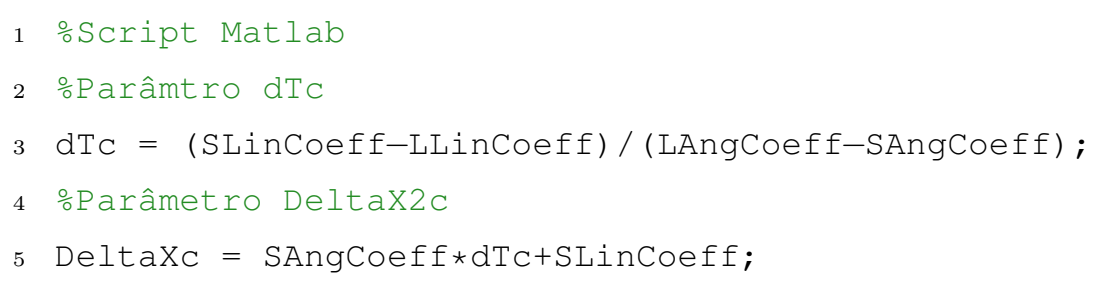

\subsubsection{Parâmetros da FsFA}

A FsFA foi elaborada por meio da execução dos seguintes passos (GILFRICHE et al., 2018) 11:

1. Os sinais analisados foram inicialmente integrados:

$$
x_{i n t}[k]=\sum_{n=1}^{N}(x[n])
$$

Sendo:

$$
\begin{aligned}
& N=\text { número de amostras. } \\
& x[n]=A P[n], \text { para } \alpha_{-} S_{A P} \text { e } \alpha_{-} L_{A P} \\
& x[n]=M L[n], \text { para } \alpha_{-} S_{M L} \text { e } \alpha_{-} L_{M L}
\end{aligned}
$$

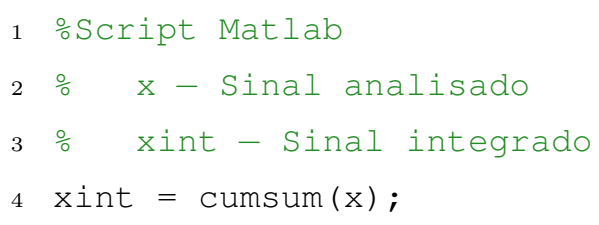

2. Os sinais integrados foram divididos em $\frac{N}{L}$ janelas $(\boldsymbol{W})$ com tamanhos $(L)$ variando, em escala logarítmica, de 10 a $50 \operatorname{amostras}(10-2 \mathrm{~Hz})$ e de 200 a $\frac{N}{4} \operatorname{amostras}(0,5-$ $0 \mathrm{~Hz}$ ), sem sobreposição:

$$
\boldsymbol{W}_{x}[j, L]=\left[\begin{array}{c}
x_{i n t}[(j-1) L+1] \\
x_{i n t}[(j-1) L+2] \\
\cdot \\
\cdot \\
x_{i n t}[(j-1) L+L]
\end{array}\right], j=1,2, \ldots, \frac{N}{L}
$$

\footnotetext{
${ }^{11}$ Em (GILFRICHE et al. 2018), na seção DETRENDED FLUCTUATION ANALYSIS (DFA) AND ITS PITFALLS é apresentada uma sequência intuitiva de passos para a obtenção dos parâmetros do método de FsFA.
} 


$$
\begin{aligned}
& L=10.10^{i \cdot\left(\frac{\log (5)}{9}\right)} \mathrm{i}=0,1,2, \ldots .9, \text { para } 10-2 \mathrm{~Hz} . \\
& L=200.10^{i \cdot\left(\frac{\log (N /(800))}{9}\right)} \mathrm{i}=0,1,2, \ldots 9,0,5-0 \mathrm{~Hz} .
\end{aligned}
$$

Sendo:

$$
\begin{aligned}
& \boldsymbol{W}_{x}=\text { Janelas } \\
& x_{\text {int }}[n]=\text { Sinal } x[n] \text { integrado. }
\end{aligned}
$$

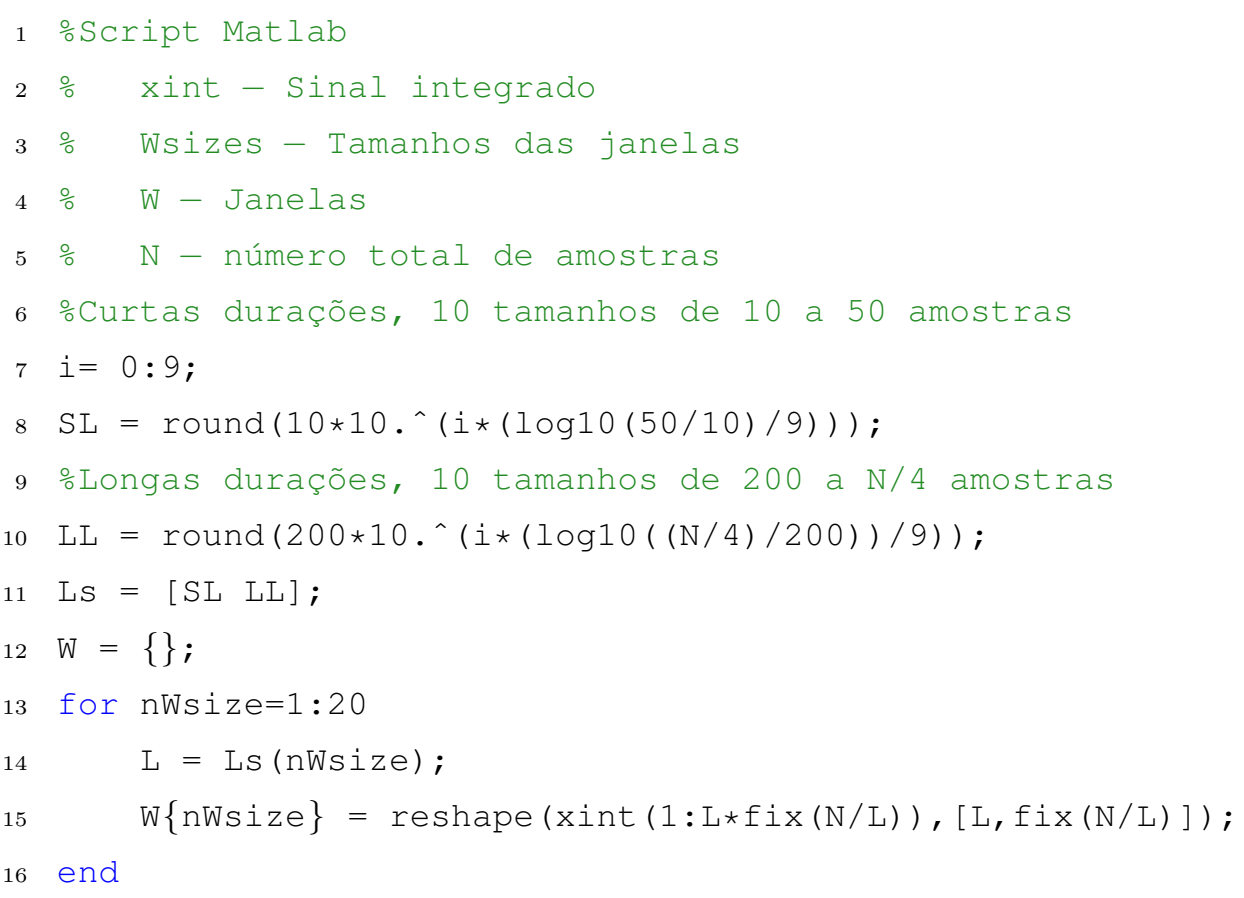

3. Em cada janela $\boldsymbol{W}_{x}[j, L]$, foi realizada a subtração da tendência linear por meio da função detrend( ${ }^{12}$ do Matlab:

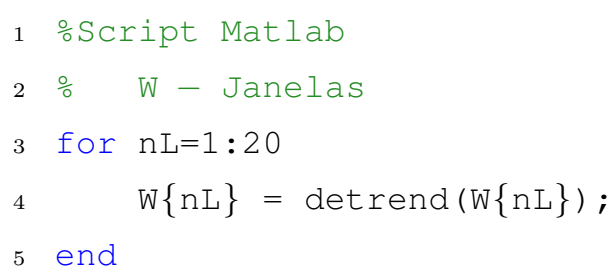

4. O RMS de cada janela $\boldsymbol{W}_{x}[j, L]$ foi obtido:

$$
R M S_{W}[j, L]=\sqrt{\frac{1}{L} \sum_{k=1}^{L}\left(\boldsymbol{W}_{x}[j, L][k]\right)^{2}}
$$

Sendo:

$$
\boldsymbol{W}_{x}[j, L][k]=k \text {-ésima amostra dentro de cada janela } \boldsymbol{W}_{x}[j, L] . \mathrm{k}=1,2,3 \ldots \mathrm{L}
$$

\footnotetext{
${ }^{12}$ Função do software Matlab que remove tendências lineares de séries temporais.
} 


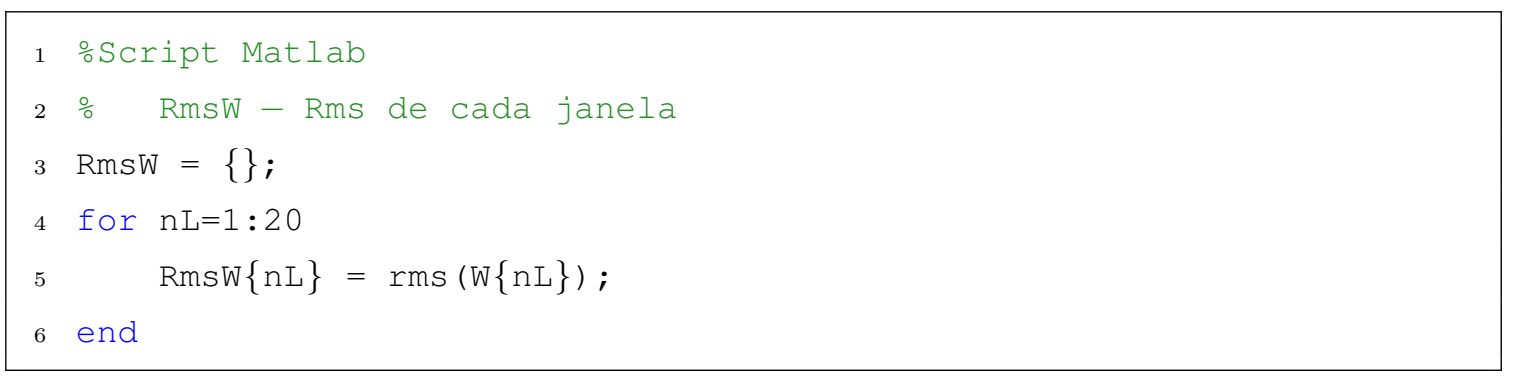

5. Os valores da curva $F[L]$ (ou $F(n)$ ) foram obtidos pelo cálculo do RMS dos RMSs das janelas $\boldsymbol{W}_{x}[j, L]$ :

$$
F[L]=\sqrt{\frac{1}{N / L} \sum_{j=1}^{N / L}\left(R M S_{W}[j, L]\right)^{2}}
$$

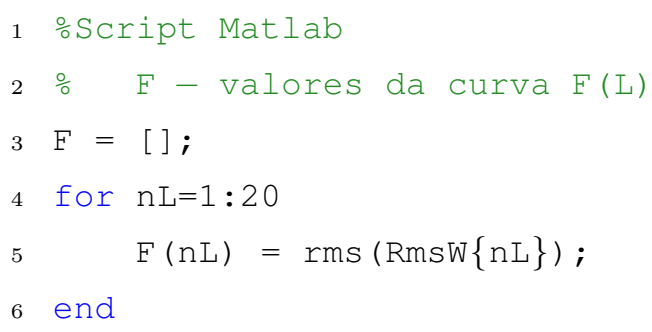

6. Os parâmetros $\alpha \_\mathbf{S}$ e $\alpha \_\mathbf{L}$ foram obtidos dos coeficientes angulares das regressões lineares realizadas na curva $(F(L) \times L)$ em escala $\log$ - Log, em curtas durações (10-2Hz) e em longas durações $(0,5-0 \mathrm{~Hz})$, por meio da função polyfit() do Matlab:

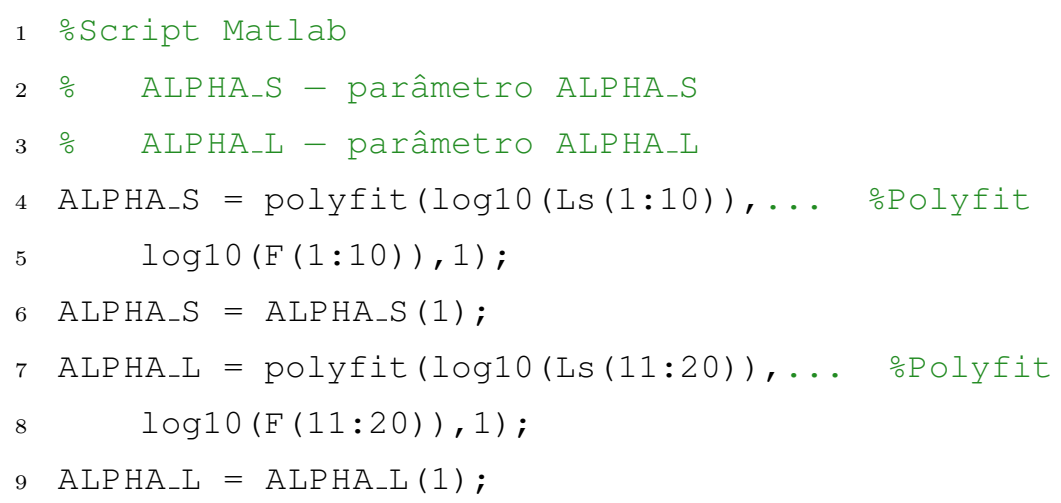

\footnotetext{
${ }^{12}$ Os parâmeros $\alpha_{-} L$ obtidos em janelas de tamanho $200 \leq L \leq \frac{N}{4}(0 H z \leq f . \leq 0,5 H z)$ estão relacionados com loops do controle postural associados ao sistema visio-vestibular. Os parâmeros $\alpha_{-} S$ obtidos em janelas de tamanho $10 \leq W \leq 50(2 \mathrm{~Hz} \leq f \leq 20 \mathrm{~Hz})$ estão relacionados com loops do controle postural associados ao sistema proprioceptivo (GILFRICHE et al., 2018).
} 


\subsubsection{Parâmetros da MSE}

O parâmetro $C I$ da MSE foi obtido por meio dos seguintes passos ${ }^{13}$ (BUSA; EMMERIK, 2016; PINCUS; GOLDBERGER, 1994):

1. Os sinais foram inicialmente filtrados com filtro linear passa-altas do tipo Butterworth de quarta ordem com frequência de corte de $0,5 \mathrm{~Hz}$. De modo que o período da inicialização do filtro digital não influenciasse os resultados experimentais, os primeiros 2,8 segundos dos sinais ${ }^{14}$, após a filtragem, foram descartados:

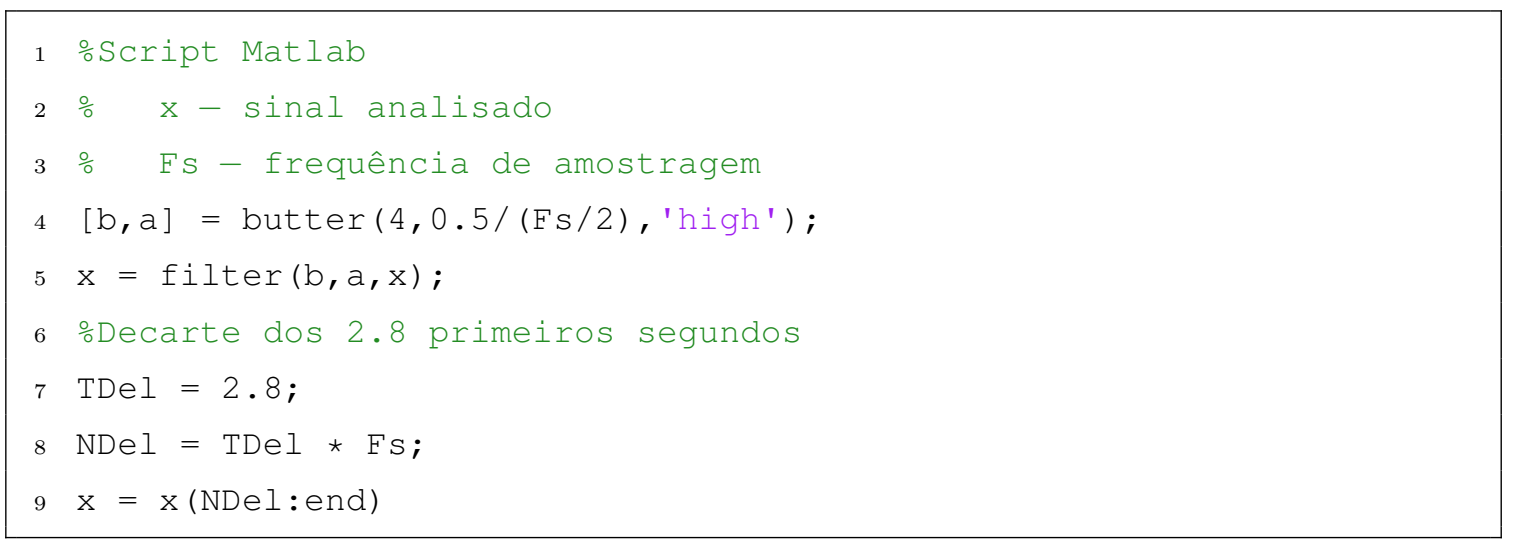

2. Os coeficientes $C I$ da MSE foram calculados pela somatória dos valores das entropias dos sinais, obtidas pelo método sample entropy (SamEn), em dez escalas de tempo, entre $30 \mathrm{~ms}$ e $330 \mathrm{~ms}$ :

$$
C I_{x}=\sum \operatorname{SampEn}\left(u_{x}[j, S]\right) \quad S=30,60,90, \ldots 330 m s
$$

Para transformar o sinal $x[n]$ em diferentes escalas:

$$
u_{x}[j, S]=\frac{1}{F s . S} \sum_{n=(j-1)(F s . S)+1}^{j(F s . S)} x[n] \quad j=1,2,3, \ldots \frac{N}{F s . S}
$$

Sendo:

\footnotetext{
${ }^{13}$ Uma explicação intuitiva de parte da MSE pode ser obtida em (PINCUS; GOLDBERGER, 1994)

${ }^{14} 2.8$ segundos corresponde ao settling time do filtro Butterworth passa-altas de quarta ordem com frequência de corte de $0,5 \mathrm{~Hz}$ quando um sinal do tipo degrau é aplicado em sua entrada. Esse valor pode ser obtido pela função stepinfo() do Matlab.
} 
Fs $=$ Frequência de amostragem em $\mathrm{Hz}$.

$S \quad=$ Escala do sinal.

$u_{x}[j, S]=$ Sinal $x[n]$ na escala $S$.

$x[n]=A P[n]$, para $C I_{A P}$.

$x[n]=A P_{v}[n]$, para $C I_{A P_{v}}$.

$x[n]=M L[n]$, para $C I_{M L}$

$x[n]=M L_{v}[n]$, para $C I_{M L_{v}}$.

A sample entropy (SamEn) foi obtida por:

$$
\operatorname{SampEn}(y[n])=-\ln \left(\frac{\Phi_{y}[m+1]}{\Phi_{y}[m]}\right) \quad m=2, r=0.15
$$

Sendo:

(a)

$$
\Phi_{y}[m]=\frac{1}{N-(m-1)} \sum_{i=1}^{N-(m-1)} \phi_{y}[i, m]
$$

(b)

$$
\phi_{y}[i, m]=\frac{\left(\sum_{j=1}^{N-(m-1)} \sigma_{y}[i, j, m]\right)-1}{N-(m-1)}
$$

(c)

$$
\sigma_{y}[i, j, m]\left\{\begin{array}{l}
=1, \text { se } d_{y}[i, j, m] \leq r . s t d(x[n]) \\
=0, \text { se } d_{y}[i, j, m]>\operatorname{r.std}(x[n])
\end{array}\right.
$$

(d)

$$
d_{y}[i, j, m]=\max \left(\left|\boldsymbol{W}_{y}[i, m]-\boldsymbol{W}_{y}[j, m]\right|\right)
$$

(e)

$$
\boldsymbol{W}_{\boldsymbol{y}}[i, m]=\left[\begin{array}{c}
y[i] \\
\cdot \\
\cdot \\
\cdot \\
y[i+m-1]
\end{array}\right]
$$

$y[n]=$ sinal que se deseja calcular a SamEn.

$N=$ Número de amostras de $y[n]$. 
$3 \% Y(d t s)$ - Sinais $x[n]$ nas escalas dts $(0.03,0.06, \ldots, 0.330)$

4 : SamEn - sample entropia

$5 \quad \mathrm{CI}=\operatorname{sum}(\operatorname{SamEn}(\mathrm{Y}(\mathrm{dt} \mathrm{s})))$

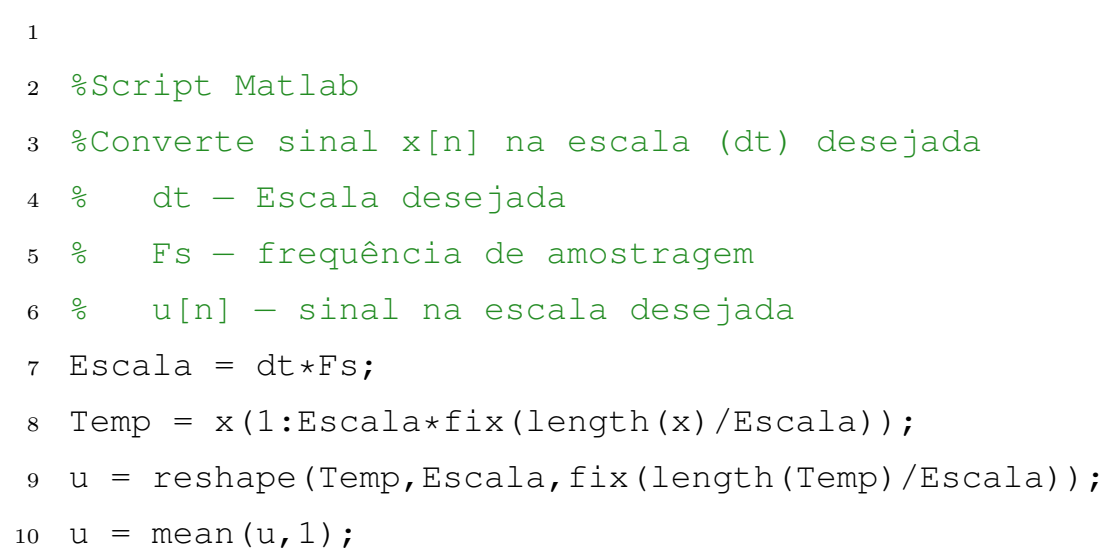




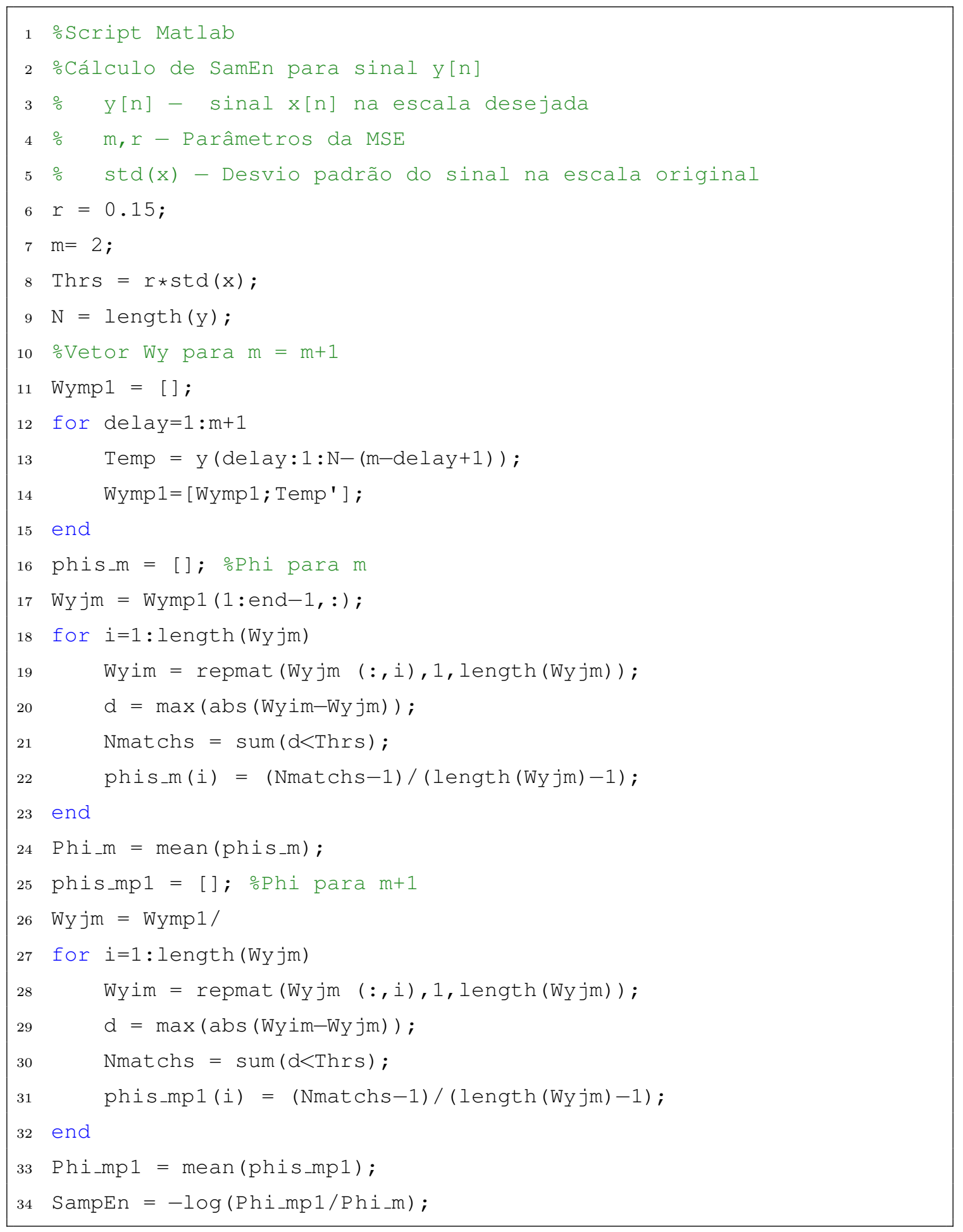

\subsubsection{Análise do protocolo experimental}

\subsubsection{Hipótese 5 - Efeito da tsDCS na PEO}

Os resultados experimentais foram pré-processados antes da análise estatística da seguinte forma: 
1. Remoção de valores outliers dos cinco valores de cada parâmetro obtidos em cada período to, t1 e t2 e protocolo de estimulação elétrica (Placebo, (A-T10,C-CiDeE) e (C-T10,A-CiDeE) de cada sujeito, pela regra 1,5 X faixa interquartil (IQR) (TUKEY, 1977).

2. Cálculo da média de cada parâmetro, após a remoção dos outliers, em cada período to, t1 e t2 e protocolo de estimulação elétrica (Placebo, (A-T10,C-CiDeE) e (CT10,A-CiDeE) de cada sujeito.

3. Remoção de sujeitos que apresentavam valores de média outliers, definidos pela regra 1,5 X $\mathrm{IQR}$, em pelo menos um protocolo de estimulação elétrica, em qualquer período, dos parâmetros $S D_{A P}$ ou $M V E L O_{A P}$.

A análise estatística dos resultados experimentais foi conduzida no software IBM SPSS Statistics 20 (IBM, EUA) de modo a verificar diferenças estatisticamente significativas das médias dos parâmetros obtidos do COP nos três períodos do protocolo de estimulação elétrica $\mathbf{t 0}, \mathbf{t 1} \mathrm{e} \mathbf{t 2})$ e nas três condições de protocolo de estimulação elétrica $(\mathbf{A - T 1 0 , C}-$ CiDeE), PLACEBO e (C-T10,A-CiDeE).

Após a verificação da normalidade, por meio do teste de Shapiro-Wilk, da esfericidade, por meio do teste de Mauchly, cada conjunto de parâmetros do COP foi submetido à análise de variância (ANOVA) de duas vias com fatores principais "Intervenção" (medidas repetidas, 3 níveis: (A-T10,C-CiDeE), PLACEBO ou (C-T10,A-CiDeE) e "Tempo" (medidas repetidas, 3 níveis: to, tr1 et t2 com nível de significância $p \leq 0,05$. Em casos em que a esfericidade foi significante $(p<0,05)$, foi utilizada a correção dos graus de liberdade de Greenhouse-Geisser para valores de $\epsilon$ menores do que 0,75 e a correção de Huynh-Feldt para valores de $\epsilon$ maiores do que 0,75 (FIELD, 2007).

O software de análise estatística também foi configurado para calcular os poderes estatísticos obtidos na análise de cada parâmetro e também o tamanho do efeito $\left(\eta_{p}^{2}\right)$ observado. Em análises em que o poder estatístico alcançado é maior do que 0,8, a ocorrência do erro do tipo II (não rejeição da hipótese nula em casos em que deveria ser rejeitada) é minimizada (FIELD, 2007). Valores de $\left(\eta_{p}^{2}\right)$ maiores do que 0,14 indicam tamanho do efeito grande (LAKENS, 2013), indicando que diferenças entre médias podem existir mesmo em situações em que o teste estatístico não apresenta resultado significativo $(p \leq 0,05)$.

Em parâmetros em que se observou a rejeição da hipótese nula foi conduzida uma análise post hoc de comparações de pares utilizando o procedimento de Bonferroni de modo a identificar as condições que apresentaram diferenças estatisticamente significativas (FI- 
ELD, 2007).

Tanto para parâmetros que apresentaram diferença significativa na ANOVA quanto para parâmetros calculados na direção AP que apresentaram valores de tamanho de efeito $\left(\eta_{p}^{2}\right)$ maiores do que 0,14 na iteração (Protocolo x Período), foram realizadas análises gráficas dos valores desses parâmetros nos diferentes protocolos de estimulação elétrica e períodos. 


\section{RESULTADOS}

\subsection{Resultados das simulações computacionais}

\subsubsection{Hipótese 1 - Utilização de um modelo computacional sim- plificado}

A utilização de um modelo computacional elaborado com o modelo de tronco humano simplificado resultou em uma estimativa do campo elétrico induzido na medula espinhal semelhante à obtida no modelo computacional com geometria de tronco humano complexa (FERNANDES et al., 2018), na configuração de tsDCS (MS-2) "Estimulação de 2,5 mA com Eletrodo de $25 \mathrm{~cm}^{2}$ sobre a vértebra T10 e eletrodo de $25 \mathrm{~cm}^{2}$ sobre a crista ilíaca direita" (Figura 51).

O módulo do campo elétrico estimado pelo modelo computacional simplificado, em média, não diferiu mais do que 8,45\% do estimado pelo modelo complexo (Figura 52).

Os campos elétricos nas direções AP (Figura 53) e ML (Figura 54) apresentaram módulos menores do que $0,15 \mathrm{~V} / \mathrm{m}$ ao longo da medula nos dois modelos.

O campo elétrico, na direção RC, estimado pelo modelo computacional simplificado, em média, não diferiu mais do que 11,9\% do estimado pelo modelo complexo (Figura 55).

O tamanho e localização da região da medula espinhal estimulada por um campo maior do que $0,15 \mathrm{~V} / \mathrm{m}$ não diferiu mais do que $7,5 \%$ nos dois modelos computacionais (Tabela 6).

Por meio dos resultados foi possível concluir que a hipótese de que, no processo de estimação do campo elétrico gerado na medula espinhal pela tsDCS, um modelo computacional elaborado com a geometria simplificada do tronco humano pode gerar resultados próximos aos de um modelo computacional desenvolvido com uma geometria mais complexa, é verdadeira. 


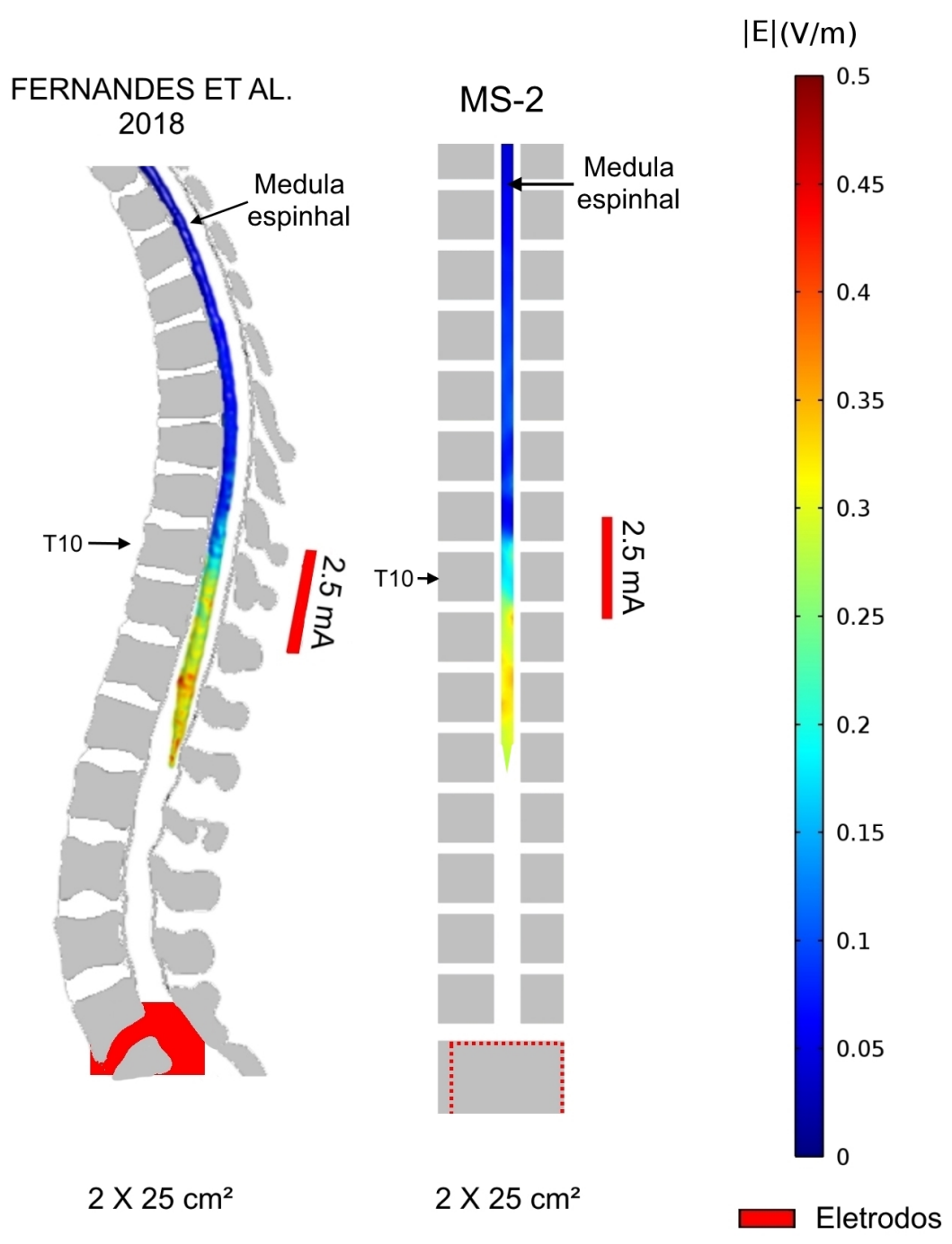

Figura 51: Representações dos módulos dos campos elétricos na medula espinhal obtidos por um modelo computacional complexo e pelo modelo computacional simplificado. À esquerda) Representação no plano sagital do módulo do campo elétrico obtido por um modelo computacional utilizando uma geometria complexa do tronco humano (FERNANDES et al., 2018) na configuração de tsDCS "Estimulação de 2,5 mA com Eletrodo de $25 \mathrm{~cm}^{2}$ sobre a vértebra T10 e eletrodo de $25 \mathrm{~cm}^{2}$ sobre a crista ilíaca direita". À direita) Representação no plano sagital do módulo do campo elétrico obtido pelo modelo computacional utilizando uma geometria simplificada do tronco humano, na mesma configuração de tsDCS (MS-2). 

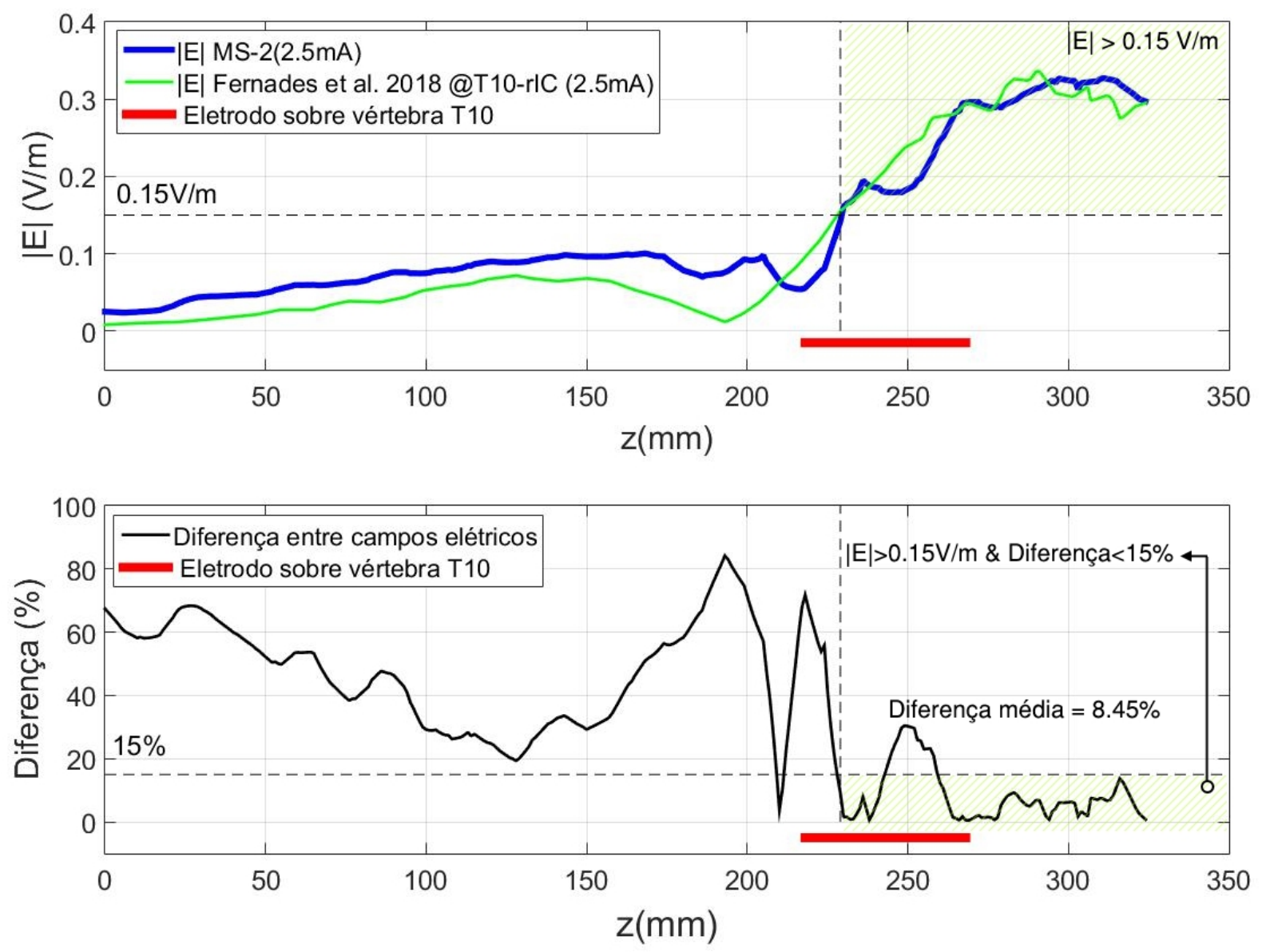

Figura 52: Módulo e diferença dos campos elétricos na medula espinhal, desde a altura da vértebra T2 $(Z=0 \mathrm{~mm})$ até a altura da vértebra $\mathrm{L} 1(\mathrm{Z}=324 \mathrm{~mm})$, obtidos pelo modelo computacional complexo (FERNANDES et al., 2018) e pelo modelo computacional simplificado na configuração de tsDCS "Estimulação de $2,5 \mathrm{~mA}$ com Eletrodo de $25 \mathrm{~cm}^{2}$ sobre a vértebra T10 e eletrodo de $25 \mathrm{~cm}^{2}$ sobre a crista ilíaca direita". Acima: Módulo dos campos elétricos obtidos no centro da medula espinhal pelo modelo computacional com geometria do tronco humano complexa e pelo modelo com geometria simplificada. A região do gráfico hachurada em verde claro corresponde à região da medula espinhal em que o módulo do campo elétrico, obtido pelo modelo de tronco humano com geometria complexa, é maior do que $0,15 \mathrm{~V} / \mathrm{m}$ Abaixo: Diferença, em porcentagem em relação ao modelo complexo, dos módulos do campo elétrico obtido no modelo complexo e no modelo simplificado. A região do gráfico hachurada em verde claro corresponde à região da medula espinhal em que o módulo do campo elétrico, obtido pelo modelo de tronco humano com geometria complexa, é maior do que $0,15 \mathrm{~V} / \mathrm{m}$ e apresenta diferença menor do que $15 \%$. 


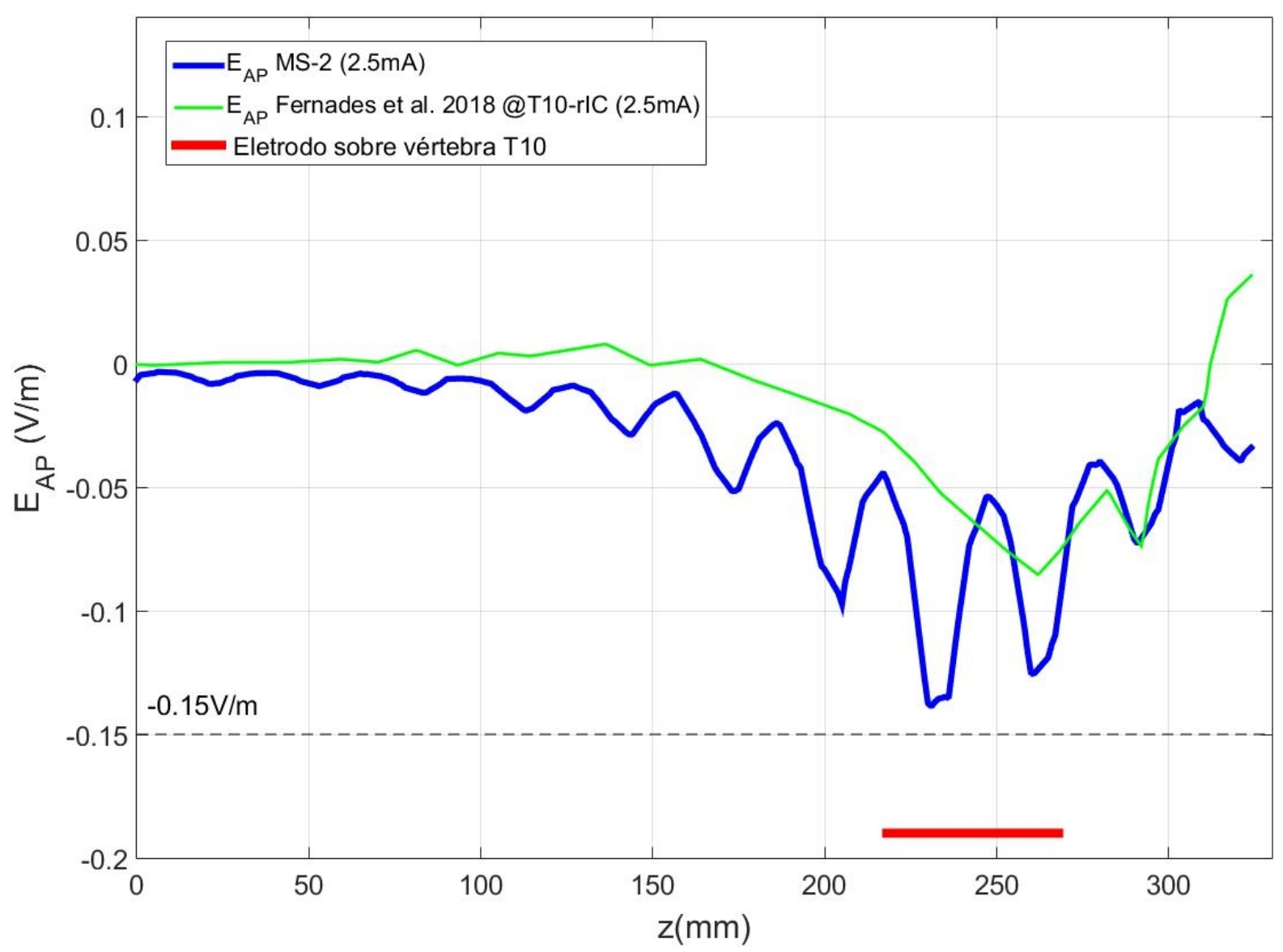

Figura 53: Valor dos campos elétricos, na direção AP, no centro da medula espinhal, desde a altura da vértebra $\mathrm{T} 2(\mathrm{Z}=0 \mathrm{~mm})$ até a altura da vértebra $\mathrm{L1}(\mathrm{Z}=324 \mathrm{~mm})$, obtido pelo modelo computacional com geometria do tronco humano complexa e pelo modelo com geometria simplificada (MS-2) na configuração de tsDCS "Estimulação de 2,5 mA com Eletrodo de $25 \mathrm{~cm}^{2}$ sobre a vértebra T10 e eletrodo de $25 \mathrm{~cm}^{2}$ sobre a crista ilíaca direita". 


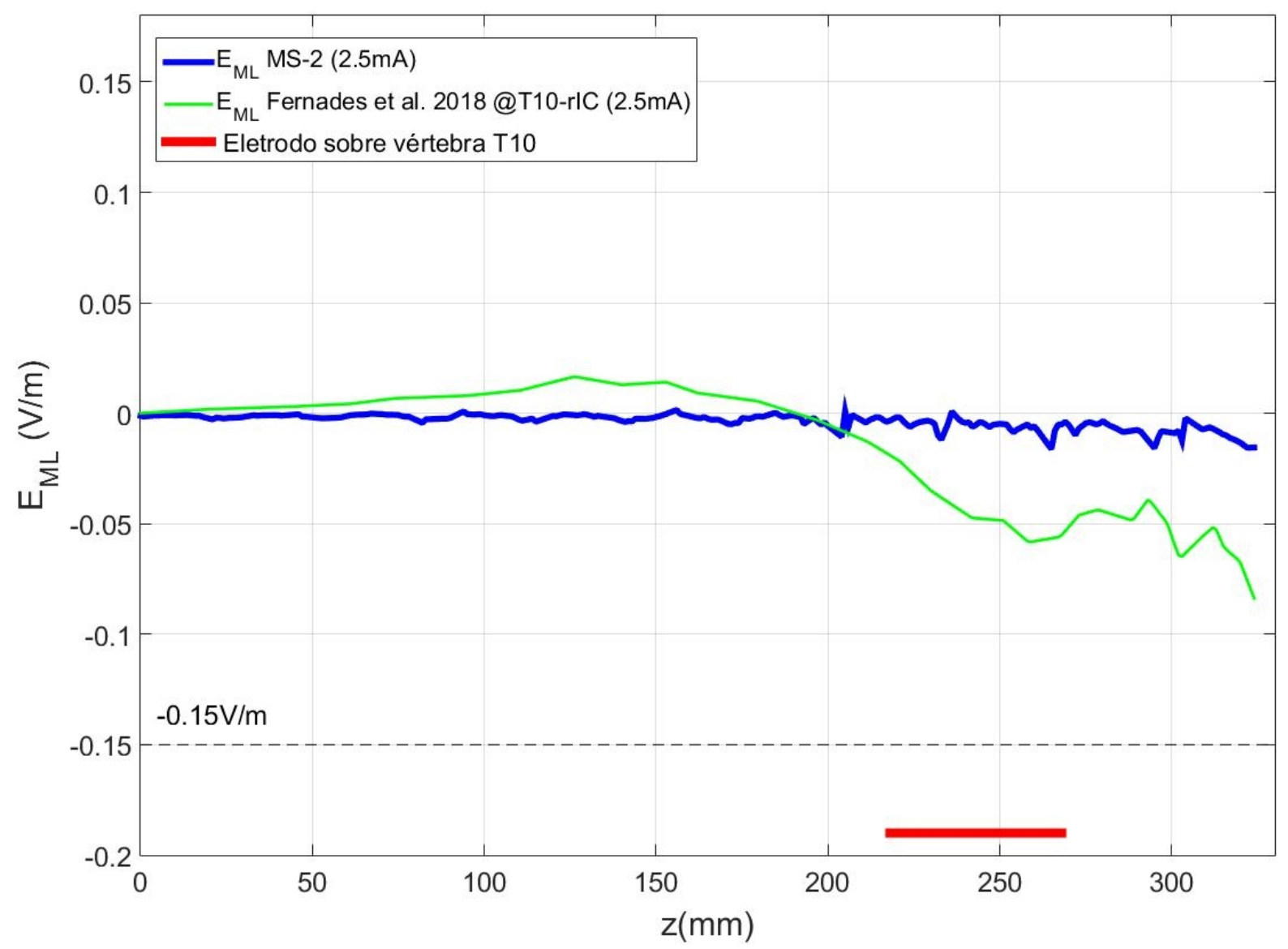

Figura 54: Valor dos campos elétricos, na direção ML, no centro da medula espinhal, desde a altura da vértebra $\mathrm{T} 2(\mathrm{Z}=0 \mathrm{~mm})$ até a altura da vértebra $\mathrm{L} 1(\mathrm{Z}=324 \mathrm{~mm})$, obtido pelo modelo computacional com geometria do tronco humano complexa (FERNANDES et al. 2018) e pelo modelo com geometria simplificada (MS-2) na configuração de tsDCS "Estimulação de 2,5 mA com Eletrodo de $25 \mathrm{~cm}^{2}$ sobre a vértebra T10 e eletrodo de 25 $\mathrm{cm}^{2}$ sobre a crista ilíaca direita". 

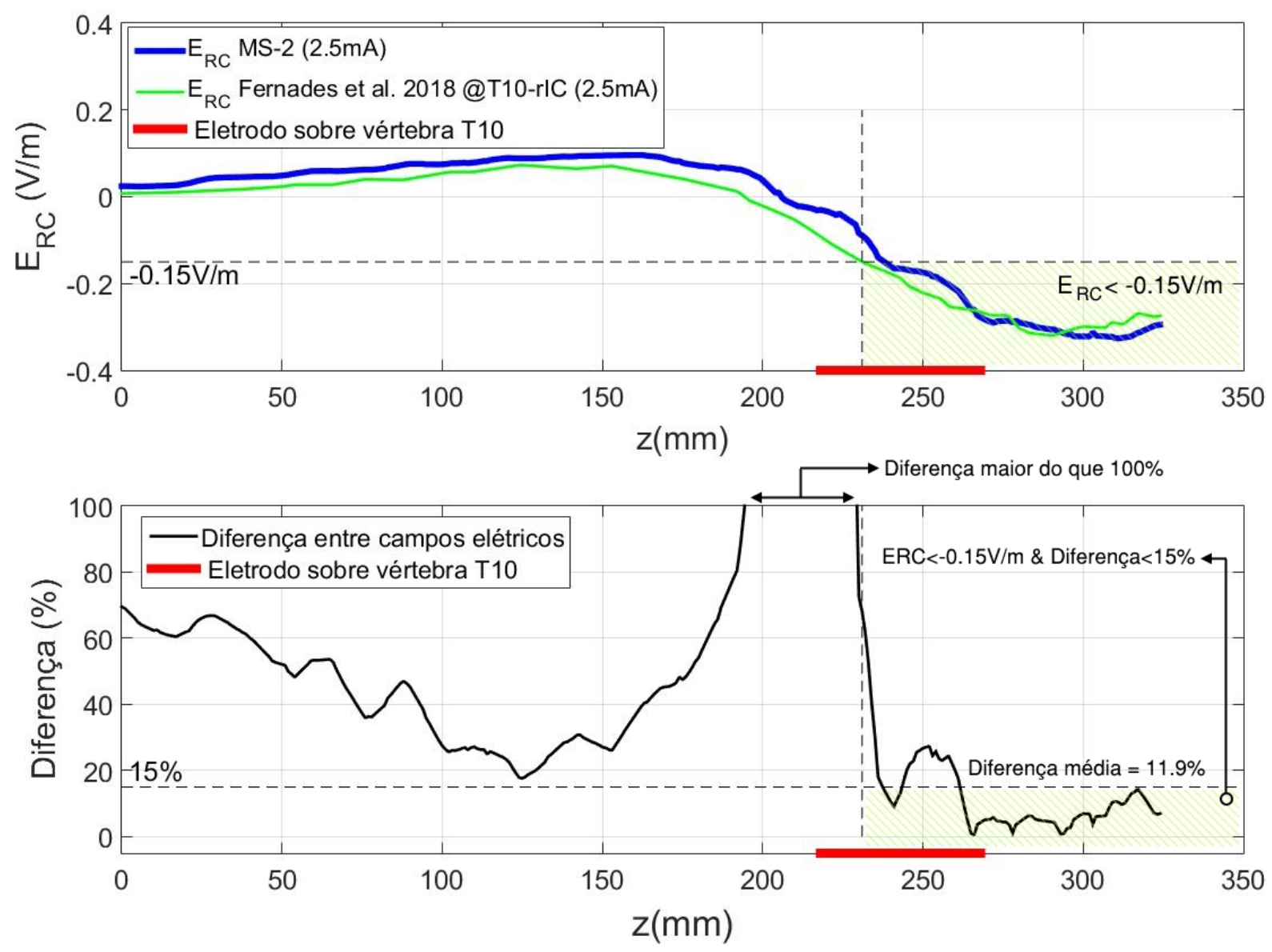

Figura 55: Valor e diferença dos valores dos campos elétricos, na direção RC, no centro da medula espinhal, desde a altura da vértebra T2 $(\mathrm{Z}=0 \mathrm{~mm})$ até a altura da vértebra L1 $(\mathrm{Z}=324 \mathrm{~mm})$, obtidos pelo modelo computacional complexo (FERNANDES et al. 2018) e pelo modelo computacional simplificado na configuração de tsDCS "Estimulação de 2,5 $m A$ com Eletrodo de $25 \mathrm{~cm}^{2}$ sobre a vértebra T10 e eletrodo de $25 \mathrm{~cm}^{2}$ sobre a crista ilíaca direita". Acima: Valor dos campos elétricos, na direção RC, obtido no centro da medula espinhal pelo modelo computacional complexo e pelo modelo com geometria simplificada MS-2). Abaixo: Diferença absoluta, em porcentagem em relação ao modelo complexo, do valor do campo elétrico obtido no modelo complexo e no modelo simplificado. Nota-se que para valores de campo elétrico próximos a $0 \mathrm{~V} / \mathrm{m}$, o valor da diferença entre os campos aumenta drasticamente pois ocorre a divisão matemática por um valor quase nulo. 
Tabela 6: Tamanho e localização da região da medula espinhal estimulada com campo elétrico maior do que $0,15 \mathrm{~V} / \mathrm{m}$ obtidos por um modelo computacional complexo (FERNANDES et al., 2018) e pelo modelo computacional simplificado na configuração de tsDCS MS-2 "Estimulação de 2,5 mA com eletrodo de $25 \mathrm{~cm}^{2}$ sobre a vértebra T10 e eletrodo de $25 \mathrm{~cm}^{2}$ sobre a crista ilíaca direita”. Início $(\mathrm{mm})$ : Início da região da medula com campo elétrico maior do que $0,15 \mathrm{~V} / \mathrm{m}$, calculado à partir da vértebra T2. Fim (mm): Término da região da medula com campo elétrico maior do que $0,15 \mathrm{~V} / \mathrm{m}$, calculado à partir da vértebra T2, Tamanho $(\mathrm{mm})=(\mathbf{F i m}(\mathrm{mm})$ - Início $(\mathrm{mm}))$. Diferença $=$ 100x ((FERNANDES et al.- MS-2)/(FERNANDES et al. $))$. $|E|$ - Parâmetros obtidos da análise do módulo do campo elétrico. $\left|E_{R C}\right|$ - Parâmetros obtidos da análise do campo elétrico na direção $\mathrm{RC}$.

\begin{tabular}{|c|c|c|c|c|c|}
\hline & \multicolumn{4}{|c|}{$\begin{array}{c}\text { Região da medula estimulada } \\
\text { com campo elétrico maior do que } \\
0,15 \mathrm{~V} / \mathrm{m}\end{array}$} \\
\hline & & Início & Fim & Tamanho & Figura \\
\hline \multirow{3}{*}{$|E|$} & MS-2 & $229 \mathrm{~mm}$ & $324 \mathrm{~mm}$ & $95 \mathrm{~mm}$ & \multirow{3}{*}{52} \\
\hline & FERNANDES et al. & $228 \mathrm{~mm}$ & $324 \mathrm{~mm}$ & $96 \mathrm{~mm}$ & \\
\hline & Diferença & $0,4 \%$ & $0 \%$ & $1 \%$ & \\
\hline \multirow{3}{*}{$E_{R C}$} & MS-2 & $238 \mathrm{~mm}$ & $324 \mathrm{~mm}$ & $86 \mathrm{~mm}$ & \multirow{3}{*}{55} \\
\hline & FERNANDES et al. & $231 \mathrm{~mm}$ & $324 \mathrm{~mm}$ & $93 \mathrm{~mm}$ & \\
\hline & Diferença & $3 \%$ & $0 \%$ & $7,5 \%$ & \\
\hline
\end{tabular}




\subsubsection{Hipótese 2 - Adição de um terceiro eletrodo}

A análise do modelo computacional simplificado nas configurações MS-2 e MS-3 revelou que a adição de um terceiro eletrodo de $25 \mathrm{~cm}^{2}$ posicionado sobre a crista ilíaca esquerda, conectado eletricamente ao eletrodo posicionado sobre a crista ilíaca direita, na configuração "Um eletrodo de $25 \mathrm{~cm}^{2}$ sobre T10 e um eletrodo de $25 \mathrm{~cm}^{2}$ sobre a crista ilíaca direita" não alterou de forma significativa o campo elétrico produzido ao longo da medula espinhal (Figura 56).

A adição do terceiro eletrodo produziu diferença média entre os módulos de campos elétricos, em regiões com intensidades de campos elétricos maiores do que $0,15 \mathrm{~V} / \mathrm{m}$, de $1,04 \%$ (Figura 57 ).

Os campos elétricos nas direções AP (Figura 58) e ML (Figura 59) apresentaram módulos menores do que $0,15 \mathrm{~V} / \mathrm{m}$ ao longo da medula nas duas configurações.

O campo elétrico, na direção $\mathrm{RC}$, em média, não diferiu nas duas configurações mais do que $1,23 \%$ (Figura 60).

O tamanho e localização da região da medula espinhal estimulada por um campo maior do que $0,15 \mathrm{~V} / \mathrm{m}$ não apresentou diferenças significativas (Tabela 7 ).

Por meio dos resultados obtidos foi possível concluir que a hipótese de que a adição de um terceiro eletrodo de $25 \mathrm{~cm}^{2}$, posicionado sobre a crista ilíaca esquerda, conectado eletricamente ao eletrodo da crista ilíıaca direita, não modifica significativamente o campo elétrico gerado na medula espinhal, é verdadeira. 


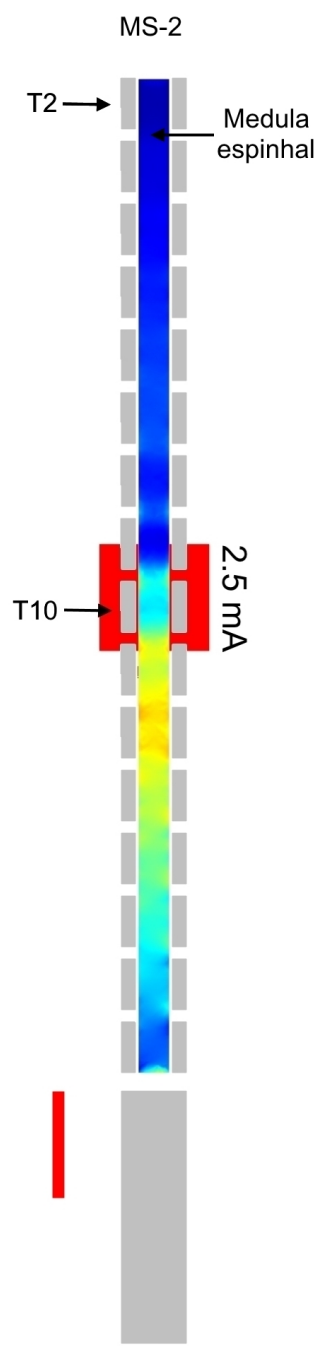

$2 \times 25 \mathrm{~cm}^{2}$

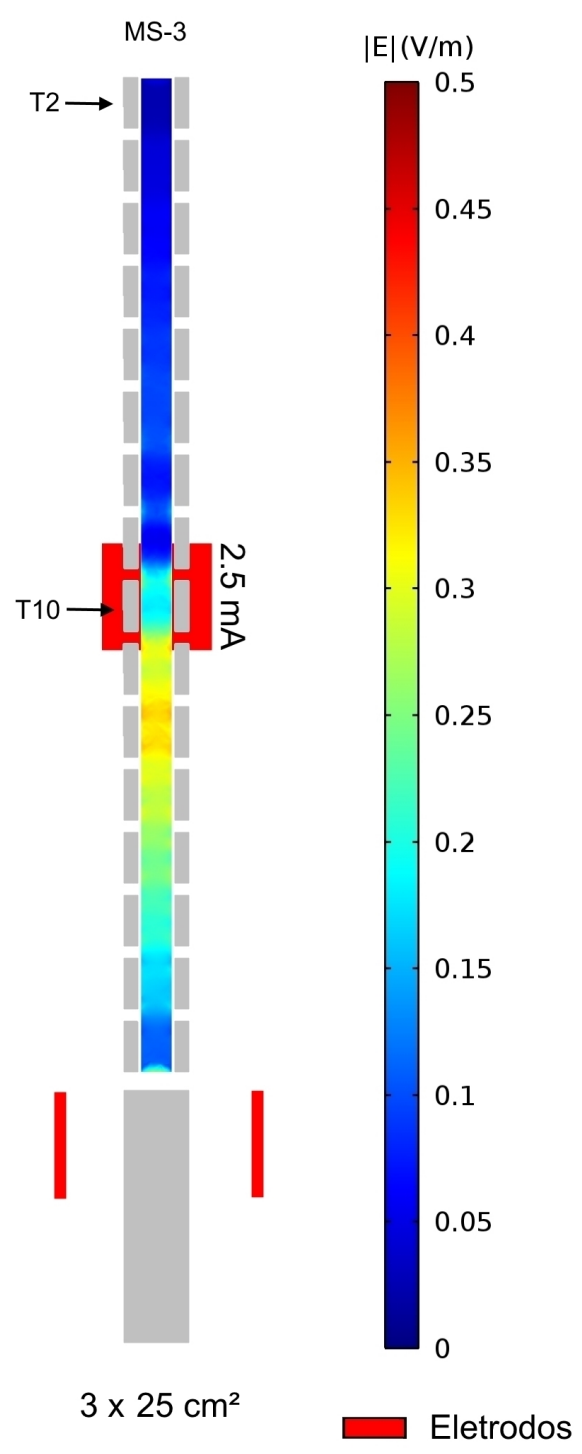

Figura 56: Representações dos módulos dos campos elétricos na medula espinhal obtidos no modelo computacional simplificado nas configurações MS-2 e MS-3. À esquerda) Representação no plano sagital do módulo do campo elétrico obtido no modelo simplificado na configuração MS-2 (Um eletrodo de $25 \mathrm{~cm}^{2}, 5 \mathrm{~cm}$ x $5 \mathrm{~cm}$, sobre T10 e um eletrodo de $25 \mathrm{~cm}^{2}, 5 \mathrm{~cm} \times 5 \mathrm{~cm}$, sobre a crista ilíaca direita e corrente de estimulação de $2,5 \mathrm{~mA}$ ). À direita) Representação no plano sagital do módulo do campo elétrico obtido no modelo simplificado na configuração MS-3 (Um eletrodo de $25 \mathrm{~cm}^{2}, 5 \mathrm{~cm}$ x $5 \mathrm{~cm}$, sobre T10 e dois eletrodos de $25 \mathrm{~cm}^{2}, 5 \mathrm{~cm} \mathrm{x} 5 \mathrm{~cm}$, sobre a crista ilíaca direita e sobre a crista ilíaca esquerda e corrente de estimulação de $2,5 \mathrm{~mA}$ ). 

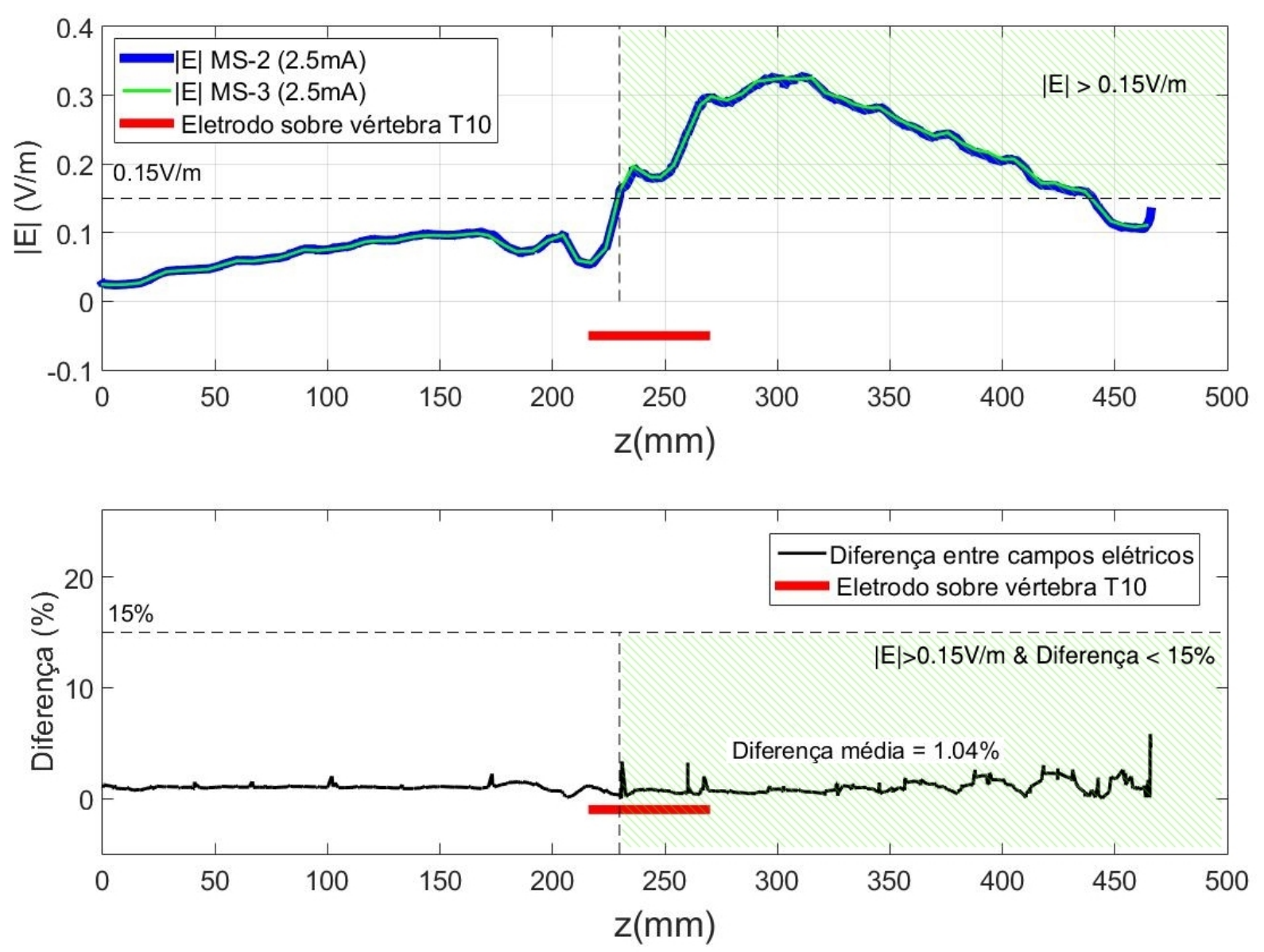

Figura 57: Módulo e diferença dos campos elétricos na medula espinhal, desde a altura da vértebra $\mathrm{T} 2(\mathrm{Z}=0 \mathrm{~mm})$ até a altura da vértebra $\mathrm{L} 5(\mathrm{Z} \approx 465 \mathrm{~mm})$, obtidos no modelo simplificado nas configurações MS-2 e MS-3 e estimulação de 2,5 mA. Acima: Módulo dos campos elétricos obtidos no centro da medula espinhal pelo modelo simplificado nas duas configurações. A região do gráfico hachurada em verde claro corresponde à região da medula espinhal em que o módulo do campo elétrico, obtido pelo modelo simplificado na configuração MS-2, é maior do que 0,15 V/m Abaixo: Diferença, em porcentagem em relação ao modelo simplificado na configuração MS-2, dos módulos do campo elétrico obtidos na configuração MS-3 e MS-2, A região do gráfico hachurada em verde claro corresponde à região da medula espinhal em que o módulo do campo elétrico, obtido na configuração MS-2, é maior do que $0,15 \mathrm{~V} / \mathrm{m}$ e apresenta diferença menor do que $15 \%$. 


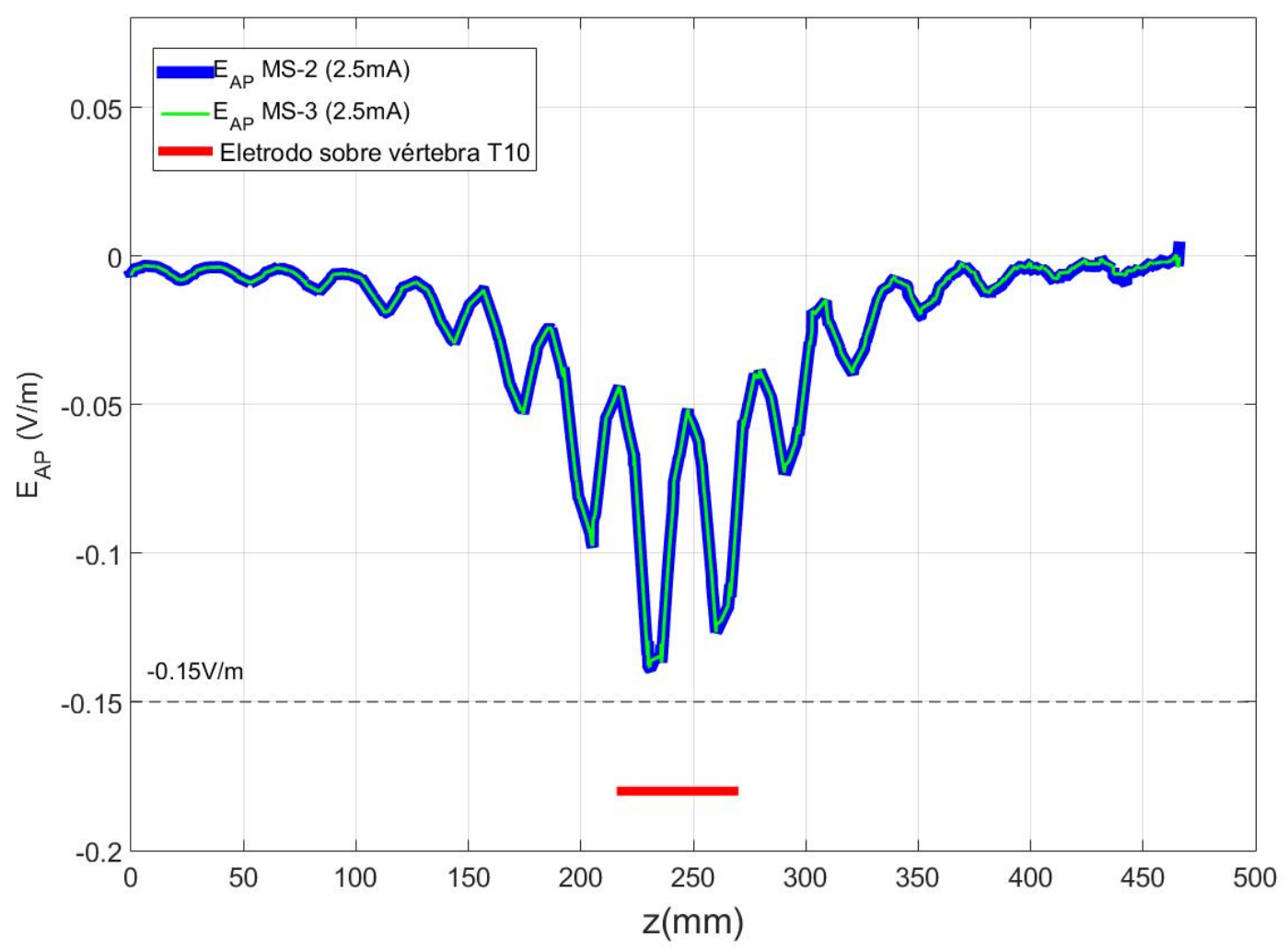

Figura 58: Valor dos campos elétricos, na direção AP, no centro da medula espinhal, desde a altura da vértebra $\mathrm{T} 2(\mathrm{Z}=0 \mathrm{~mm})$ até a altura da vértebra $\mathrm{L} 5(\mathrm{Z} \approx 465 \mathrm{~mm})$, obtido no modelo simplificado nas configurações MS-2 e MS-3. 


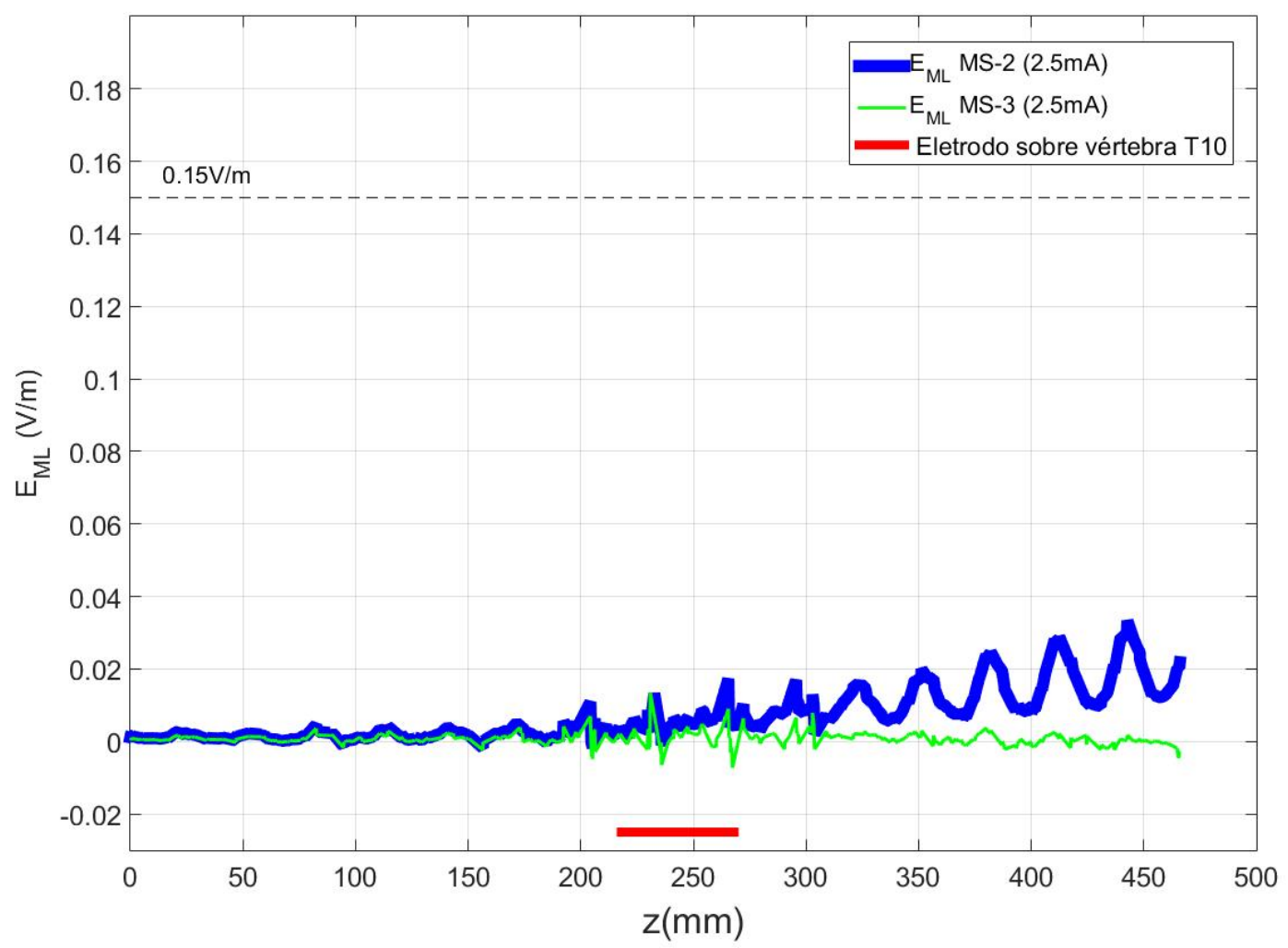

Figura 59: Valor dos campos elétricos, na direção ML, no centro da medula espinhal, desde a altura da vértebra $\mathrm{T} 2(\mathrm{Z}=0 \mathrm{~mm})$ até a altura da vértebra $\mathrm{L} 5(\mathrm{Z} \approx 465 \mathrm{~mm})$, obtido no modelo simplificado nas configurações MS-2 e MS-3. 

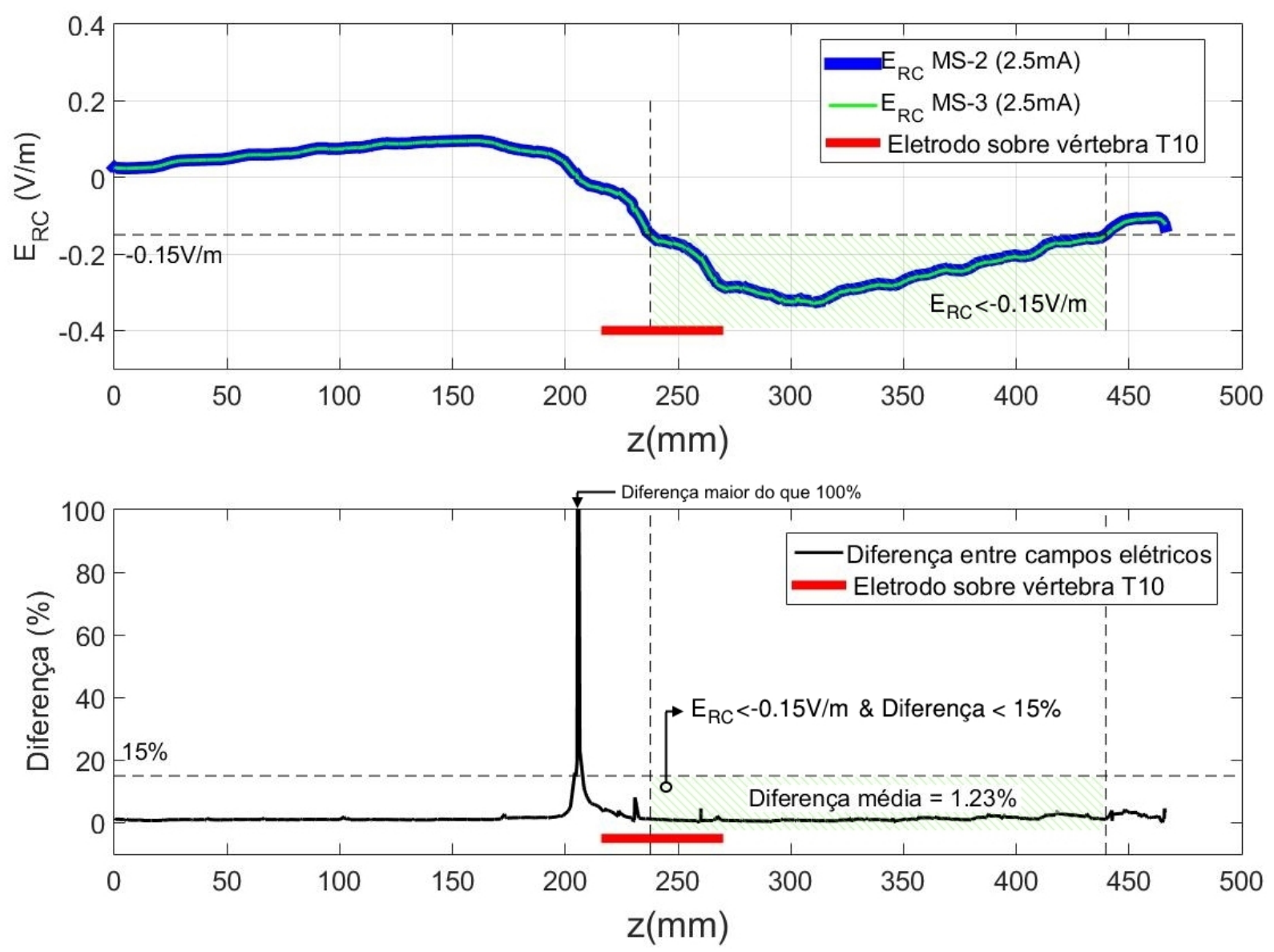

Figura 60: Valor e diferença dos valores dos campos elétricos, na direção RC, no centro da medula espinhal, desde a altura da vértebra T2 $(\mathrm{Z}=0 \mathrm{~mm})$ até a altura da vértebra L5 ( $\mathrm{Z} \approx 465 \mathrm{~mm}$ ), obtidos no modelo simplificado nas configurações MS-2 e MS-3. Acima: Valor dos campos elétricos, na direção RC, obtido no centro da medula espinhal pelo modelo computacional simplificado nas configurações MS-2 e MS-3. Abaixo: Diferença absoluta, em porcentagem em relação à configuração MS-2, do valor do campo elétrico obtido na configuração MS-3 e na configuração MS-2. Nota-se que para valores de campo elétrico próximos a $0 \mathrm{~V} / \mathrm{m}$, o valor da diferença entre os campos aumenta drasticamente pois ocorre a divisão matemática por um valor quase nulo. 
Tabela 7: Tamanho e localização da região da medula espinhal estimulada com campo elétrico maior do que $0,15 \mathrm{~V} / \mathrm{m}$ obtidos pelo modelo computacional simplificado nas configurações MS-2 e MS-3. Início(mm): Início da região da medula com campo elétrico maior do que $0,15 \mathrm{~V} / \mathrm{m}$, calculado à partir da vértebra T2, $\mathbf{F i m}(\mathrm{mm})$ : Término da região da medula com campo elétrico maior do que $0,15 \mathrm{~V} / \mathrm{m}$, calculado à partir da vértebra T2. $\operatorname{Tamanho}(\mathrm{mm})=(\boldsymbol{F i m}(\mathrm{mm})-\operatorname{In} \mathbf{c}$ cio $(\mathrm{mm}))$. Diferença $=100 \mathrm{x}(\mathrm{MS}-3$ - MS-2 $)$ MS-2 . $|E|$ - Parâmetros obtidos da análise do módulo do campo elétrico. $\left|E_{R C}\right|$ - Parâmetros obtidos da análise do campo elétrico na direção RC.

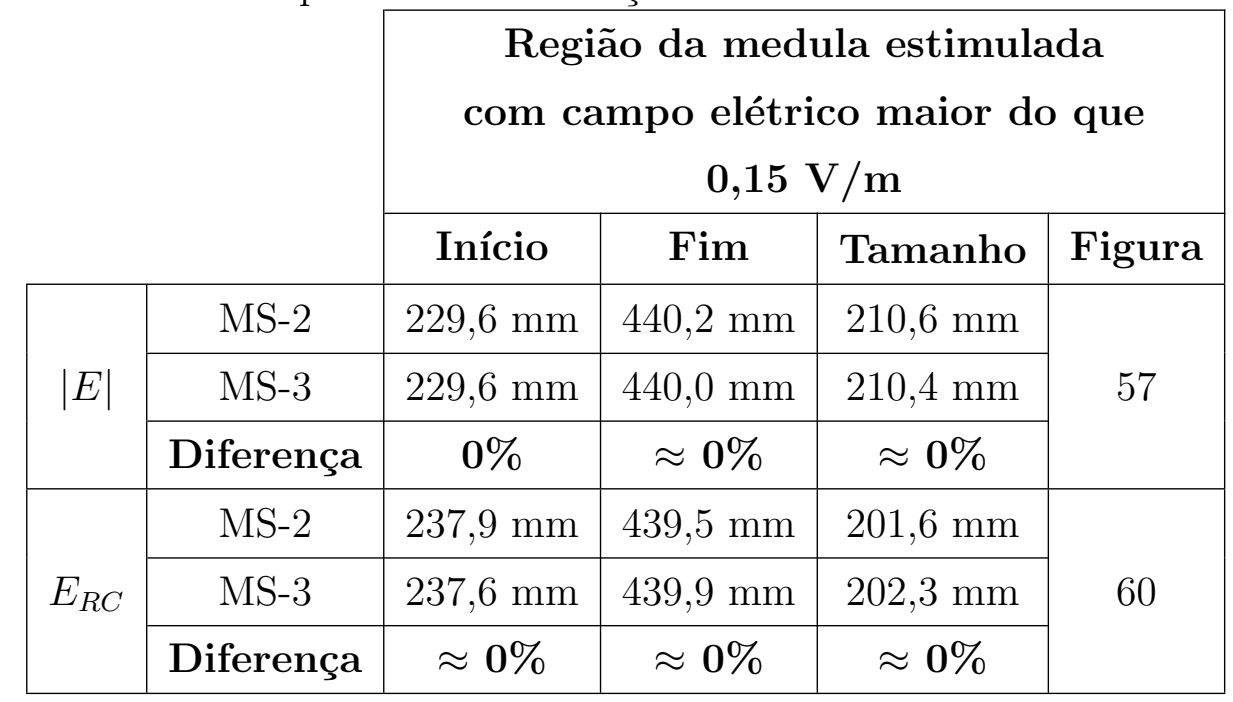

\subsubsection{Hipótese 3 - Aumento da dimensão do eletrodo}

A análise do modelo computacional simplificado nas configurações MS-3 e MS-EXP revelou que o aumento da dimensão dos eletrodos para $50 \mathrm{~cm}^{2}$, na configuração " $U m$ eletrodo de $25 \mathrm{~cm}^{2}$ sobre T10 e dois eletrodos de $25 \mathrm{~cm}^{2}$ sobre a crista ilíaca direita e sobre a crista ilíaca esquerda" não alterou de forma significativa o campo elétrico produzido ao longo da medula espinhal (Figura 61).

O aumento da dimensão dos eletrodos produziu diferença média dos módulos de campos elétricos, em regiões com intensidades de campos elétricos maiores do que 0,15 V/m, de $4,69 \%$ (Figura 62).

Os campos elétricos nas direções AP (Figura 63) e ML (Figura 64) apresentaram módulos menores do que $0,15 \mathrm{~V} / \mathrm{m}$ ao longo da medula nas duas configurações.

O campo elétrico, na direção RC, em média, não diferiu nas duas configurações mais do que $5.1 \%$ (Figura 65).

O tamanho e localização da região da medula espinhal estimulada por um campo maior do que $0,15 \mathrm{~V} / \mathrm{m}$ não apresentou diferenças significativas (Tabela 8). 
Por meio dos resultados obtidos foi possível concluir que a hipótese de que a utilização de eletrodos de maior dimensão $\left(50 \mathrm{~cm}^{2}, 10 \mathrm{~cm}\right.$ x $\left.5 \mathrm{~cm}\right)$ na configuração "um eletrodo sobre a vértebra T10, um eletrodo sobre a crista ilíaca direita e um eletrodo sobre a crista ilíaca esquerda, estimulação de 2,5 mA”, pode permitir que uma região maior da medula espinal seja estimulada por um campo elétrico de no mínimo $0,15 \mathrm{~V} / \mathrm{m}$, em comparação com a utilização de eletrodos de menor dimensão $\left(25 \mathrm{~cm}^{2}, 5 \mathrm{~cm} \mathrm{x} 5 \mathrm{~cm}\right)$, não é verdadeira. 


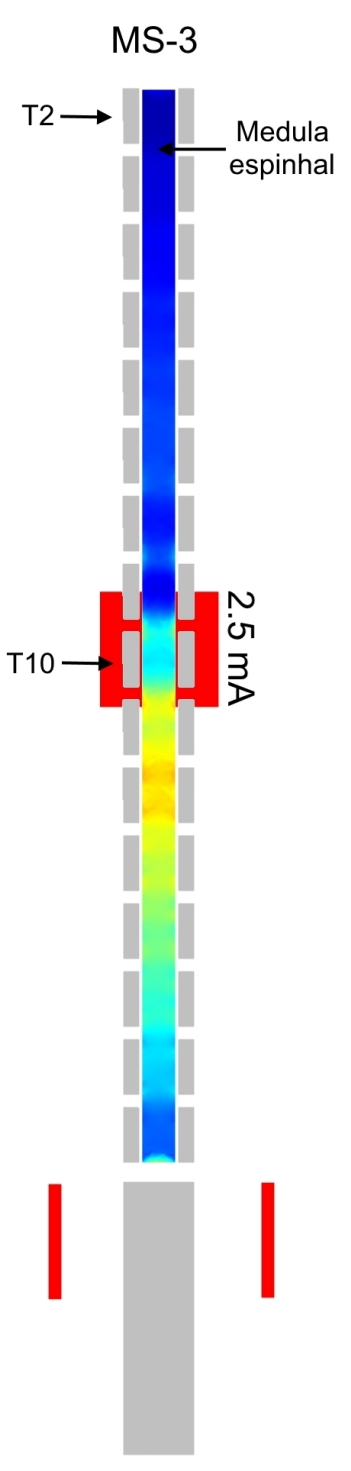

$3 \times 25 \times m^{2}$

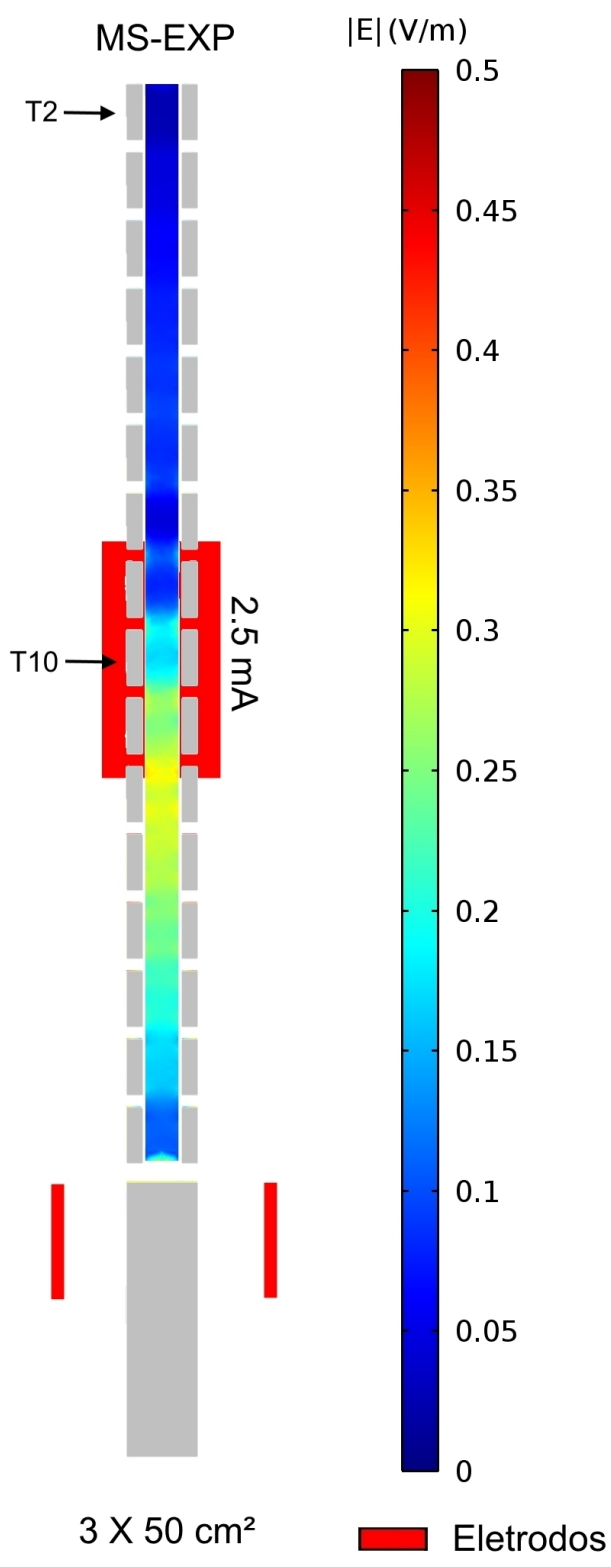

Figura 61: Representações dos módulos dos campos elétricos na medula espinhal obtidos no modelo computacional simplificado nas configurações MS-3 e MS-EXP. À esquerda) Representação no plano sagital do módulo do campo elétrico obtido no modelo simplificado na configuração MS-3 (Um eletrodo de $25 \mathrm{~cm}^{2}, 5 \mathrm{~cm}$ x $5 \mathrm{~cm}$, sobre T10 dois eletrodos de $25 \mathrm{~cm}^{2}, 5 \mathrm{~cm} \times 5 \mathrm{~cm}$, sobre a crista ilíaca direita e sobre a crista ilíaca esquerda e corrente de estimulação de 2,5 mA). À direita) Representação no plano sagital do módulo do campo elétrico obtido no modelo simplificado na configuração MS-EXP (Um eletrodo de $50 \mathrm{~cm}^{2}, 10 \mathrm{~cm} \mathrm{x} 5 \mathrm{~cm}$, sobre T10 e dois eletrodos de $50 \mathrm{~cm}^{2}, 10 \mathrm{~cm} \mathrm{x} 5 \mathrm{~cm}$, sobre a crista ilíaca direita e sobre a crista ilíaca esquerda e corrente de estimulação de 2,5 mA). 

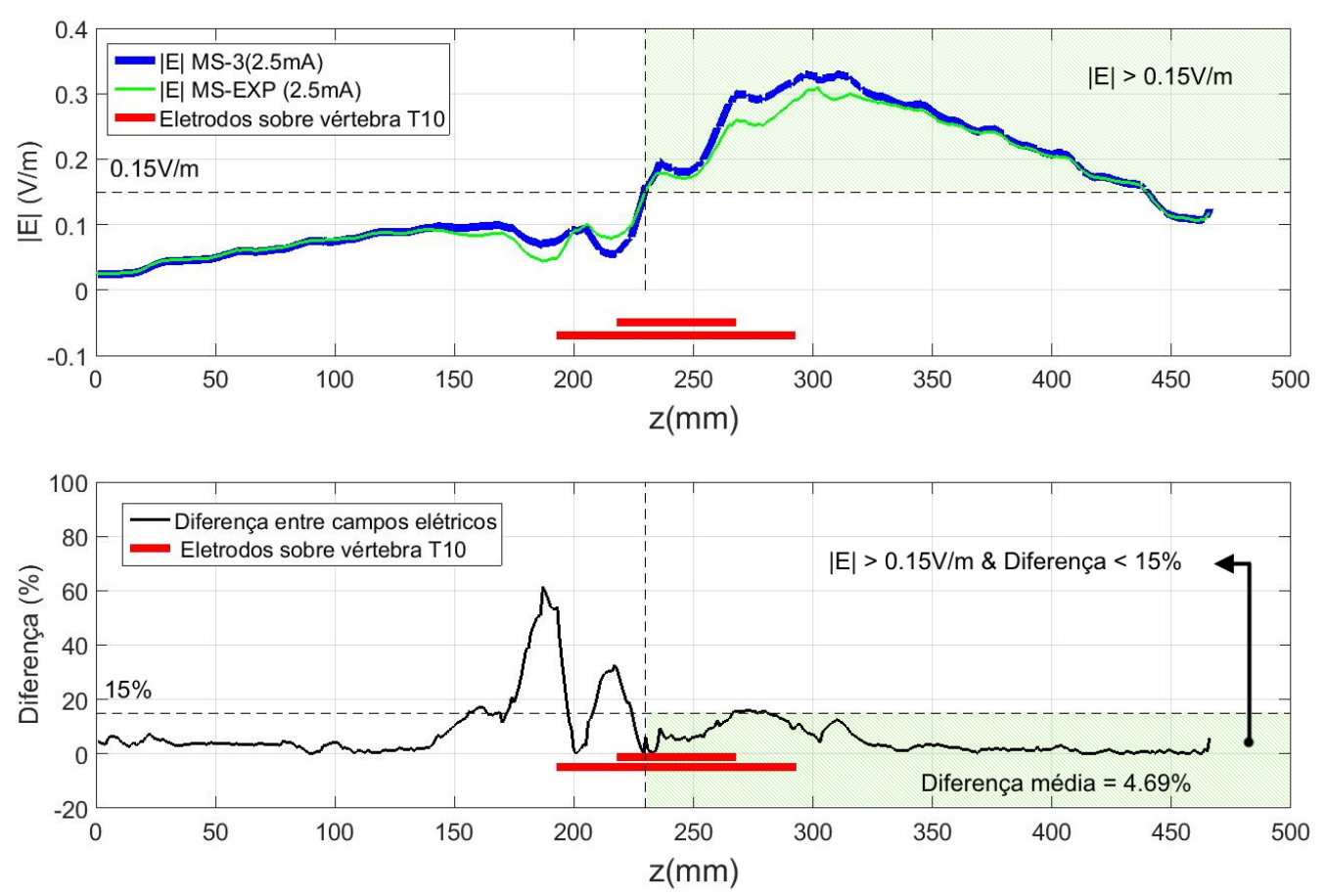

Figura 62: Módulo e diferença dos campos elétricos na medula espinhal, desde a altura da vértebra $\mathrm{T} 2(\mathrm{Z}=0 \mathrm{~mm})$ até a altura da vértebra $\mathrm{L5}(\mathrm{Z} \approx 465 \mathrm{~mm})$, obtidos no modelo computacional simplificado nas configurações MS-3 e MS-EXP e estimulação de 2,5 mA. Acima: Módulo dos campos elétricos obtidos no centro da medula espinhal pelo modelo simplificado nas duas configurações. A região do gráfico hachurada em verde claro corresponde à região da medula espinhal em que o módulo do campo elétrico, obtido pelo modelo simplificado na configuração MS-3, é maior do que 0,15 V/m Abaixo: Diferença, em porcentagem em relação ao modelo simplificado na configuração MS-3, dos módulos do campo elétrico obtidos na configuração MS-EXP e MS-3. A região do gráfico hachurada em verde claro corresponde à região da medula espinhal em que o módulo do campo elétrico, obtido na configuração MS-3, é maior do que $0,15 \mathrm{~V} / \mathrm{m}$ e apresenta diferença menor do que $15 \%$. 


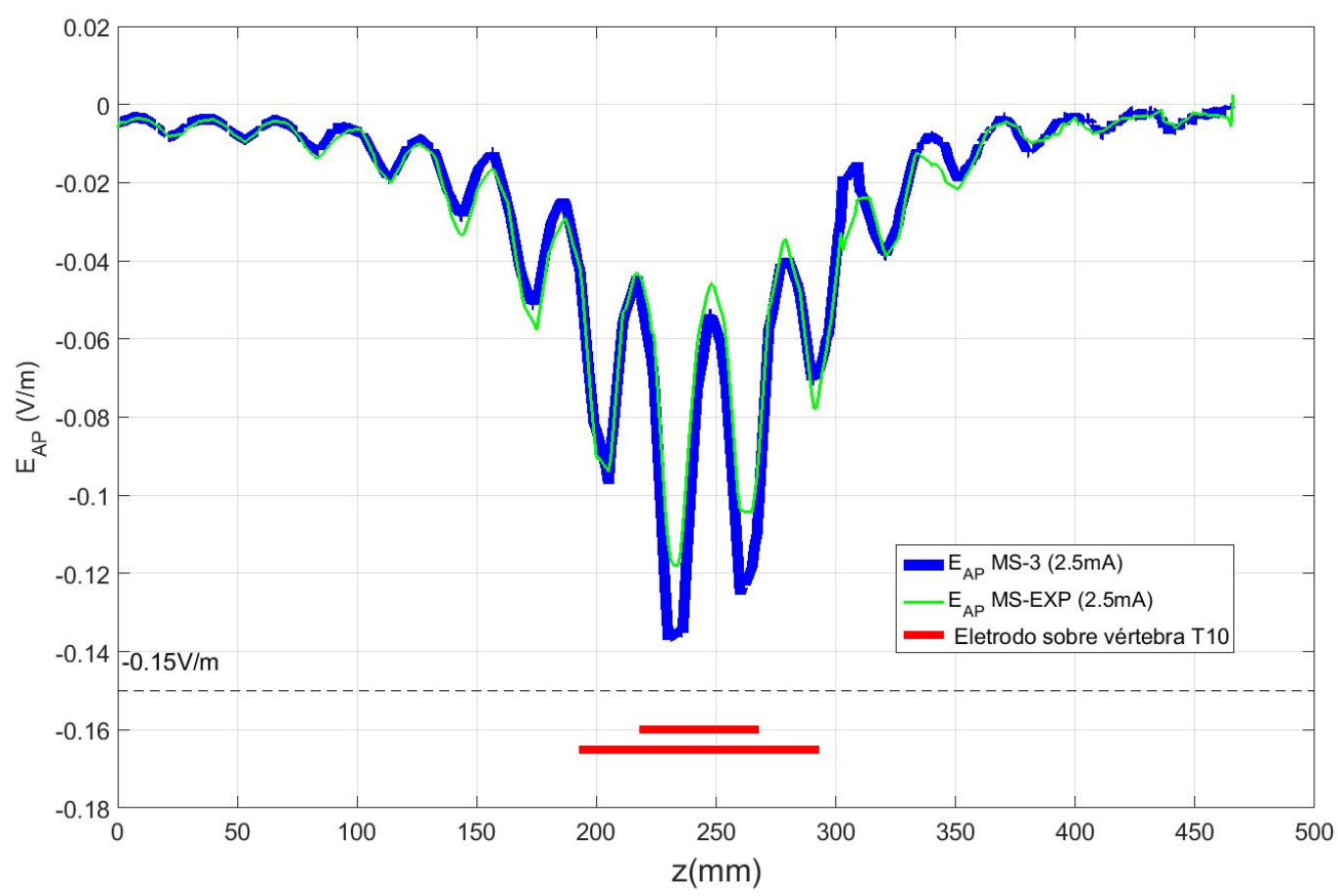

Figura 63: Valor dos campos elétricos, na direção AP, no centro da medula espinhal, desde a altura da vértebra $\mathrm{T} 2(\mathrm{Z}=0 \mathrm{~mm})$ até a altura da vértebra $\mathrm{L} 5(\mathrm{Z} \approx 465 \mathrm{~mm})$, obtido no modelo simplificado nas configurações MS-3 e MS-EXP. 


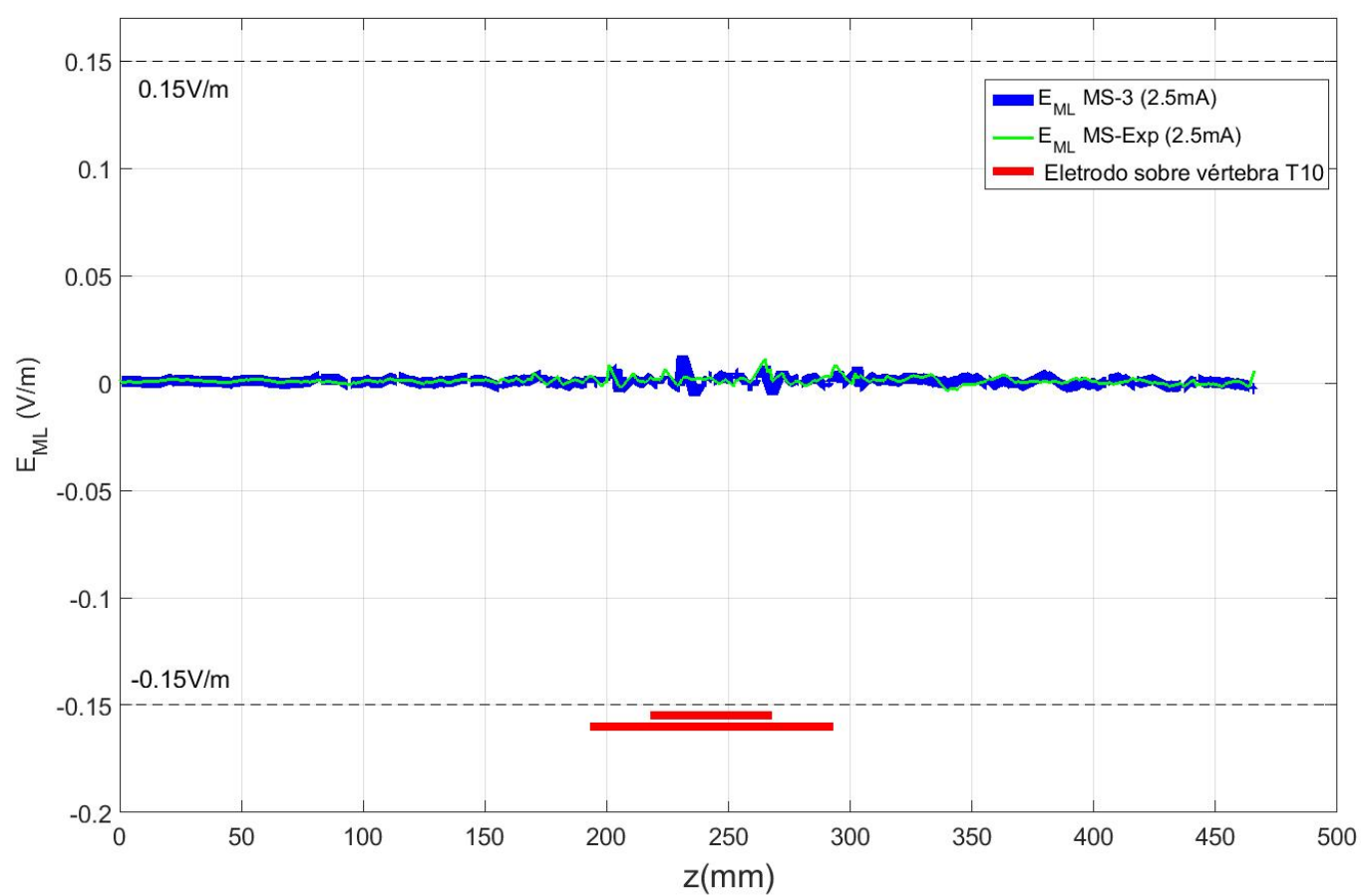

Figura 64: Valor dos campos elétricos, na direção ML, no centro da medula espinhal, desde a altura da vértebra $\mathrm{T} 2(\mathrm{Z}=0 \mathrm{~mm})$ até a altura da vértebra $\mathrm{L} 5(\mathrm{Z} \approx 465 \mathrm{~mm})$, obtido no modelo simplificado nas configurações MS-3 e MS-EXP. 

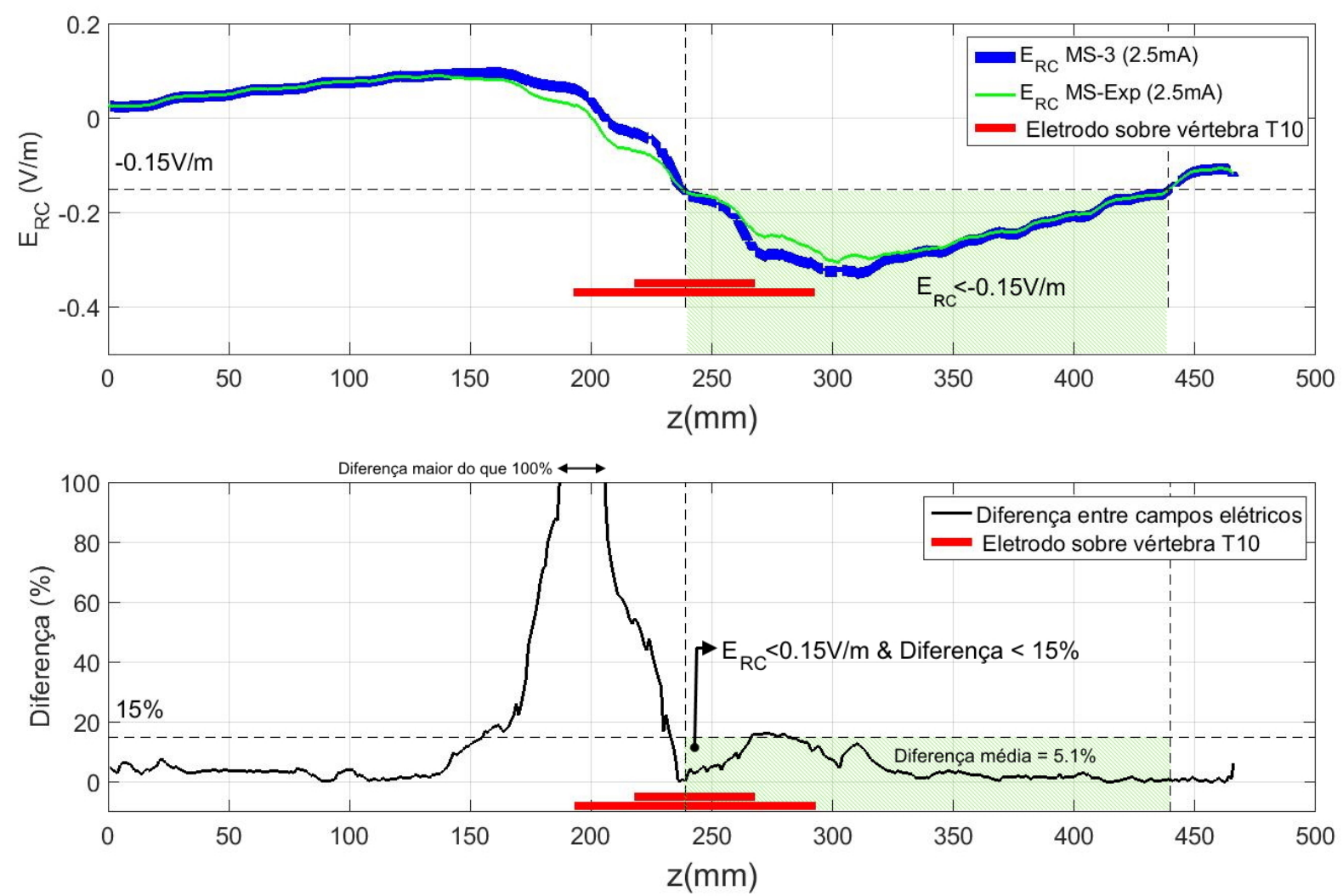

Figura 65: Valor e diferença dos valores dos campos elétricos, na direção RC, no centro da medula espinhal, desde a altura da vértebra $\mathrm{T} 2(\mathrm{Z}=0 \mathrm{~mm})$ até a altura da vértebra L5 $(\mathrm{Z} \approx 465 \mathrm{~mm})$, obtidos no modelo computacional simplificado nas configurações MS3 e MS-EXP. Acima: Valor dos campos elétricos, na direção RC, obtido no centro da medula espinhal pelo modelo computacional simplificado nas configurações MS-3 e MSEXP. Abaixo: Diferença absoluta, em porcentagem em relação à configuração MS-3, do valor do campo elétrico obtido na configuração MS-3 e na configuração MS-EXP. Nota-se que para valores de campo elétrico próximos a $0 \mathrm{~V} / \mathrm{m}$, o valor da diferença entre os campos aumenta drasticamente pois ocorre a divisão matemática por um valor quase nulo. 
Tabela 8: Tamanho e localização da região da medula espinhal estimulada com campo elétrico maior do que $0,15 \mathrm{~V} / \mathrm{m}$ obtidos pelo modelo computacional simplificado nas configurações MS-3 e MS-EXP. Início(mm): Início da região da medula com campo elétrico maior do que $0,15 \mathrm{~V} / \mathrm{m}$, calculado à partir da vértebra T2. Fim(mm): Término da região da medula com campo elétrico maior do que $0,15 \mathrm{~V} / \mathrm{m}$, calculado à partir da vértebra T2. $\operatorname{Tamanho}(\mathrm{mm})=(\boldsymbol{F i m}(\mathrm{mm})-\operatorname{Início}(\mathrm{mm}))$. Diferença $=100 x($ MS-EXP. MS3)/MS-3). $|E|$ - Parâmetros obtidos da análise do módulo do campo elétrico. $\left|E_{R C}\right|$ Parâmetros obtidos da análise do campo elétrico na direção $\mathrm{RC}$.

\begin{tabular}{|c|c|c|c|c|c|}
\hline & \multicolumn{4}{|c|}{$\begin{array}{c}\text { Região da medula estimulada } \\
\text { com campo elétrico maior do que } \\
0,15 \mathrm{~V} / \mathrm{m}\end{array}$} \\
\hline & & Início & Fim & Tamanho & Figura \\
\hline \multirow{3}{*}{$|E|$} & MS-3 & $229,6 \mathrm{~mm}$ & $440,0 \mathrm{~mm}$ & $210,4 \mathrm{~mm}$ & \multirow{3}{*}{62} \\
\hline & MS-EXP & $229,8 \mathrm{~mm}$ & $440,0 \mathrm{~mm}$ & $210,2 \mathrm{~mm}$ & \\
\hline & Diferença & $\approx 0 \%$ & $0 \%$ & $\approx 0 \%$ & \\
\hline \multirow{3}{*}{$E_{R C}$} & MS-3 & $237,6 \mathrm{~mm}$ & $439,9 \mathrm{~mm}$ & $202,3 \mathrm{~mm}$ & \multirow{3}{*}{65} \\
\hline & MS-EXP & $237,4 \mathrm{~mm}$ & $439,7 \mathrm{~mm}$ & $202,3 \mathrm{~mm}$ & \\
\hline & Diferença & $\approx 0 \%$ & $\approx 0 \%$ & $0 \%$ & \\
\hline
\end{tabular}

\subsubsection{Hipótese 4 - Aumento da corrente de estimulação}

A análise do modelo computacional simplificado na configuração MS-EXP revelou que o aumento da corrente elétrica de estimulação de $2,5 \mathrm{~mA}$ para $5 \mathrm{~mA}$ na configuração " $U m$ eletrodo de $50 \mathrm{~cm}^{2}$ sobre T10 e dois eletrodos de $50 \mathrm{~cm}^{2}$ sobre a crista ilíaca direita e sobre a crista ilíaca esquerda" alterou de forma significativa o campo elétrico produzido ao longo da medula espinhal (Figura 66).

O aumento da corrente elétrica de estimulação para $5 \mathrm{~mA}$ elevou a intensidade do campo elétrico na região com módulo de campo elétrico maior do que $0,15 \mathrm{~V} / \mathrm{m}$ em comparação com a estimulação de 2,5 mA (Figura 67).

A estimulação de 2,5 mA não é suficiente para produzir campo elétrico na direção AP com intensidade maior do que $0,15 \mathrm{~V} / \mathrm{m}$, já a estimulação de $5 \mathrm{~mA}$ produziu campo elétrico na direção AP com módulo maior do que $0,15 \mathrm{~V} / \mathrm{m}$ (Figura 68).

O campo elétrico na direção ML (Figura 69) apresentou módulo menor do que 0,15 V/m ao longo da medula nas duas configurações.

A intensidade do campo elétrico observado na direção $\mathrm{RC}$ aumentou em consequência da 
estimulação de $5 \mathrm{~mA}$, em comparação com a estimulação de 2,5 mA (Figura 70).

O tamanho e localização da região da medula espinhal estimulada por um campo maior do que $0,15 \mathrm{~V} / \mathrm{m}$ apresentou diferenças significativas. O tamanho dessa região foi aumentado em $79 \%$ na estimulação de $5 \mathrm{~mA}$ em relação à estimulação de $2,5 \mathrm{~mA}$. A localização do início dessa região foi reduzida em $62 \%$ na estimulação de $5 \mathrm{~mA}$ em comparação com a estimulação de 2,5 mA (Tabela 9).

A estimulação de $5 \mathrm{~mA}$ produziu na medula espinhal módulo de densidade de corrente elétrica menor do que $6,3 \mathrm{~A} / \mathrm{m}^{2}$ (Figura 71).

Na configuração MS-EXP foi observada densidade de corrente elétrica na medula espinhal maior do que $6,3 \mathrm{~A} / \mathrm{m}^{2}$ apenas quando a corrente de estimulação foi configurada com valor maior ou igual a $\mathbf{2 5 0} \mathbf{~ m A ~ ( F i g u r a ~ 7 1 ) . ~}$

Por meio dos resultados obtidos foi possível concluir que a hipótese de que a utilização de uma estimulação de $5 \mathrm{~mA}$ no posicionamento "um eletrodo sobre a vértebra T10, um eletrodo sobre a crista ilíaca direita e um eletrodo sobre a crista ilíaca esquerda" com eletrodos de $50 \mathrm{~cm}^{2}$ pode estimular uma região maior da medula espinhal com campo elétrico de no mínimo $0,15 \mathrm{~V} / \mathrm{m}$, em relação a uma estimulação realizada com $2,5 \mathrm{~mA}$, e também gera densidade de corrente elétrica na medula espinhal menor do que o limite máximo que causa danos em tecidos neurais, é verdadeira. 


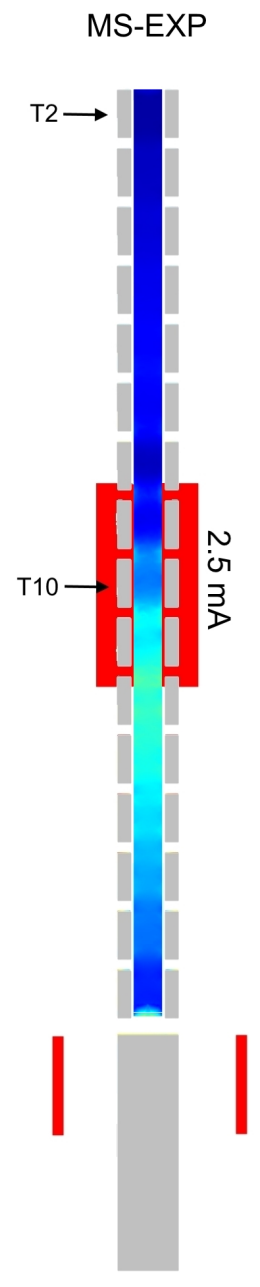

$3 \times 50 \mathrm{~cm}^{2}$

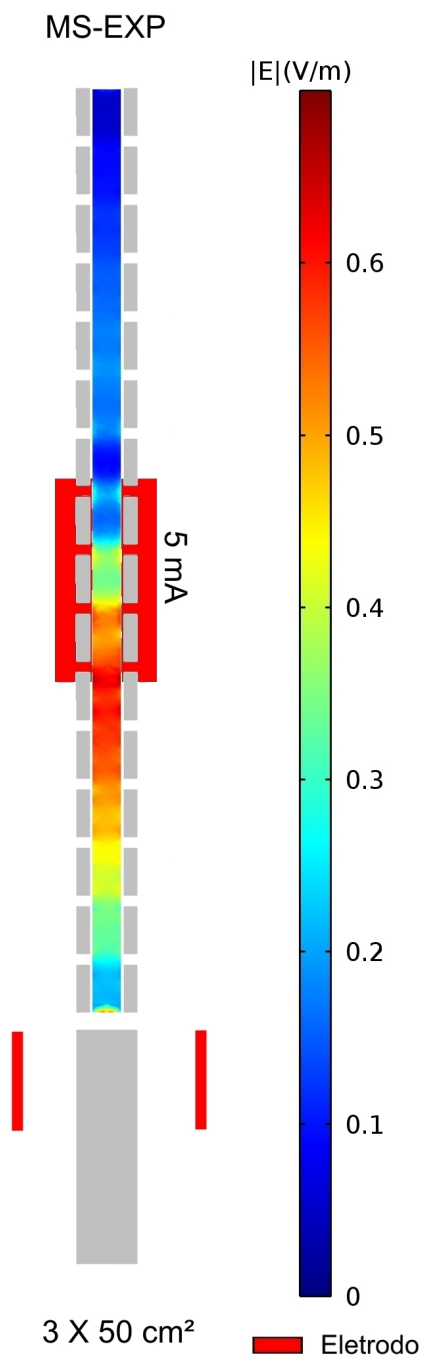

Figura 66: Representações dos módulos dos campos elétricos na medula espinhal obtidos no modelo computacional simplificado na configuração MS-EXP com estimulação elétrica de $2,5 \mathrm{~mA}$ e $5 \mathrm{~mA}$. À esquerda) Representação no plano sagital do módulo do campo elétrico obtido no modelo simplificado na configuração MS-EXP(Um eletrodo de $50 \mathrm{~cm}^{2}$, $10 \mathrm{~cm} \mathrm{x} 5 \mathrm{~cm}$, sobre T10 e dois eletrodos de $50 \mathrm{~cm}^{2}, 10 \mathrm{~cm} \times 5 \mathrm{~cm}$, sobre a crista ilíaca direita e sobre a crista ilíaca esquerda e corrente de estimulação de 2,5 mA). À direita) Representação no plano sagital do módulo do campo elétrico obtido no modelo simplificado na configuração MS-EXP (Um eletrodo de $50 \mathrm{~cm}^{2}, 10 \mathrm{~cm}$ x $5 \mathrm{~cm}$, sobre T10 e dois eletrodos de $50 \mathrm{~cm}^{2}, 10 \mathrm{~cm}$ x $5 \mathrm{~cm}$, sobre a crista ilíaca direita e sobre a crista ilíaca esquerda e corrente de estimulação de $5 \mathrm{~mA}$ ). 


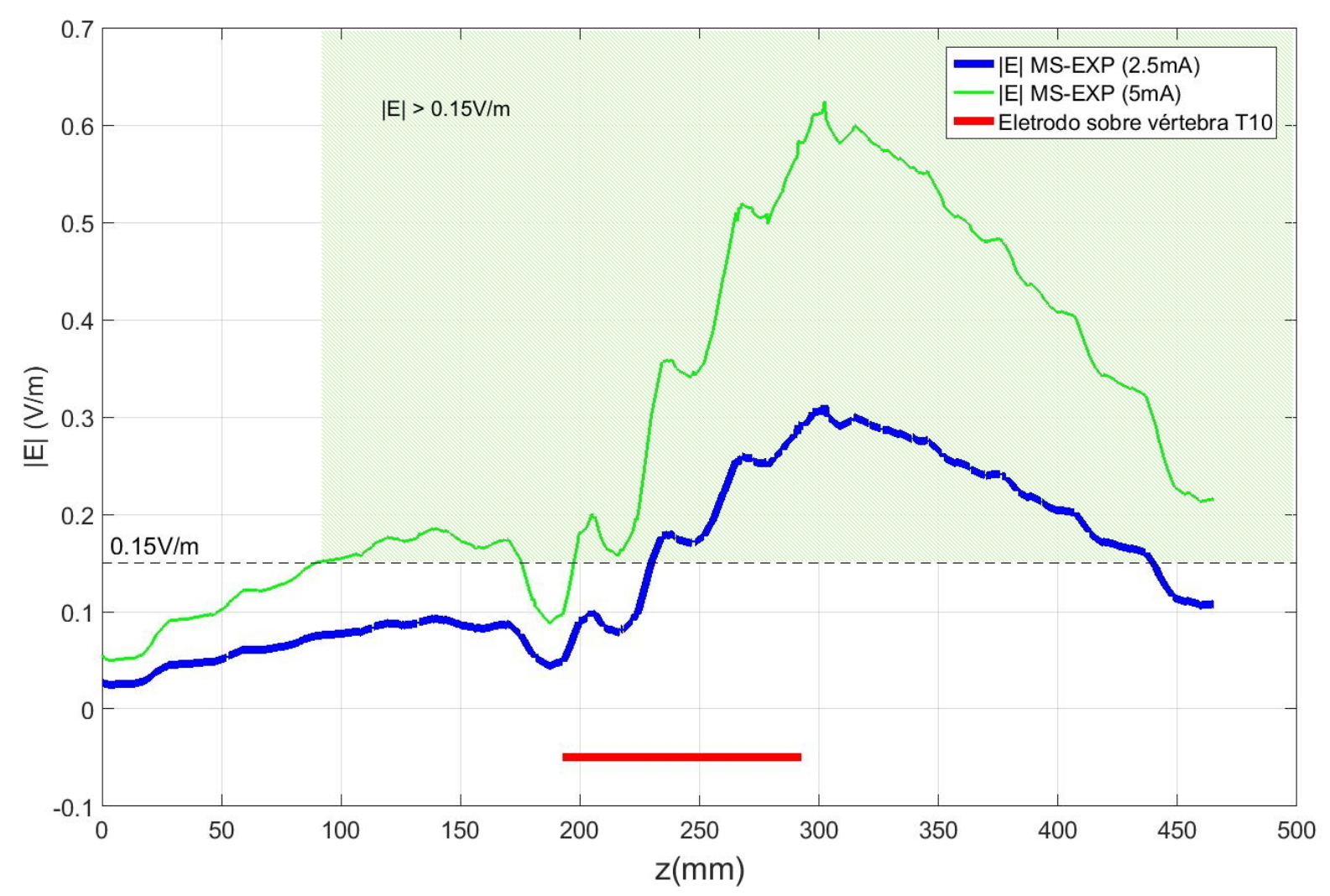

Figura 67: Módulo dos campos elétricos na medula espinhal, desde a altura da vértebra T2 $(\mathrm{Z}=0 \mathrm{~mm})$ até a altura da vértebra $\mathrm{L5}(\mathrm{Z} \approx 465 \mathrm{~mm})$, obtidos no modelo computacional simplificado na configuração MS-EXP com estimulação elétrica de 2,5 mA e de $5 \mathrm{~mA}$. A região do gráfico hachurada em verde claro corresponde à região em que o módulo do campo elétrico, na estimulação de $5 \mathrm{~mA}$, é maior do que $0,15 \mathrm{~V} / \mathrm{m}$. 


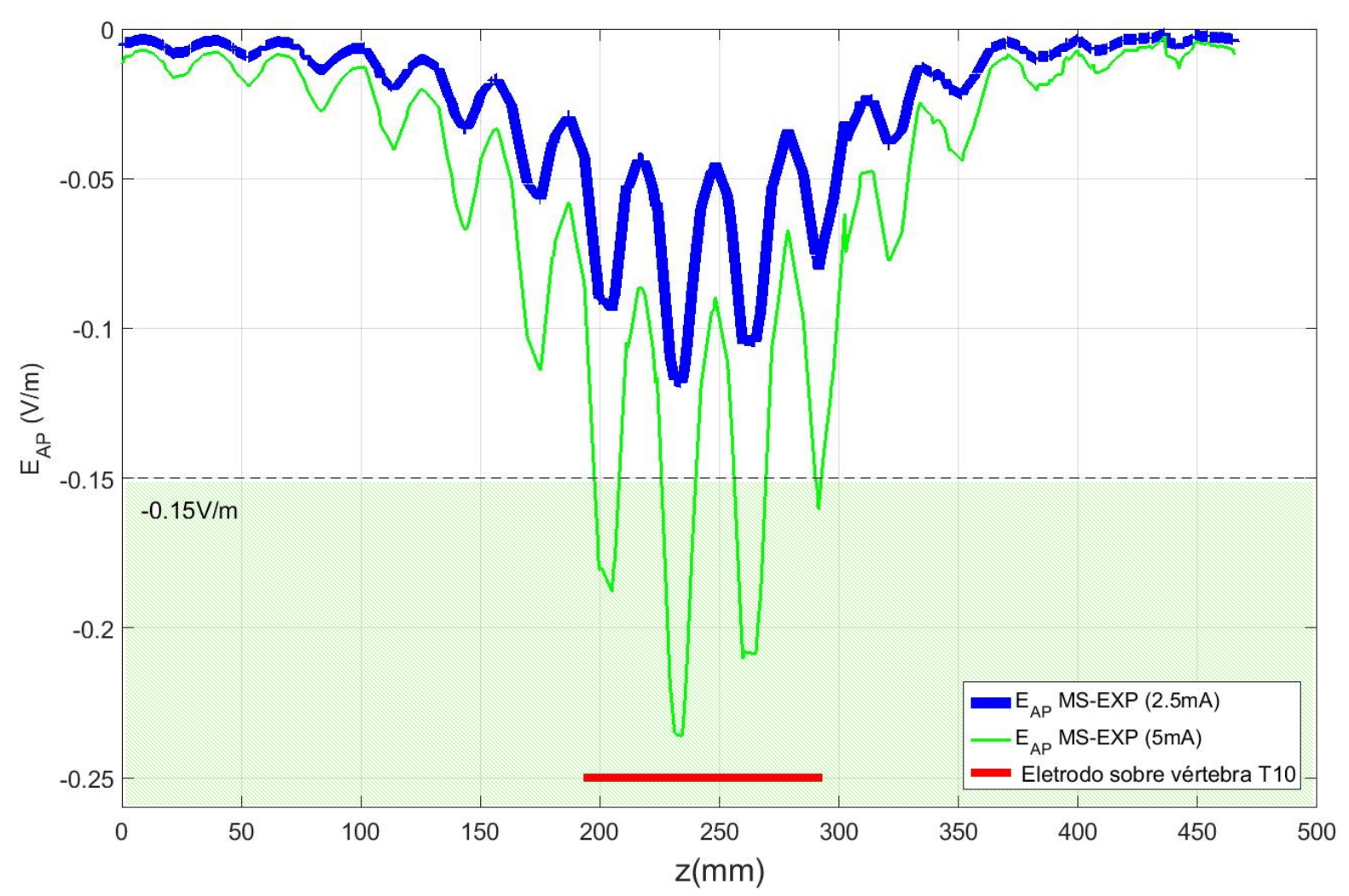

Figura 68: Valor dos campos elétricos, na direção $\mathrm{AP}$, no centro da medula espinhal, desde a altura da vértebra $\mathrm{T2}(\mathrm{Z}=0 \mathrm{~mm})$ até a altura da vértebra $\mathrm{L} 5(\mathrm{Z} \approx 465 \mathrm{~mm})$, obtido no modelo simplificado na configuração MS-EXP com estimulação elétrica de 2,5 $\mathrm{mA}$ e de $5 \mathrm{~mA}$. A região do gráfico hachurada em verde claro corresponde à região em que o módulo do campo elétrico na direção $\mathrm{AP}$, na estimulação de $5 \mathrm{~mA}$, é maior do que $0,15 \mathrm{~V} / \mathrm{m}$. 


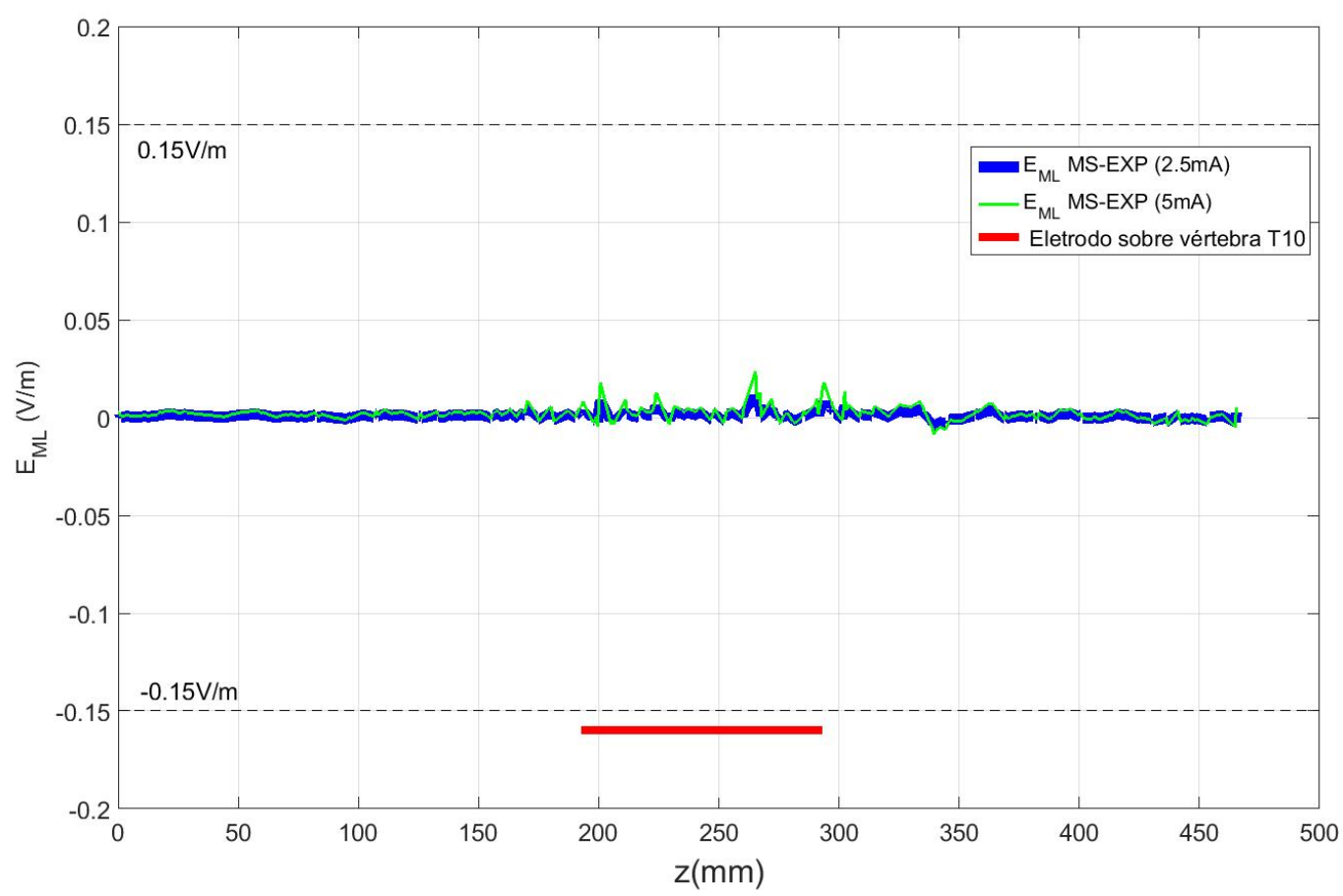

Figura 69: Valor dos campos elétricos, na direção ML, no centro da medula espinhal, desde a altura da vértebra $\mathrm{T} 2(\mathrm{Z}=0 \mathrm{~mm})$ até a altura da vértebra $\mathrm{L} 5(\mathrm{Z} \approx 465 \mathrm{~mm})$, obtido no modelo simplificado na configuração MS-EXP com estimulação elétrica de 2,5 $\mathrm{mA}$ e de $5 \mathrm{~mA}$. 


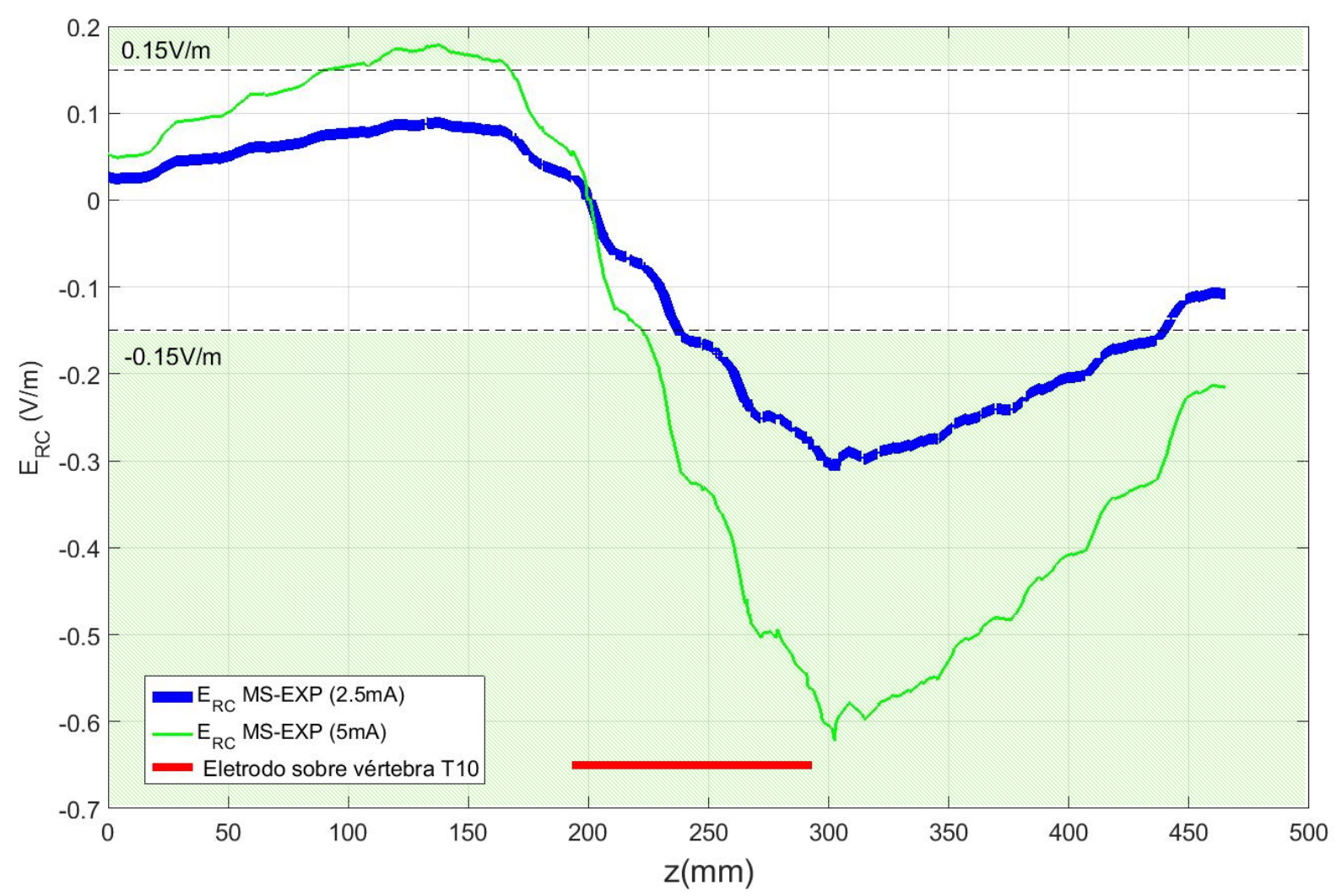

Figura 70: Valor dos campos elétricos, na direção RC, no centro da medula espinhal, desde a altura da vértebra $\mathrm{T} 2(\mathrm{Z}=0 \mathrm{~mm})$ até a altura da vértebra $\mathrm{L} 5(\mathrm{Z} \approx 465 \mathrm{~mm})$, obtidos no modelo computacional simplificado na configuração MS-EXP com estimulação elétrica de 2,5 mA e de $5 \mathrm{~mA}$. A região do gráfico hachurada em verde claro corresponde à região em que o módulo do campo elétrico na direção $\mathrm{RC}$, na estimulação de $5 \mathrm{~mA}$, é maior do que $0,15 \mathrm{~V} / \mathrm{m}$. 


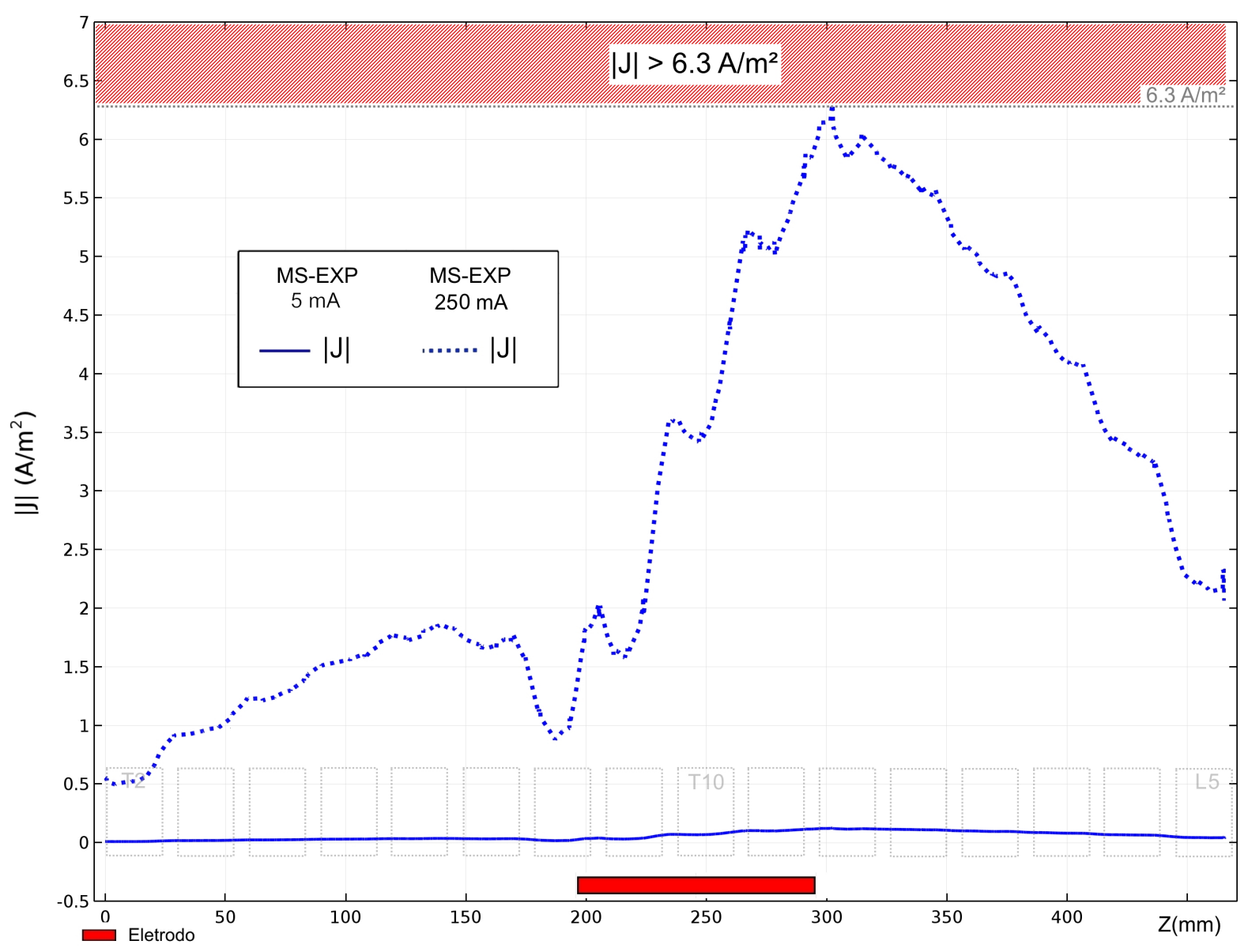

Figura 71: Valor dos módulos da densidade de corrente elétrica $(|J|)$, no centro da medula

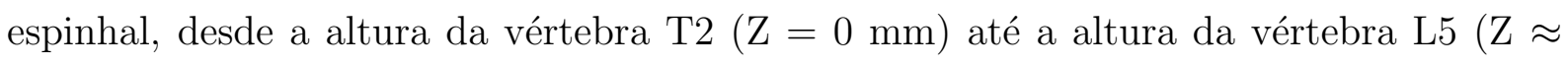
$465 \mathrm{~mm}$ ), obtido no modelo computacional simplificado na configuração MS-EXP com estimulação elétrica de $5 \mathrm{~mA}$ e $250 \mathrm{~mA}$. A região do gráfico hachurada em vermelho corresponde à região em que o módulo da densidade elétrica é maior do que $6,3 \mathrm{~A} / \mathrm{m}^{2}$. 
Tabela 9: Tamanho e localização da região da medula espinhal estimulada com campo elétrico maior do que $0,15 \mathrm{~V} / \mathrm{m}$ obtidos pelo modelo computacional simplificado nas configurações MS-EXP com corrente de estimulação de 2,5 mA e MS-EXP com corrente de estimulação de $5 \mathrm{~mA}$. Início(mm): Início da região da medula com campo elétrico maior do que $0,15 \mathrm{~V} / \mathrm{m}$, calculado à partir da vértebra T2, $\mathbf{F i m}(\mathrm{mm})$ : Término da região da medula com campo elétrico maior do que $0,15 \mathrm{~V} / \mathrm{m}$, calculado à partir da vértebra T2. $\operatorname{Tamanho}(\mathrm{mm})=(\boldsymbol{F i m}(\mathrm{mm})-\operatorname{Início}(\mathrm{mm}))$. Diferença $=100 x($ MS-EXP $[5 \mathrm{~mA}]$ - MSEXP $[2,5 \mathrm{~mA}]) / \mathrm{MS}-\mathrm{EXP}[2,5 \mathrm{~mA}]) .|E|$ - Parâmetros obtidos da análise do módulo do campo elétrico. $\left|E_{R C}\right|$ - Parâmetros obtidos da análise do campo elétrico na direção $\mathrm{RC}$. Nesta tabela não está incluída a análise da componente $E_{A P}$ pois apenas a configuração MS-EXP [5 mA] apresentou valor de campo elétrico maior do que 0,15 V/m. Na configuração MS-EXP [5 mA], o início da região da medula estimulada com campo elétrico maior do que $0,15 \mathrm{~V} / \mathrm{m}$ foi definido como o ponto em que pela primeira vez, na direção rostro caudal, o módulo do campo elétrico atingiu valor maior do que $0,15 \mathrm{~V} / \mathrm{m}$.

\begin{tabular}{|c|c|c|c|c|c|}
\hline & \multicolumn{4}{|c|}{$\begin{array}{c}\text { Região da medula estimulada } \\
\text { com campo elétrico maior do que } \\
0,15 \mathrm{~V} / \mathrm{m}\end{array}$} \\
\hline & & Início & Fim & Tamanho & Figura \\
\hline \multirow{3}{*}{$|E|$} & MS-EXP2,5 mA & $229,8 \mathrm{~mm}$ & $440,0 \mathrm{~mm}$ & $210,2 \mathrm{~mm}$ & \multirow{3}{*}{67} \\
\hline & MS-EXP5 mA & $89,2 \mathrm{~mm}$ & $465,4 \mathrm{~mm}$ & $376,2 \mathrm{~mm}$ & \\
\hline & Diferença & $61 \%$ & $6 \%$ & $79 \%$ & \\
\hline \multirow{3}{*}{$E_{R C}$} & MS-EXP2,5 mA & $237,4 \mathrm{~mm}$ & $439,7 \mathrm{~mm}$ & $202,3 \mathrm{~mm}$ & \multirow{3}{*}{70} \\
\hline & MS-EXP5 mA & $91,2 \mathrm{~mm}$ & $465,4 \mathrm{~mm}$ & $374,2 \mathrm{~mm}$ & \\
\hline & Diferença & $62 \%$ & $6 \%$ & $85 \%$ & \\
\hline
\end{tabular}

\subsection{Resultados do protocolo experimental}

\subsubsection{Hipótese 5 - Efeito da tsDCS na PEO}

No total 20 (vinte) indivíduos concordaram em participar do protocolo experimental. Três indivíduos foram excluídos da participação do protocolo experimental logo após a identificação da ocorrência de pequenas lesões cutâneas na região de contato entre os eletrodos de estimulação e a pele. O pré-processamento de dados identificou três participantes, dos 17 (dezessete) participantes restantes, que apresentaram valores de média outliers, em pelo menos um dos protocolos de estimulação elétrica, em qualquer período, 
dos parâmetros $S D_{A P}$ ou $M V E L O_{A P}$. Com isso, no total foram utilizados na análise estatística os dados de apenas 14 (quatorze) participantes (Tabela 10).

A Figura 72 apresenta a característica típica dos sinais do COP obtidos por posturografia por plataforma de força utilizados para o cálculo dos parâmetros do COP. Os resultados das médias e desvios padrões de todos os parâmetros calculados são exibidos no anexo A.5.

Os resultados das ANOVAs indicaram que apenas 2 (dois) parâmetros $\left(\alpha L_{M L}\right.$ e $\left.C I_{M L}\right)$ dos 53 (cinquenta e três) apresentaram alterações estatisticamente significativas nos diferentes protocolos experimentais (Tabela 11). O poder estatístico alcançado foi maior do que $80 \%$ na análise estatística de apenas um parâmetro $\left(\alpha L_{M L}\right)$.

A análise post hoc (Tabela 12) indicou que o parâmetro $\alpha L_{M L}$ apresentou diferenças estatisticamente significativas $(p \leq 0,05)$ entre períodos $\mathrm{t0} \times \mathrm{t} 2 \mathrm{et}$ × $\mathrm{t} 2 \mathrm{l}$ e nas interações ( t0 x t1 e t0 x t2 no protocolo (A-T10,C-CiDeE) e na interação (A-T10,C-CiDeE) x (C-T10,A-CiDeE) no período t1). O parâmetro $\alpha C I_{M L}$ apresentou alterações estatisticamente significativas entre protocolos (PLACEBO x (A-T10,C-CiDeE).

Os parâmetros $f 50 p_{-} P S D_{A P}, \alpha_{M L}, C I_{M L}$ e $C I_{A P v}$ foram selecionados para a análise gráfica.

O parâmetro $f 50 p_{-} P S D_{A P}$ apresentou tamanho de efeito $\left(\eta_{p}^{2}\right)$ maior do que 0,14 na interação (Protocolo x Período). A análise gráfica desse parâmetro (Figura 73) permitiu identificar que é possível que tanto o protocolo (A-T10,C-CiDeE) quanto o protocolo (CT10,A-CiDeE) tenham causado pequeno aumento desse parâmetro nos períodos t1 e t2 em relação ao observado no protocolo Placebo.

O parâmetro $\alpha L_{M L}$ apresentou diferença significante na ANOVA. A análise gráfica desse parâmetro (Figura 74) permitiu identificar que no protocolo (A-T10,C-CiDeE) ocorre o pequeno aumento desse parâmetro nos períodos t1 e t2 em relação ao período t0. A análise gráfica utilizada não permite verificar de forma direta a diferença existente entre períodos to x t2 e t1 x t2 ou entre protocolos (A-T10,C-CiDeE $\times$ (C-T10,A-CiDeE) no período t1.

O parâmetro CIAPv apresentou tamanho de efeito $\left(\eta_{p}^{2}\right)$ maior do que 0,14 na interação (Protocolo x Período). A análise gráfica desse parâmetro (Figura 75 permitiu identificar que é possível que o protocolo (C-T10,A-CiDeE) causou pequeno aumento desse parâmetro nos períodos t1 e t2 em relação ao observado no protocolo Placebo.

O parâmetro $C I_{M L}$ apresentou diferença significante na ANOVA. A análise gráfica desse parâmetro (Figura 76) permitiu identificar diferença entre os protocolos Placebo e (AT10,C-CiDeE) aparentemente gerada pelo offset do valor desse parâmetro nos diferentes protocolos, não sendo possível identificar visualmente diferença induzida pelo protocolo 
de estimulação elétrica.

Tabela 10: Informações dos participantes do protocolo experimental. Para cada participante foi atribuída aleatoriamente uma cor de identificação utilizada nas análises gráficas dos resultados dos parâmetros selecionados. $\mathbf{I M C}=$ Índice de massa corporal. $\mathbf{F}=$ Feminino. $\mathbf{M}=$ Masculino. $\mathbf{D}=\operatorname{Direita}(\mathrm{o}) . \mathbf{E}=\operatorname{Esquerda}(\mathrm{o})$

\begin{tabular}{|c|c|c|c|c|c|c|c|c|}
\hline Participante & $\begin{array}{c}\text { Cor de } \\
\text { identificação }\end{array}$ & Sexo & Idade & Massa (kg) & Altura & IMC & $\begin{array}{c}\text { Mão } \\
\text { dominante }\end{array}$ & $\begin{array}{c}\text { Pé } \\
\text { dominante }\end{array}$ \\
\hline 1 & & $\mathrm{~F}$ & 28 & 54 & 1,55 & 22 & $\mathrm{D}$ & $\mathrm{D}$ \\
\hline 2 & $\mathrm{M}$ & 21 & 87 & 1,73 & 29 & $\mathrm{D}$ & $\mathrm{E}$ \\
\hline 3 & $\mathrm{~F}$ & 25 & 60 & 1,63 & 23 & $\mathrm{D}$ & $\mathrm{D}$ \\
\hline 4 & $\mathrm{M}$ & 19 & 68 & 1,64 & 25 & $\mathrm{D}$ & $\mathrm{D}$ \\
\hline 5 & $\mathrm{M}$ & 23 & 69 & 1,70 & 24 & $\mathrm{D}$ & $\mathrm{D}$ \\
\hline 6 & $\mathrm{~F}$ & 21 & 54 & 1,65 & 20 & $\mathrm{D}$ & $\mathrm{D}$ \\
\hline 7 & $\mathrm{M}$ & 19 & 64 & 1,64 & 24 & $\mathrm{D}$ & $\mathrm{D}$ \\
\hline 8 & $\mathrm{~F}$ & 22 & 55 & 1,71 & 19 & $\mathrm{D}$ & $\mathrm{D}$ \\
\hline 9 & $\mathrm{M}$ & 19 & 75 & 1,82 & 23 & $\mathrm{D}$ & $\mathrm{D}$ \\
\hline 10 & $\mathrm{M}$ & 29 & 60 & 1,71 & 21 & $\mathrm{D}$ & $\mathrm{D}$ \\
\hline 11 & $\mathrm{M}$ & 26 & 69 & 1,66 & 25 & $\mathrm{D}$ & $\mathrm{D}$ \\
\hline 12 & $\mathrm{~F}$ & 22 & 68 & 1,69 & 24 & $\mathrm{D}$ & $\mathrm{D}$ \\
\hline 13 & $\mathrm{~F}$ & 20 & 56 & 1,60 & 22 & $\mathrm{D}$ & $\mathrm{D}$ \\
\hline 14 & M & 25 & 86 & 1,86 & 25 & $\mathrm{D}$ & $\mathrm{D}$ \\
\hline
\end{tabular}



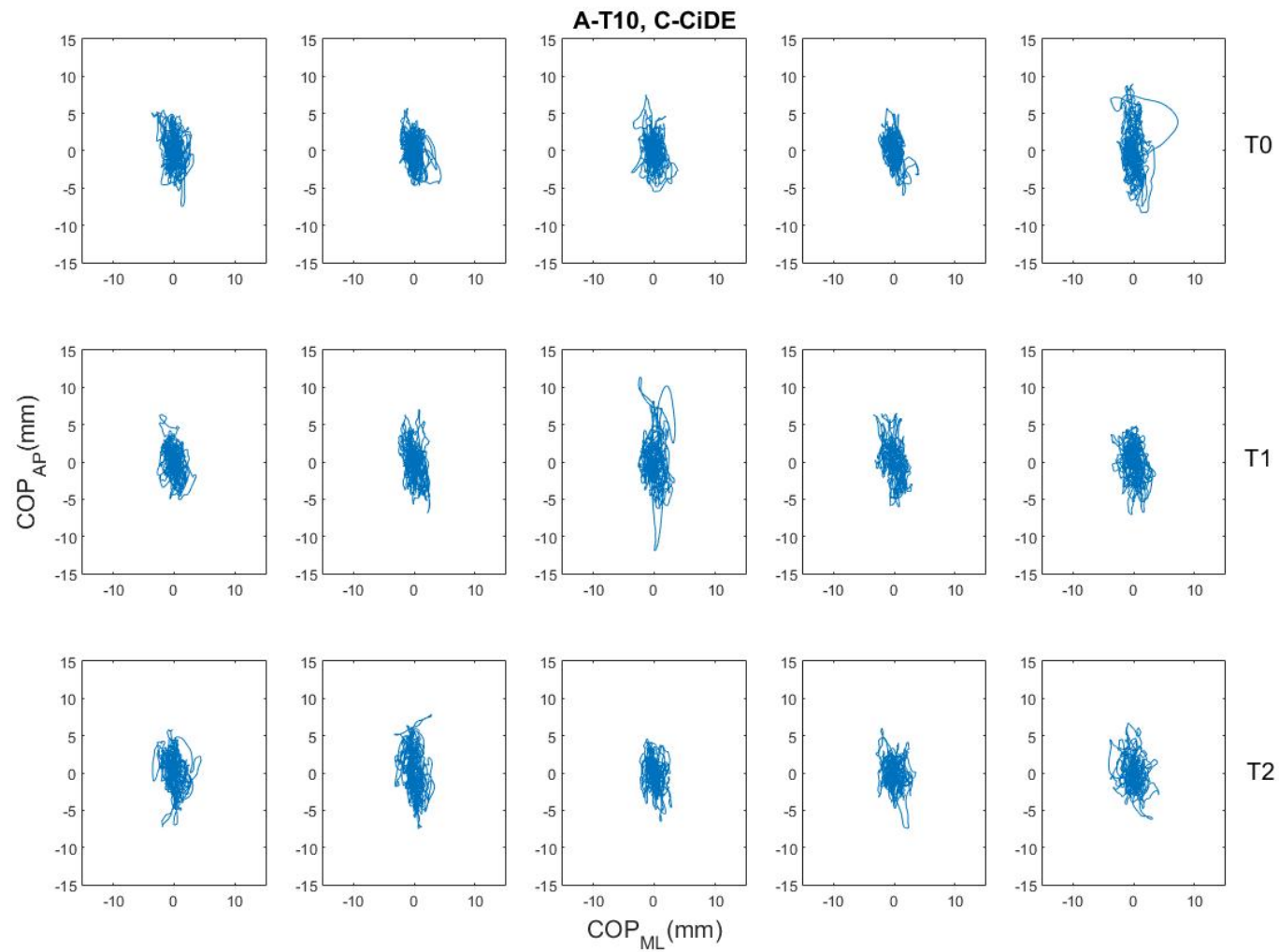

Figura 72: Dados de posturografia por plataforma de força obtidos de um participante durante o protocolo experimental na sessão de estimulação elétrica de tsDCS (A-T10,CCiDeE), Na primeira linha, de cima para baixo, são apresentados os estabilogramas das cinco sequências de 90 segundos de execução da $\mathrm{PEO}$ antes da estimulação elétrica (to). $\mathrm{Na}$ segunda linha, os estabilogramas obtidos durante a estimulação elétrica (t1). Na terceira linha, os estabilogramas obtidos após a estimulação elétrica (t2). 
Tabela 11: Resultados das ANOVAs realizadas nos valores dos parâmetros obtidos dos dados experimentais, Valores de $p$ menores do que 0,05 estão destacados na cor verde, indicando situações em que a diferença estatística é significativa, Valores de $\eta_{P}^{2}$ maiores do que 0,14 estão destacados em amarelo, indicando situações em que o tamanho do efeito é grande (LAKENS. 2013, $P$ corresponde ao valor do poder estatístico obtido,

\begin{tabular}{|c|c|c|c|c|c|c|c|c|c|c|c|c|}
\hline \multirow[b]{2}{*}{ Parâmetro } & \multicolumn{4}{|c|}{ Protocolo } & \multicolumn{4}{|c|}{$\begin{array}{l}\text { ANOVA } \\
\text { Período }\end{array}$} & \multicolumn{4}{|c|}{ Protocolo x Período } \\
\hline & $\begin{array}{c}F(d f \text { dferror }) \\
F\end{array}$ & $p$ & $\eta_{p}^{2}$ & $P$ & $\begin{array}{c}F\left(d f \begin{array}{c}d f \text { error } \\
F\end{array}\right. \\
\end{array}$ & $p$ & $\eta_{p}^{2}$ & $P$ & $\begin{array}{c}F(d f \text { dferror }) \\
F\end{array}$ & $p$ & $\eta_{p}^{2}$ & $P$ \\
\hline$S D_{A P \_R a m}(\mathrm{~mm})$ & $\begin{array}{c}\mathrm{F}(2,0026,00) \\
2,40\end{array}$ & 0,11 & 0,16 & 0,44 & $\begin{array}{c}\mathrm{F}(1,28 \quad 16,62) \\
1,01\end{array}$ & 0,35 & 0,07 & 0,17 & $\begin{array}{c}\mathrm{F}(2,1027,33) \\
0,56\end{array}$ & 0,59 & 0,04 & 0,13 \\
\hline$S D_{\text {AP_Tre }}(\mathrm{mm})$ & $\begin{array}{c}\mathrm{F}(1,3517,57) \\
0,98\end{array}$ & 0,36 & 0,07 & 0,17 & $\begin{array}{c}\mathrm{F}(2,0026,00) \\
0,83\end{array}$ & 0,45 & 0,06 & 0,18 & $\begin{array}{c}\mathrm{F}(1,8624,15) \\
2,05\end{array}$ & 0,15 & 0,14 & 0,37 \\
\hline$S D_{A P}(\mathrm{~mm})$ & $\begin{array}{c}\mathrm{F}(1,3817,94) \\
1,32\end{array}$ & 0,28 & 0,09 & 0,22 & $\begin{array}{c}\mathrm{F}(2,0026,00) \\
1,15\end{array}$ & 0,33 & 0,08 & 0,23 & $\begin{array}{c}\mathrm{F}(1,9024,76) \\
1,00\end{array}$ & 0,38 & 0,07 & 0,20 \\
\hline$S D_{A P_{-} v}(\mathrm{~mm} / \mathrm{s})$ & $\begin{array}{c}\mathrm{F}(2,0026,00) \\
2,09\end{array}$ & 0,14 & 0,14 & 0,39 & $\begin{array}{c}\mathrm{F}(1,2015,54) \\
1,53\end{array}$ & 0,24 & 0,11 & 0,23 & $\begin{array}{c}\mathrm{F}(1,48 \quad 19,21) \\
1,05\end{array}$ & 0,35 & 0,07 & 0,19 \\
\hline$S D_{M L \_R a m}(\mathrm{~mm})$ & $\begin{array}{c}\mathrm{F}(2,0026,00) \\
1,10\end{array}$ & 0,35 & 0,08 & 0,22 & $\begin{array}{c}\mathrm{F}(2,0026,00) \\
1,64\end{array}$ & 0,21 & 0,11 & 0,31 & $\begin{array}{c}\mathrm{F}(1,6221,06) \\
0,39\end{array}$ & 0,64 & 0,03 & 0,10 \\
\hline$S D_{M L \_T r e}(\mathrm{~mm})$ & $\begin{array}{c}\mathrm{F}(2,0026,00) \\
1,83\end{array}$ & 0,18 & 0,12 & 0,35 & $\begin{array}{c}\mathrm{F}(2,0026,00) \\
1,49\end{array}$ & 0,25 & 0,10 & 0,29 & $\begin{array}{c}\mathrm{F}(1,6020,77) \\
0,51\end{array}$ & 0,57 & 0,04 & 0,12 \\
\hline$S D_{M L}(\mathrm{~mm})$ & $\begin{array}{c}\mathrm{F}(1,3417,36) \\
1,22\end{array}$ & 0,30 & 0,09 & 0,20 & $\begin{array}{c}\mathrm{F}(2,0026,00) \\
1,45\end{array}$ & 0,25 & 0,10 & 0,28 & $\begin{array}{c}\mathrm{F}(4,0052,00) \\
2,19\end{array}$ & 0,08 & 0,14 & 0,61 \\
\hline$S D_{M L \_v}(\mathrm{~mm} / \mathrm{s})$ & $\begin{array}{c}\mathrm{F}(1,4218,49) \\
0,45\end{array}$ & 0,58 & 0,03 & 0,11 & $\begin{array}{c}\mathrm{F}(2,0026,00) \\
0,38\end{array}$ & 0,69 & 0,03 & 0,11 & $\begin{array}{c}\mathrm{F}(1,9124,78) \\
0,75\end{array}$ & 0,48 & 0,06 & 0,16 \\
\hline$M V E L O_{A P \_R a m}(\mathrm{~mm} / \mathrm{s})$ & $\begin{array}{c}\mathrm{F}(1,2616,32) \\
1,28\end{array}$ & 0,29 & 0,09 & 0,20 & $\begin{array}{c}\mathrm{F}(2,0026,00) \\
1,57\end{array}$ & 0,23 & 0,11 & 0,30 & $\begin{array}{c}\mathrm{F}(4,0052,00) \\
1,84\end{array}$ & 0,14 & 0,12 & 0,52 \\
\hline$M V E L O_{A P_{-} T r e}(\mathrm{~mm} / \mathrm{s})$ & $\begin{array}{c}\mathrm{F}(1,3617,74) \\
1,19\end{array}$ & 0,31 & 0,08 & 0,20 & $\begin{array}{c}\mathrm{F}(2,0026,00) \\
0,79\end{array}$ & 0,46 & 0,06 & 0,17 & $\begin{array}{c}\mathrm{F}(2,2729,46) \\
0,95\end{array}$ & 0,41 & 0,07 & 0,21 \\
\hline$M V E L O_{A P}(\mathrm{~mm} / \mathrm{s})$ & $\begin{array}{c}\mathrm{F}(2,0026,00) \\
0,96\end{array}$ & 0,39 & 0,07 & 0,20 & $\begin{array}{c}\mathrm{F}(1,3417,42) \\
2,61\end{array}$ & 0,12 & 0,17 & 0,38 & $\begin{array}{c}\mathrm{F}(2,2729,56) \\
1,30\end{array}$ & 0,29 & 0,09 & 0,28 \\
\hline
\end{tabular}


Tabela 11, continuação da página anterior.

\begin{tabular}{|c|c|c|c|c|c|c|c|c|c|c|c|c|}
\hline \multirow[b]{2}{*}{ Parâmetro } & \multicolumn{4}{|c|}{ Protocolo } & \multicolumn{4}{|c|}{$\begin{array}{c}\text { ANOVA } \\
\text { Período }\end{array}$} & \multicolumn{4}{|c|}{ Protocolo x Período } \\
\hline & $\begin{array}{c}F(d f \text { dferror }) \\
F\end{array}$ & $p$ & $\eta_{p}^{2}$ & $P$ & $\begin{array}{c}F(d f \text { dferror }) \\
F\end{array}$ & $p$ & $\eta_{p}^{2}$ & $P$ & $\begin{array}{c}F(d f \text { dferror }) \\
F\end{array}$ & $p$ & $\eta_{p}^{2}$ & $P$ \\
\hline$M V E L O_{M L \_R a m}(\mathrm{~mm} / \mathrm{s})$ & $\begin{array}{c}\mathrm{F}(2,0026,00) \\
1,02\end{array}$ & 0,38 & 0,07 & 0,21 & $\begin{array}{c}\mathrm{F}(2,0026,00) \\
0,13\end{array}$ & 0,88 & 0,01 & 0,07 & $\begin{array}{c}\mathrm{F}(1,9325,02) \\
0,33\end{array}$ & 0,72 & 0,03 & 0,10 \\
\hline$M V E L O_{M L-T r e}(\mathrm{~mm} / \mathrm{s})$ & $\begin{array}{c}\mathrm{F}(2,0026,00) \\
1,12\end{array}$ & 0,34 & 0,08 & 0,23 & $\begin{array}{c}\mathrm{F}(1,3317,29) \\
2,49\end{array}$ & 0,13 & 0,16 & 0,36 & $\begin{array}{c}\mathrm{F}(2,2529,24) \\
1,14\end{array}$ & 0,34 & 0,08 & 0,24 \\
\hline$M V E L O_{M L}(\mathrm{~mm} / \mathrm{s})$ & $\begin{array}{c}\mathrm{F}(2,0026,00) \\
1,41\end{array}$ & 0,26 & 0,10 & 0,27 & $\begin{array}{c}\mathrm{F}(1,3617,63) \\
1,33\end{array}$ & 0,28 & 0,09 & 0,22 & $\begin{array}{c}\mathrm{F}(1,7022,09) \\
0,35\end{array}$ & 0,68 & 0,03 & 0,10 \\
\hline$A R E A E_{\text {Ram }}\left(\mathrm{mm}^{2}\right)$ & $\begin{array}{c}\mathrm{F}(1,3617,64) \\
1,59\end{array}$ & 0,23 & 0,11 & 0,25 & $\begin{array}{c}\mathrm{F}(1,3617,68) \\
2,86\end{array}$ & 0,10 & 0,18 & 0,41 & $\begin{array}{c}\mathrm{F}(4,0052,00) \\
0,77\end{array}$ & 0,55 & 0,06 & 0,23 \\
\hline$A R E A E_{\text {Tre }}\left(\mathrm{mm}^{2}\right)$ & $\begin{array}{c}\mathrm{F}(2,0026,00) \\
1,18\end{array}$ & 0,32 & 0,08 & 0,24 & $\begin{array}{c}\mathrm{F}(1,33 \quad 17,33) \\
0,53\end{array}$ & 0,53 & 0,04 & 0,11 & $\begin{array}{c}\mathrm{F}(2,1327,73) \\
0,38\end{array}$ & 0,70 & 0,03 & 0,11 \\
\hline$A R E A E\left(\mathrm{~mm}^{2}\right)$ & $\begin{array}{c}\mathrm{F}(1,3617,69) \\
1,69\end{array}$ & 0,21 & 0,12 & 0,26 & $\begin{array}{c}\mathrm{F}(1,3817,90) \\
2,72\end{array}$ & 0,11 & 0,17 & 0,40 & $\begin{array}{c}\mathrm{F}(4,0052,00) \\
0,72\end{array}$ & 0,58 & 0,05 & 0,22 \\
\hline$P S D \_A R E A \_H F_{A P}\left(\mathrm{~mm}^{2}\right)$ & $\begin{array}{c}\mathrm{F}(1,2416,18) \\
1,13\end{array}$ & 0,32 & 0,08 & 0,18 & $\begin{array}{c}\mathrm{F}(2,0026,00) \\
1,39\end{array}$ & 0,27 & 0,10 & 0,27 & $\begin{array}{c}\mathrm{F}(2,3830,98) \\
1,71\end{array}$ & 0,19 & 0,12 & 0,36 \\
\hline$P S D \_A R E A \_H F_{M L}\left(\mathrm{~mm}^{2}\right)$ & $\begin{array}{c}\mathrm{F}(2,0026,00) \\
0,85\end{array}$ & 0,44 & 0,06 & 0,18 & $\begin{array}{c}\mathrm{F}(1,27 \quad 16,49) \\
1,23\end{array}$ & 0,30 & 0,09 & 0,20 & $\begin{array}{c}\mathrm{F}(1,5920,73) \\
0,25\end{array}$ & 0,74 & 0,02 & 0,08 \\
\hline$P S D \_A R E A_{-} L F_{A P}\left(\mathrm{~mm}^{2}\right)$ & $\begin{array}{c}\mathrm{F}(1,1915,52) \\
0,95\end{array}$ & 0,36 & 0,07 & 0,16 & $\begin{array}{c}\mathrm{F}(1,3617,67) \\
0,85\end{array}$ & 0,41 & 0,06 & 0,15 & $\begin{array}{c}\mathrm{F}(4,0052,00) \\
0,68\end{array}$ & 0,61 & 0,05 & 0,21 \\
\hline$P S D \_A R E A \_L F_{M L}\left(\mathrm{~mm}^{2}\right)$ & $\begin{array}{c}\mathrm{F}(2,0026,00) \\
0,92\end{array}$ & 0,41 & 0,07 & 0,19 & $\begin{array}{c}\mathrm{F}(1,3517,51) \\
1,17\end{array}$ & 0,31 & 0,08 & 0,19 & $\begin{array}{c}\mathrm{F}(1,7322,43) \\
0,39\end{array}$ & 0,65 & 0,03 & 0,10 \\
\hline$f 50 p_{-} P S D_{A P \_R a m}(\mathrm{~Hz})$ & $\begin{array}{c}\mathrm{F}(2,0026,00) \\
0,01\end{array}$ & 0,99 & 0,00 & 0,05 & $\begin{array}{c}\mathrm{F}(2,0026,00) \\
0,23\end{array}$ & 0,80 & 0,02 & 0,08 & $\begin{array}{c}\mathrm{F}(2,6334,20) \\
1,39\end{array}$ & 0,26 & 0,10 & 0,32 \\
\hline$f 50 p_{-} P S D_{A P \_T r e}(\mathrm{~Hz})$ & $\begin{array}{c}\mathrm{F}(2,0026,00) \\
2,97\end{array}$ & 0,07 & 0,19 & 0,53 & $\begin{array}{c}\mathrm{F}(1,3517,60) \\
2,35\end{array}$ & 0,14 & 0,15 & 0,35 & $\begin{array}{c}\mathrm{F}(2,7135,21) \\
1,33\end{array}$ & 0,28 & 0,09 & 0,31 \\
\hline$f 50 p_{-} P S D_{A P}(\mathrm{~Hz})$ & $\begin{array}{c}\mathrm{F}(2,0026,00) \\
0,73\end{array}$ & 0,49 & 0,05 & 0,16 & $\begin{array}{c}\mathrm{F}(2,0026,00) \\
1,21\end{array}$ & 0,31 & 0,09 & 0,24 & $\begin{array}{c}\mathrm{F}(4,0052,00) \\
2,49\end{array}$ & 0,05 & 0,16 & 0,67 \\
\hline$f 50 p \_P S D_{A P v}(\mathrm{~Hz})$ & $\begin{array}{c}\mathrm{F}(2,0026,00) \\
1,45\end{array}$ & 0,25 & 0,10 & 0,28 & $\begin{array}{c}\mathrm{F}(1,32 \quad 17,10) \\
0,46\end{array}$ & 0,56 & 0,03 & 0,10 & $\begin{array}{c}\mathrm{F}(4,0052,00) \\
1,72\end{array}$ & 0,16 & 0,12 & 0,49 \\
\hline
\end{tabular}


Tabela 11, continuação da página anterior.

\begin{tabular}{|c|c|c|c|c|c|c|c|c|c|c|c|c|}
\hline \multirow[b]{3}{*}{ Parâmetro } & \multicolumn{8}{|c|}{ ANOVA } & \multirow{2}{*}{\multicolumn{4}{|c|}{ Protocolo x Período }} \\
\hline & \multicolumn{4}{|c|}{ Protocolo } & \multicolumn{4}{|c|}{ Período } & & & & \\
\hline & $\begin{array}{c}F(d f \text { dferror }) \\
F\end{array}$ & $p$ & $\eta_{p}^{2}$ & $P$ & $\begin{array}{c}F(d f \text { df error }) \\
F\end{array}$ & $p$ & $\eta_{p}^{2}$ & $P$ & $\begin{array}{c}F(d f \text { dferror }) \\
F\end{array}$ & $p$ & $\eta_{p}^{2}$ & $P$ \\
\hline$f 50 p \_P S D_{M L \_R a m}(\mathrm{~Hz})$ & $\begin{array}{c}\mathrm{F}(2,0026,00) \\
0,49\end{array}$ & 0,62 & 0,04 & 0,12 & $\begin{array}{c}\mathrm{F}(2,0026,00) \\
1,26\end{array}$ & 0,30 & 0,09 & 0,25 & $\begin{array}{c}\mathrm{F}(4,0052,00) \\
0,73\end{array}$ & 0,58 & 0,05 & 0,22 \\
\hline$f 50 p_{-} P S D_{M L \_T r e}(\mathrm{~Hz})$ & $\begin{array}{c}\mathrm{F}(2,0026,00) \\
0,75\end{array}$ & 0,48 & 0,06 & 0,16 & $\begin{array}{c}\mathrm{F}(2,0026,00) \\
3,04\end{array}$ & 0,07 & 0,19 & 0,54 & $\begin{array}{c}\mathrm{F}(4,0052,00) \\
0,04\end{array}$ & 1,00 & 0,00 & 0,06 \\
\hline$f 50 p_{-} P S D_{M L}(\mathrm{~Hz})$ & $\begin{array}{c}\mathrm{F}(2,0026,00) \\
0,53\end{array}$ & 0,59 & 0,04 & 0,13 & $\begin{array}{c}\mathrm{F}(2,0026,00) \\
0,54\end{array}$ & 0,59 & 0,04 & 0,13 & $\begin{array}{c}\mathrm{F}(4,0052,00) \\
0,34\end{array}$ & 0,85 & 0,03 & 0,12 \\
\hline$f 50 p \_P S D_{M L v}(\mathrm{~Hz})$ & $\begin{array}{c}\mathrm{F}(2,0026,00) \\
1,37\end{array}$ & 0,27 & 0,10 & 0,27 & $\begin{array}{c}\mathrm{F}(2,0026,00) \\
1,07\end{array}$ & 0,36 & 0,08 & 0,22 & $\begin{array}{c}\mathrm{F}(4,0052,00) \\
0,94\end{array}$ & 0,45 & 0,07 & 0,28 \\
\hline$f 80 p_{-} P S D_{A P \_R a m}(\mathrm{~Hz})$ & $\begin{array}{c}\mathrm{F}(2,0026,00) \\
1,40\end{array}$ & 0,27 & 0,10 & 0,27 & $\begin{array}{c}\mathrm{F}(2,0026,00) \\
0,99\end{array}$ & 0,39 & 0,07 & 0,20 & $\begin{array}{c}\mathrm{F}(4,0052,00) \\
1,66\end{array}$ & 0,17 & 0,11 & 0,47 \\
\hline$f 80 p_{-} P S D_{A P \_T r e}(\mathrm{~Hz})$ & $\begin{array}{c}\mathrm{F}(1,2416,06) \\
1,29\end{array}$ & 0,28 & 0,09 & 0,20 & $\begin{array}{c}\mathrm{F}(1,3918,11) \\
2,21\end{array}$ & 0,15 & 0,15 & 0,33 & $\begin{array}{c}\mathrm{F}(2,5332,87) \\
0,58\end{array}$ & 0,61 & 0,04 & 0,15 \\
\hline$f 80 p_{-} P S D_{A P}(\mathrm{~Hz})$ & $\begin{array}{c}\mathrm{F}(2,0026,00) \\
2,89\end{array}$ & 0,07 & 0,18 & 0,52 & $\begin{array}{c}\mathrm{F}(2,0026,00) \\
0,00\end{array}$ & 1,00 & 0,00 & 0,05 & $\begin{array}{c}\mathrm{F}(4,0052,00) \\
0,48\end{array}$ & 0,75 & 0,04 & 0,15 \\
\hline$f 80 p_{-} P S D_{A P v}(\mathrm{~Hz})$ & $\begin{array}{c}\mathrm{F}(2,0026,00) \\
0,14\end{array}$ & 0,87 & 0,01 & 0,07 & $\begin{array}{c}\mathrm{F}(1,2616,40) \\
0,70\end{array}$ & 0,45 & 0,05 & 0,13 & $\begin{array}{c}\mathrm{F}(4,0052,00) \\
0,92\end{array}$ & 0,46 & 0,07 & 0,27 \\
\hline$f 80 p_{-} P S D_{M L \_} \operatorname{Ram}(\mathrm{Hz})$ & $\begin{array}{c}\mathrm{F}(2,0026,00) \\
0,82\end{array}$ & 0,45 & 0,06 & 0,18 & $\begin{array}{c}\mathrm{F}(2,0026,00) \\
1,16\end{array}$ & 0,33 & 0,08 & 0,23 & $\begin{array}{c}\mathrm{F}(4,0052,00) \\
1,06\end{array}$ & 0,38 & 0,08 & 0,31 \\
\hline$f 80 p_{-} P S D_{M L \_T r e}(\mathrm{~Hz})$ & $\begin{array}{c}\mathrm{F}(2,0026,00) \\
0,58\end{array}$ & 0,57 & 0,04 & 0,14 & $\begin{array}{c}\mathrm{F}(2,0026,00) \\
3,14\end{array}$ & 0,06 & 0,20 & 0,55 & $\begin{array}{c}\mathrm{F}(4,0052,00) \\
0,43\end{array}$ & 0,78 & 0,03 & 0,14 \\
\hline$f 80 p_{-} P S D_{M L}(\mathrm{~Hz})$ & $\begin{array}{c}\mathrm{F}(2,0026,00) \\
1,01\end{array}$ & 0,38 & 0,07 & 0,21 & $\begin{array}{c}\mathrm{F}(2,0026,00) \\
2,10\end{array}$ & 0,14 & 0,14 & 0,39 & $\begin{array}{c}\mathrm{F}(4,0052,00) \\
0,02\end{array}$ & 1,00 & 0,00 & 0,05 \\
\hline$f 80 p_{-} P S D_{M L v}(\mathrm{~Hz})$ & $\begin{array}{c}\mathrm{F}(2,0026,00) \\
2,81\end{array}$ & 0,08 & 0,18 & 0,51 & $\begin{array}{c}\mathrm{F}(2,0026,00) \\
1,94\end{array}$ & 0,16 & 0,13 & 0,37 & $\begin{array}{c}\mathrm{F}(2,5533,12) \\
0,39\end{array}$ & 0,73 & 0,03 & 0,11 \\
\hline$\Delta T c_{A P}(\mathrm{~s})$ & $\begin{array}{c}\mathrm{F}(1,2816,64) \\
1,23\end{array}$ & 0,30 & 0,09 & 0,20 & $\begin{array}{c}\mathrm{F}(1,0313,39) \\
1,37\end{array}$ & 0,26 & 0,10 & 0,19 & $\begin{array}{c}\mathrm{F}(1,0814,07) \\
0,99\end{array}$ & 0,34 & 0,07 & 0,16 \\
\hline$\Delta T c_{M L}(\mathrm{~s})$ & $\begin{array}{c}\mathrm{F}(1,3417,48) \\
0,60\end{array}$ & 0,49 & 0,04 & 0,12 & $\begin{array}{c}\mathrm{F}(1,3417,42) \\
1,05\end{array}$ & 0,34 & 0,08 & 0,18 & $\begin{array}{c}\mathrm{F}(1,7422,56) \\
0,31\end{array}$ & 0,70 & 0,02 & 0,09 \\
\hline
\end{tabular}


Tabela 11, continuação da página anterior.

\begin{tabular}{|c|c|c|c|c|c|c|c|c|c|c|c|c|}
\hline \multirow[b]{2}{*}{ Parâmetro } & \multicolumn{4}{|c|}{ Protocolo } & \multicolumn{4}{|c|}{$\begin{array}{l}\text { ANOVA } \\
\text { Período }\end{array}$} & \multicolumn{4}{|c|}{ Protocolo x Período } \\
\hline & $\begin{array}{c}F\left(d f \begin{array}{l}\text { dferror }) \\
F\end{array}\right. \\
F\end{array}$ & $p$ & $\eta_{p}^{2}$ & $P$ & $\begin{array}{c}F(d f \text { dferror }) \\
F\end{array}$ & $p$ & $\eta_{p}^{2}$ & $P$ & $\begin{array}{c}F\left(d f \begin{array}{c}\text { dferror } \\
F\end{array}\right. \\
F\end{array}$ & $p$ & $\eta_{p}^{2}$ & $P$ \\
\hline$\left\langle\Delta X_{C O P_{A P}}^{2}\right\rangle_{C}\left(\mathrm{~mm}^{2}\right)$ & $\begin{array}{c}\mathrm{F}(1,0613,81) \\
2,40\end{array}$ & 0,14 & 0,16 & 0,31 & $\begin{array}{c}\mathrm{F}(1,0113,17) \\
1,22\end{array}$ & 0,29 & 0,09 & 0,18 & $\begin{array}{c}\mathrm{F}(1,0513,66) \\
1,05\end{array}$ & 0,33 & 0,08 & 0,16 \\
\hline$\left\langle\Delta X_{C O P_{M L}}^{2}\right\rangle_{C}\left(\mathrm{~mm}^{2}\right)$ & $\begin{array}{c}\mathrm{F}(2,0026,00) \\
0,97\end{array}$ & 0,39 & 0,07 & 0,20 & $\begin{array}{c}\mathrm{F}(2,0026,00) \\
2,16\end{array}$ & 0,14 & 0,14 & 0,40 & $\begin{array}{c}\mathrm{F}(2,1628,11) \\
0,27\end{array}$ & 0,78 & 0,02 & 0,09 \\
\hline$D l_{A P}\left(\mathrm{~mm}^{2} / \mathrm{s}\right)$ & $\begin{array}{c}\mathrm{F}(1,3117,05) \\
1,76\end{array}$ & 0,20 & 0,12 & 0,27 & $\begin{array}{c}\mathrm{F}(2,0026,00) \\
2,63\end{array}$ & 0,09 & 0,17 & 0,48 & $\begin{array}{c}\mathrm{F}(1,5019,48) \\
0,62\end{array}$ & 0,50 & 0,05 & 0,13 \\
\hline$D l_{M L}\left(\mathrm{~mm}^{2} / \mathrm{s}\right)$ & $\begin{array}{c}\mathrm{F}(2,0026,00) \\
1,85\end{array}$ & 0,18 & 0,13 & 0,35 & $\begin{array}{c}\mathrm{F}(2,0026,00) \\
1,79\end{array}$ & 0,19 & 0,12 & 0,34 & $\begin{array}{c}\mathrm{F}(1,9525,40) \\
0,64\end{array}$ & 0,53 & 0,05 & 0,14 \\
\hline$D s_{A P}\left(\mathrm{~mm}^{2} / \mathrm{s}\right)$ & $\begin{array}{c}\mathrm{F}(1,1815,39) \\
1,15\end{array}$ & 0,31 & 0,08 & 0,18 & $\begin{array}{c}\mathrm{F}(2,0026,00) \\
0,60\end{array}$ & 0,56 & 0,04 & 0,14 & $\begin{array}{c}\mathrm{F}(2,3029,84) \\
1,03\end{array}$ & 0,38 & 0,07 & 0,22 \\
\hline$D s_{M L}\left(\mathrm{~mm}^{2} / \mathrm{s}\right)$ & $\begin{array}{c}\mathrm{F}(2,0026,00) \\
1,70\end{array}$ & 0,20 & 0,12 & 0,33 & $\begin{array}{c}\mathrm{F}(1,1715,27) \\
1,04\end{array}$ & 0,34 & 0,07 & 0,17 & $\begin{array}{c}\mathrm{F}(1,5820,50) \\
0,28\end{array}$ & 0,71 & 0,02 & 0,09 \\
\hline$\alpha \_L_{A P}$ & $\begin{array}{c}\mathrm{F}(2,0026,00) \\
1,65\end{array}$ & 0,21 & 0,11 & 0,32 & $\begin{array}{c}\mathrm{F}(1,3717,85) \\
1,21\end{array}$ & 0,31 & 0,09 & 0,20 & $\begin{array}{c}\mathrm{F}(2,7335,53) \\
0,51\end{array}$ & 0,66 & 0,04 & 0,14 \\
\hline$\alpha \_L_{M L}$ & $\begin{array}{c}\mathrm{F}(2,0026,00 \\
0,94\end{array}$ & 0,40 & 0,07 & 0,19 & $\begin{array}{c}\mathrm{F}(2,0026,00 \\
6,86\end{array}$ & 0,00 & 0,35 & 0,89 & $\begin{array}{c}\mathrm{F}(4,0052,00 \\
3,06\end{array}$ & 0,03 & 0,19 & 0,77 \\
\hline$\alpha_{-} S_{A P}$ & $\begin{array}{c}\mathrm{F}(2,0026,00 \\
0,37\end{array}$ & 0,69 & 0,03 & 0,10 & $\begin{array}{c}\mathrm{F}(1,4118,34 \\
0,17\end{array}$ & 0,77 & 0,01 & 0,07 & $\begin{array}{c}\mathrm{F}(1,6421,38 \\
0,46\end{array}$ & 0,60 & 0,03 & 0,11 \\
\hline$\alpha \_S_{M L}$ & $\begin{array}{c}\mathrm{F}(2,0026,00 \\
1,80\end{array}$ & 0,19 & 0,12 & 0,34 & $\begin{array}{c}\mathrm{F}(2,0026,00 \\
1,81\end{array}$ & 0,18 & 0,12 & 0,34 & $\begin{array}{c}\mathrm{F}(4,0052,00 \\
0,43\end{array}$ & 0,79 & 0,03 & 0,14 \\
\hline$C I_{A P}$ & $\begin{array}{c}\mathrm{F}(2,0026,00 \\
0,68\end{array}$ & 0,52 & 0,05 & 0,15 & $\begin{array}{c}\mathrm{F}(2,0026,00 \\
0,40\end{array}$ & 0,67 & 0,03 & 0,11 & $\begin{array}{c}\mathrm{F}(4,0052,00 \\
1,31\end{array}$ & 0,28 & 0,09 & 0,38 \\
\hline$C I_{A P v}$ & $\begin{array}{c}\mathrm{F}(2,0026,00 \\
0,54\end{array}$ & 0,59 & 0,04 & 0,13 & $\begin{array}{c}\mathrm{F}(2,0026,00 \\
0,10\end{array}$ & 0,91 & 0,01 & 0,06 & $\begin{array}{c}\mathrm{F}(4,0052,00 \\
2,16\end{array}$ & 0,09 & 0,14 & 0,60 \\
\hline$C I_{M L}$ & $\begin{array}{c}\mathrm{F}(2,0026,00 \\
3,64\end{array}$ & 0,04 & 0,22 & 0,62 & $\begin{array}{c}\mathrm{F}(2,0026,00 \\
0,28\end{array}$ & 0,76 & 0,02 & 0,09 & $\begin{array}{c}\mathrm{F}(4,0052,00 \\
0,67\end{array}$ & 0,62 & 0,05 & 0,20 \\
\hline$C I_{M L v}$ & $\begin{array}{c}\mathrm{F}(2,0026,00 \\
3,28\end{array}$ & 0,05 & 0,20 & 0,57 & $\begin{array}{c}\mathrm{F}(2,0026,00 \\
0,82\end{array}$ & 0,45 & 0,06 & 0,18 & $\begin{array}{c}\mathrm{F}(2,5733,37 \\
1,21\end{array}$ & 0,32 & 0,09 & 0,27 \\
\hline
\end{tabular}


Tabela 12: Resultado da análise post hoc realizada nos parâmetros que apresentaram diferenças significativas $(p \leq 0,05) . \mathbf{P}=$ Protocolo Placebo. $\mathbf{C}=$ Protocolo $(\mathrm{C}-\mathrm{T} 10, \mathrm{~A}-$ CiDeE), $\mathbf{A}=$ Protocolo (A-T10,C-CiDeE), t0 = período antes do protocolo de estimulação elétrica. $\mathrm{t1}$ = período durante o protocolo de estimulação elétrica. t2 = período depois do protocolo de estimulação elétrica. Exemplo de interpretação da tabela: A análise posthoc indicou que o parâmetro $C I_{M L}$ apresentou diferenças significativas entre os protocolos Placebo e (A-T10,C-CiDeE).

\begin{tabular}{|c|c|c|c|c|c|c|c|c|c|c|c|c|c|c|c|c|c|c|}
\hline & \multicolumn{3}{|c|}{$\mathbf{P}$} & \multicolumn{3}{|c|}{$\mathrm{C}$} & \multicolumn{3}{|c|}{ A } & \multicolumn{3}{|c|}{ to } & \multicolumn{3}{|c|}{ t1 } & \multicolumn{3}{|c|}{ t2 } \\
\hline Parâmetro & to & t1 & $\mathrm{t} 2$ & to & t1 & t2 & to & t1 & t2 & $\mathbf{P}$ & $\mathrm{C}$ & A & $\mathbf{P}$ & $\mathrm{C}$ & A & $\mathbf{P}$ & $\mathrm{C}$ & A \\
\hline \multicolumn{19}{|l|}{$\alpha_{-} L_{M L}$} \\
\hline \multicolumn{19}{|l|}{$C I_{M L}$} \\
\hline & & & & & & & & & \multicolumn{10}{|c|}{ Diferença significativa entre protocolos } \\
\hline & & & & & & & & & \multicolumn{10}{|c|}{ Diferença significativa entre períodos } \\
\hline & & & & & & & & & \multicolumn{10}{|c|}{ Diferença significativa nas interações } \\
\hline
\end{tabular}



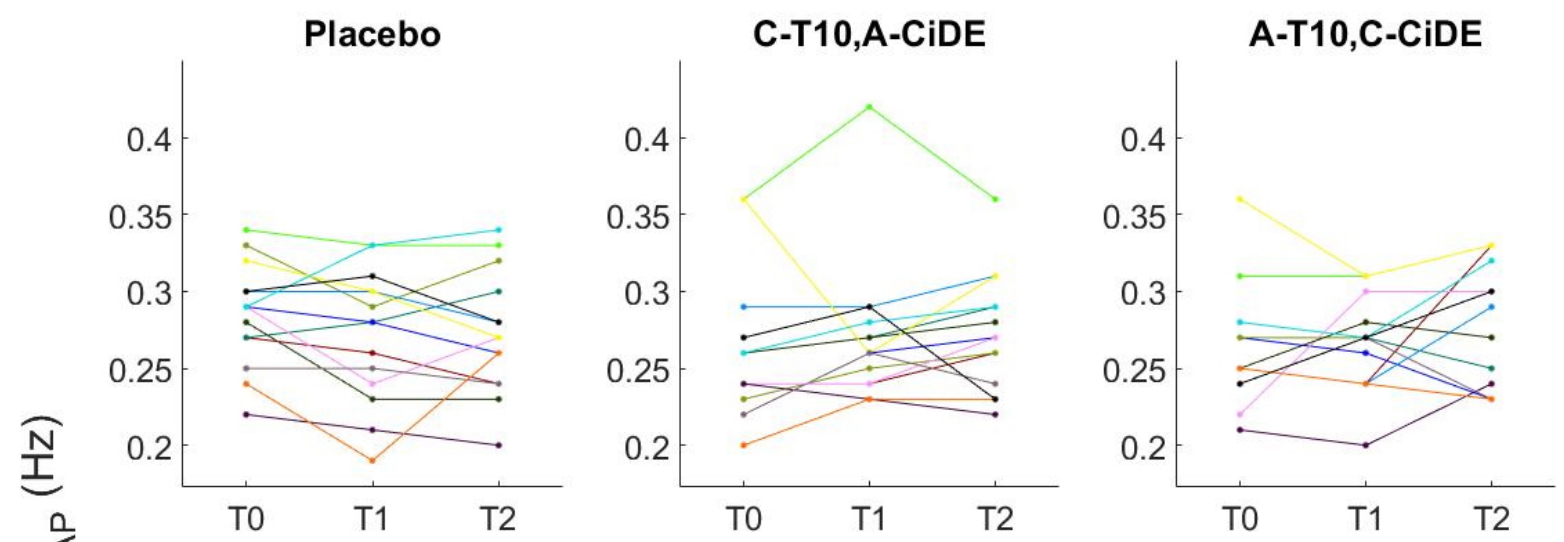

잉

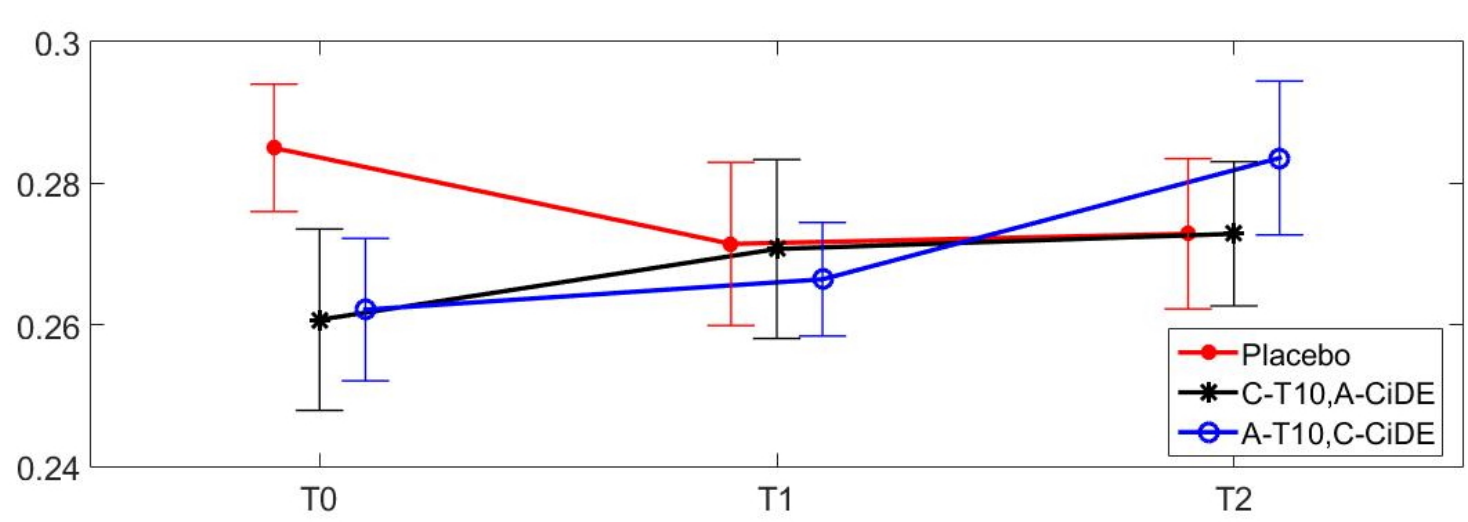

Figura 73: Dados experimentais do parâmetro $f 50 p P S D_{A P}$. Acima: Valores do parâmetro $f 50 p P S D_{A P}$ obtidos da posturografia por plataforma de força de cada participante do experimento, em cada protocolo (Placebo, (C-T10,A-CiDeE) e (A-T10,CCiDeE) , nos três períodos do protocolo (t0, t1 e t2). Os resultados de cada participante são diferenciados por diferentes cores de linhas exibidas nos gráficos (Tabela 10). Abaixo: Valores das médias, calculadas dos dados obtidos de todos os participantes, do parâmetro f50pPSD $D_{A P}$, nos três protocolos em cada período do protocolo. A barra de erro exibida indica o erro padrão da média obtida. 

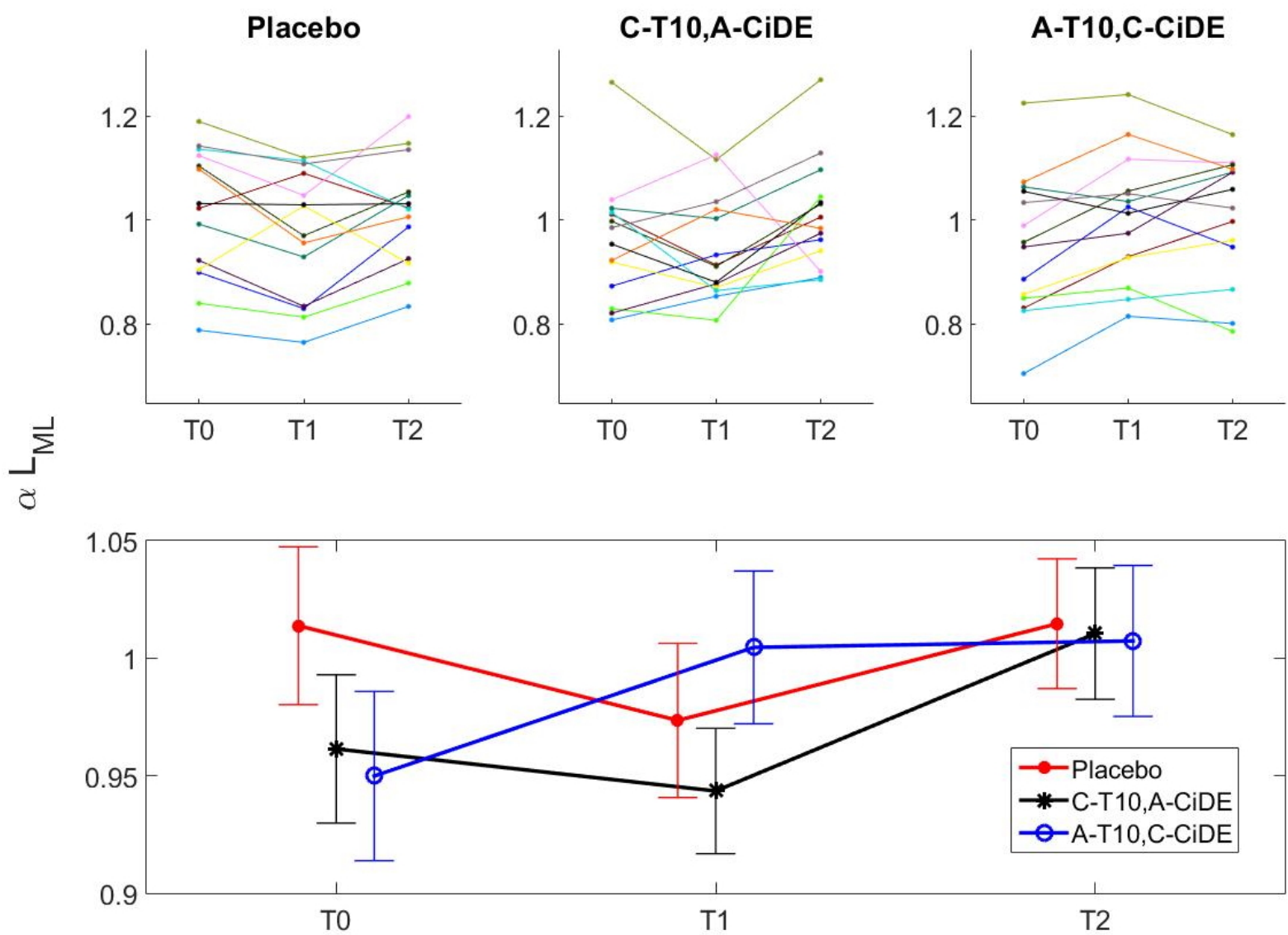

Figura 74: Dados experimentais do parâmetro $\alpha L_{M L}$. Acima: Valores do parâmetro $\alpha L_{M L}$ obtidos da posturografia por plataforma de força de cada participante do experimento, em cada protocolo (Placebo, (C-T10,A-CiDeE) e (A-T10,C-CiDeE), nos três períodos do protocolo t t0, t1 e t2 . Os resultados de cada participante são diferenciados por diferentes cores de linhas exibidas nos gráficos (Tabela 10). Abaixo: Valores das médias, calculadas dos dados obtidos de todos os participantes, do parâmetro $\alpha L_{M L}$, nos três protocolos em cada período do protocolo. A barra de erro exibida indica o erro padrão da média obtida. 


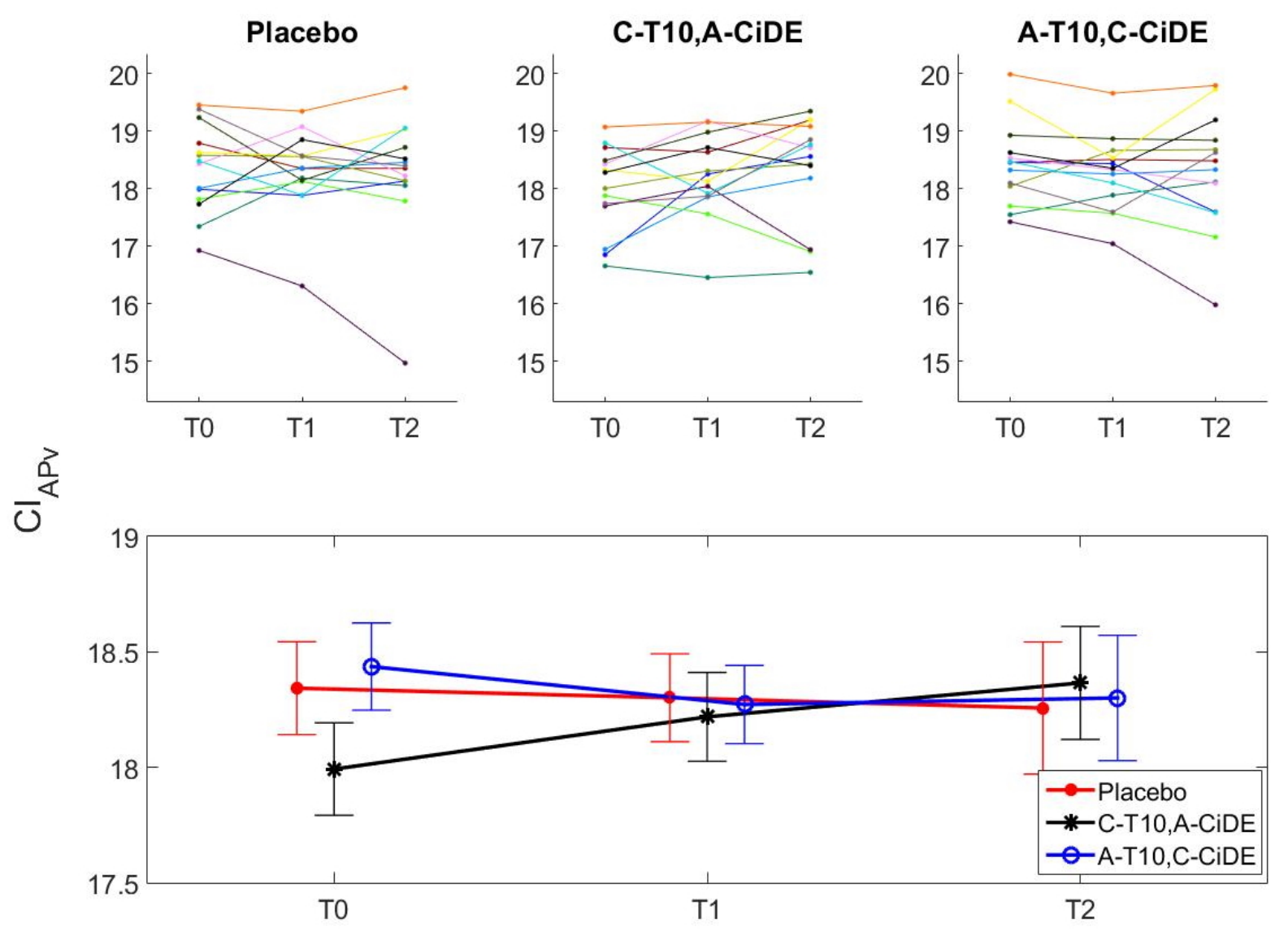

Figura 75: Dados experimentais do parâmetro $C I_{A P v}$. Acima: Valores do parâmetro $C I_{A P v}$ obtidos da posturografia por plataforma de força de cada participante do experimento, em cada protocolo (Placebo, (C-T10,A-CiDeE) e (A-T10,C-CiDeE) $)$, nos três períodos do protocolo to, t1 e t2 . Os resultados de cada participante são diferenciados por diferentes cores de linhas exibidas nos gráficos (Tabela 10). Abaixo: Valores das médias, calculadas dos dados obtidos de todos os participantes, do parâmetro $C I_{A P v}$, nos três protocolos em cada período do protocolo. A barra de erro exibida indica o erro padrão da média obtida. 

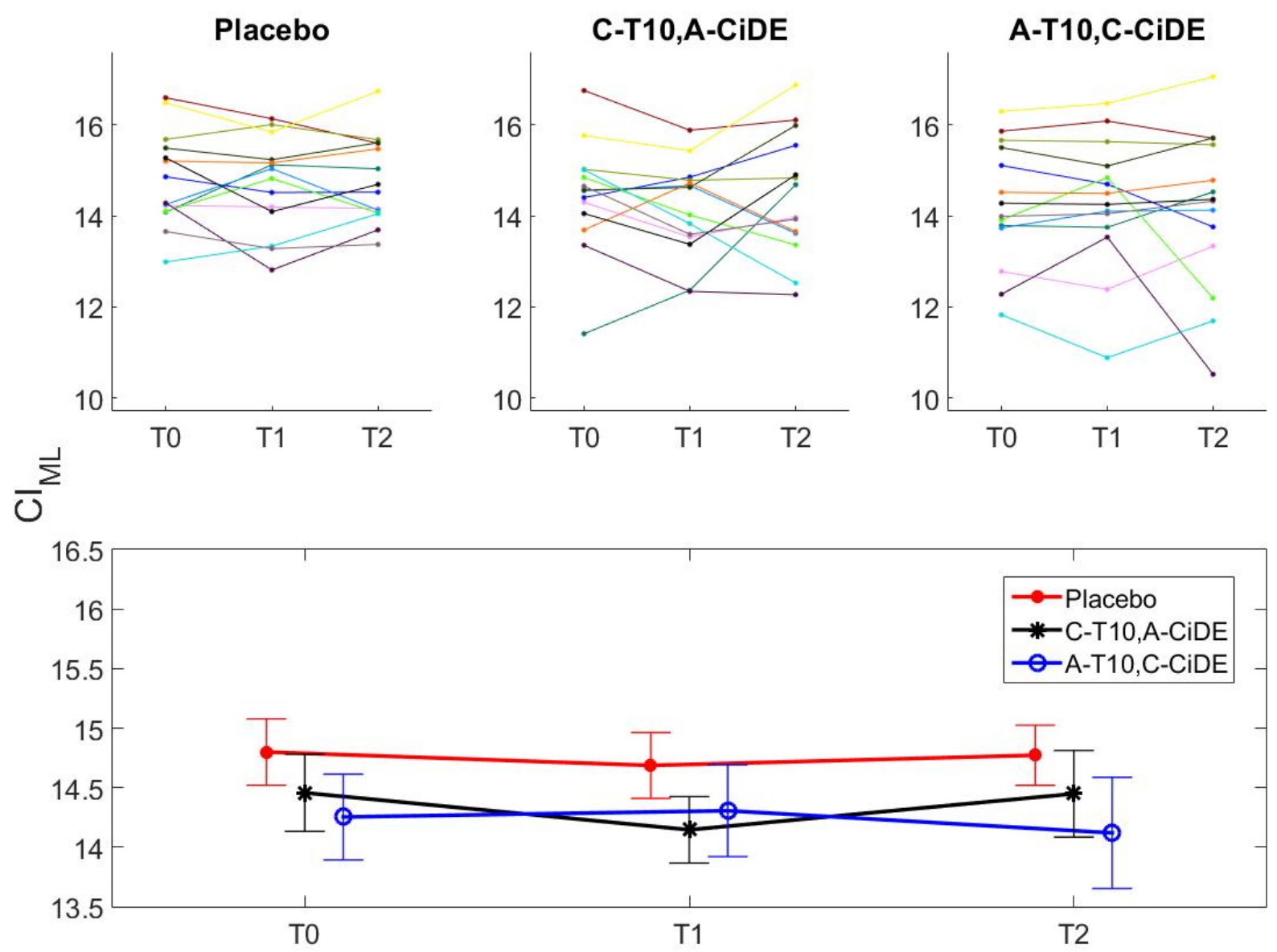

Figura 76: Dados experimentais do parâmetro $C I_{M L}$. Acima: Valores do parâmetro $C I_{M L}$ obtidos da posturografia por plataforma de força de cada participante do experimento, em cada protocolo (Placebo, (C-T10,A-CiDeE) e (A-T10,C-CiDeE) $)$, nos três períodos do protocolo t $\mathrm{t} 0$, t1 e t2). Os resultados de cada participante são diferenciados por diferentes cores de linhas exibidas nos gráficos (Tabela 10). Abaixo: Valores das médias, calculadas dos dados obtidos de todos os participantes, do parâmetro $C I_{M L}$, nos três protocolos em cada período do protocolo. A barra de erro exibida indica o erro padrão da média obtida. 


\section{DISCUSSÃO}

A utilização de um modelo computacional geométrico simplificado do tronco humano para a estimação do campo elétrico em protocolos de tsDCS possibilitou a análise qualitativa rápida de algumas configurações de eletrodos e intensidades de estimulação com nível de exatidão aceitável. As intensidades do campo elétrico obtidas por esse modelo simplificado apresentou valores semelhantes aos encontrados em outros estudos (KUCK; STEGEMAN; ASSELDONK, 2017; PARAZZINI et al., 2014). Nesse trabalho o resultado do cálculo da distribuição do campo elétrico em cada configuração foi obtido em aproximadamente 44 segundos (Intel Core 17870 2,93GHz, 16Gb RAM, Microsoft Windows 7 Professional). Além do tempo de processamento aceitável, o modelo simplificado permitiu o rápido posicionamento dos eletrodos sobre a superfície do modelo do tronco humano, já que nesse modelo, a superfície do tronco humano é plana. Em superfícies não planas, como observadas em modelos de tronco complexo (FERNANDES et al., 2018; KUCK; STEGEMAN; ASSELDONK, 2017), para o posicionamento dos eletrodos no modelo é necessária a utilização de ferramentas de modelagem 3D específicas que, em geral, além de necessitarem o correto alinhamento do eletrodo e a superfície, demandando tempo para a construção do modelo, acabam modificando a área total de contato da superfície do eletrodo durante o processo de moldagem do eletrodo ao contorno da superfície. Na literatura não foram encontrados estudos de análise da influência da complexidade do modelo do tronco humano na exatidão dos resultados obtidos na estimação do campo elétrico gerado pela tsDCS, Para a tDCS a inclusão de um número maior de camadas de tecidos e a utilização de características anisotrópicas, especialmente do tecido neural e do crânio, produziu diferenças de até $30 \%$ nos resultados de simulação computacional (SHAHID; WEN; AHFOCK, 2012), porém a análise qualitativa da distribuição do campo elétrico não foi influenciada pela omissão das propriedades anisotrópicas dos tecidos SHAHID et al., 2014). O campo elétrico produzido pela tDCS possivelmente apresenta distribuição mais complexa do que o produzido pela tsDCS, já que os eletrodos de estimulação na tDCS, em geral, são posicionados com distanciamentos menores do que na tsDCS. Sendo assim é possível argumentar que a utilização de um modelo simplificado, como o utilizado 
nesse trabalho, para análises qualitativas da distribuição do campo elétrico na tsDCS é válida. Porém a utilização desse modelo simplificado para análise de outras configurações de eletrodos e intensidades de estimulação, diferentes das apresentadas nesse estudo, demanda maiores validações a serem realizadas com outros modelos complexos já que a validação desse modelo foi realizada apenas na configuração e intensidade de estimulação de maior interesse.

A adição de um terceiro eletrodo sobre a crista ilíaca esquerda permite a redução da densidade de corrente elétrica na área de contato entre a pele e os eletrodos posicionados sobre a região da crista ilíaca sem aparentemente causar mudanças significativas da distribuição do campo elétrico na medula espinhal, possivelmente melhorando o cegamento experimental. Porém, por meio do modelo simplificado do tronco humano, é possível verificar a existência de uma pequena discrepância entre as distribuições dos campos elétricos em regiões distais da medula nas configurações MS-2 e MS-3 na orientação ML (Figura 59), possivelmente gerada pela assimetria da distribuição de corrente elétrica produzida pela a configuração que utiliza apenas dois eletrodos. A comparação entre os resultados obtidos por um modelo complexo e pelo modelo simplificado permite notar que o resultado do modelo simplificado é menor na orientação ML na configuração MS-2. Sendo assim, pode ser possível que, caso fosse utilizado um modelo complexo para analisar a diferença entre as configurações MS-2 e MS-3, fosse verificada uma diferença significativa entre as duas configurações em regiões distais ao cone medular, como por exemplo na cauda equina. Porém possivelmente a estimulação elétrica de regiões distais ao cone medular não é significativa para os efeitos observados da tsDCS (PEREIRA et al., 2018) que estão possivelmente principalmente relacionados com a despolarização elétrica das terminações axonais dos neurônios da medula (KUCK; STEGEMAN; ASSELDONK, 2017). Com isso, mesmo que a estimulação tsDCS na configuração MS-2 possa produzir campo elétrico não desprezível na região da cauda equina, os efeitos da tsDCS realizada na configuração MS-2 e MS-3 possivelmente ainda podem ser consideradas equivalentes.

Diferentemente do esperado, por meio da utilização do modelo simplificado do tronco humano foi possível verificar que o aumento da dimensão dos eletrodos de estimulação não aumentou a região da medula estimulada com campo elétrico com módulo maior do que $0,15 \mathrm{~V} / \mathrm{m}$ (Figura 62), sendo inclusive observada uma pequena redução da intensidade do campo elétrico na medula espinhal com o aumento da dimensão dos eletrodos de estimulação. Resultado semelhante foi obtido por FARIA; HALLETT; MIRANDA em um estudo sobre tDCS que observaram que, para uma mesma intensidade de corrente de estimulação, eletrodos de estimulação maiores produziam intensidades menores de campos elétricos em tecidos neurais do cérebro para (FARIA; HALLETT; MIRANDA, 
2011). Para a tsDCS na configuração MS-3, caso a redução da intensidade do campo elétrico causada pela utilização de eletrodos maiores seja considerada desprezível, embora o aumento da dimensão do eletrodo não possa ser considerado um método eficaz para ampliar a região da medula estimulada por um campo elétrico com módulo maior do que $0,15 \mathrm{~V} / \mathrm{m}$, pode ser considerado um método eficaz para a redução da densidade de corrente elétrica na área de contato entre a pele e os eletrodos de estimulação sem que ocorra modificação significativa do tamanho e da localização da região da medula estimulada com campo elétrico de pelos menos $0,15 \mathrm{~V} / \mathrm{m}$, permitindo a possível melhoria do cegamento experimental, além de diminuir a probabilidade de causar eritema ou lesões de pele.

Por meio do modelo simplificado do tronco humano foi possível verificar que a estimulação elétrica de $5 \mathrm{~mA}$, na configuração MS-EXP aumentou em $79 \%$ o tamanho da região da medula espinhal estimulada com campo elétrico com intensidade maior do que $0,15 \mathrm{~V} / \mathrm{m}$ em relação a estimulação de 2,5 mA (Tabela 9). Embora a intensidade do campo elétrico observado na medula espinhal aparentemente tenha apresentado relação linear com a intensidade da corrente elétrica de estimulação (Figura 67), foi observado que o tamanho da região da medula espinhal estimulada com campo elétrico de pelo menos $0,15 \mathrm{~V} / \mathrm{m}$ não apresentou relação linear com a intensidade de estimulação (Tabela 8). O aumento de corrente elétrica é um método eficaz para aumentar o tamanho da região da medula estimulada com campo de no mínimo $0,15 \mathrm{~V} / \mathrm{m}$, porém não foram encontrados estudos que verificaram a relação entre a magnitude dos efeitos fisiológicos observados da estimulação tsDCS e o aumento da região da medula espinhal estimulada.

Estudos de tsDCS, assim como de tDCS, em geral utilizam critérios de segurança elétrica que foram propostos em estudos que verificaram danos provocados em tecido neural de animais (MCCREERY et al., 1990; YUEN et al., 1981), e não levam em conta a distribuição da densidade de corrente elétrica gerada dentro do corpo humano pela configuração de estimulação adotada. Nesse estudo, caso esses critérios fossem adotados, o limite máximo de corrente elétrica que poderia ser utilizado sem que fossem observados danos nos tecidos neurais da medula seria de 1.25 A (Limites máximos: $25 \mathrm{~mA} / \mathrm{cm}^{2}$ e $216 \mathrm{C} / \mathrm{cm}^{2}$ ). Estudos recentes de tDCS sugerem a utilização de critérios de segurança que levem em conta a densidade de corrente elétrica gerada nos tecidos neurais obtida como por exemplo pela utilização de modelos computacionais (KNOTKOVA et al., 2019c). Não foram encontrados estudos de tsDCS que analisaram o limite de segurança da estimulação elétrica por meio dessa metodologia. Esse possivelmente é o primeiro estudo de tsDCS que adotou um modelo computacional para verificar o limite de corrente elétrica que pode ser utilizado sem que a densidade de corrente elétrica dentro da medula espinhal ultrapasse $6,3 \mathrm{~A} / \mathrm{m}^{2}$ (Figura 71). Essa análise permitiu verificar que esse limite seria de $250 \mathrm{~mA}$, valor cinco 
vezes menor do que o obtido por meio dos critérios convencionais. Embora esses valores limítrofes não sejam utilizados em protocolos de estimulação de CC, já que densidades de corrente elétrica maiores do $0,02857 \mathrm{~mA} / \mathrm{cm}^{2}$ causam desconforto na região de contato entre a pele e os eletrodos de estimulação (NITSCHE, 2003), esses critérios são úteis para argumentar que os valores de corrente elétrica utilizados nos protocolos experimentais são pelo menos uma ordem de grandeza menores do que os valores necessários para gerar danos em tecidos neurais (KNOTKOVA et al., 2019c).

Embora alguns estudos tenham verificado que a tsDCS alterou o desempenho de indivíduos em tarefas motoras (AWOSIKA et al., 2019; BERRY; TATE; CONWAY, 2017) e também modificou sinais eletrofisiológicos relacionados com vias neurais medulares do sistema somatossensorial e motor dos membros inferiores, como por exemplo: SEP (COGIAMANIAN et al., 2008), HD (WINKLER; HERING; STRAUBE, 2010; LAMY et al., 2012; LAMY; BOAKYE, 2013; HEIDE et al., 2014) e PSI (YAMAGUCHI et al., 2013), assim como de vias supramedulares (MURRAY; TAHAYORI; KNIKOU, 2018), nesse estudo não foram observadas alterações estatisticamente significativas do comportamento das oscilações posturais na direção AP de indivíduos saudáveis durante a execução da PEO induzidas pela tsDCS (Tabela 11).

Alguns estudos, não relacionados com tsDCS, mostraram que é possível reduzir a amplitude da oscilação postural durante a $\mathrm{PEO}$ ou por meio de alteração das entradas sensoriais (KRISHNAMOORTHY; SLIJPER; LATASH, 2002) ou por meio de estimulação elétrica (MAGALHÃES; KOHN, 2012) ou mecânica (PRIPLATA et al., 2002), em condições semelhantes às adotas nesse trabalho (jovens saudáveis executando a PEO . Sendo assim é possível argumentar que a não obtenção de alterações significativas de parâmetros do COP na direção $\mathrm{AP}$ nesse estudo não está relacionada com a impossibilidade de causar melhora ou alteração do controle postural durante a PEO na condição analisada. É possível que alterações significativas possam ser observadas com a utilização de um tamanho de espaço amostral maior, já que a ANOVA apresentou poder estatístico baixo $(P \leq 0.8)$ (Tabela 11), ou de um outro grupo de indivíduos, como por exemplo: idosos, idosos com histórico de quedas, ou indivíduos com alguma neuropatia específica, para as mesmas condições analisadas nesse estudo.

Em geral estudos sobre os efeitos da tsDCS relacionados a membros inferiores utilizaram intensidade de corrente de estimulação elétrica de 2,5 mA (COGIAMANIAN et al., 2008; WINKLER; HERING; STRAUBE, 2010; LAMY et al., 2012; HUBLI et al., 2013; BOCCI et al., 2014; MURRAY; TAHAYORI; KNIKOU, 2018). Nesse estudo, de modo a aumentar a região da medula espinhal estimulada com campo elétrico com módulo maior do que $0,15 \mathrm{~V} / \mathrm{m}$ (Tabela 9), foi utilizada uma intensidade de estimulação elétrica de $5 \mathrm{~mA}$. 
Alguns estudos de tDCS sugerem que a relação entre intensidade de corrente e efeito da estimulação pode ser não linear, indicando que o aumento da corrente da estimulação pode não resultar no aumento do efeito observado (BATSIKADZE et al., 2013; LEARMONTH et al., 2017; ESMAEILPOUR et al., 2018; VIGNAUD et al., 2018; HOY et al., 2013) ou pode até mesmo resultar na redução ou anulação do mesmo (JAMIL et al., 2017). Sendo assim, é possível que nesse estudo a utilização de uma corrente de estimulação de $5 \mathrm{~mA}$, ao invés de 2,5 mA, pode ter causado a redução ou a anulação do efeito da tsDCS. Em um estudo de efeitos da tsDCS relacionados a membros superiores, a estimulação elétrica de 3 mA não alterou o MEP ou a HD (DONGÉS et al., 2017). Em membros inferiores, foram observadas alterações significativas corticais, corticomedulares e medulares de saídas motoras para uma estimulação elétrica de até 4 mA (MURRAY; TAHAYORI; KNIKOU, 2018). A utilização de uma corrente elétrica de $5 \mathrm{~mA}$ também pode ter provocado dos participantes do experimento um aumento nas experiências sensoriais, como por exemplo formigamento e queimação na região de contato entre os eletrodos de estimulação e a pele, no início do protocolo de estimulação elétrica, induzindo a alteração do estado de atenção e nível de ansiedade durante todo o experimento e consequentemente podendo ter provocado o mascaramento dos efeitos induzidos pela tsDCS, Esse mesmo efeito também pode ter sido obtido pela otimização da estimulação elétrica da região da intumescência lombossacral gerada pelo posicionamento de eletrodos selecionado (FERNANDES et al. 2018).

O posicionamento dos eletrodos de estimulação selecionado também difere do de outros estudos que verificaram os efeitos da tsDCS relacionados com membros inferiores, que em geral utilizaram um eletrodo posicionado sobre T10 ou T11 e outro eletrodo posicionado sobre o ombro direito. Um estudo que utilizou posicionamento semelhante ao utilizado nesse estudo também não observou alterações significativas dos sinais eletrofisiológicos relacionados com vias neurais medulares de membros inferiores (PEREIRA et al., 2018). O posicionamento de eletrodos sobre T10 ou T11 sobre o ombro direito provoca a maior estimulação de regiões medulares acima da altura de T11, enquanto que o posicionamento de eletrodos sobre T11 e sobre a crista ilíaca direita induz a maior estimulação de regiões medulares abaixo da altura de T11 (FERNANDES et al., 2018). Sendo assim, pode ser que os efeitos da tsDCS em membros inferiores estejam principalmente relacionados com a estimulação de regiões acima da intumescência lombossacral da medula espinhal podendo ser esta também uma das possíveis explicações para a não observação de efeitos da tsDCS nesse estudo. Essa hipótese pode ser válida já que alguns estudos verificaram que os efeitos da tsDCS possivelmente estão relacionadas com alterações tanto do comportamento medular quanto supramedular (SCHWEIZER et al., 2017; MARANGOLO et al., 
2020). Outra explicação poderia ser a diferença da orientação do campo elétrico induzido na medula espinhal, principalmente na região da intumescência lombossacral, nas diferentes configurações de posicionamento de eletrodos, já que diferentes orientações do campo elétrico produzem diferentes alterações do potencial de membrana dos compartimentos dos neurônios na medula espinhal (KUCK; STEGEMAN; ASSELDONK, 2017).

Os efeitos observados da tsDCS podem ser modulados pelo poliformismo do gene BDNF (LAMY; BOAKYE, 2013). Nesse estudo não foi analisado se os participantes do experimento eram portadores do alelo Val/Val ou do alelo Met desse gene. A diversidade do gene BDNF é variável na população global, podendo ser observadas populações que não apresentam a ocorrência do alelo Val (PETRYSHEN et al., 2010). Uma possível explicação para a não observação de efeitos da tsDCS nesse estudo pode ter sido a seleção de participantes majoritariamente portadores do alelo Met, sendo estes menos propensos aos efeitos da tsDCS (LAMY; BOAKYE, 2013). Porém vale ressaltar que a relação entre os efeitos da tsDCS e o poliformismo do gene BDNF ainda não é totalmente aceita KUCK et al., 2018).

Embora a maior parte dos estudos de tsDCS não relatam dificuldades para a obtenção do cegamento experimental do participante em relação ao tipo de protocolo de estimulação elétrica aplicada, foi observado em nosso Laboratório que os métodos de estimulação propostos na literatura não são eficientes para a obtenção do cegamento experimental. Nesse estudo foi utilizado um novo método de inicialização do protocolo de estimulação elétrica, de modo que a experiência sensorial da estimulação elétrica se tornasse semelhante nos três protocolos de estimulação (Placebo, (C-T10,A-CiDeE) e (A-T10,C-CiDeE) . A utilização desse método pode ter minimizado a influência dos efeitos da tsDCS resultantes dessa informação sensorial proveniente da região de contato dos eletrodos, de modo que a não obtenção de efeitos nesse estudo possa indicar que os efeitos da tsDCS observados em outros estudos possam também estar associados às experiências sensoriais da estimulação e não apenas à estimulação da medula espinhal.

Os efeitos observados da tDCS podem depender da tarefa executada pelo indivíduo durante a estimulação elétrica (POPE; MIALL, 2012; MARQUEZ et al., 2013). Essa dependência pode estar relacionada com os possíveis efeitos da estimulação DC nos neurônios. O mecanismo primário de ação da tDCS possivelmente é a pequena modificação do potencial de membrana dos compartimentos de alguns neurônios da região do cérebro estimulada pela CC (KNOTKOVA et al., 2019b). Essa modificação de potencial elétrico pode provocar alterações no tempo e na frequência de disparo tanto dos neurônios estimulados quanto de neurônios que se integram aos neurônios estimulados KNOTKOVA et al. 2019b). O possível mecanismo secundário de ação da tDCS, decorrente do meca- 
nismo primário, responsável pelos efeitos de longa duração da tDCS, é possivelmente a modificação de canais iônicos L-VGCC e de receptores NMDA dos neurônios causada pela alteração do tempo e frequência de disparos de PA (KNOTKOVA et al., 2019b) que dependem da tarefa executada pelo indivíduo durante a estimulação. Os possíveis mecanismos de ação da tDCS podem ser os responsáveis pelos efeitos observados na tsDCS, de modo que esses efeitos também possam ser tarefa-dependentes. Em ratos foi verificado que alguns efeitos de longa duração da tsDCS não possuíam dependência com a atividade executada (JANKOWSKA et al., 2016). Alguns estudos já verificaram a ocorrência de efeitos provocados pela tsDCS em tarefas de salto (BERRY; TATE; CONWAY, 2017) e de locomoção (AWOSIKA et al., 2019), porém não foram encontrados estudos em humanos que verificaram a dependência dos efeitos da tsDCS e a atividade executada. Sendo assim, uma outra possível hipótese para os resultados experimentais obtidos nesse estudo é a possível dependência dos efeitos da tsDCS e a tarefa executada, sendo que a execução da PEO, nas condições adotadas nesse estudo, pode ter inibido os efeitos da tsDCS ou os eventuais mecanismos afetados pela tsDCS não seriam determinantes na tarefa de execução da $\mathrm{PEO}$.

O tamanho e o tipo de eletrodos de estimulação utilizados podem influenciar a distribuição do campo elétrico gerado no corpo humano (HO et al., 2016; BASTANI; JABERZADEH, 2013: SATURNINO; ANTUNES; THIELSCHER, 2015). Embora nesse estudo o resultado da simulação computacional utilizando o modelo de tronco simplificado tenha evidenciado que a utilização de um eletrodo de dimensão maior não influenciasse o tamanho e posição da região da medula espinhal estimulada com campo elétrico maior dod que $0,15 \mathrm{~V} / \mathrm{m}$, foi verificado que a utilização de um eletrodo de maior dimensão resultaria em intensidades de campo elétrico menores do que as obtidas com um eletrodo de dimensão menor (Figura 61) podendo ter resultado na redução do efeito da tsDCS, A utilização de eletrodos de diferentes dimensões, na tDCS, pode provocar alterações dos efeitos da estimulação $\mathrm{HO}$ et al. 2016: BASTANI; JABERZADEH, 2013). Além do tamanho, o tipo de eletrodo utilizado pode influenciar na distribuição do campo elétrico por meio da distribuição não uniforme de densidade de corrente elétrica na superfície de contato entre a pele e os eletrodos (SATURNINO; ANTUNES; THIELSCHER, 2015), podendo influenciar os efeitos da estimulação elétrica. Por praticidade experimental, nesse estudo foram utilizados eletrodos auto-adesivos, porém na maior parte dos estudos de tsDCS os eletrodos utilizados foram de esponja embebida em solução salina. Embora essa também possa ser uma das hipóteses para os resultados experimentais obtidos, durante as sessões experimentais, foi observado que na maior parte dos participantes, após o término do experimento, ao serem retirados os eletrodos, foi notada vermelhidão uniforme da região da pele em contato 
com os eletrodos de estimulação, indicando possível distribuição uniforme de densidade de corrente elétrica na superfície da pele dos participantes do experimento.

Embora não foram observadas alterações estatisticamente significativas dos parâmetros do COP na direção AP geradas pela tsDCS foi observado que tanto a estimulação (A-T10,CCiDeE) quando a (C-T10,A-CiDeE) causaram aumento tanto em t1 e t2, com tamanho de efeito grande $\left(\eta_{p}^{2}>0,14\right)$, do parâmetro $f 50 p P S D_{A P}$ em relação ao comportamento desse parâmetro no protocolo placebo (Figura 73). O aumento desse parâmetro indica que a frequência em que é observada metade da potência PSD do COP na direção AP foi deslocada para frequências maiores. Esse fenômeno pode indicar o aumento do controle das oscilações posturais por malhas de controle rápidas, que podem estar relacionadas com os circuitos neurais medulares do sistema proprioceptivo (DUPUI et al., 1990). Efeito semelhante também foi observado na análise do parâmetro $C I_{A P v}$ que apresentou comportamento temporal diferente no protocolo (C-T10,A-CiDeE) do observado nos protocolos (A-T10,C-CiDeE) e Placebo (Figura 75). Possivelmente o protocolo (C-T10,A-CiDeE) provocou o aumento da complexidade do sinal de velocidade do COP tanto durante t $\mathrm{t} 1$ quanto após (t2) a estimulação elétrica. O aumento desse parâmetro pode indicar uma melhora do controle postural provocada pela estimulação (C-T10,A-CiDeE) (PINCUS; GOLDBERGER, 1994). Porém a diferença nos resultados obtidos não são estatisticamente significantes.

Os parâmetros $C I_{M L}$ e $\alpha L_{-} M L$, apresentaram diferenças estaticamente significantes na ANOVA (Tabela 11). A diferença observada no parâmetro $C I_{M L}$, pela análise post-hoc, ocorre entre os protocolos (A-T10,C-CiDeE) e Placebo, porém esta diferença possivelmente foi gerada pelo comportamento não homogêneo da dinâmica postural dos participantes do experimento nos diferentes dias de coletas de dados experimentais. É possível notar que a diferença do parâmetro $C I_{M L}$ entre o protocolo (A-T10,C-CiDeE) e Placebo não é modificada ao longo da duração dos protocolos de estimulação elétrica , estando presente desde o período t0 (Figura 76). A diferença observada no protocolo $\alpha L \_M L$ ocorre entre períodos da estimulação nos três protocolos (Marcações vermelhas na tabela 12), possivelmente resultante do comportamento não homogêneo da dinâmica postural dos participantes nos diferentes dias de coletas de dados, mas também ocorre entre os períodos do protocolo (A-T10,C-CiDeE) (Marcações azuis na tabela 12. A tsDCS gerou o aumento estatisticamente significante do parâmetro $\alpha L_{-} M L$ tanto durante quanto após o protocolo (A-T10,C-CiDeE), O aumento desse parâmetro pode indicar um aumento do comportamento fractal do sinal do COP na direção ML em janelas de tempo de longa duração (GILFRICHE et al., 2018). Embora em estudos anteriores (COLLINS; LUCA, 1993) a análise fractal dos sinais do COP tenha sido utilizada para a análise das carac- 
terísticas da malha de controle do sistema de controle postural, atualmente acredita-se que essa análise possa não ser apropriada (PETERKA, 2000).

Nesse estudo, dados coletados de três participantes foram excluídos do processamento por ter sido notada a presença de algum tipo de lesão cutânea na região de contato entre a pele e eletrodos após o protocolo de estimulação elétrica. Embora uma possível explicação para o surgimento dessas lesões pudesse ser a utilização de eletrodos descartáveis, esse tipo de lesão também foi notada em protocolos de tDCS que utilizaram eletrodos de esponja embebidos em solução líquida (água da torneira ou solução salina) (FRANK, 2010; PALM et al., 2008; WANG et al., 2015). Essas lesões podem estar associadas com a ocorrência de uma distribuição não uniforme da corrente elétrica na área do eletrodo, causada pela alta impedância de contato entre pele e eletrodos ( (PALM et al., 2008), ou pela ocorrência de reações eletroquímicas em regiões da superfície do eletrodo que produzem o acúmulo de substâncias nocivas à pele (FRANK, 2010). A frequência de ocorrência desse tipo de lesão é possivelmente proporcional à intensidade de corrente elétrica empregada no protocolo de estimulação (PALM et al., 2008), de forma que as intercorrências observadas nesse estudo podem estar associadas com a densidade de corrente de estimulação elétrica nos eletrodos selecionada de $5 \mathrm{~mA} / 50 \mathrm{~cm}^{2}$, maior do que a utilizada em outros estudos de tsDCS. 


\section{CONCLUSÃO}

Nesse trabalho foi verificado que a utilização de um modelo computacional simplificado do tronco humano permitiu a análise rápida do campo elétrico gerado pela tsDCS dentro do corpo humano, em diferentes configurações de protocolos de estimulação, sem sacrificar de forma expressiva a acurácia dos resultados.

Por meio da utilização do modelo computacional simplificado foi verificado que:

1. A adição de um terceiro eletrodo posicionado sobre a crista ilíaca esquerda, conectado eletricamente ao eletrodo posicionado sobre a crista ilíaca direita, na configuração "Um eletrodo sobre T10 e outro eletrodo sobre a crista ilíaca esquerda", não provocou alteração significativa do tamanho e localização da região da medula espinhal estimulada com campo elétrico com intensidade maior do que $0,15 \mathrm{~V} / \mathrm{m}$.

2. O aumento da dimensão dos eletrodos de estimulação na realização da tsDCS, na configuração "Um eletrodo sobre T10 e dois eletrodos sobre as cristas ilíacas" não provocou o aumento da região da medula espinhal estimulada com campo elétrico com intensidade maior do que $0,15 \mathrm{~V} / \mathrm{m}$.

3. O aumento da intensidade corrente de estimulação da tsDCS, na configuração "Um eletrodo sobre T10 e dois eletrodos sobre as cristas ilíacas", de 2,5 mA para $5 \mathrm{~mA}$, aumentou o tamanho da região da medula estimulada com campo elétrico maior do que $0,15 \mathrm{~V} / \mathrm{m}$ em pelo menos $79 \%$.

4. A máxima corrente de estimulação elétrica da tsDCS, na configuração "Um eletrodo sobre T10 e dois eletrodos sobre as cristas ilíacas" que pode ser utilizada sem gerar densidade de corrente maior do que $6,3 \mathrm{~A} / \mathrm{m}^{2}$ na medula espinhal é de $250 \mathrm{~mA}$.

A análise de parâmetros obtidos do COP em 17 (dezessete) participantes jovens saudáveis indicou que a tsDCS não alterou significantemente o comportamento das oscilações posturais durante a execução da $\mathrm{PEO}$, tanto durante quanto depois da estimulação elétrica realizada com intensidade de $5 \mathrm{~mA}$, com eletrodos de $50 \mathrm{~cm}^{2}$ posicionados sobre T10 e cristas ilíacas, em diferentes polarizações . 


\section{ANEXOS}

A.1 Termo de consentimento livre e esclarecido (TCLE) 
TERMO DE CONSENTIMENTO LIVRE E ESCLARECIDO

\section{I - DADOS DE IDENTIFICAÇÃO DO SUJEITO DA PESQUISA OU RESPONSÁVEL LEGAL}

\section{DADOS DO INDIVÍDUO}

Nome completo

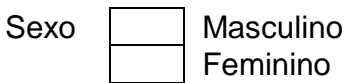

RG

Data de nascimento

Endereço completo

CEP

Fone

e-mail

\section{RESPONSÁVEL LEGAL}

Nome completo

Natureza (grau de parentesco, tutor, curador, etc.)

Sexo $\square$ Masculino

RG

Data de nascimento

Endereço completo

CEP

Fone

e-mail

\section{II - DADOS SOBRE A PESQUISA CIENTÍFICA}

1. Título do Projeto de Pesquisa

Efeito da estimulação transcutânea por corrente contínua nas oscilações posturais durante a postura quieta e ereta em seres humanos

\section{Pesquisador Responsável}

André Fábio Kohn

3. Cargo/Função

Professor Titular da Universidade de São Paulo

4. Avaliação do risco da pesquisa:
$\mathrm{X}$ RISCO MíNIMO
RISCO BAIXO
RISCO MÉDIO
(probabilidade de que o indivíduo sofra algum dano como conseqüência imediata ou tardia do estudo)

5. Duração da Pesquisa

18 meses 


\section{III - EXPLICAÇÕES DO PESQUISADOR AO INDIVÍDUO OU SEU REPRESENTANTE LEGAL SOBRE A} PESQUISA, DE FORMA CLARA E SIMPLES, CONSIGNANDO:

1. Você irá participar de uma pesquisa que investiga os efeitos sobre as suas oscilações posturais de estimulação elétrica de corrente contínua de baixa intensidade aplicada sobre a pele nas suas costas na região da coluna.

2. Iremos avaliar o seu desempenho em postura ereta (em pé) e quieta. Você irá fazer 3 (três) visitas à sala D2-18 do Laboratório de Engenharia Biomédica (LEB) localizado na Escola Politécnica da Universidade de São Paulo (USP).

No começo da primeira visita, você irá preencher um questionário que avalia o histórico de doenças/afecções/lesões prévias e preferência de uso dos membros durante atividades motoras (também chamada de dominância).

Durante as visitas será solicitado que você, por algumas vezes, fique em postura quieta e ereta (ficar de pé, de olhos fechados e escutando ruído em um fone de ouvido) sobre uma plataforma que medirá as forças aplicadas pelos seus pés no solo, por um determinado período de tempo. Periodicamente você será solicitado a permanecer sentando em uma cadeira para descanso.

Durante essas sessões, eletrodos de superfície (pequenas laminas condutoras de eletricidade ligadas a fios) serão posicionados nas suas pernas, na coluna vertebral e em osso lateral do quadril (altura do umbigo) de maneira não invasiva. Para o posicionamento em lugar correto da coluna, será realizada uma palpação dos processos espinhosos das vértebras (pontas ósseas da coluna nas costas, do pescoço até à cintura). Para a fixação dos eletrodos, primeiramente, efetuaremos a limpeza da sua pele com gel abrasivo e álcool. Os eletrodos serão usados tanto para captar a atividade elétrica dos seus músculos como também para estimular eletricamente as suas costas (medula espinhal). Um estímulo elétrico de baixa intensidade, sem percepção ou de baixa percepção, será aplicado nas suas costas por 15 minutos. Cada sessão tem duração média de 1 hora e 30 minutos. Caso necessário, para melhor desempenho dos eletrodos, sua pele poderá ter que ser depilada (tricotomia).

3. As técnicas utilizadas para realização desta pesquisa não devem gerar nenhum desconforto. Os eletrodos de superfícies não causam nenhum dano à sua saúde e serão totalmente removidos após os procedimentos experimentais. A corrente elétrica usada na estimulação das suas costas será muito menor do que limites associados a danos à sua pele.

4. A abrasão da sua pele para a colocação dos eletrodos, a estimulação elétrica que será aplicada nas suas costas, ou possíveis alergias aos produtos utilizados durante o experimento, em raros casos poderão causar irritações de pele que saem facilmente em pouco tempo.

5. Benefícios para a área de conhecimento: As investigações propostas nesta pesquisa serão importantes tanto para uma melhor compreensão dos mecanismos neurais relacionados ao controle postural humano (manutenção da posição em pé) bem como para propor técnicas que possam melhorar o desempenho do controle postural. Os resultados dessa pesquisa poderão no futuro levar ao estabelecimento de uma nova técnica de reabilitação que poderá beneficiar a todos, inclusive a você. Os possíveis benefícios poderão ser relacionados à melhoria dos movimentos de membros e do corpo e uma melhoria na estabilidade postural..

6. Benefícios diretos ao voluntário: A pesquisa poderá não trazer benefícios diretos a você a curto prazo, pois usaremos uma técnica que ainda está em desenvolvimento. A estimulação elétrica que você irá receber como parte da pesquisa tem a possibilidade de melhorar a curtíssimo prazo (durante a aplicação da estimulação e talvez meia hora depois) o funcionamento de uma parte pequena do seu sistema nervoso, embora não se saiba se o efeito pode ter uma duração maior ou não.

\section{IV - ESCLARECIMENTOS DADOS PELO PESQUISADOR SOBRE GARANTIAS DO SUJEITO DA PESQUISA:}

1. Você tem total acesso aos seus dados coletados durante a pesquisa e poderá solicitá-los a qualquer momento. Novamente, enfatizamos que os riscos dos procedimentos experimentais são baixos, pois todas as técnicas são largamente utilizadas e os pesquisadores responsáveis pelo estudo tem conhecimento específico sobre as mesmas.

2. Você tem a liberdade de se retirar desta pesquisa a qualquer momento sem que isto lhe traga qualquer tipo de prejuízo e/ou constrangimento. Além disso, manteremos nossa assistência, caso necessário, independentemente de sua retirada voluntariamente desta pesquisa.

3. Os resultados desta pesquisa serão divulgados em eventos científicos e publicações de circulação internacional. Entretanto, dados pessoais dos indivíduos serão mantidos em sigilo total e absoluto, garantindo assim sua privacidade e a confidencialidade.

4. Caso haja necessidade, em função de algum procedimento da pesquisa, os sujeitos serão encaminhados ao HU ou HC da Universidade de São Paulo, seguindo as normas e procedimentos de tais locais. Também forneceremos a nossa assistência caso necessário.

5. Esse projeto foi aprovado pela escola politécnica da Universidade de São Paulo e pelo Comitê de Ética em Pesquisa (CEP) da Escola de Educação Física e Esportes da USP. 
V - INFORMAÇÕES DE NOMES, ENDEREÇOS E TELEFONES DOS RESPONSÁVEIS PELO ACOMPANHAMENTO DA PESQUISA, PARA CONTATO EM CASO DE INTERCORRÊNCIAS CLÍNICAS E REAÇÕES ADVERSAS.

Caso necessite, entre em contato com algum dos pesquisadores responsáveis pelo acompanhamento desta pesquisa:

1. Felipe Fava de Lima / Telefone: (11) 3091-5541 E-mail: felipefavadelima@usp.br

2. André Fabio Kohn / Telefone: (11) 3091-5535 / E-mail: andfkohn@leb.usp.br

Endereço dos pesquisadores: Laboratório de Engenharia Biomédica, Escola Politécnica da Universidade de São Paulo. Av. Prof. Luciano Gualberto, trav. 3, n. 158. CEP: 05508-900. São Paulo, SP.

\section{VI. - OBSERVAÇÕES COMPLEMENTARES}

A qualquer momento você pode entrar em contato com o Comitê de Ética em Pesquisa (CEP) da Escola de Educação Física e Esportes da USP para eventuais esclarecimentos sobre esta pesquisa.

Endereço: Av. Prof. Mello de Moraes, n. 65. Cidade Universitária. CEP: 05508-030. São Paulo, SP.

Telefone: (11) 3091-3097

Email: cep39@usp.br

\section{VII - CONSENTIMENTO PÓS-ESCLARECIDO}

Declaro que, após convenientemente esclarecido pelo pesquisador e ter entendido o que me foi explicado, consinto em participar do presente Projeto de Pesquisa.

São Paulo,

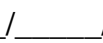

assinatura do sujeito da pesquisa ou responsável legal assinatura do pesquisador

(carimbo ou nome legível) 
A.2 Questionário 1 do protocolo experimental 


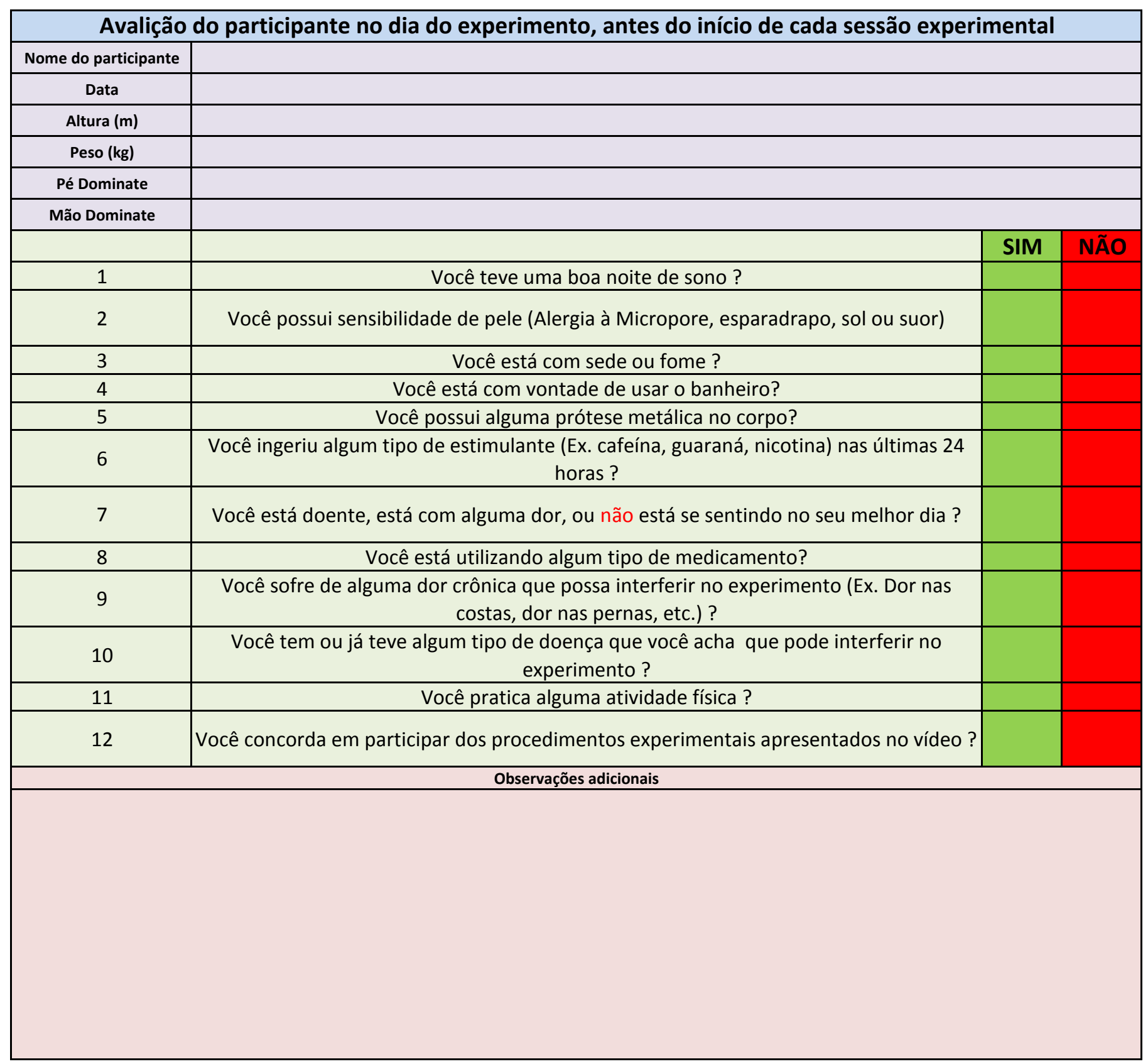


A.3 Questionário 2 do protocolo experimental 
Avaliação da estimulação elétrica, após termino de cada sessão experimental

\begin{tabular}{|c|c|}
\hline & Escala de intensidade \\
\hline Nenhuma & Não senti a sensação \\
\hline Suave & Senti levemente a sensação \\
\hline Moderado & Senti moderadamente a sensação \\
\hline Intenso & Senti intensamente a sensação \\
\hline
\end{tabular}

\begin{tabular}{|l|l|l|l|l|}
\hline \multicolumn{1}{|c|}{ Sensação } & Nenhuma & Suave & Moderado & Intenso \\
\hline Coceira & & & & \\
\hline Dor & & & & \\
\hline Queimação & & & & \\
\hline Aquecimento & & & & \\
\hline Outra & & & & \\
\hline
\end{tabular}

\begin{tabular}{|l|c|c|c|c|c|}
\hline \multicolumn{6}{|c|}{ Em caso de sensação percebida, em que momento ela começou ? } \\
\hline & Coceira & Dor & Queimação & Aquecimento & Outra \\
\hline No começo do experimento & & & & & \\
\hline No meio do experimento & & & & & \\
\hline No fim do experimento & & & & & \\
\hline
\end{tabular}

\begin{tabular}{|l|c|c|c|c|c|}
\hline \multicolumn{6}{|c|}{ Em caso de sensação percebida, qual a duração dessa sensação ? } \\
\hline & Coceira & Dor & Queimação & Aquecimento & Outra \\
\hline Muito curta & & & & & \\
\hline Nem muito curta nem muito longa & & & & & \\
\hline Muito longa & & & & & \\
\hline
\end{tabular}

Em caso de sensação percebida, quanto essa sensação afetou a execução do experimento?

\begin{tabular}{|l|l|l|l|l|l|}
\hline & Coceira & Dor & Queimação & Aquecimento & Outra \\
\hline Nada & & & & & \\
\hline Nem nada nem muito. & & & & & \\
\hline Muito & & & & & \\
\hline
\end{tabular}

\begin{tabular}{|l|l|l|l|l|l|}
\hline \multicolumn{7}{|c|}{ Em caso de sensação percebida, em que lugar você sentiu essa sensação? } \\
\hline & Coceira & Dor & Queimação & Aquecimento & Outra \\
\hline Nas costas & & & & & \\
\hline No lado direito do quadril & & & & & \\
\hline No lado esquerdo do quadril & & & & & \\
\hline Difusa & & & & & \\
\hline Localizada & & & & & \\
\hline Perto do Eletrodo & & & & & \\
\hline
\end{tabular}

Você sentiu alguma outra sensação que julga importante relatar? 


\section{A.4 Parâmetros da plataforma de força}

Modelo da plataforma de força: AMTI OR6-7-1000

Número serial da plataforma de força: 4281

Data do certificado de calibração: 6/12/2001

$$
\begin{aligned}
& \boldsymbol{R}_{\text {cross }}=\left(\begin{array}{cccccc}
1,4986 & -, 0141 & , 0019 & -, 0107 & -, 0043 & , 0029 \\
, 0212 & 1,4938 & -, 0213 & -, 0068 & -, 0049 & -, 0020 \\
-, 0063 & , 0296 & 5,8425 & , 0074 & , 0114 & -, 0009 \\
-, 0001 & -, 0010 & , 0009 & , 5881 & -, 0010 & -, 0015 \\
-, 0010 & -, 0003 & , 0022 & , 0008 & , 5880 & -, 0030 \\
-, 0025 & , 0010 & , 0028 & -, 0019 & , 0001 & , 3028
\end{array}\right)\left(\frac{\mathrm{N}}{\mu \mathrm{V} \cdot \mathrm{V}}, \frac{\mathrm{N} \cdot \mathrm{m}}{\mu \mathrm{V} \cdot \mathrm{V}}\right) \\
& \left(\begin{array}{l}
G F x \\
G F y \\
G F z \\
G M x \\
G M y \\
G M z
\end{array}\right)=\left(\begin{array}{l}
3932,5 \\
3993,6 \\
3967,9 \\
3952,6 \\
3963,0 \\
3985,1
\end{array}\right) \text { (Sem unidade) } \\
& \left(\begin{array}{lll}
x 0 & y 0 & z 0
\end{array}\right)=\left(\begin{array}{lll}
0,375 & -0,155 & -43,577
\end{array}\right)(\mathrm{mm}) \\
& c_{c h}\left(F_{x}, F_{y}, M_{x}, M_{y}, M_{z}\right)=6,083 \mathrm{mV} / \mathrm{m}(1,854 \mathrm{mV} / \mathrm{ft} @ 10 \mathrm{~V}) \\
& c_{c h}\left(F_{y}\right)=12,162 \mathrm{mV} / \mathrm{m}(3,707 \mathrm{mV} / \mathrm{ft} @ 10 \mathrm{~V}) \\
& V_{\text {Amp }}=9,996(\mathrm{~V}) \\
& L=10(\mathrm{~m})
\end{aligned}
$$




\section{A.5 Resultados experimentais}

Tabela 13: Médias e desvios padrões dos resultados experi-

mentais obtidos de 14 (quatorze) participantes,

\begin{tabular}{|c|c|c|c|c|c|c|c|c|c|}
\hline & \multicolumn{9}{|c|}{ Média (devio padrão) } \\
\hline Protocolo & \multicolumn{3}{|c|}{ Placebo } & \multicolumn{3}{|c|}{ C-T10,A-CiDE } & \multicolumn{3}{|c|}{ A-T10,C-CiDE } \\
\hline Parâmetro \Tempo & to & t1 & t2 & to & t1 & t2 & to & t1 & t2 \\
\hline$S D_{A P \_R a m}(\mathrm{~mm})$ & $\begin{array}{c}2,71 \\
(0,44)\end{array}$ & $\begin{array}{c}2,64 \\
(0,47)\end{array}$ & $\begin{array}{c}2,73 \\
(0,61)\end{array}$ & $\begin{array}{c}2,84 \\
(0,59)\end{array}$ & $\begin{array}{c}2,73 \\
(0,58)\end{array}$ & $\begin{array}{c}2,87 \\
(0,84)\end{array}$ & $\begin{array}{c}2,70 \\
(0,44)\end{array}$ & $\begin{array}{c}2,61 \\
(0,46)\end{array}$ & $\begin{array}{c}2,61 \\
(0,56)\end{array}$ \\
\hline$S D_{A P \_T r e}(\mathrm{~mm})$ & $\begin{array}{c}4,54 \\
(1,41) \\
\end{array}$ & $\begin{array}{c}4,25 \\
(0,94) \\
\end{array}$ & $\begin{array}{c}4,34 \\
(1,17) \\
\end{array}$ & $\begin{array}{c}4,41 \\
(1,74) \\
\end{array}$ & $\begin{array}{c}4,40 \\
(1,76) \\
\end{array}$ & $\begin{array}{c}4,54 \\
(1,93) \\
\end{array}$ & $\begin{array}{c}4,06 \\
(1,17) \\
\end{array}$ & $\begin{array}{c}4,15 \\
(1,25) \\
\end{array}$ & $\begin{array}{c}4,27 \\
(1,30) \\
\end{array}$ \\
\hline$S D_{A P}(\mathrm{~mm})$ & $\begin{array}{c}5,89 \\
(1,57)\end{array}$ & $\begin{array}{c}5,56 \\
(1,10)\end{array}$ & $\begin{array}{c}5,73 \\
(1,35)\end{array}$ & $\begin{array}{c}5,83 \\
(1,82)\end{array}$ & $\begin{array}{c}5,76 \\
(1,88)\end{array}$ & $\begin{array}{c}5,94 \\
(2,13)\end{array}$ & $\begin{array}{c}5,44 \\
(1,30)\end{array}$ & $\begin{array}{c}5,46 \\
(1,35)\end{array}$ & $\begin{array}{c}5,56 \\
(1,47)\end{array}$ \\
\hline$S D_{A P_{-} v}(\mathrm{~mm} / \mathrm{s})$ & $\begin{array}{c}1,31 \\
(0,37)\end{array}$ & $\begin{array}{c}1,25 \\
(0,36)\end{array}$ & $\begin{array}{c}1,32 \\
(0,47)\end{array}$ & $\begin{array}{c}1,35 \\
(0,36)\end{array}$ & $\begin{array}{c}1,36 \\
(0,46)\end{array}$ & $\begin{array}{c}1,50 \\
(0,64)\end{array}$ & $\begin{array}{c}1,22 \\
(0,30)\end{array}$ & $\begin{array}{c}1,20 \\
(0,36)\end{array}$ & $\begin{array}{c}1,25 \\
(0,36)\end{array}$ \\
\hline$S D_{M L_{-} \operatorname{Ram}}(\mathrm{mm})$ & $\begin{array}{c}2,24 \\
(0,50)\end{array}$ & $\begin{array}{c}2,12 \\
(0,45)\end{array}$ & $\begin{array}{c}2,25 \\
(0,62)\end{array}$ & $\begin{array}{c}2,27 \\
(0,64)\end{array}$ & $\begin{array}{c}2,23 \\
(0,63)\end{array}$ & $\begin{array}{c}2,45 \\
(1,07)\end{array}$ & $\begin{array}{c}2,21 \\
(0,51)\end{array}$ & $\begin{array}{c}2,07 \\
(0,53)\end{array}$ & $\begin{array}{c}2,22 \\
(0,60)\end{array}$ \\
\hline$S D_{M L_{-} T r e}(\mathrm{~mm})$ & $\begin{array}{c}2,82 \\
(0,58)\end{array}$ & $\begin{array}{c}2,68 \\
(0,57)\end{array}$ & $\begin{array}{c}2,82 \\
(0,77)\end{array}$ & $\begin{array}{c}2,87 \\
(0,72)\end{array}$ & $\begin{array}{c}2,84 \\
(0,83)\end{array}$ & $\begin{array}{c}3,12 \\
(1,28)\end{array}$ & $\begin{array}{c}2,73 \\
(0,61)\end{array}$ & $\begin{array}{c}2,60 \\
(0,68)\end{array}$ & $\begin{array}{c}2,75 \\
(0,71)\end{array}$ \\
\hline$S D_{M L}(\mathrm{~mm})$ & $\begin{array}{c}3,61 \\
(0,78)\end{array}$ & $\begin{array}{c}3,67 \\
(0,80)\end{array}$ & $\begin{array}{c}4,16 \\
(1,32)\end{array}$ & $\begin{array}{c}3,88 \\
(0,92)\end{array}$ & $\begin{array}{c}3,85 \\
(0,91)\end{array}$ & $\begin{array}{c}3,98 \\
(1,21)\end{array}$ & $\begin{array}{c}3,76 \\
(0,96)\end{array}$ & $\begin{array}{c}3,54 \\
(0,70)\end{array}$ & $\begin{array}{c}3,57 \\
(0,84)\end{array}$ \\
\hline$S D_{M L_{-} v}(\mathrm{~mm} / \mathrm{s})$ & $\begin{array}{c}1,06 \\
(0,32)\end{array}$ & $\begin{array}{c}1,03 \\
(0,20)\end{array}$ & $\begin{array}{c}1,05 \\
(0,28)\end{array}$ & $\begin{array}{c}1,08 \\
(0,44)\end{array}$ & $\begin{array}{c}1,09 \\
(0,42)\end{array}$ & $\begin{array}{c}1,12 \\
(0,49)\end{array}$ & $\begin{array}{c}1,00 \\
(0,32)\end{array}$ & $\begin{array}{c}1,06 \\
(0,34)\end{array}$ & $\begin{array}{c}1,06 \\
(0,34)\end{array}$ \\
\hline$M V E L O_{A P \_R a m}(\mathrm{~mm} / \mathrm{s})$ & $\begin{array}{c}4,01 \\
(0,78)\end{array}$ & $\begin{array}{c}4,03 \\
(0,80)\end{array}$ & $\begin{array}{c}4,51 \\
(1,36)\end{array}$ & $\begin{array}{c}4,29 \\
(0,99)\end{array}$ & $\begin{array}{c}, 25 \\
(1,01)\end{array}$ & $\begin{array}{c}4,39 \\
(1,31)\end{array}$ & $\begin{array}{c}4,12 \\
(0,99)\end{array}$ & $\begin{array}{c}3,94 \\
(0,77)\end{array}$ & $\begin{array}{c}3,96 \\
(0,90)\end{array}$ \\
\hline$M V E L O_{A P \_T r e}(\mathrm{~mm} / \mathrm{s})$ & $\begin{array}{c}7,80 \\
(2,11)\end{array}$ & $\begin{array}{c}7,36 \\
(1,45)\end{array}$ & $\begin{array}{c}7,56 \\
(1,82)\end{array}$ & $\begin{array}{c}7,79 \\
(2,48)\end{array}$ & $\begin{array}{c}7,69 \\
(2,70)\end{array}$ & $\begin{array}{c}7,89 \\
(3,04)\end{array}$ & $\begin{array}{c}7,19 \\
(1,77)\end{array}$ & $\begin{array}{c}7,26 \\
(1,83)\end{array}$ & $\begin{array}{c}7,39 \\
(1,96)\end{array}$ \\
\hline$M V E L O_{A P}(\mathrm{~mm} / \mathrm{s})$ & $\begin{array}{c}1,95 \\
(0,61)\end{array}$ & $\begin{array}{c}1,78 \\
(0,55)\end{array}$ & $\begin{array}{c}1,99 \\
(0,79)\end{array}$ & $\begin{array}{c}1,87 \\
(0,76)\end{array}$ & $\begin{array}{c}1,97 \\
(0,92)\end{array}$ & $\begin{array}{c}2,28 \\
(1,15)\end{array}$ & $\begin{array}{c}1,77 \\
(0,68)\end{array}$ & $\begin{array}{c}1,82 \\
(0,71)\end{array}$ & $\begin{array}{c}1,88 \\
(0,74)\end{array}$ \\
\hline$M V E L O_{M L \_R a m}(\mathrm{~mm} / \mathrm{s})$ & $\begin{array}{c}0,59 \\
(0,18)\end{array}$ & $\begin{array}{c}0,56 \\
(0,20)\end{array}$ & $\begin{array}{c}0,58 \\
(0,22)\end{array}$ & $\begin{array}{c}0,61 \\
(0,24)\end{array}$ & $\begin{array}{c}0,65 \\
(0,31)\end{array}$ & $\begin{array}{c}0,66 \\
(0,36)\end{array}$ & $\begin{array}{c}0,60 \\
(0,25)\end{array}$ & $\begin{array}{c}0,58 \\
(0,30)\end{array}$ & $\begin{array}{c}0,60 \\
(0,28)\end{array}$ \\
\hline
\end{tabular}


Tabela 13, continuação da página anterior.

\begin{tabular}{|c|c|c|c|c|c|c|c|c|c|}
\hline & \multicolumn{9}{|c|}{ Média (devio padrão) } \\
\hline Protocolo & \multicolumn{3}{|c|}{ Placebo } & \multicolumn{3}{|c|}{ C-T10,A-CiDE } & \multicolumn{3}{|c|}{ A-T10,C-CiDE } \\
\hline Parâmetro \Tempo & t0 & t1 & t2 & to & t1 & t2 & to & t1 & t2 \\
\hline$M V E L O_{M L \_T r e}(\mathrm{~mm} / \mathrm{s})$ & $\begin{array}{c}2,09 \\
(0,63)\end{array}$ & $\begin{array}{c}1,94 \\
(0,58)\end{array}$ & $\begin{array}{c}2,13 \\
(0,82)\end{array}$ & $\begin{array}{c}2,05 \\
(0,79)\end{array}$ & $\begin{array}{c}2,16 \\
(1,02)\end{array}$ & $\begin{array}{c}2,46 \\
(1,21)\end{array}$ & $\begin{array}{c}1,92 \\
(0,72)\end{array}$ & $\begin{array}{c}1,97 \\
(0,77)\end{array}$ & $\begin{array}{c}2,04 \\
(0,79)\end{array}$ \\
\hline$M V E L O_{M L}(\mathrm{~mm} / \mathrm{s})$ & $\begin{array}{c}3,83 \\
(0,88)\end{array}$ & $\begin{array}{c}3,64 \\
(0,88)\end{array}$ & $\begin{array}{c}3,85 \\
(1,20)\end{array}$ & $\begin{array}{c}3,96 \\
(1,14)\end{array}$ & $\begin{array}{c}3,97 \\
(1,31)\end{array}$ & $\begin{array}{c}4,29 \\
(1,92)\end{array}$ & $\begin{array}{c}3,78 \\
(0,95)\end{array}$ & $\begin{array}{c}3,62 \\
(1,03)\end{array}$ & $\begin{array}{c}3,94 \\
(1,28)\end{array}$ \\
\hline$A R E A E_{\text {Ram }}\left(\mathrm{mm}^{2}\right)$ & $\begin{array}{l}186,80 \\
(87,85)\end{array}$ & $\begin{array}{c}175,59 \\
(83,64)\end{array}$ & $\begin{array}{c}227,12 \\
(158,48)\end{array}$ & $\begin{array}{c}203,82 \\
(117,91)\end{array}$ & $\begin{array}{c}217,61 \\
(160,16)\end{array}$ & $\begin{array}{c}262,90 \\
(195,66)\end{array}$ & $\begin{array}{l}184,85 \\
(91,60)\end{array}$ & $\begin{array}{l}175,14 \\
(81,65)\end{array}$ & $\begin{array}{c}192,90 \\
(126,19)\end{array}$ \\
\hline$A R E A E_{T r e}\left(\mathrm{~mm}^{2}\right)$ & $\begin{array}{c}18,36 \\
(9,67)\end{array}$ & $\begin{array}{c}16,98 \\
(8,39)\end{array}$ & $\begin{array}{c}18,68 \\
(12,12)\end{array}$ & $\begin{array}{c}20,32 \\
(14,74)\end{array}$ & $\begin{array}{c}22,67 \\
(21,78)\end{array}$ & $\begin{array}{c}24,28 \\
(22,76)\end{array}$ & $\begin{array}{c}17,96 \\
(10,95)\end{array}$ & $\begin{array}{c}18,89 \\
(13,88)\end{array}$ & $\begin{array}{c}19,79 \\
(13,74)\end{array}$ \\
\hline$A R E A E\left(\mathrm{~mm}^{2}\right)$ & $\begin{array}{c}228,98 \\
(106,99)\end{array}$ & $\begin{array}{c}214,31 \\
(102,15)\end{array}$ & $\begin{array}{c}272,95 \\
(187,34)\end{array}$ & $\begin{array}{c}252,05 \\
(144,59)\end{array}$ & $\begin{array}{c}270,03 \\
(206,69)\end{array}$ & $\begin{array}{c}319,56 \\
(232,88)\end{array}$ & $\begin{array}{c}223,15 \\
(104,11)\end{array}$ & $\begin{array}{c}216,24 \\
(102,75)\end{array}$ & $\begin{array}{c}235,14 \\
(146,92)\end{array}$ \\
\hline$P S D_{-} A R E A_{-} H F_{A P}\left(\mathrm{~mm}^{2}\right)$ & $\begin{array}{c}1,10 \\
(0,73)\end{array}$ & $\begin{array}{c}0,90 \\
(0,45)\end{array}$ & $\begin{array}{c}0,98 \\
(0,57)\end{array}$ & $\begin{array}{c}1,04 \\
(0,92)\end{array}$ & $\begin{array}{c}1,04 \\
(0,95)\end{array}$ & $\begin{array}{c}1,15 \\
(1,17)\end{array}$ & $\begin{array}{c}0,83 \\
(0,56)\end{array}$ & $\begin{array}{c}0,88 \\
(0,60)\end{array}$ & $\begin{array}{c}0,92 \\
(0,54)\end{array}$ \\
\hline$P S D \_A R E A \_H F_{M L}\left(\mathrm{~mm}^{2}\right)$ & $\begin{array}{c}0,23 \\
(0,12)\end{array}$ & $\begin{array}{c}0,23 \\
(0,10)\end{array}$ & $\begin{array}{c}0,25 \\
(0,14)\end{array}$ & $\begin{array}{c}0,26 \\
(0,16)\end{array}$ & $\begin{array}{c}0,25 \\
(0,17)\end{array}$ & $\begin{array}{c}0,33 \\
(0,41)\end{array}$ & $\begin{array}{c}0,25 \\
(0,13)\end{array}$ & $\begin{array}{c}0,21 \\
(0,11)\end{array}$ & $\begin{array}{c}0,27 \\
(0,18)\end{array}$ \\
\hline$P S D \_A R E A \_L F_{A P}\left(\mathrm{~mm}^{2}\right)$ & $\begin{array}{c}6,99 \\
(2,69)\end{array}$ & $\begin{array}{c}6,60 \\
(2,67)\end{array}$ & $\begin{array}{c}7,76 \\
(5,48)\end{array}$ & $\begin{array}{c}8,52 \\
(4,96)\end{array}$ & $\begin{array}{c}7,80 \\
(5,10)\end{array}$ & $\begin{array}{c}8,46 \\
(6,00)\end{array}$ & $\begin{array}{c}7,30 \\
(3,26)\end{array}$ & $\begin{array}{c}7,01 \\
(2,78)\end{array}$ & $\begin{array}{c}7,02 \\
(3,97)\end{array}$ \\
\hline$P S D \_A R E A \_L F_{M L}\left(\mathrm{~mm}^{2}\right)$ & $\begin{array}{c}1,53 \\
(1,68)\end{array}$ & $\begin{array}{c}1,44 \\
(1,58) \\
\end{array}$ & $\begin{array}{c}1,72 \\
(2,05)\end{array}$ & $\begin{array}{c}1,77 \\
(1,90) \\
\end{array}$ & $\begin{array}{c}2,32 \\
(3,25)\end{array}$ & $\begin{array}{c}2,45 \\
(2,62) \\
\end{array}$ & $\begin{array}{c}1,37 \\
(1,63) \\
\end{array}$ & $\begin{array}{c}1,48 \\
(2,16) \\
\end{array}$ & $\begin{array}{c}1,65 \\
(1,95) \\
\end{array}$ \\
\hline$f 50 p_{-} P S D_{A P \_R a m}(\mathrm{~Hz})$ & $\begin{array}{c}0,22 \\
(0,02)\end{array}$ & $\begin{array}{c}0,21 \\
(0,02)\end{array}$ & $\begin{array}{c}0,21 \\
(0,02)\end{array}$ & $\begin{array}{c}0,21 \\
(0,02)\end{array}$ & $\begin{array}{c}0,22 \\
(0,02)\end{array}$ & $\begin{array}{c}0,22 \\
(0,02)\end{array}$ & $\begin{array}{c}0,21 \\
(0,02)\end{array}$ & $\begin{array}{c}0,21 \\
(0,02)\end{array}$ & $\begin{array}{c}0,22 \\
(0,02)\end{array}$ \\
\hline$f 50 p \_P S D_{A P \_T r e}(\mathrm{~Hz})$ & $\begin{array}{c}0,59 \\
(0,10)\end{array}$ & $\begin{array}{c}0,59 \\
(0,12)\end{array}$ & $\begin{array}{c}0,56 \\
(0,11)\end{array}$ & $\begin{array}{c}0,59 \\
(0,12)\end{array}$ & $\begin{array}{c}0,54 \\
(0,10)\end{array}$ & $\begin{array}{c}0,53 \\
(0,10)\end{array}$ & $\begin{array}{c}0,55 \\
(0,13)\end{array}$ & $\begin{array}{c}0,54 \\
(0,11)\end{array}$ & $\begin{array}{c}0,53 \\
(0,09)\end{array}$ \\
\hline$f 50 p_{-} P S D_{A P}(\mathrm{~Hz})$ & $\begin{array}{c}0,28 \\
(0,03)\end{array}$ & $\begin{array}{c}0,27 \\
(0,04)\end{array}$ & $\begin{array}{c}0,27 \\
(0,04)\end{array}$ & $\begin{array}{c}0,26 \\
(0,05)\end{array}$ & $\begin{array}{c}0,27 \\
(0,05)\end{array}$ & $\begin{array}{c}0,27 \\
(0,04)\end{array}$ & $\begin{array}{c}0,26 \\
(0,04)\end{array}$ & $\begin{array}{c}0,27 \\
(0,03)\end{array}$ & $\begin{array}{c}0,28 \\
(0,04)\end{array}$ \\
\hline$f 50 p_{-} P S D_{A P v}(\mathrm{~Hz})$ & $\begin{array}{c}0,88 \\
(0,17)\end{array}$ & $\begin{array}{c}0,90 \\
(0,18) \\
\end{array}$ & $\begin{array}{c}0,86 \\
(0,16)\end{array}$ & $\begin{array}{c}0,85 \\
(0,22)\end{array}$ & $\begin{array}{c}0,83 \\
(0,17)\end{array}$ & $\begin{array}{c}0,82 \\
(0,19) \\
\end{array}$ & $\begin{array}{c}0,86 \\
(0,21) \\
\end{array}$ & $\begin{array}{c}0,82 \\
(0,19) \\
\end{array}$ & $\begin{array}{c}0,87 \\
(0,16)\end{array}$ \\
\hline$f 50 p_{-} P S D_{M L_{-} R a m}(\mathrm{~Hz})$ & $\begin{array}{c}0,27 \\
(0,05)\end{array}$ & $\begin{array}{c}0,27 \\
(0,05)\end{array}$ & $\begin{array}{c}0,26 \\
(0,05)\end{array}$ & $\begin{array}{c}0,27 \\
(0,07)\end{array}$ & $\begin{array}{c}0,26 \\
(0,06)\end{array}$ & $\begin{array}{c}0,27 \\
(0,08)\end{array}$ & $\begin{array}{c}0,28 \\
(0,05)\end{array}$ & $\begin{array}{c}0,28 \\
(0,06)\end{array}$ & $\begin{array}{c}0,27 \\
(0,05)\end{array}$ \\
\hline$f 50 p_{-} P S D_{M L \_}$Tre $(\mathrm{Hz})$ & $\begin{array}{c}0,55 \\
(0,16)\end{array}$ & $\begin{array}{c}0,53 \\
(0,12)\end{array}$ & $\begin{array}{c}0,55 \\
(0,12)\end{array}$ & $\begin{array}{c}0,52 \\
(0,13)\end{array}$ & $\begin{array}{c}0,51 \\
(0,15)\end{array}$ & $\begin{array}{c}0,53 \\
(0,14)\end{array}$ & $\begin{array}{c}0,55 \\
(0,13)\end{array}$ & $\begin{array}{c}0,52 \\
(0,11)\end{array}$ & $\begin{array}{c}0,55 \\
(0,11)\end{array}$ \\
\hline
\end{tabular}


Tabela 13, continuação da página anterior.

\begin{tabular}{|c|c|c|c|c|c|c|c|c|c|}
\hline & \multicolumn{9}{|c|}{ Média (devio padrão) } \\
\hline Protocolo & \multicolumn{3}{|c|}{ Placebo } & \multicolumn{3}{|c|}{ C-T10,A-CiDE } & \multicolumn{3}{|c|}{ A-T10,C-CiDE } \\
\hline Parâmetro \Tempo & t0 & t1 & $\mathrm{t} 2$ & to & t1 & t2 & to & t1 & t2 \\
\hline$f 50 p \_P S D_{M L}(\mathrm{~Hz})$ & $\begin{array}{c}0,36 \\
(0,11)\end{array}$ & $\begin{array}{c}0,35 \\
(0,10)\end{array}$ & $\begin{array}{c}0,36 \\
(0,12)\end{array}$ & $\begin{array}{c}0,35 \\
(0,12)\end{array}$ & $\begin{array}{c}0,35 \\
(0,12)\end{array}$ & $\begin{array}{c}0,35 \\
(0,13)\end{array}$ & $\begin{array}{c}0,38 \\
(0,09)\end{array}$ & $\begin{array}{c}0,37 \\
(0,09)\end{array}$ & $\begin{array}{c}0,37 \\
(0,09)\end{array}$ \\
\hline$f 50 p_{-} P S D_{M L v}(\mathrm{~Hz})$ & $\begin{array}{c}0,81 \\
(0,27)\end{array}$ & $\begin{array}{c}0,80 \\
(0,24)\end{array}$ & $\begin{array}{c}0,82 \\
(0,27)\end{array}$ & $\begin{array}{c}0,83 \\
(0,30)\end{array}$ & $\begin{array}{c}0,78 \\
(0,26)\end{array}$ & $\begin{array}{c}0,78 \\
(0,27)\end{array}$ & $\begin{array}{c}0,85 \\
(0,27)\end{array}$ & $\begin{array}{c}0,84 \\
(0,26)\end{array}$ & $\begin{array}{c}0,87 \\
(0,27)\end{array}$ \\
\hline$f 80 p_{-} P S D_{A P \_R a m}(\mathrm{~Hz})$ & $\begin{array}{c}0,32 \\
(0,03)\end{array}$ & $\begin{array}{c}0,31 \\
(0,04)\end{array}$ & $\begin{array}{c}0,31 \\
(0,04)\end{array}$ & $\begin{array}{c}0,30 \\
(0,03)\end{array}$ & $\begin{array}{c}0,31 \\
(0,03)\end{array}$ & $\begin{array}{c}0,31 \\
(0,02)\end{array}$ & $\begin{array}{c}0,31 \\
(0,05)\end{array}$ & $\begin{array}{c}0,31 \\
(0,03)\end{array}$ & $\begin{array}{c}0,32 \\
(0,04)\end{array}$ \\
\hline$f 80 p_{-} P S D_{A P \_T r e}(\mathrm{~Hz})$ & $\begin{array}{c}1,00 \\
(0,16)\end{array}$ & $\begin{array}{c}1,00 \\
(0,17)\end{array}$ & $\begin{array}{c}0,97 \\
(0,14)\end{array}$ & $\begin{array}{c}0,98 \\
(0,20)\end{array}$ & $\begin{array}{c}0,93 \\
(0,14)\end{array}$ & $\begin{array}{c}0,93 \\
(0,17)\end{array}$ & $\begin{array}{c}0,98 \\
(0,20)\end{array}$ & $\begin{array}{c}0,94 \\
(0,18)\end{array}$ & $\begin{array}{c}0,96 \\
(0,15)\end{array}$ \\
\hline$f 80 p_{-} P S D_{A P}(\mathrm{~Hz})$ & $\begin{array}{c}0,51 \\
(0,09)\end{array}$ & $\begin{array}{c}0,51 \\
(0,11)\end{array}$ & $\begin{array}{c}0,49 \\
(0,12)\end{array}$ & $\begin{array}{c}0,46 \\
(0,14)\end{array}$ & $\begin{array}{c}0,46 \\
(0,11)\end{array}$ & $\begin{array}{c}0,47 \\
(0,09)\end{array}$ & $\begin{array}{c}0,46 \\
(0,11)\end{array}$ & $\begin{array}{c}0,46 \\
(0,10)\end{array}$ & $\begin{array}{c}0,47 \\
(0,09)\end{array}$ \\
\hline$f 80 p_{-} P S D_{A P v}(\mathrm{~Hz})$ & $\begin{array}{c}1,67 \\
(0,19)\end{array}$ & $\begin{array}{c}1,66 \\
(0,20)\end{array}$ & $\begin{array}{c}1,65 \\
(0,20)\end{array}$ & $\begin{array}{c}1,63 \\
(0,21)\end{array}$ & $\begin{array}{c}1,64 \\
(0,22)\end{array}$ & $\begin{array}{c}1,64 \\
(0,35)\end{array}$ & $\begin{array}{c}1,71 \\
(0,23)\end{array}$ & $\begin{array}{c}1,61 \\
(0,21)\end{array}$ & $\begin{array}{c}1,65 \\
(0,26)\end{array}$ \\
\hline$f 80 p_{-} P S D_{M L \_R a m}(\mathrm{~Hz})$ & $\begin{array}{c}0,42 \\
(0,11)\end{array}$ & $\begin{array}{c}0,41 \\
(0,10)\end{array}$ & $\begin{array}{c}0,41 \\
(0,11)\end{array}$ & $\begin{array}{c}0,41 \\
(0,13)\end{array}$ & $\begin{array}{c}0,39 \\
(0,11)\end{array}$ & $\begin{array}{c}0,40 \\
(0,12)\end{array}$ & $\begin{array}{c}0,43 \\
(0,11)\end{array}$ & $\begin{array}{c}0,43 \\
(0,10)\end{array}$ & $\begin{array}{c}0,41 \\
(0,09)\end{array}$ \\
\hline$f 80 p_{-} P S D_{M L \_T r e}(\mathrm{~Hz})$ & $\begin{array}{c}0,84 \\
(0,24)\end{array}$ & $\begin{array}{c}0,82 \\
(0,18)\end{array}$ & $\begin{array}{c}0,87 \\
(0,19)\end{array}$ & $\begin{array}{c}0,84 \\
(0,22)\end{array}$ & $\begin{array}{c}0,80 \\
(0,22)\end{array}$ & $\begin{array}{c}0,85 \\
(0,23)\end{array}$ & $\begin{array}{c}0,85 \\
(0,19)\end{array}$ & $\begin{array}{c}0,84 \\
(0,19)\end{array}$ & $\begin{array}{c}0,90 \\
(0,21)\end{array}$ \\
\hline$f 80 p \_P S D_{M L}(\mathrm{~Hz})$ & $\begin{array}{c}0,56 \\
(0,17)\end{array}$ & $\begin{array}{c}0,54 \\
(0,14)\end{array}$ & $\begin{array}{c}0,55 \\
(0,16)\end{array}$ & $\begin{array}{c}0,53 \\
(0,18)\end{array}$ & $\begin{array}{c}0,51 \\
(0,18)\end{array}$ & $\begin{array}{c}0,52 \\
(0,18)\end{array}$ & $\begin{array}{c}0,57 \\
(0,15)\end{array}$ & $\begin{array}{c}0,55 \\
(0,14)\end{array}$ & $\begin{array}{c}0,56 \\
(0,16)\end{array}$ \\
\hline$f 80 p_{-} P S D_{M L v}(\mathrm{~Hz})$ & $\begin{array}{c}1,95 \\
(0,54)\end{array}$ & $\begin{array}{c}1,96 \\
(0,56)\end{array}$ & $\begin{array}{c}1,90 \\
(0,46)\end{array}$ & $\begin{array}{c}1,99 \\
(0,55)\end{array}$ & $\begin{array}{c}1,95 \\
(0,54)\end{array}$ & $\begin{array}{c}1,94 \\
(0,65)\end{array}$ & $\begin{array}{c}2,16 \\
(0,65)\end{array}$ & $\begin{array}{c}2,06 \\
(0,58)\end{array}$ & $\begin{array}{c}2,05 \\
(0,55)\end{array}$ \\
\hline$\Delta T c_{A P}(\mathrm{~s})$ & $\begin{array}{c}2,26 \\
(1,54)\end{array}$ & $\begin{array}{c}2,01 \\
(0,88)\end{array}$ & $\begin{array}{c}1,26 \\
(2,88)\end{array}$ & $\begin{array}{c}2,23 \\
(1,04)\end{array}$ & $\begin{array}{c}2,07 \\
(0,86)\end{array}$ & $\begin{array}{c}1,96 \\
(0,71)\end{array}$ & $\begin{array}{c}2,26 \\
(1,40)\end{array}$ & $\begin{array}{c}2,04 \\
(0,88)\end{array}$ & $\begin{array}{c}0,39 \\
(4,91)\end{array}$ \\
\hline$\Delta T c_{M L}(\mathrm{~s})$ & $\begin{array}{c}1,14 \\
(1,64)\end{array}$ & $\begin{array}{c}1,44 \\
(0,81)\end{array}$ & $\begin{array}{c}1,33 \\
(0,91)\end{array}$ & $\begin{array}{c}1,29 \\
(0,92)\end{array}$ & $\begin{array}{c}1,55 \\
(0,81)\end{array}$ & $\begin{array}{c}1,56 \\
(0,86)\end{array}$ & $\begin{array}{c}1,18 \\
(0,65)\end{array}$ & $\begin{array}{c}1,24 \\
(0,65)\end{array}$ & $\begin{array}{c}1,31 \\
(0,65)\end{array}$ \\
\hline$\left\langle\Delta X_{C O P_{A P}}^{2}\right\rangle_{C}\left(\mathrm{~mm}^{2}\right)$ & $\begin{array}{c}23,41 \\
(10,29)\end{array}$ & $\begin{array}{l}20,74 \\
(8,47)\end{array}$ & $\begin{array}{c}2,27 \\
(66,53)\end{array}$ & $\begin{array}{c}26,49 \\
(15,42)\end{array}$ & $\begin{array}{c}24,76 \\
(18,01)\end{array}$ & $\begin{array}{c}25,36 \\
(19,11)\end{array}$ & $\begin{array}{c}22,43 \\
(11,04)\end{array}$ & $\begin{array}{l}21,09 \\
(8,59)\end{array}$ & $\begin{array}{c}5,55 \\
(47,16)\end{array}$ \\
\hline$\left\langle\Delta X_{C O P_{M L}}^{2}\right\rangle_{C}\left(\mathrm{~mm}^{2}\right)$ & $\begin{array}{c}3,50 \\
(5,57)\end{array}$ & $\begin{array}{c}4,13 \\
(4,43)\end{array}$ & $\begin{array}{c}4,43 \\
(5,22)\end{array}$ & $\begin{array}{c}4,63 \\
(5,67)\end{array}$ & $\begin{array}{c}6,14 \\
(7,66)\end{array}$ & $\begin{array}{c}6,80 \\
(7,27)\end{array}$ & $\begin{array}{c}3,67 \\
(4,07)\end{array}$ & $\begin{array}{c}4,11 \\
(5,65)\end{array}$ & $\begin{array}{c}4,78 \\
(5,86)\end{array}$ \\
\hline$D l_{A P}\left(\mathrm{~mm}^{2} / \mathrm{s}\right)$ & $\begin{array}{c}0,55 \\
(0,45)\end{array}$ & $\begin{array}{c}0,42 \\
(0,28)\end{array}$ & $\begin{array}{c}0,84 \\
(1,01)\end{array}$ & $\begin{array}{c}0,45 \\
(0,43)\end{array}$ & $\begin{array}{c}0,44 \\
(0,28)\end{array}$ & $\begin{array}{c}0,52 \\
(0,35)\end{array}$ & $\begin{array}{c}0,43 \\
(0,44)\end{array}$ & $\begin{array}{c}0,38 \\
(0,25)\end{array}$ & $\begin{array}{c}0,57 \\
(0,35)\end{array}$ \\
\hline
\end{tabular}


Tabela 13, continuação da página anterior.

\begin{tabular}{|c|c|c|c|c|c|c|c|c|c|}
\hline & \multicolumn{9}{|c|}{ Média (devio padrão) } \\
\hline Protocolo & \multicolumn{3}{|c|}{ Placebo } & \multicolumn{3}{|c|}{ C-T10,A-CiDE } & \multicolumn{3}{|c|}{ A-T10,C-CiDE } \\
\hline Parâmetro \Tempo & to & t1 & t2 & t0 & t1 & t2 & to & t1 & t2 \\
\hline$D l_{M L}\left(\mathrm{~mm}^{2} / \mathrm{s}\right)$ & $\begin{array}{c}0,15 \\
(0,15)\end{array}$ & $\begin{array}{c}0,14 \\
(0,14)\end{array}$ & $\begin{array}{c}0,19 \\
(0,14)\end{array}$ & $\begin{array}{c}0,13 \\
(0,16)\end{array}$ & $\begin{array}{c}0,23 \\
(0,32)\end{array}$ & $\begin{array}{c}0,29 \\
(0,37)\end{array}$ & $\begin{array}{c}0,12 \\
(0,13)\end{array}$ & $\begin{array}{c}0,12 \\
(0,11)\end{array}$ & $\begin{array}{c}0,16 \\
(0,17)\end{array}$ \\
\hline$D s_{A P}\left(\mathrm{~mm}^{2} / \mathrm{s}\right)$ & $\begin{array}{c}6,65 \\
(3,78) \\
\end{array}$ & $\begin{array}{c}5,78 \\
(2,16) \\
\end{array}$ & $\begin{array}{c}6,21 \\
(2,87)\end{array}$ & $\begin{array}{c}6,99 \\
(5,01)\end{array}$ & $\begin{array}{c}6,87 \\
(5,60)\end{array}$ & $\begin{array}{c}7,25 \\
(6,17)\end{array}$ & $\begin{array}{c}5,69 \\
(3,12) \\
\end{array}$ & $\begin{array}{c}5,94 \\
(3,11)\end{array}$ & $\begin{array}{c}6,08 \\
(3,32)\end{array}$ \\
\hline$D s_{M L}\left(\mathrm{~mm}^{2} / \mathrm{s}\right)$ & $\begin{array}{c}1,43 \\
(0,62)\end{array}$ & $\begin{array}{c}1,36 \\
(0,81)\end{array}$ & $\begin{array}{c}1,53 \\
(0,98)\end{array}$ & $\begin{array}{c}1,64 \\
(1,01)\end{array}$ & $\begin{array}{c}1,75 \\
(1,45)\end{array}$ & $\begin{array}{c}2,11 \\
(2,34)\end{array}$ & $\begin{array}{c}1,41 \\
(0,78)\end{array}$ & $\begin{array}{c}1,34 \\
(0,93)\end{array}$ & $\begin{array}{c}1,60 \\
(1,16)\end{array}$ \\
\hline$\alpha_{-} L_{A P}$ & $\begin{array}{c}1,02 \\
(0,13)\end{array}$ & $\begin{array}{c}1,01 \\
(0,07)\end{array}$ & $\begin{array}{c}1,04 \\
(0,10)\end{array}$ & $\begin{array}{c}1,00 \\
(0,09)\end{array}$ & $\begin{array}{c}1,01 \\
(0,07)\end{array}$ & $\begin{array}{c}1,01 \\
(0,09)\end{array}$ & $\begin{array}{c}1,01 \\
(0,09)\end{array}$ & $\begin{array}{c}0,98 \\
(0,09)\end{array}$ & $\begin{array}{c}1,00 \\
(0,09)\end{array}$ \\
\hline$\alpha_{-} L_{M L}$ & $\begin{array}{c}1,01 \\
(0,13) \\
\end{array}$ & $\begin{array}{c}0,97 \\
(0,12)\end{array}$ & $\begin{array}{c}1,01 \\
(0,10)\end{array}$ & $\begin{array}{c}0,96 \\
(0,12)\end{array}$ & $\begin{array}{c}0,94 \\
(0,10)\end{array}$ & $\begin{array}{c}1,01 \\
(0,10)\end{array}$ & $\begin{array}{c}0,95 \\
(0,13) \\
\end{array}$ & $\begin{array}{c}1,00 \\
(0,12)\end{array}$ & $\begin{array}{c}1,01 \\
(0,12)\end{array}$ \\
\hline$\alpha \_S_{A P}$ & $\begin{array}{c}1,90 \\
(0,02)\end{array}$ & $\begin{array}{c}1,90 \\
(0,02)\end{array}$ & $\begin{array}{c}1,90 \\
(0,02)\end{array}$ & $\begin{array}{c}1,90 \\
(0,02)\end{array}$ & $\begin{array}{c}1,90 \\
(0,02)\end{array}$ & $\begin{array}{c}1,90 \\
(0,04)\end{array}$ & $\begin{array}{c}1,90 \\
(0,03)\end{array}$ & $\begin{array}{c}1,90 \\
(0,03)\end{array}$ & $\begin{array}{c}1,90 \\
(0,03)\end{array}$ \\
\hline$\alpha \_S_{M L}$ & $\begin{array}{c}1,87 \\
(0,05)\end{array}$ & $\begin{array}{c}1,88 \\
(0,04)\end{array}$ & $\begin{array}{c}1,88 \\
(0,04)\end{array}$ & $\begin{array}{c}1,87 \\
(0,05)\end{array}$ & $\begin{array}{c}1,88 \\
(0,05)\end{array}$ & $\begin{array}{c}1,87 \\
(0,06)\end{array}$ & $\begin{array}{c}1,86 \\
(0,05)\end{array}$ & $\begin{array}{c}1,87 \\
(0,05)\end{array}$ & $\begin{array}{c}1,86 \\
(0,05)\end{array}$ \\
\hline$C I_{A P}$ & $\begin{array}{l}15,60 \\
(0,80)\end{array}$ & $\begin{array}{c}15,60 \\
(0,91)\end{array}$ & $\begin{array}{c}15,53 \\
(0,96)\end{array}$ & $\begin{array}{c}15,34 \\
(0,78)\end{array}$ & $\begin{array}{c}15,34 \\
(0,69)\end{array}$ & $\begin{array}{c}15,57 \\
(0,89)\end{array}$ & $\begin{array}{l}15,79 \\
(0,83)\end{array}$ & $\begin{array}{l}15,44 \\
(0,89)\end{array}$ & $\begin{array}{l}15,59 \\
(1,13)\end{array}$ \\
\hline$C I_{A P v}$ & $\begin{array}{l}18,34 \\
(0,75)\end{array}$ & $\begin{array}{c}18,30 \\
(0,71)\end{array}$ & $\begin{array}{l}18,26 \\
(1,07)\end{array}$ & $\begin{array}{c}17,99 \\
(0,75)\end{array}$ & $\begin{array}{l}18,22 \\
(0,72)\end{array}$ & $\begin{array}{l}18,37 \\
(0,92)\end{array}$ & $\begin{array}{l}18,44 \\
(0,71)\end{array}$ & $\begin{array}{l}18,27 \\
(0,63)\end{array}$ & $\begin{array}{l}18,30 \\
(1,01)\end{array}$ \\
\hline$C I_{M L}$ & $\begin{array}{l}14,80 \\
(1,04)\end{array}$ & $\begin{array}{l}14,69 \\
(1,04)\end{array}$ & $\begin{array}{c}14,77 \\
(0,94)\end{array}$ & $\begin{array}{c}14,46 \\
(1,21)\end{array}$ & $\begin{array}{l}14,15 \\
(1,04)\end{array}$ & $\begin{array}{l}14,45 \\
(1,36)\end{array}$ & $\begin{array}{l}14,25 \\
(1,35)\end{array}$ & $\begin{array}{l}14,31 \\
(1,44)\end{array}$ & $\begin{array}{l}14,12 \\
(1,75)\end{array}$ \\
\hline$C I_{M L v}$ & $\begin{array}{c}18,12 \\
(1,16)\end{array}$ & $\begin{array}{c}18,09 \\
(1,21)\end{array}$ & $\begin{array}{c}18,01 \\
(1,33)\end{array}$ & $\begin{array}{l}17,57 \\
(1,47)\end{array}$ & $\begin{array}{l}17,38 \\
(1,28)\end{array}$ & $\begin{array}{l}17,52 \\
(1,38)\end{array}$ & $\begin{array}{l}17,50 \\
(1,22)\end{array}$ & $\begin{array}{l}17,54 \\
(1,32)\end{array}$ & $\begin{array}{l}17,04 \\
(1,79)\end{array}$ \\
\hline
\end{tabular}




\section{REFERÊNCIAS}

AHMED, Z. Trans-spinal direct current stimulation modifies spinal cord excitability through synaptic and axonal mechanisms. Physiological reports, Wiley Online Library, v. 2, n. 9, p. e12157, 2014.

AMOUD, H. et al. Fractal time series analysis of postural stability in elderly and control subjects. Journal of neuroengineering and rehabilitation, Springer, v. 4, n. 1, p. 12, 2007.

AMTI, A. M. T. Instruction Manual Model OR6-5 Biomechanics Platform. [S.l.], 1991.

AMTI Advanced Mechanical Technology, Inc. OR6-7-10. EUA. Disponível em: $\langle$ https://www.amti.biz〉.

AMTI Force and Motion WebSite. Optima force platforma. 2020. Disponível em: $\langle$ https://www.amti.biz/optima.aspx .

Ankit Rohatgi. Web Plot Digitizer - Web Based Plot Digitizer. 2019. Disponível em: $\langle$ https://apps.automeris.io/wpd/〉.

ASSLÄNDER, L.; PETERKA, R. J. Sensory reweighting dynamics in human postural control. Journal of neurophysiology, American Physiological Society Bethesda, MD, v. 111, n. 9, p. 1852-1864, 2014.

AWOSIKA, O. O. et al. Transcutaneous spinal direct current stimulation improves locomotor learning in healthy humans. Brain stimulation, Elsevier, v. 12, n. 3, p. 628-634, 2019.

Axelgaard Manufacturing CO., LTD. ValuTrode VL4595. EUA. Disponível em: $\langle$ https://www.axelgaard.com/〉.

BARATTO, L. et al. A new look at posturographic analysis in the clinical context: sway-density versus other parameterization techniques. Motor control, Human Kinetics, Inc., v. 6, n. 3, p. 246-270, 2002.

BASTANI, A.; JABERZADEH, S. a-tdcs differential modulation of corticospinal excitability: the effects of electrode size. Brain stimulation, Elsevier, v. 6, n. 6, p. 932-937, 2013.

BATSIKADZE, G. et al. Partially non-linear stimulation intensity-dependent effects of direct current stimulation on motor cortex excitability in humans. The Journal of physiology, Wiley Online Library, v. 591, n. 7, p. 1987-2000, 2013.

BEAR, M. F.; CONNORS, B.; PARADISO, M. Neuroscience: Exploring the brain. In:_. Lippincott Williams \& Wilkins, 2001. cap. 4 - The action Potencial, p. 73-97. ISBN 9780781739443. Disponível em: 〈https://books.google.com.br/books?id= 1v6iwwEACAAJ). 
BENABID, A. L. et al. Long-term suppression of tremor by chronic stimulation of the ventral intermediate thalamic nucleus. The Lancet, Elsevier, v. 337, n. 8738, p. 403-406, 1991.

BERRY, H. R.; TATE, R. J.; CONWAY, B. A. Transcutaneous spinal direct current stimulation induces lasting fatigue resistance and enhances explosive vertical jump performance. PloS one, Public Library of Science, v. 12, n. 4, p. e0173846, 2017.

BING, Z.; GREENHALGH, S. Finite element three dimensional direct current resistivity modelling: accuracy and efficiency considerations. Geophysical Journal International, Blackwell Science Ltd Oxford, UK, v. 145, n. 3, p. 679-688, 2001.

BIOPAC System,Inc. STMISOL-1. EUA. Disponível em: 〈https://www.biopac.com〉.

BOCCI, T. et al. Spinal direct current stimulation modulates short intracortical inhibition. Neuromodulation: Technology at the Neural Interface, Wiley Online Library, v. 18, n. 8 , p. 686-693, 2015.

BOCCI, T. et al. Transcutaneous spinal direct current stimulation modulates human corticospinal system excitability. Journal of neurophysiology, American Physiological Society Bethesda, MD, v. 114, n. 1, p. 440-446, 2015.

BOCCI, T. et al. Cathodal transcutaneous spinal direct current stimulation (tsdcs) improves motor unit recruitment in healthy subjects. Neuroscience letters, Elsevier, v. 578, p. $75-79,2014$.

BOLBECKER, A. R. et al. Disturbances of postural sway components in cannabis users. Drug and alcohol dependence, Elsevier, v. 190, p. 54-61, 2018.

BOLLT, E. M.; SKUFCA, J. D.; MCGREGOR, S. J. Control entropy: A complexity measure for nonstationary signals. Mathematical Biosciences \& Engineering, American Institute of Mathematical Sciences, v. 6, n. 1, p. 1, 2009.

BRINKLEY, D.; MASTERS, H. The depth of the spinal cord below the skin. The British journal of radiology, The British Institute of Radiology, v. 40, n. 469, p. 66-68, 1967.

BRONZINO, J. The biomedical engineering handbook. In: CRC-Press, 2000. (Electrical Engineering Handbook), cap. 12 - Numerical Methods for Bioelectric Field Problems. ISBN 9780849385940. Disponível em: 〈https://books.google.com.br/books? id=2LGdxwEACAAJ $\rangle$.

BRUnONI, A. R. Princípios e Práticas do Uso da Neuromodulação Não Invasiva em Psiquiatria. [S.l.]: Artmed, 2016. ISBN 8582713517.

BRUNONI, A. R. Princípios e práticas do uso da neuromodulação não invasiva em psiquiatria. In: . [S.l.]: Artmed, 2016. cap. 1. ISBN 8582713517.

BUSA, M. A.; EMMERIK, R. E. van. Multiscale entropy: A tool for understanding the complexity of postural control. Journal of Sport and Health Science, Elsevier, v. 5, n. 1, p. 44-51, 2016.

Cambridge Electronic Desing Limited. Power1401. Reino Unido. Disponível em: $\langle$ https://www.amti.biz〉. 
CARPENTER, M. B. Human neuroanatomy. In: 7. ed. [S.1.]: The Willians \& Wilkins Company, 1976. cap. 9, p. 213-235.

CHIARI, L.; ROCCHI, L.; CAPPELLO, A. Stabilometric parameters are affected by anthropometry and foot placement. Clinical biomechanics, Elsevier, v. 17, n. 9-10, p. 666-677, 2002.

CICCONE, A. Lack of an effect of transspinal and transcranial direct current stimulation on performance, perception of effort, and physiologic function in humans. Tese (Doutorado) - University of Kansas, 2018.

CISI, R. R.; KOHN, A. F. Simulation system of spinal cord motor nuclei and associated nerves and muscles, in a web-based architecture. Journal of computational neuroscience, Springer, v. 25, n. 3, p. 520-542, 2008.

CISI, R. R. L. Sistema de simulação de circuitos neuronais da medula espinhal desenvolvido em arquitetura web. Tese (Doutorado) — Universidade de São Paulo, 2007.

COGIAMANIAN, F. et al. Effect of spinal transcutaneous direct current stimulation on somatosensory evoked potentials in humans. Clinical Neurophysiology, Elsevier, v. 119, n. 11, p. 2636-2640, 2008.

COGIAMANIAN, F. et al. Transcutaneous spinal cord direct current stimulation inhibits the lower limb nociceptive flexion reflex in human beings. PAIN $R$, Elsevier, v. 152, n. 2, p. $370-375,2011$.

COLLINS, J.; LUCA, C. D. Upright, correlated random walks: A statistical-biomechanics approach to the human postural control system. Chaos: An Interdisciplinary Journal of Nonlinear Science, American Institute of Physics, v. 5, n. 1, p. 57-63, 1995.

COLLINS, J. et al. Age-related changes in open-loop and closed-loop postural control mechanisms. Experimental brain research, Springer, v. 104, n. 3, p. 480-492, 1995.

COLLINS, J. J.; LUCA, C. J. D. Open-loop and closed-loop control of posture: a random-walk analysis of center-of-pressure trajectories. Experimental brain research, Springer, v. 95, n. 2, p. 308-318, 1993.

COMSOL Inc. COMSOL Multiphysicsß. EUA. Disponível em: 〈https://www.comsol. $\operatorname{com}\rangle$.

CONFORTO, S. et al. Hemodynamics as a possible internal mechanical disturbance to balance. Gait \&S posture, Elsevier, v. 14, n. 1, p. 28-35, 2001.

COSTA, M.; GOLDBERGER, A. L.; PENG, C.-K. Multiscale entropy analysis of complex physiologic time series. Physical review letters, APS, v. 89, n. 6, p. 068102, 2002.

DAFNY, N. Chapter 3: Anatomy of the Spinal Cord. 1997. Disponível em: $\langle$ https://nba.uth.tmc.edu/neuroscience/m/s2/chapter03.html〉.

Dassault Systemes. SolidWorks 2016. França. Disponível em: 〈https://www.solidworks. comp.

DESILVA, R. A. et al. Cardioversion and defibrillation. American heart journal, Elsevier, v. 100, n. 6, p. $881-895,1980$. 
DESSEILLIGNY,BURKE. The Circuitry of the Human Spinal Cord: Spinal and Corticospinal Mechanisms of Movement. 1. ed. [S.1.]: Cambridge University Press, 2012. ISBN 0521192587.

DIENER, H. et al. The significance of proprioception on postural stabilization as assessed by ischemia. Brain research, Elsevier, v. 296, n. 1, p. 103-109, 1984.

DIENER, H.-C. et al. Quantification of postural sway in normals and patients with cerebellar diseases. Electroencephalography and clinical neurophysiology, Elsevier, v. 57, n. 2 , p. $134-142,1984$.

DMOCHOWSKI, J. P. et al. Optimized multi-electrode stimulation increases focality and intensity at target. Journal of neural engineering, IOP Publishing, v. 8, n. 4, p. 046011, 2011.

DONGÉS, S. C. et al. The effects of cervical transcutaneous spinal direct current stimulation on motor pathways supplying the upper limb in humans. PloS one, Public Library of Science San Francisco, CA USA, v. 12, n. 2, p. e0172333, 2017.

DOYLE, R. J. et al. Generalizability of center of pressure measures of quiet standing. Gait 85 posture, Elsevier, v. 25, n. 2, p. 166-171, 2007.

DUARTE, M.; FREITAS, S. M. Revisão sobre posturografia baseada em plataforma de força para avaliação do equilíbrio. Revista Brasileira de Fisioterapia, Associação Brasileira de Pesquisa e Pós-Graduação em Fisioterapia, v. 14, n. 3, p. 183-192, 2010.

DUARTE, M.; STERNAD, D. Complexity of human postural control in young and older adults during prolonged standing. Experimental brain research, Springer, v. 191, n. 3, p. 265-276, 2008.

DUARTE, M.; ZATSIORSKY, V. M. Effects of body lean and visual information on the equilibrium maintenance during stance. Experimental brain research, Springer, v. 146, n. 1 , p. 60-69, 2002.

DUPUI, P. et al. Interet de l'analyse fréquentielle des oscillations posturales lors de l'équilibre dynamique. Societé d'études et de recherches multi-disciplinaires sur la locomotion. Paris: Collège de France, 1990.

ELIAS, L.; WATANABE, R.; KOHN, A. Spinal mechanisms may provide a combination of intermittent and continuous control of human posture. 2014.

ESMAEILPOUR, Z. et al. Incomplete evidence that increasing current intensity of tdcs boosts outcomes. Brain stimulation, Elsevier, v. 11, n. 2, p. 310-321, 2018.

FARIA, P.; HALLETT, M.; MIRANDA, P. C. A finite element analysis of the effect of electrode area and inter-electrode distance on the spatial distribution of the current density in tdcs. Journal of neural engineering, IOP Publishing, v. 8, n. 6, p. 066017, 2011.

FERNANDES, S. R. et al. Transcutaneous spinal direct current stimulation of the lumbar and sacral spinal cord: a modelling study. Journal of neural engineering, IOP Publishing, v. 15, n. 3, p. 036008, 2018. 
FIELD, A. Discovering Statistics Using SPSS. SAGE Publications, 2007. (Introducing Statistical Methods Series). ISBN 9780857020963. Disponível em: 〈https://books.google. com.br/books?id=5253SAL5nDgC).

FINKEL, A. S.; REDMAN, S. J. The synaptic current evoked in cat spinal motoneurones by impulses in single group 1a axons. The Journal of Physiology, Wiley Online Library, v. 342 , n. 1, p. 615-632, 1983.

FIOCCHI, S. et al. Modelling of the temperature changes induced by transcutaneous spinal direct current stimulation (tsdcs). IEEE Journal of Electromagnetics, RF and Microwaves in Medicine and Biology, IEEE, 2020.

FITZPATRICK, R.; MCCLOSKEY, D. Proprioceptive, visual and vestibular thresholds for the perception of sway during standing in humans. The Journal of physiology, Wiley Online Library, v. 478, n. 1, p. 173-186, 1994.

FITZPATRICK, R.; ROGERS, D. K.; MCCLOSKEY, D. Stable human standing with lower-limb muscle afferents providing the only sensory input. The Journal of physiology, Wiley Online Library, v. 480, n. 2, p. 395-403, 1994.

FORSEEN, N. M. B. S. E. Imaging anatomy of the human spine: A comprehensive atlas including adjacent structures. In: . [S.l.]: Springer Publishing Company, 2015. cap. 2, p. 55-118. ISBN 9781936287826.

FRANK, E. Anodal skin lesions after treatment with transcranial direct current stimulation. Brain Stimul, v. 3, p. 58-59, 2010.

FROSTELL, A. et al. A review of the segmental diameter of the healthy human spinal cord. Frontiers in neurology, Frontiers, v. 7, p. 238, 2016.

GAERLAN, M. G. The role of visual, vestibular, and somatosensory systems in postural balance. 2010.

GIBSON, J.; TREMBLAY, F. Differential modulation of pressure pain threshold in response to transcutaneous spinal direct current stimulation with physical activity level. Neuroscience letters, Elsevier, v. 698, p. 154-159, 2019.

GILFRICHE, P. et al. Frequency-specific fractal analysis of postural control accounts for control strategies. Frontiers in physiology, Frontiers, v. 9, p. 293, 2018.

GOLOVAC, S. Spinal cord stimulation: Uses and applications. In: Image-Guided Spine Interventions. [S.1.]: Springer, 2010. p. 375-396.

GORSHKOV, O. Stabilogram diffusion analysis algorithm to estimate the hurst exponent of high-dimensional fractals. Journal of Statistical Mechanics: Theory and Experiment, IOP Publishing, v. 2012, n. 04, p. P04014, 2012.

GUARIENTI, F. et al. Reducing transcranial direct current stimulation-induced erythema with skin pretreatment: considerations for sham-controlled clinical trials. Neuromodulation: Technology at the Neural Interface, Wiley Online Library, v. 18, n. 4, p. 261-265, 2015. 
HAGIO, K.; OBATA, H.; NAKAZAWA, K. Effects of breathing movement on the reduction of postural sway during postural-cognitive dual tasking. PloS one, Public Library of Science, v. 13, n. 5, p. e0197385, 2018.

HANSEN, C. et al. Sample entropy, univariate, and multivariate multi-scale entropy in comparison with classical postural sway parameters in young healthy adults. Frontiers in human neuroscience, Frontiers, v. 11, p. 206, 2017.

HEIDE, A. et al. Effects of transcutaneous spinal direct current stimulation in idiopathic restless legs patients. Brain stimulation, Elsevier, v. 7, n. 5, p. 636-642, 2014.

HERCULANO-HOUZEL, S. The human brain in numbers: a linearly scaled-up primate brain. Frontiers in human neuroscience, Frontiers, v. 3, p. 31, 2009.

HERNÁNDEZ-LABRADO, G. R. et al. Spinal cord direct current stimulation: finite element analysis of the electric field and current density. Medical $\&$ biological engineering Ef computing, Springer, v. 49, n. 4, p. 417-429, 2011.

HO, K.-A. et al. The effect of transcranial direct current stimulation (tdcs) electrode size and current intensity on motor cortical excitability: evidence from single and repeated sessions. Brain stimulation, Elsevier, v. 9, n. 1, p. 1-7, 2016.

HOWLETT, O. A. et al. Functional electrical stimulation improves activity after stroke: a systematic review with meta-analysis. Archives of physical medicine and rehabilitation, Elsevier, v. 96, n. 5, p. 934-943, 2015.

HOY, K. E. et al. Testing the limits: investigating the effect of tdcs dose on working memory enhancement in healthy controls. Neuropsychologia, Elsevier, v. 51, n. 9, p. 1777-1784, 2013.

HUBLI, M. et al. Modulation of spinal neuronal excitability by spinal direct currents and locomotion after spinal cord injury. Clinical Neurophysiology, Elsevier, v. 124, n. 6, p. 1187-1195, 2013.

HYDE, D. E.; WARFIELD, S. K. Anisotropic equivalent conductivity tensors for bioelectric modeling of partial volume effects in cerebrospinal fluid spaces. In: IEEE. 2011 IEEE International Symposium on Biomedical Imaging: From Nano to Macro. [S.l.], 2011. p. 1109-1112.

IBM. IBM SPSS Statistics 20. EUA. Disponível em: 〈https://www.ibm.com/br-pt/ analytics/spss-statistics-software).

JADCZAK, Ł. et al. Jumping height does not increase in well trained volleyball players after transcutaneous spinal direct current stimulation. Frontiers in Physiology, Frontiers Media SA, v. 10, 2019.

JAMIL, A. et al. Systematic evaluation of the impact of stimulation intensity on neuroplastic after-effects induced by transcranial direct current stimulation. The Journal of physiology, Wiley Online Library, v. 595, n. 4, p. 1273-1288, 2017.

JANKOWSKA, E. et al. Evidence that some long-lasting effects of direct current in the rat spinal cord are activity-independent. European Journal of Neuroscience, Wiley Online Library, v. 43, n. 10, p. 1400-1411, 2016. 
JORGENSEN, M. et al. Time-of-day influences postural balance in older adults. Gait \& posture, Elsevier, v. 35, n. 4, p. 653-657, 2012.

JR, O. S. Psd computations using welch's method. NASA STI/Recon Technical Report $N$, v. $92,1991$.

KANDEL JAMES H. SCHWARTZ, T. M. J. S. A. S. A. J. H. E. R. Principles of neural science. In: 5. ed. [S.l.]: McGraw-Hill Education, 2012. cap. The Autonomic Motor System and the Hypothalamus, p. 1056-1078.

KAPLAN, D. T.; FURMAN, M. I.; PINCUS, S. M. Techniques for analyzing complexity in heart rate and beat-to-beat blood pressure signals. In: IEEE. [1990] Proceedings Computers in Cardiology. [S.1.], 1990. p. 243-246.

KAWAKITA, T. et al. Body sway induced by depth linear vection in reference to central and peripheral visual field. The Japanese journal of physiology, THE PHYSIOLOGICAL SOCIETY OF JAPAN, v. 50, n. 3, p. 315-321, 2000.

KNOTKOVA, H. et al. Practical Guide to Transcranial Direct Current Stimulation: Principles, Procedures and Applications. Springer International Publishing, 2019. ISBN 9783319959474. Disponível em: 〈https://books.google.com.br/books?id= 1VtKuAEACAAJ $\rangle$.

KNOTKOVA, H. et al. Practical guide to transcranial direct current stimulation: Principles, procedures and applications. In: Springer International Publishing, 2019. cap. 3 - Mechanisms of Acute and After Effects of Transcranial Direct Current Stimulation, p. 81-114. ISBN 9783319959474. Disponível em: 〈https: //books.google.com.br/books?id=1VtKuAEACAAJ $\rangle$.

KNOTKOVA, H. et al. Practical guide to transcranial direct current stimulation: Principles, procedures and applications. In: __. Springer International Publishing, 2019. cap. 6 - Safety of Transcranial Direct Current Stimulation, p. 167-195. ISBN 9783319959474. Disponível em: 〈https://books.google.com.br/books?id= 1VtKuAEACAAJ $\rangle$.

KNOTKOVA, H. et al. Practical guide to transcranial direct current stimulation: Principles, procedures and applications. In: Springer International Publishing, 2019. cap. 1 - Transcranial Direct Current Stimulation Among Technologies for LowIntensity Transcranial Electrical Stimulation: Classification, History, and Terminology, p. 3-45. ISBN 9783319959474. Disponível em: 〈https://books.google.com.br/books?id= $1 \mathrm{VtKuAEACAAJ}\rangle$.

KRISHNAMOORTHY, V.; SLIJPER, H.; LATASH, M. L. Effects of different types of light touch on postural sway. Experimental Brain Research, Springer, v. 147, n. 1, p. 71-79, 2002.

KUCK, A.; STEGEMAN, D.; ASSELDONK, E. V. Modeling trans-spinal direct current stimulation for the modulation of the lumbar spinal motor pathways. Journal of neural engineering, IOP Publishing, v. 14, n. 5, p. 056014, 2017.

KUCK, A. et al. Changes in h-reflex recruitment after trans-spinal direct current stimulation with multiple electrode configurations. Frontiers in neuroscience, Frontiers, v. 12 , p. $151,2018$. 
KUCZYŃSKI, M.; WIELOCH, M. Effects of accelerated breathing on postural stability. Human movement, Versita, v. 9, n. 2, p. 107-110, 2008.

KUO, A. D. et al. Effect of altered sensory conditions on multivariate descriptors of human postural sway. Experimental brain research, Springer, v. 122, n. 2, p. 185-195, 1998.

LADENBAUER, J. Simulation of the excitation of human lower spinal cord structures with surface electrodes: 3D finite element analysis and nerve fiber modeling. na, 2008. Disponível em: 〈https://books.google.com.br/books?id=4HXujbP7VSwC〉.

LAFOND, D.; DUARTE, M.; PRINCE, F. Comparison of three methods to estimate the center of mass during balance assessment. Journal of biomechanics, Elsevier, v. 37, n. 9, p. 1421-1426, 2004.

LAKENS, D. Calculating and reporting effect sizes to facilitate cumulative science: a practical primer for t-tests and anovas. Frontiers in psychology, Frontiers, v. 4, p. 863, 2013.

LAMY, J.-C.; BOAKYE, M. Bdnf val66met polymorphism alters spinal de stimulationinduced plasticity in humans. Journal of neurophysiology, American Physiological Society Bethesda, MD, v. 110, n. 1, p. 109-116, 2013.

LAMY, J.-C. et al. Modulation of soleus h reflex by spinal dc stimulation in humans. Journal of neurophysiology, American Physiological Society Bethesda, MD, v. 108, n. 3, p. 906-914, 2012.

LEACH, J. M. et al. Day-to-day variability of postural sway and its association with cognitive function in older adults: a pilot study. Frontiers in aging neuroscience, Frontiers, v. 10, p. 126, 2018.

LEARMONTH, G. et al. No interaction between tdcs current strength and baseline performance: A conceptual replication. Frontiers in Neuroscience, Frontiers, v. 11, p. 664, 2017.

LENOIR, C.; JANKOVSKI, A.; MOURAUX, A. Anodal transcutaneous spinal direct current stimulation (tsdcs) selectively inhibits the synaptic efficacy of nociceptive transmission at spinal cord level. Neuroscience, Elsevier, v. 393, p. 150-163, 2018.

LI, L.; ZHANG, S.; DOBSON, J. The contribution of small and large sensory afferents to postural control in patients with peripheral neuropathy. Journal of sport and health science, Elsevier, v. 8, n. 3, p. 218-227, 2019.

LIM, C.-Y.; SHIN, H.-I. Noninvasive dc stimulation on neck changes mep. Neuroreport, LWW, v. 22, n. 16, p. 819-823, 2011.

LIPPOLD, O.; REDFEARN, J. Mental changes resulting from the passage of small direct currents through the human brain. The British Journal of Psychiatry, Cambridge University Press, v. 110, n. 469, p. 768-772, 1964.

MAGALHÃES, F. H.; KOHN, A. F. Imperceptible electrical noise attenuates isometric plantar flexion force fluctuations with correlated reductions in postural sway. Experimental brain research, Springer, v. 217, n. 2, p. 175-186, 2012. 
MAKI, B.; MCLLROY, W. Influence of arousal and attention on the control of postural sway. Journal of Vestibular Research, IOS Press, v. 6, n. 1, p. 53-59, 1996.

MÄKINEN, T. M. et al. Postural sway during single and repeated cold exposures. Aviation, space, and environmental medicine, Aerospace Medical Association, v. 76, n. 10, p. 947-953, 2005.

MALMIVUO, R. P. J. Bioelectromagnetism: principles and applications of bioelectric and biomagnetic fields. [S.l.]: Oxford University Press, 1995.

MANCINI, M. et al. Postural sway as a marker of progression in parkinson's disease: a pilot longitudinal study. Gait $\&$ posture, Elsevier, v. 36, n. 3, p. 471-476, 2012.

MARANGOLO, P. et al. Stairways to the brain: Transcutaneous spinal direct current stimulation (tsdcs) modulates a cerebellar-cortical network enhancing verb recovery. Brain Research, Elsevier, v. 1727, p. 146564, 2020.

MARQUEZ, C. M. S. et al. Task-specific effect of transcranial direct current stimulation on motor learning. Frontiers in human neuroscience, Frontiers, v. 7, p. 333, 2013.

MathWorks. Matlab 2015a. EUA. Disponível em: 〈https://www.mathworks.com/〉.

MAURER, C.; PETERKA, R. J. A new interpretation of spontaneous sway measures based on a simple model of human postural control. Journal of neurophysiology, American Physiological Society, v. 93, n. 1, p. 189-200, 2005.

MCCREERY, D. B. et al. Charge density and charge per phase as cofactors in neural injury induced by electrical stimulation. IEEE Transactions on Biomedical Engineering, IEEE, v. 37, n. 10, p. 996-1001, 1990.

MEYER-FRIESSEM, C. et al. Transcutaneous spinal dc stimulation reduces pain sensitivity in humans. Neuroscience letters, Elsevier, v. 589, p. 153-158, 2015.

MIGNARDOT, J.-B. et al. Postural sway, falls, and cognitive status: a cross-sectional study among older adults. Journal of Alzheimer's Disease, IOS Press, v. 41, n. 2, p. 431-439, 2014.

MIKLAVČIČ, D.; PAVŠELJ, N.; HART, F. X. Electric properties of tissues. Wiley encyclopedia of biomedical engineering, Wiley Online Library, 2006.

MIRANDA, P. C. et al. The electric field in the cortex during transcranial current stimulation. Neuroimage, Elsevier, v. 70, p. 48-58, 2013.

MOCHIZUKI, L.; AMADIO, A. C. As informações sensoriais para o controle postural. Fisioterapia em movimento, v. 19, n. 2, p. 11-18, 2006.

MURRAY, L. M.; TAHAYORI, B.; KNIKOU, M. Transspinal direct current stimulation produces persistent plasticity in human motor pathways. Scientific reports, Nature Publishing Group, v. 8, n. 1, p. 717, 2018.

National Bioscience Database Center. Body Parts 3D. Japão. Disponível em: $\langle$ http://dbarchive.biosciencedbc.jp/en/bodyparts3d/download.html〉.

National Instruments ${ }^{T M}$. Labview 2014. EUA. Disponível em: 〈https://www.ni.com〉. 
National Instruments ${ }^{T M}$. USB-6212. EUA. Disponível em: 〈https://www.ni.com〉.

NEJC, S. et al. Sensitivity of body sway parameters during quiet standing to manipulation of support surface size. Journal of sports science $\mathscr{E}$ medicine, Dept. of Sports Medicine, Medical Faculty of Uludag University, v. 9, n. 3, p. 431, 2010.

NIH U.S. National Library of Medicine. The visible human project. USA. Disponível em: $\langle$ https://www.nlm.nih.gov/research/visible/visible_human.html〉.

NITSCHE, M. A. Safety criteria for transcranial direct current stimulation (tdcs) in humans. Clin Neurophysiol, v. 114, p. 2220-2222, 2003.

NNOAHAM, K. E.; KUMBANG, J. Transcutaneous electrical nerve stimulation (tens) for chronic pain. Cochrane Database of Systematic Reviews, John Wiley \& Sons, Ltd, n. $3,2008$.

OLIVEIRA, J. M. de. Statokinesigram normalization method. Behavior research methods, Springer, v. 49, n. 1, p. 310-317, 2017.

PAILLARD, T.; NOÉ, F. Techniques and methods for testing the postural function in healthy and pathological subjects. BioMed research international, Hindawi, v. 2015, 2015.

PALM, U. et al. 4c/fpo. Brain stimulation, v. 1, p. 386-7, 2008.

PALMIERI, R. M. et al. Center-of-pressure parameters used in the assessment of postural control. Journal of sport rehabilitation, Human Kinetics, Inc., v. 11, n. 1, p. 51-66, 2002.

PARAZZINI, M. et al. Modeling the current density generated by transcutaneous spinal direct current stimulation (tsdcs). Clinical Neurophysiology, Elsevier, v. 125, n. 11, p. 2260-2270, 2014.

PARK, S. H. et al. Effects of sound on postural stability during quiet standing. Journal of neuroengineering and rehabilitation, BioMed Central, v. 8, n. 1, p. 67, 2011.

PATAT, A.; FOULHOUX, P. Effect on postural sway of various benzodiazepine tranquillizers. British journal of clinical pharmacology, Wiley Online Library, v. 20, n. 1, p. $9-16,1985$.

PELLECCHIA, G. L. Postural sway increases with attentional demands of concurrent cognitive task. Gait \& posture, Elsevier, v. 18, n. 1, p. 29-34, 2003.

PENG, C.-K. et al. Quantification of scaling exponents and crossover phenomena in nonstationary heartbeat time series. Chaos: an interdisciplinary journal of nonlinear science, American Institute of Physics, v. 5, n. 1, p. 82-87, 1995.

PEREIRA, M. et al. Neuromodulation of lower limb motor responses with transcutaneous lumbar spinal cord direct current stimulation. Clinical Neurophysiology, Elsevier, v. 129, n. 9, p. 1999-2009, 2018.

PERROTTA, A. et al. Modulation of temporal summation threshold of the nociceptive withdrawal reflex by transcutaneous spinal direct current stimulation in humans. Clinical Neurophysiology, Elsevier, v. 127, n. 1, p. 755-761, 2016. 
PETERKA, R. J. Postural control model interpretation of stabilogram diffusion analysis. Biological cybernetics, Springer, v. 82, n. 4, p. 335-343, 2000.

PETRYSHEN, T. L. et al. Population genetic study of the brain-derived neurotrophic factor (bdnf) gene. Molecular psychiatry, Nature Publishing Group, v. 15, n. 8, p. $810-815,2010$.

PINCUS, S. M. Approximate entropy as a measure of system complexity. Proceedings of the National Academy of Sciences, National Acad Sciences, v. 88, n. 6, p. 2297-2301, 1991.

PINCUS, S. M.; GOLDBERGER, A. L. Physiological time-series analysis: what does regularity quantify? American Journal of Physiology-Heart and Circulatory Physiology, American Physiological Society Bethesda, MD, v. 266, n. 4, p. H1643-H1656, 1994.

PLONSEY, R.; HEPPNER, D. B. Considerations of quasi-stationarity in electrophysiological systems. The Bulletin of mathematical biophysics, Springer, v. 29, n. 4, p. 657-664, 1967.

POPE, P. A.; MIALL, R. C. Task-specific facilitation of cognition by cathodal transcranial direct current stimulation of the cerebellum. Brain stimulation, Elsevier, v. 5, n. 2, p. 84-94, 2012.

PRIETO, T. E. et al. Measures of postural steadiness: differences between healthy young and elderly adults. IEEE Transactions on biomedical engineering, IEEE, v. 43, n. 9, p. 956-966, 1996.

PRIORI, A. et al. Polarization of the human motor cortex through the scalp. Neuroreport, LWW, v. 9, n. 10, p. 2257-2260, 1998.

PRIPLATA, A. et al. Noise-enhanced human balance control. Physical review letters, APS, v. 89, n. 23, p. 238101, 2002.

PUTZ, R. P. R. Atlas de anatomia humana sobotta, volume 1 cabeça, pescoço e extremidade superior. In: v. 1, cap. Encéfalo, p. 341-346. 21. ed. [S.l.]: Editora Guanabara Hoogan S.A., 2000.

QIU, H.; XIONG, S. Center-of-pressure based postural sway measures: Reliability and ability to distinguish between age, fear of falling and fall history. International Journal of Industrial Ergonomics, Elsevier, v. 47, p. 37-44, 2015.

RAHMATI, Z. et al. Disentangling stability and flexibility degrees in parkinson's disease using a computational postural control model. Journal of neuroengineering and rehabilitation, BioMed Central, v. 16, n. 1, p. 1-14, 2019.

RAYMAKERS, J.; SAMSON, M.; VERHAAR, H. The assessment of body sway and the choice of the stability parameter (s). Gait $\mathcal{E}$ posture, Elsevier, v. 21, n. 1, p. 48-58, 2005.

REIMANN, A. F.; ANSON, B. J. Vertebral level of termination of the spinal cord with report of a case of sacral cord. The Anatomical Record, Wiley Online Library, v. 88, n. 1, p. $127-138,1944$. 
RICHMAN, J. S.; MOORMAN, J. R. Physiological time-series analysis using approximate entropy and sample entropy. American Journal of Physiology-Heart and Circulatory Physiology, American Physiological Society Bethesda, MD, v. 278, n. 6, p. H2039-H2049, 2000.

ROBERTSON GRAHAM CALDWELL, J. H. G. K. S. W. G. Research methods in biomechanics. In: . [S.l.]: Human Kinetics, 2004. cap. Forces and their Measurement, p. 90.

ROMAN-LIU, D. Age-related changes in the range and velocity of postural sway. Archives of gerontology and geriatrics, Elsevier, v. 77, p. 68-80, 2018.

RUHE, A.; FEJER, R.; WALKER, B. The test-retest reliability of centre of pressure measures in bipedal static task conditions-a systematic review of the literature. Gait $\&$ posture, Elsevier, v. 32, n. 4, p. 436-445, 2010.

SAMADDAR, S. et al. Transspinal direct current stimulation modulates migration and proliferation of adult newly born spinal cells in mice. Journal of Applied Physiology, American Physiological Society Bethesda, MD, v. 122, n. 2, p. 339-353, 2016.

SANT'ANNA, P. et al. Posturographic analysis of older adults without dementia and patients with alzheimer's disease: A cross-sectional study. Dementia $\&$ Neuropsychologia, SciELO Brasil, v. 13, n. 2, p. 196-202, 2019.

SARMIENTO, C.; SAN-JUAN, D.; PRASATH, V. Letter to the editor: Brief history of transcranial direct current stimulation (tdcs): from electric fishes to microcontrollers. Psychological medicine, Cambridge University Press, v. 46, n. 15, p. 3259-3261, 2016.

SATURNINO, G. B.; ANTUNES, A.; THIELSCHER, A. On the importance of electrode parameters for shaping electric field patterns generated by tdcs. Neuroimage, Elsevier, v. 120 , p. $25-35,2015$.

SAYENKO, D. G. et al. Spinal segment-specific transcutaneous stimulation differentially shapes activation pattern among motor pools in humans. Journal of Applied Physiology, American Physiological Society Bethesda, MD, v. 118, n. 11, p. 1364-1374, 2015.

SCHMID, M. et al. Respiration and postural sway: detection of phase synchronizations and interactions. Human movement science, Elsevier, v. 23, n. 2, p. 105-119, 2004.

SCHWEIZER, L. et al. Transcutaneous spinal direct current stimulation alters resting-state functional connectivity. Brain Connectivity, Mary Ann Liebert, Inc. 140 Huguenot Street, 3rd Floor New Rochelle, NY 10801 USA, v. 7, n. 6, p. 357-365, 2017.

SHAHID, S.; WEN, P.; AHFOCK, T. Effects of model complexity and tissue anisotropic conductivity on cortical modulation during transcranial direct current stimulation. IET Science, Measurement \&S Technology, IET, v. 6, n. 6, p. 464-473, 2012.

SHAHID, S. S. et al. The value and cost of complexity in predictive modelling: role of tissue anisotropic conductivity and fibre tracts in neuromodulation. Journal of neural engineering, IOP Publishing, v. 11, n. 3, p. 036002, 2014. 
SHIN, S.; MOTL, R. W.; SOSNOFF, J. J. A test of the rambling and trembling hypothesis: multiple sclerosis and postural control. Motor Control, Human Kinetics, Inc., v. 15, n. 4, p. 568-579, 2011.

SILVA, C. R.; MAGALHÃES, F. H.; KOHN, A. F. Fingertip-coupled spindle signaling does not contribute to reduce postural sway under light touch. Frontiers in physiology, Frontiers, v. 10, p. 1072, 2019.

SMITH, S. S.; CHENG, T.; KERR, G. K. The effect of extended wake on postural control in young adults. Experimental brain research, Springer, v. 221, n. 3, p. 329-335, 2012.

SONG, W.; MARTIN, J. H. Spinal cord direct current stimulation differentially modulates neuronal activity in the dorsal and ventral spinal cord. Journal of neurophysiology, American Physiological Society Bethesda, MD, v. 117, n. 3, p. 1143-1155, 2016.

TANG, Y. et al. Total regional and global number of synapses in the human brain neocortex. Synapse, Wiley Online Library, v. 41, n. 3, p. 258-273, 2001.

TRUINI, A. et al. Transcutaneous spinal direct current stimulation inhibits nociceptive spinal pathway conduction and increases pain tolerance in humans. European Journal of Pain, Wiley Online Library, v. 15, n. 10, p. 1023-1027, 2011.

TSOUCALAS, G. et al. The "torpedo" effect in medicine. International maritime health, v. 65 , n. 2 , p. $65-67,2014$.

TUKEY, J. W. Exploratory data analysis. [S.l.]: Reading, MA, 1977. v. 2.

VIEIRA, T.; OLIVEIRA, L.; NADAL, J. Estimation procedures affect the center of pressure frequency analysis. Brazilian Journal of Medical and Biological Research, SciELO Brasil, v. 42, n. 7, p. 665-673, 2009.

VIGNAUD, P. et al. Duration but not intensity influences transcranial direct current stimulation (tdcs) after-effects on cortical excitability. Neurophysiologie Clinique, Elsevier, v. 48, n. 2, p. 89-92, 2018.

VITKOVIC, J. et al. The contribution of hearing and hearing loss to balance control. Audiology and neurotology, Karger Publishers, v. 21, n. 4, p. 195-202, 2016.

WANG, J. et al. Skin burn after single session of transcranial direct current stimulation (tdcs). Brain stimulation, v. 8, n. 1, p. 165, 2015.

WARWICK, P. L. W. R. Gray's anatomy. In: 35. ed. [S.1.]: W.B. Saunders Company, 1973. cap. Neurology, p. 806-839.

WEBSTER, J. Medical instrumentation: Application and design. In: . Wiley, 2009. cap. 5 - Biopotential and electrodes, p. 189-240. ISBN 9780471676003. Disponível em: 〈https://books.google.com.br/books?id=muRmDwAAQBAJ〉.

WINKLER, T.; HERING, P.; STRAUBE, A. Spinal dc stimulation in humans modulates post-activation depression of the h-reflex depending on current polarity. Clinical neurophysiology, Elsevier, v. 121, n. 6, p. 957-961, 2010. 
WINTER, D. A. Human balance and posture control during standing and walking. Gait $\&$ posture, Elsevier, v. 3, n. 4, p. 193-214, 1995.

WORLD MEDICAL ASSOCIATION et al. World medical association declaration of helsinki. ethical principles for medical research involving human subjects. Bulletin of the World Health Organization, World Health Organization, v. 79, n. 4, p. 373, 2001.

YAGGIE, J. A.; MCGREGOR, S. J. Effects of isokinetic ankle fatigue on the maintenance of balance and postural limits. Archives of physical Medicine and Rehabilitation, Elsevier, v. 83, n. 2, p. 224-228, 2002.

YAMAGUCHI, T. et al. Effects of transcutaneous spinal de stimulation on plasticity of the spinal circuits and corticospinal tracts in humans. In: IEEE. 2013 6th International IEEE/EMBS Conference on Neural Engineering (NER). [S.l.], 2013. p. 275-278.

YAMAMOTO, T. et al. Universal and individual characteristics of postural sway during quiet standing in healthy young adults. Physiological reports, Wiley Online Library, v. 3, n. 3, p. e12329, 2015.

YUEN, T. G. et al. Histological evaluation of neural damage from electrical stimulation: considerations for the selection of parameters for clinical application. Neurosurgery, Oxford University Press, v. 9, n. 3, p. 292-299, 1981.

ZATSIORSKY, V. M.; DUARTE, M. Instant equilibrium point and its migration in standing tasks: rambling and trembling components of the stabilogram. Motor control, Human Kinetics, Inc., v. 3, n. 1, p. 28-38, 1999.

ZATSIORSKY, V. M.; DUARTE, M. Rambling and trembling in quiet standing. Motor control, Human Kinetics, Inc., v. 4, n. 2, p. 185-200, 2000. 